\title{
Paediatric asthma, obesity, and exercise: secondary prevention of asthma by a weight reduction intervention
}

Citation for published version (APA):

Willeboordse, M. (2014). Paediatric asthma, obesity, and exercise: secondary prevention of asthma by a weight reduction intervention. [Doctoral Thesis, Maastricht University]. Maastricht University.

https://doi.org/10.26481/dis.20141107mw

Document status and date:

Published: 01/01/2014

DOI:

10.26481/dis.20141107mw

Document Version:

Publisher's PDF, also known as Version of record

Please check the document version of this publication:

- A submitted manuscript is the version of the article upon submission and before peer-review. There can be important differences between the submitted version and the official published version of record.

People interested in the research are advised to contact the author for the final version of the publication, or visit the DOI to the publisher's website.

- The final author version and the galley proof are versions of the publication after peer review.

- The final published version features the final layout of the paper including the volume, issue and page numbers.

Link to publication

\footnotetext{
General rights rights.

- You may freely distribute the URL identifying the publication in the public portal. please follow below link for the End User Agreement:

www.umlib.nl/taverne-license

Take down policy

If you believe that this document breaches copyright please contact us at:

repository@maastrichtuniversity.nl

providing details and we will investigate your claim.
}

Copyright and moral rights for the publications made accessible in the public portal are retained by the authors and/or other copyright owners and it is a condition of accessing publications that users recognise and abide by the legal requirements associated with these

- Users may download and print one copy of any publication from the public portal for the purpose of private study or research.

- You may not further distribute the material or use it for any profit-making activity or commercial gain

If the publication is distributed under the terms of Article $25 \mathrm{fa}$ of the Dutch Copyright Act, indicated by the "Taverne" license above, 
Paediatric asthma, obesity, and exercise:

Secondary prevention of asthma by a weight reduction intervention 
'Life begins at the end of your comfortzone'

(C) Maartje Willeboordse, Maastricht 2014

Design logo, omslag en illustraties: Marcel de Jong (marceldejong.info)

Layout: Tiny Wouters \& Maartje Willeboordse

Printed by: Gildeprint

ISBN: 9789461087645

The research presented in this thesis was conducted at the School for Public health and primary Care (CAPHRI), Department Paediatrics, of Maastricht University. CAPHRI participates in the Netherlands school of Primary Care Research (CARE). CAPHRI was classified as 'excellent' by the external evaluation committee of leading international experts that reviewed CAPHRI in December 2010.

This PhD research was funded by grants from the Lung Foundation Netherlands (NLF: 3.4.09.002) and TEVA pharmaceuticals BV. Financial support for printing of this thesis was kindly provided by: Lung Foundation Netherlands, Stichting Astma Bestrijding, TEVA Pharmaceuticals BV, Stichting ter bevordering Kindergeneeskunde, Glaxosmithkline BV, Boehringer Ingelheim BV and ABN AMRO BANK NV. 


\title{
Paediatric asthma, obesity, and exercise: \\ Secondary prevention of asthma by a weight reduction intervention
}

\author{
PROEFSCHRIFT \\ Ter verkrijging van de graad van doctor \\ aan de Universiteit Maastricht, \\ op gezag van de Rector Magnificus, \\ Prof. dr. L.L.G. Soete \\ volgens het besluit van het college van Decanen, \\ in het openbaar te verdedigen \\ op vrijdag 7 november 2014 om 14:00 uur.
}

door

Maartje Willeboordse 


\section{Promotores}

Prof. dr. E. Dompeling

Prof. dr. C.P. van Schayck

\section{Copromotor}

Dr. K.D.G. van de Kant

\section{Beoordelingscommissie}

Prof. dr. F.J.M. Feron (voorzitter)

Prof. dr. W.M.C. van Aalderen (Universiteit van Amsterdam)

Prof. dr. T. van der Molen (Rijksuniversiteit van Groningen)

Dr. A.C.E. Vreugdenhil

Prof. dr. L.J.I. Zimmermann 


\section{Contents}

$\begin{array}{lll}\text { Chapter } 1 & \text { General introduction } & 7\end{array}$

Chapter 2 Sex differences in the relationship between asthma and 23 overweight in Dutch children: a survey study

PLoS One. 2013;8:e77574

Chapter 3 Exercise training in children with asthma: a systematic review

Br J Sports Med. 2014;8(13):1024-31

Chapter 4 Paediatric physical activity: associations with asthma and obesity

Submitted

Chapter 5 Multifactorial intervention for children with asthma and overweight (MIKADO): study design of a randomised controlled trial

BMC Public Health. 2013;13:494

Chapter 6 A multifactorial weight reduction program in children with overweight and asthma: a randomised controlled trial Submitted

Chapter 7 Attrition in a paediatric weight reduction program: perspectives from participants and parents

Submitted

Chapter $8 \quad$ General discussion

Summary

Samenvatting

175

Valorisation

181

List of publications

Dankwoord

Curriculum vitae 


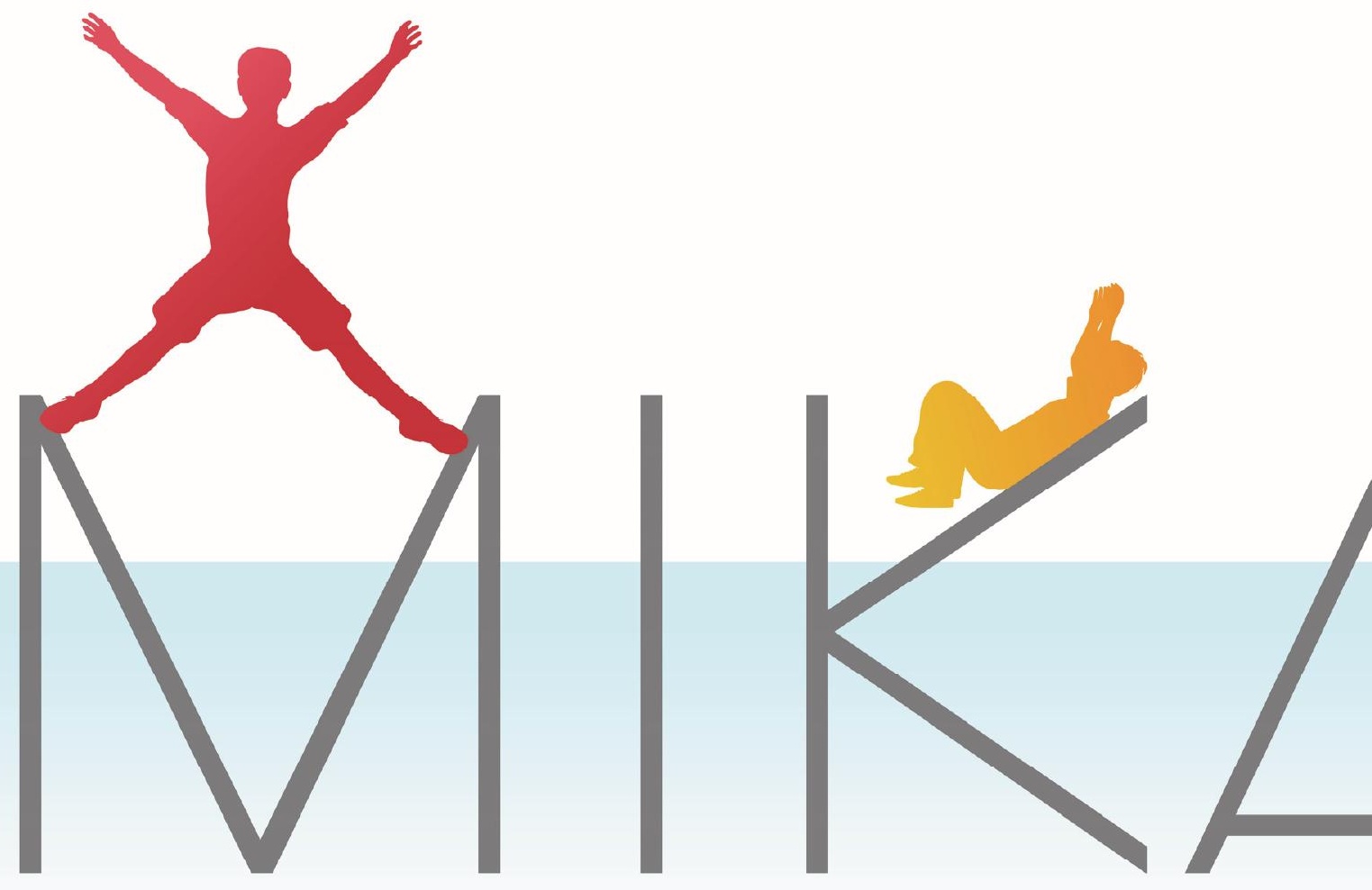


1. General introduction

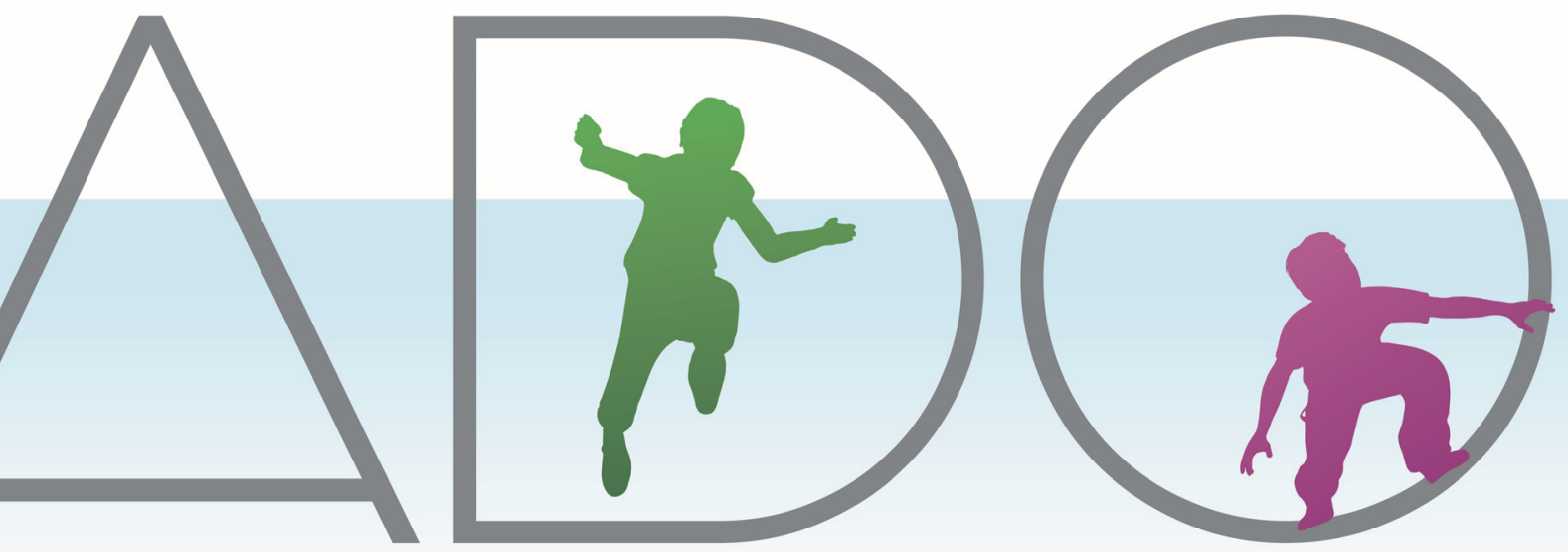




\section{Childhood asthma}

Asthma is a common disease in children characterised by chronic airway inflammation ${ }^{1,2}$. Common symptoms in asthma are recurrent episodes of wheezing, breathlessness, coughing and chest tightness ${ }^{1,2}$. Children with asthma often experience a variable but reversible airflow obstruction ${ }^{1,2}$. Approximately $40-90 \%$ of all asthmatics suffer from exercise-induced bronchoconstriction (EIB $)^{3-6}$. EIB is defined as shortness of breath during or directly after exercise, caused by narrowing of the airways ${ }^{7}$. Asthma can have significant consequences in daily life. Asthmatic children report more missing schooldays, have a lower quality of life, and report more visits to doctors and emergency care units than their healthy peers ${ }^{8-10}$.

The majority of patients develop asthma during childhood and global prevalence of asthma ranges from $1-18 \%^{1,11,12}$. Asthma is predominantly a Western disease, as the prevalence is highest in Western countries ${ }^{13}$. Worldwide, asthma prevalence increased since 1980, although in most Western countries a stabilisation occurred in the last decade ${ }^{13,14}$. Possible explanations for the increase in asthma prevalence since 1980 are increased alertness, improved diagnostics, and more exposure to asthma triggers such as airway pollution. In the Netherlands, asthma prevalence and respiratory symptoms increased since 1980, but a levelling off or even slight decrease can be observed since the twenty-first century ${ }^{14-16}$, which is in line with the worldwide trend. The current prevalence of diagnosed asthma among Dutch children aged 5-18 years is approximately $4 \%$, with the highest prevalence in Southern Limburg ${ }^{16,17}$.

Asthma development and expression are determined by both genetic and environmental factors ${ }^{1,2,18}$. For example, adolescents with parental asthma are up to 5 times more likely to develop asthma than adolescents without parental asthma ${ }^{19}$. Several environmental factors that are associated with the expression of asthma are the presence of allergens (e.g. house dust mite, furred animals and pollen), respiratory infections, exposure to tobacco smoke and air pollution. Currently, obesity has been recognised as an important factor in both the development and expression of asthma $^{20,21}$.

Asthma treatment focusses predominantly on improving asthma control by means of pharmacological interventions ${ }^{1,22}$. Asthma control is assessed on the basis of a combination of the following items: exacerbations, frequency and severity of respiratory symptoms, use of rescue medication, limitations and level of daytime activities, and variability of lung function ${ }^{1}$. Several medications (e.g. beta-2 agonists and inhaled corticosteroids) have been shown to be highly efficient in reducing airway inflammation and diminish airway symptoms in asthma ${ }^{1,22}$. In addition to pharmacotherapy, secondary prevention of asthma is of importance. Secondary prevention by interventions that are implemented after the diagnosis of a disease or serious risk factor, have the goal to halt or slow the progress of disease in its earliest stage. In asthma, secondary prevention is necessary to improve asthma control in order 
to achieve optimal quality of life and reduce health care costs. As obesity is one of the few modifiable risk factors for asthma development, it is of significant importance to study secondary prevention of asthma by means of weight reduction.

\section{Childhood obesity}

Overweight and obesity are both defined as 'ranges of weight that are greater than what is generally considered healthy for a given height ${ }^{23,24}$. The body mass index (BMI, calculated as height/(weight ${ }^{2}$ ) is often used as an index for adiposity ${ }^{23}$. Adults with a $\mathrm{BMI}$ between 25 and 30 are considered to be overweight, while adults with a $\mathrm{BMI}>30$ are obese. In children, weight status is not solely determined by height and weight, but also by sex and age. Therefore, overweight and obesity should be defined by the BMIstandard deviation score (BMI-SDS). BMI-SDS is measured by the deviation of age-and sex specific reference charts based on height and weight ${ }^{25}$. In this dissertation, reference charts of the Dutch nationwide growth study are used to define BMI-SDS in children ${ }^{26}$.

The obesity prevalence has increased dramatically during the last 4 decades, resulting in the striking fact that at least 3 out of 10 adults in Europe and Northern America are overweight and 2 out of 10 are obese ${ }^{27}$. In children, overweight and obesity prevalences are considerably lower than in adults. However, there is an alarming trend visible as in the previous decades the increases in childhood obesity has been growing even more rapidly than in adults ${ }^{27}$. For example in Dutch children aged 2-21 years, overweight and obesity prevalence's have increased 2 to 6 fold between 1980 and $2010^{26}$. Currently, $15 \%$ of the Dutch girls and $17 \%$ of the Dutch boys have overweight or are obese (Figure 1.1) ${ }^{26}$. In the most Southern region of the Netherlands, overweight and obesity prevalences are even higher than in the rest of the Netherlands, possibly due to a low average socioeconomic status ${ }^{28}$. Obese children have a significantly higher chance to become obese adults than their healthy weight peers ${ }^{29}$. The obesity epidemic has led to a rise in several serious health consequences, including diabetes mellitus, hypertension, cardiovascular disease, cancer, sleep apnoea and orthopaedic complications ${ }^{30}$. As previously stated, obesity is also related to asthma, which will be elaborated below.

Obesity is caused by a chronic imbalance between energy intake and expenditure, resulting in an accumulation of body fat ${ }^{31}$. Consequently, primary, secondary and tertiary prevention of childhood obesity have mainly focused on restoring this imbalance. The most effective, but most controversial methods to lose weight in children are bariatric surgery and pharmacotherapy ${ }^{32-35}$. However, in the Netherlands, bariatric surgery in children is only allowed for research purposes. Moreover, most pharmacotherapies to lose weight are not allowed in children ${ }^{36}$. Several important 
factors that limit the applicability of surgery and pharmacotherapy in children are the high level of invasiveness, adverse effects, health risks, ethical considerations and the small target population of only morbidly obese patients (in adults, morbid obesity is defined as a $\mathrm{BMI} \geq 40)^{35}$.
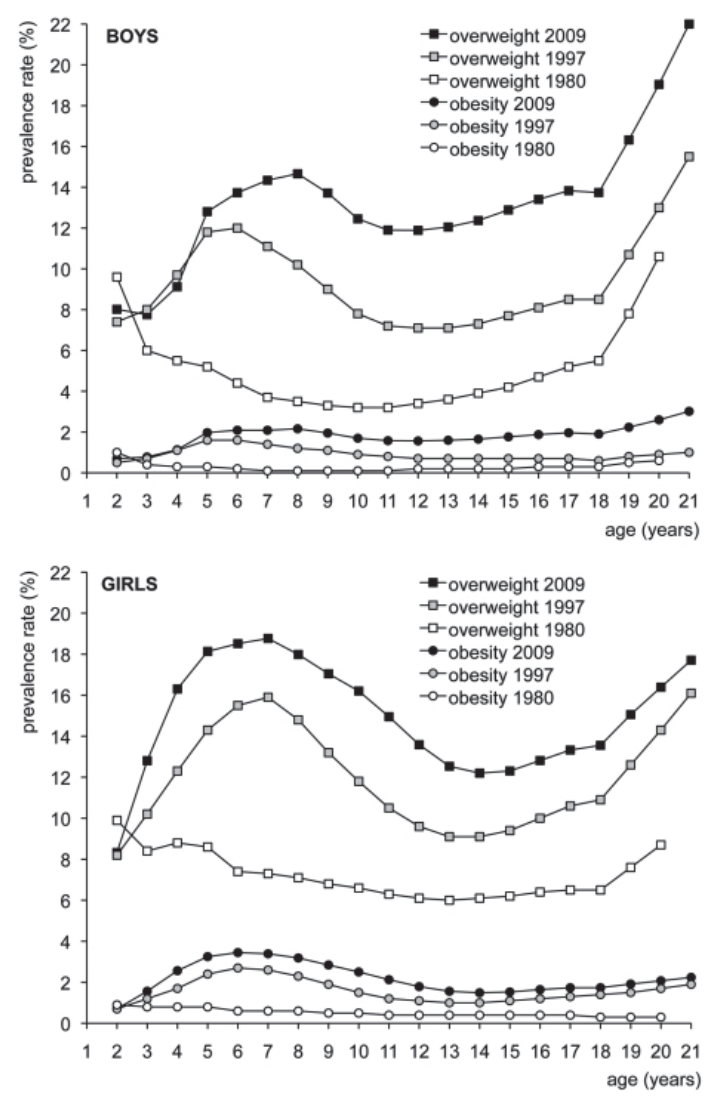

Figure 1.1 Prevalence of overweight and obesity in Dutch boys and girls from 1980-2009. Reprinted from Schönbeck et al. with permission of Plos One ${ }^{26}$.

Weight reduction by means of lifestyle interventions remains the preferred strategy for the vast majority of overweight and obese children ${ }^{32,33}$. Several reviews and metaanalyses concluded that among the allowed strategies in the Netherlands, long term (>1 year) multi-component lifestyle interventions targeted at the family level are most efficient in reducing body weight ${ }^{32,33,37}$. Components which should be included in a weight reduction intervention include nutritional education, dietary counselling, 
parenting skills, behavioural strategies, and physical-activity stimulation ${ }^{32,33,38}$. As not all studies include these critical success factors, the effectiveness of weight reduction interventions is often weak to moderate. In most studies, weight reductions barely reach clinically relevant levels ${ }^{32,39,40}$. Another common problem of current weight reduction interventions are the high rates of attrition (up to $73 \%)^{41}$.

It can be concluded that, although much efforts have been done, childhood obesity prevalences continue to rise. Although optimal components of weight reduction programs have been detected, not all studies include these critical success factors. Low effectiveness and high attrition rates are major challenges.

\section{The asthma-obesity phenotype}

There is strong evidence that persons with obesity have a higher risk to develop asthma

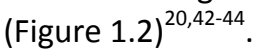

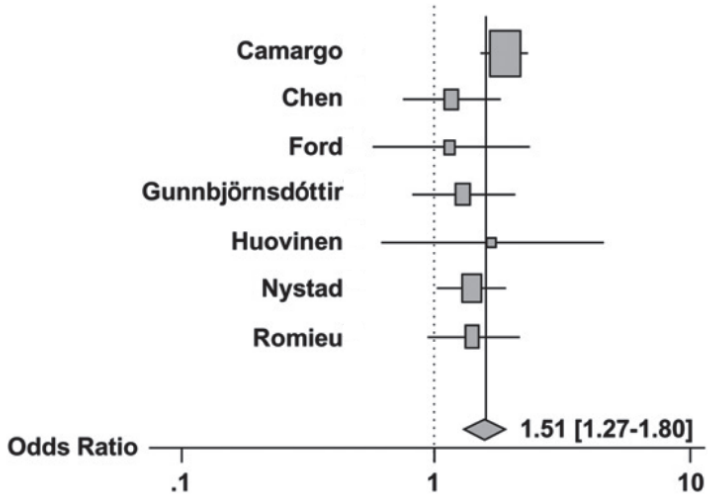

Figure 1.2 Point estimate for the summary odds of incident asthma at 1 year of follow-up, comparing obese and overweight men and women versus normal-weight men and women. A total of 333,102 unique subjects were included in this analysis. Antecedent obesity was associated with significantly increased annual odds (OR 1.51, 95\% Cl 1.27-1.80) of a new diagnosis of asthma. Reprinted from Beuther et al. with permission of the American Thoracic Society. Copyright (C) 2014 American Thoracic Society ${ }^{20}$.

In a meta-analysis of Beuther et al. among 333,102 unique adults, it was found that the odd's ratio (OR) for a new diagnosis of asthma in overweight and obese versus normalweight persons was $1.51(95 \% \mathrm{Cl} 1.27-1.80)^{20}$ (Figure 1.2). This effect is observed both in children and adults ${ }^{43,44}$. Not only an increase in incident asthma in obese persons is observed, but also a dose-response effect of BMI on asthma development ${ }^{20}$. Therefore, it is most likely that obesity precedes asthma development ${ }^{20,43,44}$. Although it is 
demonstrated that asthma and obesity are interrelated in children, several questions regarding this relationship remain unanswered. For example, the strength of the asthma-obesity relationships varies widely across studies, possibly due to different methodologies of defining asthma. Also, findings on the role of sex in the asthmaobesity relationship are inconsistent ${ }^{44}$. Some studies find stronger asthma-obesity relationship in boys ${ }^{43}$, whilst other studies report stronger asthma-obesity relationships in girls ${ }^{42,45,46}$.

The growing group of obese asthmatic patients are a major concern. A cluster-analysis detected a distinct asthma-obesity phenotype ${ }^{47}$. The typical obese asthmatic patient has a more 'severe' asthma, reflected by more medication use, a lower asthma control and higher admission rates to the intensive care unit for asthma-related problems than normal weight asthmatic peers ${ }^{48-50}$. In addition to the more 'severe asthma' characteristics, the asthma-obesity phenotype is characterised by female predominance, less atopy and a late onset of asthma ${ }^{47}$. Several studies confirm that obese asthmatic patients have low airway eosinophils counts ${ }^{47,51}$. The development of asthma in the obese might be caused by more neutrophilic patterns of airway inflammation ${ }^{52}$. Also in children, an asthma-obesity phenotype is detected which is characterised by poor asthma control ${ }^{50,53}$.

Several mechanisms are suggested that underlie the asthma-obesity relationship (Figure 1.3). Most studies focused on the mechanical and inflammatory hypothesis ${ }^{54-56}$. The mechanical hypothesis implies that due to excess abdominal and thoracic fat mass, intra-abdominal pressure increases and the downward movement of the diaphragm reduces. This results in reduced airway compliance and breathing at lower lung volumes. Consequently, expiratory reserve volume and functional residual capacity decrease ${ }^{54,56-59}$. In the extreme obese, breathing at low lung volumes in combination with a reduction in deep inspiration sighs, may also result in an adaption of the airway smooth muscle cell to generate force at shorter lengths. This could eventually lead to airway narrowing and increased airway resistance ${ }^{55,56}$. However, this last part of the mechanical hypothesis may account only for the severe obese and is therefore still under debate. The mechanical hypothesis could explain why several studies show that abdominal adiposity is more strongly related with asthma and obstructive lung function than general adiposity ${ }^{60}$.

The inflammatory hypothesis implies that the low grade systemic pro-inflammatory state as a result of increased fat mass can cause airway inflammation ${ }^{54}$. Several systemic inflammatory markers and energy-regulating hormones (e.g. TNF $\alpha$, Interleukin-6, leptin, adiponectin) derived from fat mass are related to airway inflammation ${ }^{50,54}$. Moreover, various other hypotheses can explain (parts of) the relationship between obesity and asthma. For example, in twin-studies, several genetic determinants of asthma are related to genetic determinants of obesity ${ }^{61,62}$. Also, comorbid conditions such as the metabolic syndrome, gastro-oesophageal reflux and obstructive sleep apnoea are proposed to play a role in the asthma-obesity 
relationship ${ }^{55,63}$. Those comorbidities are more prevalent in obesity, and could influence the expression of asthma, although these pathways remain to be explored. Most likely, the proposed asthma-obesity mechanisms do not exclude each other.

Although the asthma-obesity relationship satisfies several criteria of the causal relationship between a disease and a risk factor (e.g. a dose-response relationship, biological plausibility, and a correct temporal $\operatorname{order}^{21}$ ), it is still unclear whether, and how, weight reduction will influence those potential asthma-obesity mechanisms.

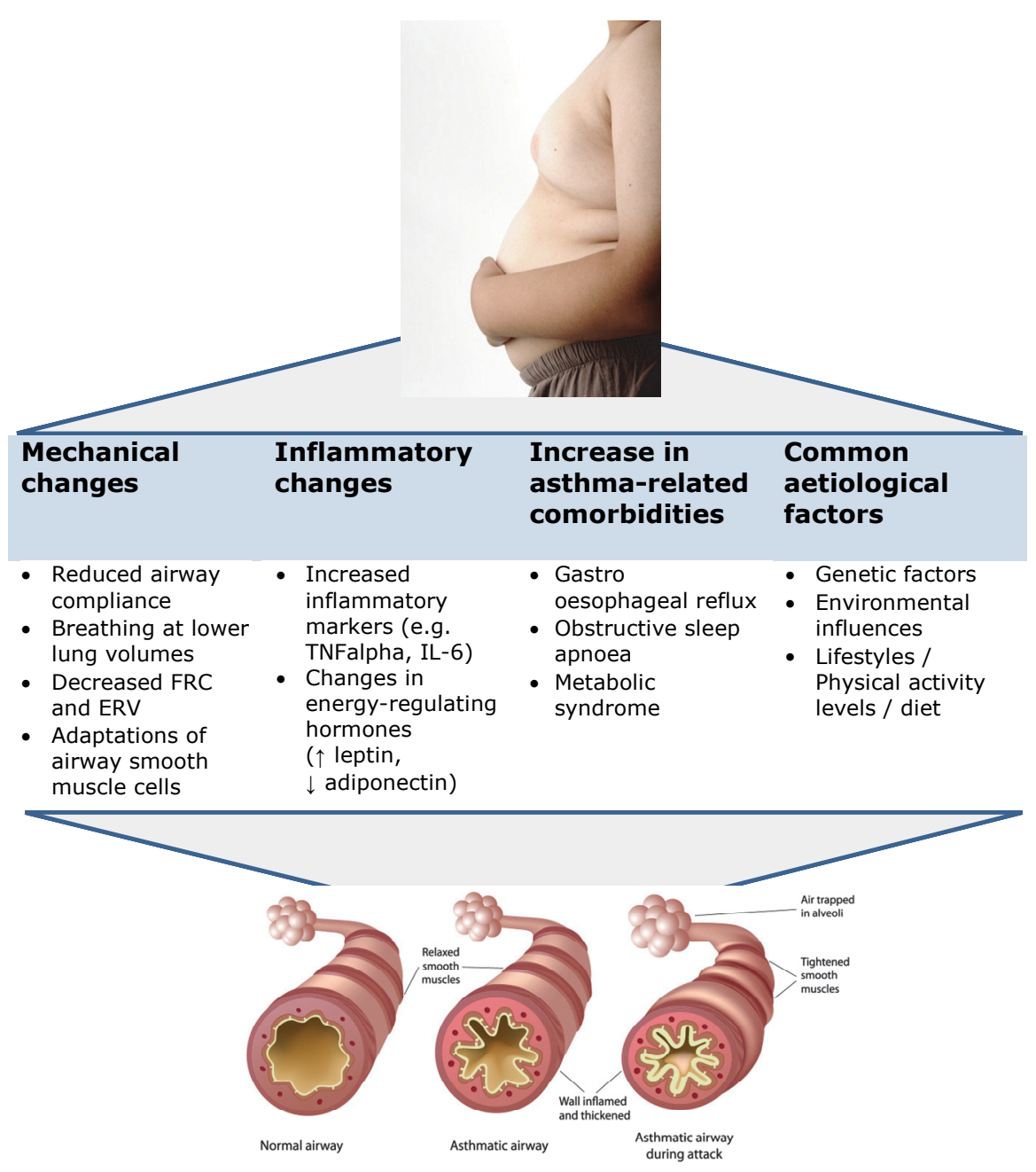

Figure 1.3 Possible mechanisms by which obesity can influence the development of asthma.

FRC: functional residual capacity, ERV: expiratory reserve volume, TNFalpha: tumour necrosis factor alpha, IL-6: interleukin-6. 


\section{Physical activity and exercise in asthma and obesity}

Asthma and obesity share several aetiological factors (Figure 1.3), which are hardly studied. Both asthma and obesity are characterised by exercise-related limitations. However, the role of physical activity in either the aetiology or preservation of the asthma-obesity relationship remains unclear. In a review by Eijkemans et al., high physical activity levels proved to be a potential protective factor for asthma development. A limitation of this review is that correction for confounding by BMI or obesity was not possible. Thus, the question remains unanswered whether the protective effect of high physical activity levels on asthma development could have been caused by a lower prevalence of obesity in physical active children ${ }^{64}$.

It can be argued that low physical activity levels cause a misbalance in the energy expenditure. This results in higher risks of obesity development, which in turn leads to a higher risk of asthma development and a more 'severe' asthma phenotype. Otherwise, most asthmatic subjects experience shortness of breath and discomfort during exercise, which could lead to avoidance of strenuous physical activity. Consequently, this can lead to a higher chance to develop obesity. However, these complex relationships are hardly studied, and it is necessary to map physical activity levels in childhood, and to identify possible relationships and interactions with asthma and obesity.

It is commonly accepted that exercise training has beneficial effects for one's health and should therefore be encouraged in children. In the Netherlands, exercise training recommendations are included in the guidelines for children with asthma ${ }^{65}$. However, the additional clinical value of exercise training in children with asthma is not clearly assessed yet. As exercise induced bronchoconstriction in children with asthma could lead to avoidance of exercise, there is a need for a clear overview of the potential beneficial effects of exercise in asthma. In addition, it is unclear what the most effective components of a training programs are for children with asthma. The lack of specific exercise goals for children with asthma hampers health professionals in their task to prescribe exercise for asthmatic children. Despite several reviews on training programs for children and adolescents with asthma, the optimal balance of type, frequency, length, duration and intensity has not been described yet ${ }^{66-68}$.

\section{Is weight reduction the solution?}

As the obesity prevalence continues to rise in the Netherlands, a large proportion of the asthmatic children has obesity, which leads to a high burden on the health care system. The question rises whether weight reduction could be an effective secondary preventive tool for asthma ${ }^{69}$. The study of Stenius-Aarniala et al. was the first in which the effects of a weight reduction intervention on several asthma features in adults with 
obesity and asthma was studied ${ }^{70}$. After an intensive 8-week lasting dietary intervention, lung function significantly improved in patients (e.g. forced expiratory volume in 1 second and forced vital capacity) up to 1 year after the intervention. Also other asthma features like asthma symptoms, dyspnoea and the use of rescue medication improved significantly ${ }^{70}$. Following this study, the effects of weight reduction in asthmatic patients, either by bariatric surgery, medication, lifestyle interventions or a combination, have been reported in several adult studies ${ }^{21,71,72}$. In general, a wide range of clinical relevant improvements were found, such as decreased symptom scores, less need for rescue medication, improved asthma control and increased lung function ${ }^{21,71,72}$. However, the majority of the studies are of low methodological quality, and there is a high need for well-designed randomised controlled studies (RCT's) ${ }^{71-73}$.

Very recently, a limited amount of studies documented the effects of a weight reduction intervention in a paediatric asthma population ${ }^{74-77}$. In the study of Da Silva et al., positive effects were reported on several domains such as lung function, symptoms, and daily rescue medication doses ${ }^{75}$. In contrary, in the studies of Jensen et al. and Van Leeuwen et al., only minimal improvements were seen on asthma control ${ }^{76}$, quality of life and degree of $\mathrm{EIB}^{77}$. These pronounced differences between studies are probably caused by differences in interventions and methodologies. Also, methodological quality is even lower than in adult studies, as only 1 study uses a RCT design, and sample sizes of intervention groups range from 10 to 26 participants. The currently published adult and paediatric studies lack power to detect the underlying mechanisms which are responsible for weight reduction ${ }^{73}$.

As lifestyle behaviours in childhood are expected to track into adulthood, there is a high need for well-designed RCT's in obese children with asthma with an emphasis on the effects of weight reduction and accompanying underlying mechanisms ${ }^{73}$. 


\section{Aims of this dissertation}

The primary aim of the current dissertation is to study the effectiveness and underlying mechanisms of secondary prevention of asthma by means of a weight reduction intervention in children with asthma and overweight/obesity.

Secondary aims are to:

1) study the strength of the asthma - obesity relationship and identify the influence of sex.

2) gain insight in the effects of exercise training on paediatric asthma and identify optimal elements of a training regime for asthmatic children.

3) map physical activity levels in paediatric asthma and obesity.

4) design an optimal study protocol to test the effects of weight reduction on asthma features.

5) provide health care professionals information to prevent attrition in paediatric weight reduction interventions.

\section{Outline of this dissertation}

In this dissertation several studies in children with asthma and obesity are described, with a focus on weight reduction, physical activity and exercise training. This dissertation opens with a study on the prevalence of paediatric asthma, overweight and obesity and the strength of the asthma-obesity relationship in the South of the Netherlands (Chapter 2). Also, the role of sex in the asthma-obesity relationship is investigated in this chapter. A systematic review on the effects of exercise training in children with asthma was performed (Chapter 3). As physical activity could play an important role in the asthma-obesity phenotype, the next step involved comparing the physical activity levels between children with only asthma, only overweight/obesity, healthy controls and children with both asthma and overweight/obesity (Chapter 4). With the knowledge of physical activity levels and the effects of exercise training in children with asthma, a longitudinal multifactorial weight reduction intervention for children with asthma and obesity was designed named MIKADO (multifactorial intervention in children with asthma and obesity) (Chapter 5). The effects of the MIKADO intervention on several asthma features, inflammatory parameters and dynamic and static lung function indices were reported (Chapter 6). As attrition was a problem in the MIKADO study, the deliberation process of parents and children for (dis)continuing this weight reduction intervention was studied (Chapter 7). This dissertation concludes with a general discussion of the outcomes, limitations, clinical relevance and future implications of the studies described (Chapter $\mathbf{8}$ ). 


\section{References}

1. From the Global Strategy for Asthma Management and Prevention, Global Initiative for Asthma (GINA) 2012. http://www.ginasthma.org/. Accessed 24-3, 2014.

2. Martinez FD, Vercelli D. Asthma. Lancet. 2013;382:1360-1372.

3. Milgrom H, Taussig LM. Keeping children with exercise-induced asthma active. Pediatrics 1999;104:e38.

4. Price JF. Choices of therapy for exercise-induced asthma in children. Allergy 2001;56 Suppl 66:12-17.

5. Weiler JM, Bonini S, Coifman R, Craig T, Delgado L, Capão-Filipe M, Passali D, Randolph C, Storms W; Ad Hoc Committee of Sports Medicine Committee of American Academy of Allergy, Asthma \& Immunology. American Academy of Allergy, Asthma \& Immunology Work Group report: exerciseinduced asthma. J Allergy Clin Immunol 2007;119: 1349-1358.

6. Randolph C. Pediatric exercise-induced bronchoconstriction: contemporary developments in epidemiology, pathogenesis, presentation, diagnosis, and therapy. Curr Allergy Asthma Rep 2013;13: 662-671.

7. Parsons JP, Hallstrand TS, Mastronarde JG, Kaminsky DA, Rundell KW, Hull JH, Storms WW, Weiler JM, Cheek FM, Wilson KC, Anderson SD. American Thoracic Society Subcommittee on Exercise-induced Bronchoconstriction. An official American Thoracic Society clinical practice guideline: exercise-induced bronchoconstriction. Am J Respirat Crit Care Med 2013;187:1016-1027.

8. Braman SS. The global burden of asthma. Chest 2006;130:4S-12S.

9. To T, Dell S, Dick P, Cicutto L. The burden of illness experienced by young children associated with asthma: a population-based cohort study. J Asthma 2008;45:45-49.

10. Bateman ED, Hurd SS, Barnes PJ, Bousquet J, Drazen JM, FitzGerald M, Gibson P, Ohta K, O'Byrne P, Pedersen SE, Pizzichini E, Sullivan SD, Wenzel SE, Zar HJ. Global strategy for asthma management and prevention: GINA executive summary. Eur Respir J 2008;31:143-178.

11. Masoli M, Fabian D, Holt S, Beasley R. Global Initiative for Asthma The global burden of asthma: executive summary of the GINA Dissemination Committee report. Allergy 2004;59:469-478.

12. Asher MI, Montefort S, Björkstén B, Lai CK, Strachan DP, Weiland SK, Williams H; ISAAC Phase Three Study Group. Worldwide time trends in the prevalence of symptoms of asthma, allergic rhinoconjunctivitis, and eczema in childhood: ISAAC Phases One and Three repeat multicountry crosssectional surveys. Lancet 2006;368:733-743.

13. Anandan $C$, Nurmatov $U$, van Schayck OC, Sheikh A. Is the prevalence of asthma declining? Systematic review of epidemiological studies. Allergy. 2010;65:152-167.

14. van Schayck CP, Smit HA. The prevalence of asthma in children: a reversing trend. Eur Respir J 2005; 26:647-650.

15. Mommers M, Gielkens-Sijstermans C, Swaen GM, van Schayck CP. Trends in the prevalence of respiratory symptoms and treatment in Dutch children over a 12 year period: results of the fourth consecutive survey. Thorax 2005;60:97-99.

16. Heijmans $M$, Spreeuwenberg, $\mathrm{P}$, Rijken, PM. Monitor zorg- en leefsituatie van mensen met astma en mensen met COPD: Trends en ontwikkelingen over de periode $2001-2008$. [Monitor of care and living climate of people with asthma and COPD: Trends and developments during the period 2001-2008.] In: Nivel, ed2009: http://www.nivel.nl/sites/default/files/bestanden/COPD-trendrapport.pdf. Accessed 243, 2014.

17. van der Wal M, Uitenbroek, DG., Verhoeff, AP. Toegenomen percentage basisschoolkinderen met astmatische klachten in Nederland, 1984/'85-1994/'95; een literatuuronderzoek. [Increased percentage elementary school children with asthmatic complaints in the Netherlands, 1984/85' -1994/95'; a literature review.] Ned Tijdschr Geneeskd 2000;144:1780-1785.

18. Wiesch DG, Meyers DA, Bleecker ER. Genetics of asthma. J Allergy Clin Immunol 1999;104:895-901.

19. Laitinen T, Rasanen M, Kaprio J, Koskenvuo M, Laitinen LA. Importance of genetic factors in adolescent asthma: a population-based twin-family study. Am J Respir Crit Care Med 1998;157:1073-1078.

20. Beuther DA, Sutherland ER. Overweight, obesity, and incident asthma: a meta-analysis of prospective epidemiologic studies. Am J Respir Crit Care Med 2007;175:661-666. 
21. Moreira A, Bonini M, Garcia-Larsen V, Bonini S, Del Giacco SR, Agache I, Fonseca J, Papadopoulos NG, Carlsen KH, Delgado L, Haahtela T. Weight loss interventions in asthma: EAACl evidence-based clinical practice guideline (part I). Allergy 2013;68:425-439.

22. Jongste JC, Vrijlandt, EJLE. Astma bij kinderen; herziene richtlijnen van de sectie kinderlongziekten van de NVK [Paediatric Asthma; revised guidelines of the paediatric department of the Dutch Paediatric Society]. Amsterdam: Jurriaans Lindenbaum Grafimedia; 2008.

23. Haslam DW, James WP. Obesity. Lancet 2005;366:1197-1209.

24. Centers for Disease Control and Prevention: Overweight and Obesity. http://www.cdc.gov/obesity/ adult/defining.html. Accessed 27-11, 2013.

25. Cole TJ, Green PJ. Smoothing reference centile curves: the LMS method and penalized likelihood. Stat Med 1992;11:1305-1319.

26. Schönbeck Y, Talma H, van Dommelen P, Bakker B, Buitendijk SE, Hirasing RA, van Buuren S. Increase in prevalence of overweight in Dutch children and adolescents: a comparison of nationwide growth studies in 1980, 1997 and 2009. PloS One 2011;6:e27608.

27. World Health Organisation Global Health Observatory Data Repository. Risk factors: Overweight/Obesity. http://apps.who.int/gho/data/node.main.A896?lang=en. Accessed 27-11, 2013.

28. Lamberts P, Steenbakkers M, Thijssen NHB, Backus-Mujakovic S, Vreede JJM de, Hajema KJ, Poos, MJJC. Een gezonde kijk op Zuid-Limburg. Regionale Volksgezondheid Toekomst Verkenning [ A healthy look at South-Limburg]. 2010 (January 28 ). http://www.regionaalkompas.nl/object_binary/ o16168_Eengezonde-kijk-op-Zuid-Limburg.pdf. Accessed 2013 Sept 16.

29. Singh AS, Mulder C, Twisk JW, van Mechelen W, Chinapaw MJ. Tracking of childhood overweight into adulthood: a systematic review of the literature. Obes Rev 2008;9:474-488.

30. Naukkarinen J, Rissanen A, Kaprio J, Pietilainen KH. Causes and consequences of obesity: the contribution of recent twin studies. Int J Obes (Lond) 2012;36:1017-1024.

31. Pereira HR, Bobbio TG, Antonio MA, Barros Filho Ade A. Childhood and adolescent obesity: how many extra calories are responsible for excess of weight? Rev Paul Pediatr 2013;31:252-257.

32. McGovern L, Johnson JN, Paulo R, Hettinger A, Singhal V, Kamath C, Erwin PJ, Montori VM. Clinical review: treatment of pediatric obesity: a systematic review and meta-analysis of randomized trials. J Clinl Endocrinol Metab 2008;93:4600-4605.

33. Oude Luttikhuis H, Baur L, Jansen H, Shrewsbury VA, O'Malley C, Stolk RP, Summerbell CD. Interventions for treating obesity in children. Cochrane Database Syst Rev 2009;CD001872.

34. Stefater MA, Jenkins T, Inge TH. Bariatric surgery for adolescents. Pediatr Diab 2013;14:1-12.

35. Kelly AS, Barlow SE, Rao G, Inge TH, Hayman LL, Steinberger J, Urbina EM, Ewing LJ, Daniels SR; American Heart Association Atherosclerosis, Hypertension, and Obesity in the Young Committee of the Council on Cardiovascular Disease in the Young, Council on Nutrition, Physical Activity and Metabolism, and Council on Clinical Cardiology. Severe obesity in children and adolescents: identification, associated health risks, and treatment approaches: a scientific statement from the American Heart Association. Circulation 2013;128:1689-1712.

36. Ligtenberg G, Heymans, J,van der Meer, FM. Bariatrische chirurgie bij kinderen en jeugdigen met ernstige obesitas. [Bariatric chirurgy in children and adolescents with severe obesity.] In: Zorgverzekeringen Cv, ed. Diemen 2012:1-9.

37. Waters E, de Silva-Sanigorski A, Hall BJ, Brown T, Campbell KJ, Gao Y, Armstrong R, Prosser L, Summerbell $C D$. Interventions for preventing obesity in children. Cochrane Database Syst Rev 2011;12:CD001871.

38. Hoelscher DM, Kirk S, Ritchie L, Cunningham-Sabo L, Academy Positions C. Position of the Academy of Nutrition and Dietetics: interventions for the prevention and treatment of pediatric overweight and obesity. J Acad Nutr Diet 2013;113:1375-1394.

39. Ho M, Garnett SP, Baur L, Burrows T, Stewart L, Neve M, Collins C. Effectiveness of lifestyle interventions in child obesity: systematic review with meta-analysis. Pediatrics 2012;130:e1647-1671.

40. Luckner H, Moss JR, Gericke CA. Effectiveness of interventions to promote healthy weight in general populations of children and adults: a meta-analysis. Eur J Public Health 2012;22:491-497.

41. Skelton JA, Beech BM. Attrition in paediatric weight management: a review of the literature and new directions. Obes Rev 2011;12:e273-281. 
42. Flaherman V, Rutherford GW. A meta-analysis of the effect of high weight on asthma. Arch Dis Child 2006;91:334-339.

43. Chen YC, Dong GH, Lin KC, Lee YL. Gender difference of childhood overweight and obesity in predicting the risk of incident asthma: a systematic review and meta-analysis. Obes Rev 2013;14:222-231.

44. Papoutsakis C, Priftis KN, Drakouli M, Prifti S, Konstantaki E, Chondronikola M, Antonogeorgos G, Matziou V. Childhood overweight/obesity and asthma: is there a link? A systematic review of recent epidemiologic evidence. J Acad Nutr Diet 2013;113:77-105.

45. Matricardi PM, Grber C, Wahn U, Lau S. The asthma-obesity link in childhood: open questions, complex evidence, a few answers only. Clin Exp Allergy 2007;37:476-484.

46. Noal RB, Menezes AM, Macedo SE, Dumith SC. Childhood body mass index and risk of asthma in adolescence: a systematic review. Obes Rev 2011;12:93-104.

47. Haldar P, Pavord ID, Shaw DE, Berry MA, Thomas M, Brightling CE, Wardlaw AJ, Green RH. Cluster analysis and clinical asthma phenotypes. Am J Respir Crit Care Med 2008;178:218-224.

48. Peters-Golden M, Swern A, Bird SS, Hustad CM, Grant E, Edelman JM. Influence of body mass index on the response to asthma controller agents. Eur Respir J 2006;27:495-503.

49. Shore SA. Obesity and asthma: possible mechanisms. J Allergy Clin Immunol 2008;121:1087-1093.

50. Jensen ME, Collins CE, Gibson PG, Wood LG. The obesity phenotype in children with asthma. Paediatr Respir Rev 2011;12:152-159.

51. Gibson PG. Obesity and asthma. Annals of the American Thoracic Society 2013;10 Suppl:S138-142.

52. Scott HA, Gibson PG, Garg ML, Wood LG. Airway inflammation is augmented by obesity and fatty acids in asthma. Eur Respir J 2011;38:594-602.

53. Holguin F, Bleecker ER, Busse WW, Calhoun WJ, Castro M, Erzurum SC, Fitzpatrick AM, Gaston B, Israel E, Jarjour NN, Moore WC, Peters SP, Yonas M, Teague WG, Wenzel SE. Obesity and asthma: an association modified by age of asthma onset. J Allergy Clin Immunol 2011;127:1486-1493

54. Ali Z, Ulrik CS. Obesity and asthma: A coincidence or a causal relationship? A systematic review. Respir Med 2013;107:1287-1300.

55. Boulet LP. Asthma and obesity. Clin Exp Allergy 2013;43:8-21.

56. Brashier B, Salvi S. Obesity and asthma: physiological perspective. J Allergy 2013;2013:198068.

57. Naimark A, Cherniack RM. Compliance of the respiratory system and its components in health and obesity. J Appl Physiol 1960;15:377-382.

58. Lucas SR, Platts-Mills TA. Paediatric asthma and obesity. Paediatr Respir Rev 2006;7:233-238.

59. Farah CS, Salome CM. Asthma and obesity: a known association but unknown mechanism. Respirology 2012;17:412-421.

60. Brumpton B, Langhammer A, Romundstad P, Chen Y, Mai XM. General and abdominal obesity and incident asthma in adults: the HUNT study. Eur Respir J 2013;41:323-329.

61. Hallstrand TS, Fischer ME, Wurfel MM, Afari N, Buchwald D, Goldberg J. Genetic pleiotropy between asthma and obesity in a community-based sample of twins. J Allergy Clin Immunol 2005;116: 1235-1241.

62. Thomsen SF, Ulrik CS, Kyvik KO, Sørensen TI, Posthuma D, Skadhauge LR, Steffensen I, Backer V. Association between obesity and asthma in a twin cohort. Allergy 2007;62:1199-1204.

63. Dixon AE, Clerisme-Beaty EM, Sugar EA, Cohen RI, Lang JE, Brown ED, Richter JE, Irvin CG, Mastronarde JG. Effects of obstructive sleep apnea and gastroesophageal reflux disease on asthma control in obesity. J Asthma 2011;48:707-713.

64. Eijkemans M, Mommers M, Draaisma JM, Thijs C, Prins MH. Physical activity and asthma: a systematic review and meta-analysis. PloS One 2012;7:e50775.

65. Bindels PJE, Van de Wouden JC, Ponsioen BP, Brand PLP, Salome PL, Van Hensbergen W. NHGstandaard Astma bij kinderen. [Dutch General Practitioners guidelines, asthma in children.] 2006;49. 2nd edition.

66. Ram FS, Robinson SM, Black PN, Picot J. Physical training for asthma. Cochrane Database Syst Rev 2005:CD001116.

67. Welsh L, Kemp J, Roberts RGD. Effects of physical conditioning on children and adolescents with asthma. Sports Med 2005;35:127-141. 
68. Carson KV, Chandratilleke MG, Picot J, Brinn MP, Esterman AJ, Smith BJ. Physical training for asthma. Cochrane Database Syst Rev 2013;9:CD001116.

69. Black MH, Smith N, Porter AH, Jacobsen SJ, Koebnick C. Higher prevalence of obesity among children with asthma. Obesity (Silver Spring) 2012;20:1041-1047.

70. Stenius-Aarniala B, Poussa T, Kvarnstrom J, Gronlund EL, Ylikahri M, Mustajoki P. Immediate and long term effects of weight reduction in obese people with asthma: randomised controlled study. BMJ 2000;320:827-832.

71. Eneli IU, Skybo T, Camargo CA, Jr. Weight loss and asthma: a systematic review. Thorax 2008;63: 671-676.

72. Adeniyi FB, Young T. Weight loss interventions for chronic asthma. Cochrane Database Syst Rev 2012;7:CD009339.

73. Dixon AE, Holguin F, Sood A, Salome CM, Pratley RE, Beuther DA, Celedón JC, Shore SA; American Thoracic Society Ad Hoc Subcommittee on Obesity and Lung Disease. An official American Thoracic Society Workshop report: obesity and asthma. Proc Am Thorac Soc 2010;7:325-335.

74. Masumoto N, Odajima H, Shimada K, Murakami Y, Motomura C, Honjo S, Okada K. Effect of weight reduction on respiratory function in obese children with asthma. Allergy 2011;60:983-992.

75. da Silva PL, de Mello MT, Cheik NC, Sanches PL, Correia FA, de Piano A, Corgosinho FC, Campos RM, do Nascimento CM, Oyama LM, Tock L, Tufik S, Dâmaso AR. Interdisciplinary therapy improves biomarkers profile and lung function in asthmatic obese adolescents. Pediatr Pulmonol 2012;47:8-17.

76. Jensen ME, Gibson PG, Collins CE, Hilton JM, Wood LG. Diet-induced weight loss in obese children with asthma: a randomized controlled trial. Clin Exp Allergy 2013;43:775-784.

77. van Leeuwen JC, Hoogstrate M, Duiverman EJ, Thio BJ. Effects of dietary induced weight loss on exercise-induced bronchoconstriction in overweight and obese children. Pediatr Pulmonol 2013. In press. 

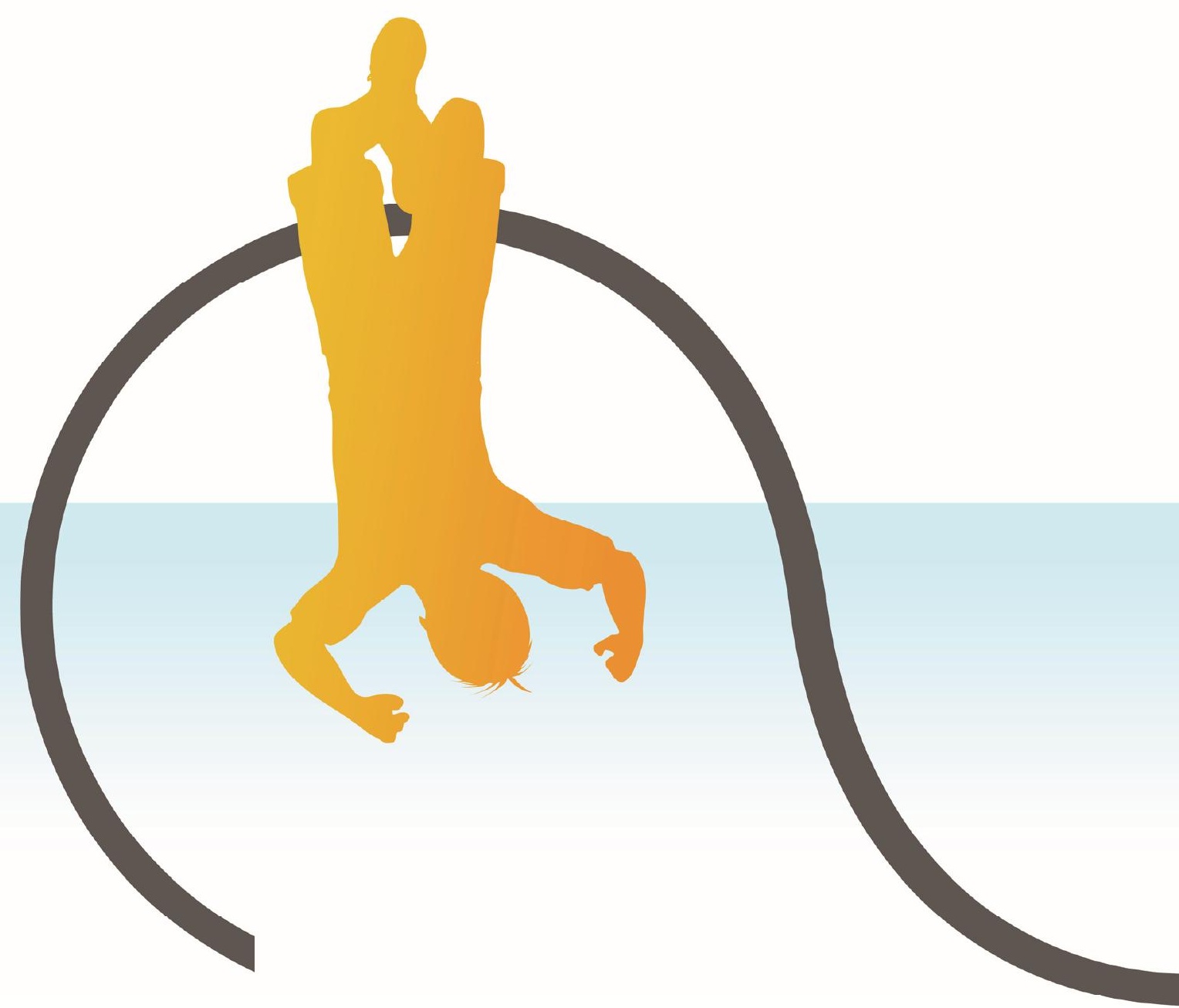


$$
z^{2}
$$




\section{Abstract}

\section{Objective}

Obesity has been identified as a risk factor for asthma in children. However, in the Netherlands, the obesity prevalence is rising while the asthma prevalence in children is stabilising. The aim of this study is to clarify the association between asthma and body mass index (BMI) in children and whether this association is influenced by sex.

\section{Study design}

Parents of 39,316 children (6-16 years) in the south of the Netherlands were invited to complete an online questionnaire on respiratory symptoms, anthropometric variables and several potential confounding factors for asthma and obesity (including sex, birth weight and breastfeeding). Data was analysed by multivariable logistic regression models and an ordinal regression model.

\section{Results}

The response rate was $24 \%$ ( $n$ boys $=4,743, n$ girls $=4,529$ ). The prevalence of asthma, overweight and obesity was $8 \%, 15 \%$ and $2 \%$ respectively. Body mass index - standard deviation score (BMISDS) was related to current asthma (adjusted OR: 1.29; 95\% Cl: 1.14-1.45, $\mathrm{p} \leq 0.001$ ). When stratified for sex, asthma and BMI-SDS were only related in girls (Girls: adjusted OR: $1.31 ; 95 \% \mathrm{Cl}$ : 1.13-1.51, $\mathrm{p} \leq 0.001$. Boys: adjusted OR: $1.01 ; 95 \% \mathrm{Cl}: 0.91-1.14, \mathrm{p}=0.72$ ).

\section{Conclusions}

The positive association between BMI-SDS and asthma is only present in girls, not boys. Future studies into obesity and asthma should correct for sex in their analyses. 


\section{Introduction}

Worldwide, there has been an epidemic increase in the prevalence of overweight and obesity, both in adults and children ${ }^{1}$. This alarming increase is also present in the Netherlands, where it has been demonstrated that more than $13 \%$ of children aged 5-16 are overweight, with the highest prevalence in girls $(17 \%)^{2}$. The increase in overweight during the last few decades has coincided with a steep increase in the worldwide asthma prevalence ${ }^{3}$. Therefore, a relationship between overweight and asthma has been hypothesized ${ }^{4}$. A recent meta-analysis by Chen et al. reported a relative risk (RR) of 1.19 (95\% $\mathrm{Cl}: 1.03-1.37)$ for children who are overweight and a RR of 2.02 (95\% Cl: 1.16-3.50) for children who are obese of developing asthma in the future ${ }^{5}$. Several possible biological underlying mechanisms have been proposed describing the potential effect of obesity on the pulmonary physiology, inflammatory mechanisms, and/or co-morbidities such as gastro-oesophageal reflux ${ }^{6,7}$.

In the Netherlands, the initial increase in asthma prevalence has stabilized or even declined since the late 1990s, especially amongst children ${ }^{3,8}$. Yet, since the prevalence of overweight and obesity is still rising in the Netherlands, the hypothesized asthmaobesity relationship can be questioned. Moreover, various aspects of the putative relationship are still unclear. For example, the influence of sex as a potential effect modifier on the asthma-obesity relationship in children has not yet been determined. In adults, it has been demonstrated that the asthma-obesity relationship is more strongly associated with the female sex ${ }^{9}$. However in children, results are conflicting ${ }^{4,5,10,11}$. Moreover, several studies have suggested that obese asthmatics have more severe asthmatic symptoms and more frequent inhaled corticosteroid (ICS) use $\mathrm{s}^{7,12}$. However, these findings have not been uniformly reported in childhood ${ }^{7,12,13}$.

This study was designed to investigate the relationship between asthma and body mass index - standard deviation score (BMI-SDS) and to evaluate the potential influence of sex in Dutch children.

\section{Methods}

\section{Study design and population}

This cross-sectional study was performed in South Limburg, a province of the Netherlands. Parents of children aged 6-16 years $(N=39,351)$ living in South Limburg received an online self-administered questionnaire about the health of their children via the local authorities. The questionnaire was sent out in May 2010. After three weeks the non-responders received a reminder (Figure 2.1). A random sample of 400 parents in the non-responding group received a short questionnaire about the main outcome parameters, in order to compare the responding and non-responding group. 
The study was approved by the Ethics Committee of the Maastricht University Medical Centre (NL28214.068.09 / MEC 09-2-088).

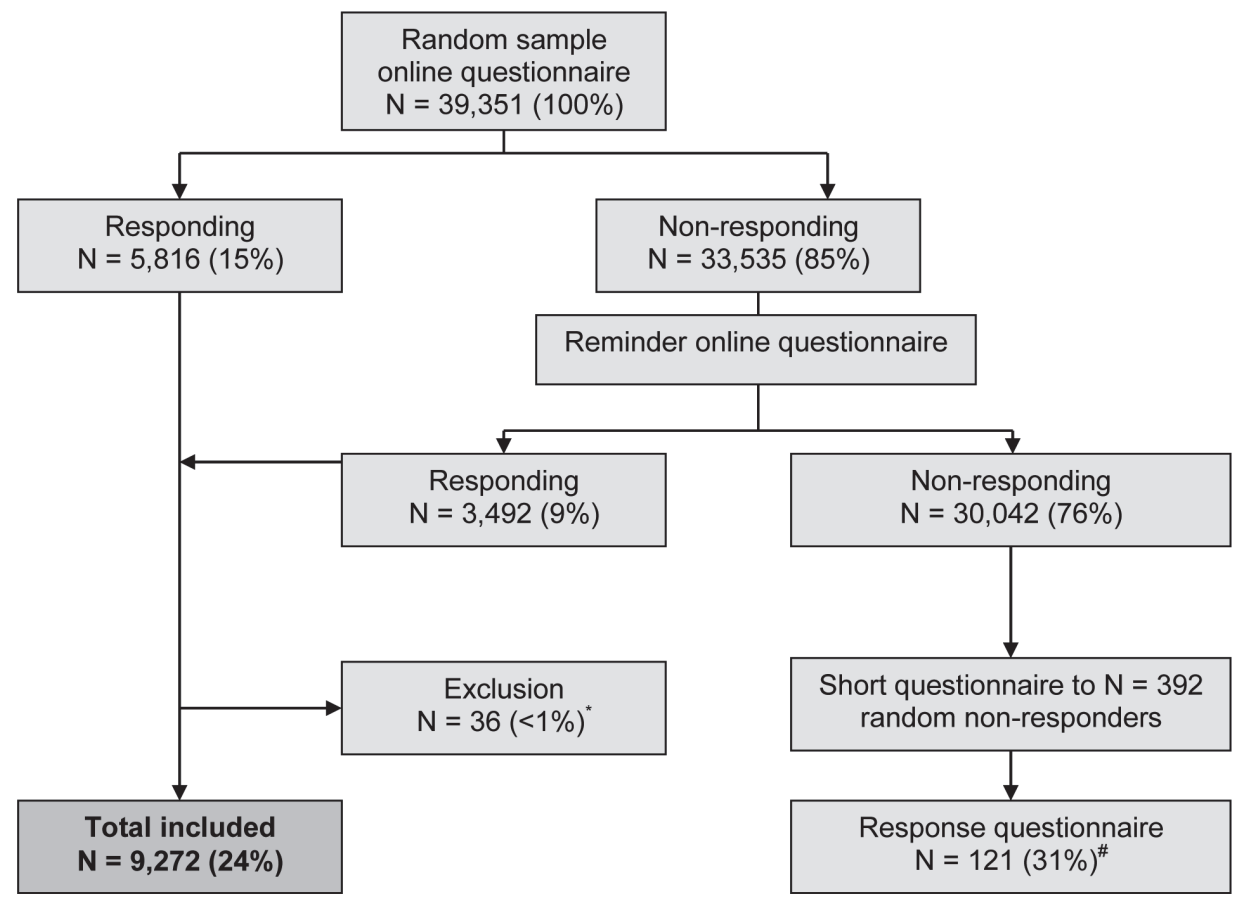

Figure 2.1 Study flow diagram. * Percentage of the total group of responders. \# Response percentage of the random group of non-responders that received the additional questionnaire.

\section{Main outcome parameters}

The online questionnaire included questions about anthropometric variables, the international study of asthma and allergy in children (ISAAC) questionnaire, and questions relating to potential confounding factors for asthma and the asthma-BMI-SDS relationship ${ }^{14,15}$.

\section{Anthropometrics}

Parental reports of the body weight (to the nearest $0.1 \mathrm{~kg}$ ) and length (to the nearest $\mathrm{cm}$ ) of the children was used. The BMI-SDS was calculated using the Lambda Mu Sigma method of Cole et al., with the reference values of the fourth national Dutch growth study $(1997)^{16,17}$. BMI-SDS was used as a continuous outcome variable. For illustrative 


\section{Sex differences in the relationship between asthma and overweight in Dutch children: a survey study}

purposes, children were also distributed into weight categories. Underweight was defined as a BMI-SDS $<-1.8$ and normal weight as a BMI-SDS $\geq-1.8$ and $<1.1$. A child was defined as overweight with a BMI-SDS $\geq 1.1$ and $<2.3$ and as obese with a BMI SDS $\geq 2.3^{18}$.

\section{Asthma}

Based on the ISAAC questionnaire, children were defined as having current asthma if the parent/caretaker reported that the child had ever been diagnosed with asthma by a health practitioner and if at least one of the following criteria had been met in the last twelve months: 1. At least one episode of wheezing or whistling in the chest; 2. A dry cough at night, apart from a cough associated with a cold or chest infection, for at least one night a week; 3 . Use of inhalation medication (bronchodilators and/or ICS).

\section{Confounders}

Based on previous research, the parameters of sex of the child and age (in years) were chosen as a priori confounders for the asthma-BMI-SDS relationship ${ }^{14,15}$. Other potential confounders which were addressed in the questionnaire included: highest educational level of parents, family history of asthma (defined as asthma in at least one first-degree family member), active smoking by the child, second-hand smoking (defined as at least one family member smoking zonce a week in the presence of the child), maternal smoking during pregnancy, breastfeeding duration (categories used: 0 months, $\leq 2$ months, 3-4 months, 5-6 months and $>6$ months), number of siblings $(0,1,2,3, \geq 4)$, ethnicity (defined as non-native when at least one of the parents was not born in the Netherlands), attendance at a day care centre before the age of 5 years, maternal antibiotic use during pregnancy, birth weight (categories used: <1500 gram, 1500-1999 gram, 2000-2499 gram, 2500-3499 gram and >3500 gram), presence of hairy pets at home since birth, growing up on a farm, and puberty (based on $\geq 10.7$ years for girls and $\geq 11.5$ for boys as defined by De Muinich-Keizer ${ }^{19}$ ).

\section{Statistical analysis}

Data were analysed with SPSS 20.0 (SPSS inc., Chicago IL, USA). Baseline characteristics and the characteristics of the responding and non-responding group were compared by using an unpaired t-test for continuous variables (as all variables were normally distributed) and a chi-square test for categorical variables. Due to the electronic structure of the questionnaire there are no missing data, except for several cases with unrealistic values in the BMI-SDS range (Figure 2.1). 


\section{Primary model}

A multivariable logistic regression model was used to evaluate the relationship between BMI-SDS and current asthma. In a pre-analysis we tested the significance of the interaction terms 'age by sex' and 'puberty by sex' as well as the following terms by BMI-SDS: 'sex', 'age', 'puberty', 'highest educational level', 'birth weight', 'passive smoking', 'smoking during pregnancy' and 'ever having breastfeeding'. In the final regression model, BMI-SDS, the a priori confounders ('sex' and 'age') and significant interaction terms were added by the enter procedure; other confounders (those mentioned above) were added by the Forward Likelihood Ratio (LR) procedure if the $p$ value was $\leq 0.10$. Separate models were created for the confounders 'age' (in years) and 'puberty' to avoid multicollinearity. Results are presented with the confounder age unless stated otherwise. For all significant interaction terms the Odds Ratio's (OR) between asthma and BMI-SDS were additionally calculated by using stratification. We adjusted for multiple testing with the Bonferroni correction. All p-values in the primary analyses are presented as Bonferroni corrected values. Results are presented as adjusted OR and their $95 \%$ confidence intervals $(95 \% \mathrm{Cl})$.

\section{Sub analyses}

Within the group of children with asthma, we investigated the effect of BMI-SDS on wheezing in the previous 12 months (categories: never, 1-3 episodes, 4-12 episodes, $>12$ episodes) and dry cough at night in the previous 12 months (categories: never, $<1$ night per month, $>1$ night per month and $<1$ night per week, $>1$ night per week) by using an ordinal regression model. We included the following selection of potential confounders: 'age' (in years), 'sex', 'family history of asthma', 'passive smoking' and 'educational level of the parents'.

The effect of BMI-SDS on the use of ICS (yes/no) was calculated using a logistic regression model. We included the following confounders a priori using the enter method: 'BMI-SDS', 'sex of the child' and 'age' (in years). The following confounders were added by using the forward LR procedure: 'family history of asthma', 'passive smoking' and 'educational level of the parents'.

\section{Sample size calculation}

A sample size calculation was performed to identify the number of participants needed to detect an OR of 1.94 between asthma and overweight in children, as described by Rodriguez et al. ${ }^{20}$. The Kelsey formula for observational epidemiology was used, taking an alpha error of $5 \%$, a power of $80 \%$ and a ratio of exposed (overweight/obese) vs. unexposed (normal weight) subjects of 1:5. If assumed that the asthma prevalence among the normal weight subjects would be 7\%, then 1,228 participants were determined to be sufficient to detect an asthma-BMI-SDS association in this population. 


\section{Sex differences in the relationship between asthma and overweight in Dutch children: a survey study}

\section{Results}

\section{Response to questionnaire}

A flow chart of the study inclusion is provided in Figure 2.1. After a reminder, the response rate to the questionnaire was $24 \%(\mathrm{~N}=9,308)$. In total, 9,272 study participants were included, as 36 children were excluded because of unrealistic values in the BMI-SDS range. The response to the questionnaire in the selected nonresponding group was $31 \%(\mathrm{~N}=121)$ (Figure 2.1$)$. The responders and non-responders groups did not differ regarding baseline characteristics such as asthma prevalence, BMISDS and asthma in a first-degree family member (supporting information Table S2.1).

\section{Baseline characteristics}

The prevalence of current asthma in the total population was $7.6 \%(\mathrm{~N}=709)$. In total, $15.2 \%(\mathrm{~N}=1,412)$ of the children were overweight and $2.4 \%(\mathrm{~N}=225)$ of the children were obese (Table 2.1). The mean age of the participants was 10.9 years (range $5.6-17.3$ years). The majority of the children were native Dutch $(\mathrm{N}=7,799,84 \%)$. Nearly half of the asthmatic children suffered from atopic symptoms such as hay fever or eczema. Three-quarters of the asthmatic children experienced at least one wheezing episode in the last year and $95 \%$ of the asthmatics used bronchodilators. Compared to the non-asthmatic children, asthmatic children were more likely to have a high BMI and BMI-SDS, parents with a low educational level, a family history of asthma and were more often boys (Table 2.1). Additional baseline characteristics can be found in the supporting information Table S2.2.

\section{Primary analyses}

After adjustment for significant confounding factors, BMI-SDS was positively associated with asthma (adjusted OR: 1.29; 95\%: 1.14-1.45, p $\leq 0.001$ ) (Table 2.2, Figure 2.2). Stratification for sex revealed that the relationship between BMI-SDS and asthma was significant in girls but not in boys (Girls: adjusted OR: $1.31 ; 95 \% \mathrm{Cl}: 1.13-1.51, \mathrm{p} \leq 0.001$. Boys: adjusted OR: 1.01; 95\% Cl: 0.91-1.14, $\mathrm{p}=0.72$ ) (Figure 2.2). Neither age nor puberty were significant confounders for the asthma-obesity relationship in both boys and girls. In addition to a high BMI-SDS in girls, several other factors were also found to predict the prevalence of asthma, including male sex, asthma in a first-degree family member and parents with a low or average educational level as opposed to a high educational level (Table 2.2). 
Table 2.1 Baseline characteristics

\begin{tabular}{|c|c|c|c|}
\hline \multirow[t]{2}{*}{ Characteristics } & \multirow{2}{*}{$\begin{array}{l}\text { Total group } \\
(\mathrm{N}=9,272)\end{array}$} & \multicolumn{2}{|c|}{ Asthma } \\
\hline & & Yes (N=709) & No $(N=8,563)$ \\
\hline Mean age, years(Range) & $10.9(5.6-17.3)$ & $11.1(6.1-17.3)$ & $10.9(5.6-17.3)$ \\
\hline Male sex, $\mathrm{N}(\%)^{*}$ & $4,743(51.2)$ & $417(58.8)$ & $4,326(50.5)$ \\
\hline Height, cm(Range) & $147(100-195)$ & $147(110-191)$ & $147(100-195)$ \\
\hline Weight, kg(Range) & $39.4(15.0-107.0)$ & $40.5(15.9-106.0)$ & $39.3(15.0-107.0)$ \\
\hline $\mathrm{BMI}, \mathrm{kg} / \mathrm{m}^{2}$ (Range)* & $17.6(10.4-44.4)$ & $18.1(11.6-37.5)$ & $17.5(10.4-44.4)$ \\
\hline BMI-SDS(Range)* & $-0.03(-5.41-4.62)$ & $0.15(-3.95-3.30)$ & $-0.04(-5.41-4.62)$ \\
\hline Underweight, $\mathrm{N}(\%)$ & $694(7.5)$ & $44(6.2)$ & $650(7.6)$ \\
\hline Normal weight, $\mathrm{N}(\%)$ & 6,941 (74.9) & $511(72.1)$ & $6,430(75.1)$ \\
\hline Overweight, N(\%) & $1,412(15.2)$ & $121(17.1)$ & $1,291(15.1)$ \\
\hline Obesity, N(\%)* & $225(2.4)$ & $33(4.7)$ & $192(2.2)$ \\
\hline Non native Dutch children, $\mathrm{N}(\%)$ & $1,473(15.9)$ & $101(14.2)$ & $1,372(16.0)$ \\
\hline Mothers with a low educational level, $\mathrm{N}(\%)^{*}$ & $1,773(19.1)$ & $175(24.7)$ & $1,598(18.7)$ \\
\hline Fathers with a low educational level, $\mathrm{N}(\%)^{*}$ & $1,898(20.5)$ & $165(23.3)$ & $1,733(20.2)$ \\
\hline Family history of asthma, $\mathrm{N}(\%)^{*}$ & $2330(25.1)$ & $389(54.9)$ & $1941(22.7)$ \\
\hline \multicolumn{4}{|l|}{ Wheezing episodes } \\
\hline No wheezing periods $s^{\#} N(\%)^{\wedge}$ & $8391(90.5)$ & $178(25.1)$ & 8213 (95.9) \\
\hline 1-3 wheezing periods ${ }^{\#}, N(\%)^{\wedge}$ & $564(6.1)$ & $308(43.4)$ & $256(3.0)$ \\
\hline 4-12 wheezing periods ${ }^{\#}, N(\%)^{\wedge}$ & $237(2.6)$ & $160(22.6)$ & $77(0.9)$ \\
\hline$>12$ wheezing periods ${ }^{\#}, N(\%)^{\wedge}$ & $80(0.9)$ & $63(8.9)$ & $17(0.2)$ \\
\hline Ever had hay fever, $\mathrm{N}(\%)^{*}$ & $1456(15.7)$ & $327(46.1)$ & $1129(13.2)$ \\
\hline Ever had eczema, $\mathrm{N}(\%)^{*}$ & $2756(29.7)$ & $398(56.1)$ & $2358(27.5)$ \\
\hline \multicolumn{4}{|l|}{ Medication use } \\
\hline Bronchodilator ${ }^{\#}, N(\%)^{\wedge}$ & $621(6.7)$ & $603(85.0)$ & $18(0.2)$ \\
\hline Inhaled corticosteroids ${ }^{\#}, N(\%)^{\wedge}$ & $441(4.8)$ & $423(59.7)$ & $18(0.2)$ \\
\hline Other asthma medication $^{\#}, N(\%)^{\wedge}$ & $104(1.1)$ & $84(11.8)$ & $20(0.2)$ \\
\hline
\end{tabular}

(\%): Percentage of the characteristic within each presented column of the table (i.e. \% of subjects with the male sex in the total group, asthma group, no asthma group respectively). ${ }^{*} p<0.05$, significant differences between asthma and no-asthma group. ${ }^{\#}$ During the previous 12 months. ^p-values were not calculated, as wheezing and medication usage were part of the asthma definition. BMI=Body Mass Index. SDS=Standard Deviation Score.

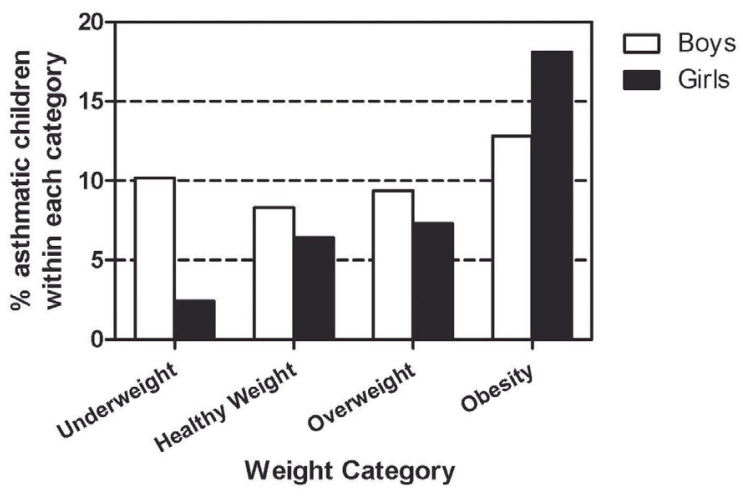

Figure 2.2 Percentage of boys and girls with asthma within different weight categories*

* Cut-off values for weight categories were chosen for illustrative purposes, analyses were performed with BMI-SDS as a continuous variable. 

overweight in Dutch children: a survey study

Table 2.2 Odds Ratios (OR) of having current asthma

\begin{tabular}{|c|c|c|c|}
\hline & Odds ratio $(95 \% \mathrm{Cl})$ & $\begin{array}{l}\text { Odds ratio }(95 \% \mathrm{Cl}) \\
\text { stratified for girls }\end{array}$ & $\begin{array}{l}\text { Odds ratio }(95 \% \mathrm{Cl}) \\
\text { stratified for boys }\end{array}$ \\
\hline BMI-SDS & $1.29(1.14-1.45)^{*}$ & $1.31(1.13-1.41)^{*}$ & $1.02(0.91-1.14)$ \\
\hline $\operatorname{Sex}^{1}$ & $1.48(1.26-1.75)^{*}$ & - & - \\
\hline Age in years & $1.01(0.99-1.05)$ & $1.03(0.98-1.07)$ & $1.01(0.97-1.05)$ \\
\hline Family history of asthma ${ }^{2}$ & $0.25(0.21-0.29)^{*}$ & $0.21(0.17-0.27)^{*}$ & $0.27(0.22-0.33)^{*}$ \\
\hline Ethnicity ${ }^{3}$ & $1.26(0.99-1.60)$ & - & $1.32(0.96-1.82)$ \\
\hline Presence of hairy pets in the household & $1.15(0.98-1.35)$ & - & - \\
\hline Low educational level ${ }^{4}$ & $1.50(1.17-1.92)^{*}$ & $1.40(0.95-2.04)$ & $1.45(1.05-2.00)$ \\
\hline Average educational level ${ }^{4}$ & $1.31(1.10-1.56)^{*}$ & $1.31(0.99-1.73)$ & $1.26(1.00-1.58)$ \\
\hline BMI-SDS $x$ Sex & $0.80(0.67-0.91)^{*}$ & - & - \\
\hline Birth weight $\leq 1500$ gram $^{5}$ & $1.08(0.60-1.96)$ & $1.77(0.80-3.94)$ & $0.66(0.26-1.66)$ \\
\hline Birth weight $1500-1999$ gram $^{5}$ & $0.98(0.61-1.57)$ & $1.13(0.57-2.26)$ & $0.87(0.45-1.68)$ \\
\hline Birth weight 2000-2499 gram $^{5}$ & $1.15(0.87-1.52)$ & $1.16(0.76-1.77)$ & $1.1(0.75-1.61)$ \\
\hline Birth weight $\geq 3500$ gram $^{5}$ & $0.87(0.72-1.04)$ & $0.99(-0.73-1.33)$ & $0.80(0.63-1.11)$ \\
\hline Birth weight $\leq 1500$ gram $\times$ BMI-SDS & $0.71(0.50-0.99)$ & $0.88(0.48-1.60)$ & $0.61(0.39-0.96)$ \\
\hline Birth weight 1500-1999 gram x BMI-SDS & $0.68(0.48-0.97)$ & $0.75(0.45-1.22)$ & $0.61(0.37-0.99)$ \\
\hline Birth weight 2000-2499 gram x BMI-SDS & $1.09(0.87-1.36)$ & $1.14(0.78-1.65)$ & $1.05(0.79-1.39)$ \\
\hline Birth weight $\geq 3500$ gram $\times$ BMI-SDS & $1.01(0.87-1.17)$ & $0.89(0.69-1.14)$ & $1.07(0.89-1.29)$ \\
\hline
\end{tabular}

${ }^{1} 0=$ female, $1=$ male $^{2} 0=$ no family history of asthma, $1=$ family history of asthma; ${ }^{3} 0=$ native ethnicity, $1=$ nonnative ethnicity; ${ }^{4}$ Opposite to a high educational level; ${ }^{5}$ Opposite to a birth weight of 2500-3499 gram; ${ }^{*} p<0.05$ after bonferroni correction. - OR could not be calculated because term could not be entered in the model (for terms including sex) or was not entered in the model by Forward LR method. BMI-SDS= Body Mass Index - Standard Deviation Score.

\section{Sub analyses}

In the subgroup of asthmatic children, BMI-SDS was not significantly related to asthma parameters, including frequency of wheezing (adjusted OR: 0.92; 95\% $\mathrm{Cl}: 0.83-1.03$, $\mathrm{p}=0.16$ ), frequency of dry cough at night (adjusted OR: $1.01 ; 95 \% \mathrm{Cl}: 0.89-1.15, \mathrm{p}=0.88$ ), and ICS use (adjusted OR: 0.95; 95\%Cl: 0.83-1.10, p=0.51).

\section{Discussion}

In this study, BMI-SDS was associated with current asthma in 6 to 16 year old children. After stratification for sex, a significant relationship between BMI-SDS and asthma was revealed only in girls. In children with asthma, BMI-SDS was not related to frequency of wheezing, dry cough at night and use of ICS.

The OR of 1.29 between asthma and BMI-SDS in our study agrees closely with a recent meta- analysis that studied the relationship between asthma and BMI in children. In this meta-analysis, a pooled RR of incident asthma in overweight children of 1.19 (95\% Cl: $1.03-1.37)$ and obese children of 2.02 (95\% Cl: $1.16-3.50)$ was calculated ${ }^{5}$. Moreover, we demonstrated that asthma prevalence was related to several other factors including male sex, family history of asthma, and parents with a low or average 
educational level as opposed to a high educational level. These findings are in agreement with factors found in previous studies ${ }^{15}$.

We verified that asthma prevalence in general was higher amongst boys than girls. When stratified for sex, BMI-SDS was not related to current asthma in boys, but there was a significant positive relationship between BMI-SDS and asthma prevalence in girls. This finding is in line with a meta-analysis performed by Beuther et al. in adults, in which the asthma-obesity relationship was stronger in woman than in men (men vs. woman: OR: 1.46 ; $95 \% \mathrm{Cl}$ : $1.05-2.02$ vs. $1.68 ; 95 \% \mathrm{Cl}: 1.45-1.94)^{21}$. In contrast, studies in children have so far shown inconsistent results. One meta-analysis concluded that obese boys had a significantly higher risk of incident asthma than obese girls (boys vs. girls: RR: $2.47 ; 95 \% \mathrm{Cl}$ : $1.57-3.87$ vs. $1.25 ; 95 \% \mathrm{Cl}: 0.51-3.03)^{5}$. However, this conclusion was based on limited studies. In several other reviews, it was argued that the association of $\mathrm{BMI}$ is generally stronger in girls than in boys, especially after puberty $^{4,10,11}$. Regardless of the direction of these findings, it is crucial that future studies on obesity and asthma should correct for sex as it is a significant confounder.

In adults, several hypotheses are described for the sex-specific asthma-obesity relationship. The most commonly used hypothesis focuses on hormonal differences; in particular, the role of oestrogen in the female sex is often described in literature ${ }^{9}$. Although the exact mechanisms are unclear, oestrogen affects lung function and inflammatory processes via various pathways ${ }^{22}$. In children, it is often hypothesized that oestrogen in the adipose tissue causes an early menarche in girls and a delayed puberty in boys ${ }^{23}$. An early menarche is related to a higher risk of developing asthma and a stronger association between BMI and asthma severity ${ }^{23,24}$. However, in our study we found no effect of either age or puberty (as defined by cut-off values based on age ${ }^{19}$ ) on the asthma-obesity relationship in both boys and girls.

In addition to the oestrogen-hypothesis, it has been suggested that adipose derived hormones such as leptin and adiponectin play a significant role in the asthma-obesity relationship ${ }^{12}$. Excessive adipose tissue is related to increased leptin levels and decreased adiponectin levels, which results in an increased leptin-adiponectin ratio. It has been hypothesized that high serum leptin levels precede airway inflammation, an important asthma characteristic ${ }^{12}$. In asthmatic children, high serum leptin levels are related to the female sex ${ }^{9,25}$. Ali Assad et al. demonstrated in a recent review that the association between serum leptin and asthma prevalence is stronger among specific population subgroups such as pre-pubertal boys and peri-pubertal or post-pubertal girls ${ }^{26}$. However, it is not known exactly how these possible sex-interactions work, and a greater understanding of the role of sex in the leptin-adiponectin ratio is necessary.

A third possible hypothesis for our findings is that girls have a genetic predisposition for the asthma-obesity phenotype. Asthma prevalence is related to the chromosomal gene Cysteinyl Leukotriene Receptor-1 (CYSLTR1) and it has been suggested that the underlying genetic pathogenesis of asthma is sex-specific ${ }^{27}$. In addition, several genes have been related to the asthma-obesity phenotype. Su et al. found that the obesity- 


\section{Sex differences in the relationship between asthma and overweight in Dutch children: a survey study}

related gene Insuline Induced Gene 2 (INSIG2) is related to childhood asthma and that there is an interaction between the inflammatory inter leukine 4 receptor alpha gene, obesity-related INSIG2 gene and anti-oxidative glutathione $S$ transferase pi gene [28]. Future studies should investigate whether asthma-obesity related genes are associated with sex-specific asthma-related genes such as CYSLTR1.

Another hypothesis is of a more methodological origin. It has been reported that women are more likely to report asthma-like symptoms than men. Under-diagnosed asthma is more frequent amongst men than women ${ }^{29}$. Moreover, there seems to be a sex-specific misclassification of obesity in adults. A study in Mexican adults suggested that the use of self-reported BMI underestimated the prevalence of obesity in men, and therefore obscured the relationship between obesity and asthma in men $^{30}$. In our study, anthropomorphic measures used to calculate BMI-SDS were parental-reported, and it is known that parents can (subconsciously) treat and assess children differently because of different body image attributions in boys and girls ${ }^{31}$.

Typical characteristics of the obese-asthmatic child are less asthma control and more frequent ICS use ${ }^{7,12}$. In our study, asthmatic children with an elevated BMI-SDS did not experience more asthmatic symptoms (wheeze, dry cough) than asthmatic children with a normal BMI-SDS. For future studies it is of interest to incorporate objective measurements of asthma such as lung function, airway inflammation markers or the presence of co-morbidities in order to elucidate the asthmatic-obese phenotype ${ }^{12}$.

An important strength of our study is that the respondents of our study are a representative sample of the population. The prevalence of asthma of $7.6 \%$ in this study is consistent with the average Dutch childhood asthma prevalence of $7.2 \%{ }^{3}$. Also, the prevalences of overweight and obesity in our population are comparable to the Dutch average ${ }^{2}$. Moreover, a comparison of the responders and non-responders on the most important outcome measures revealed no significant differences. Another advantage of this study design is that there are hardly any missing data due to the electronic structure of the questionnaire. As this study has a high number of study participants and a representative study population, there is strong evidence that our conclusions can be extrapolated to the population level.

Some challenges for future studies need to be mentioned. Firstly, as in most large-scale epidemiological studies, asthma diagnosis was not defined by objective lung function measurements ${ }^{4}$. Large-scale studies that include objective measures of asthma could add useful information to this study area. Secondly, future longitudinal studies are necessary as cross-sectional studies cannot define a causal relationship between overweight and asthma. As the exact mechanisms between asthma and obesity are still unknown, weight loss studies or longitudinal cohort studies could provide more information about the inflammatory pathways and pulmonary physiology that could contribute to the asthma-obesity phenotype ${ }^{7,12}$. Thirdly, participants with less formal education are in general underreported in large-scale cross-sectional studies ${ }^{32}$. In this study, $20 \%$ of the participants had a low educational level, as opposed to an average 
low educational level of $35 \%$ in the region ${ }^{33}$. Nevertheless, as the educational level did not interact with BMI-SDS, it is unlikely that the educational level has influenced the outcomes of this study. Future studies should focus on new study methods in which underreporting of people with less formal education could be diminished. Fourthly, a total of 36 participants were excluded because of unrealistic BMI values. As these participants represented $<0.5 \%$ of our total study sample, it is not likely that exclusion of these participants confounded our results. However, future studies could prevent this by adding a pop-up warning in their online questionnaire in case an unrealistic combination of length and weight is entered.

In conclusion, we demonstrated a small but significant positive relationship between BMI-SDS and asthma in girls, but not in boys. It is probable that several underlying mechanisms are responsible for the sex differences in the asthma-obesity relationship. Therefore, it is crucial that future studies into obesity and asthma differentiate between males and females. The role of oestrogen, leptin, adipokine, genes and epigenetics should be further investigated, as these features might play an important role in the relationship between sex, asthma and obesity. 


\section{Sex differences in the relationship between asthma and overweight in Dutch children: a survey study}

\section{Supporting information}

Table S2.1 Characteristics of the responder and non-responder group

\begin{tabular}{lcc}
\hline Variable & $\begin{array}{c}\text { Responder group } \\
(\mathrm{N}=9,272)\end{array}$ & $\begin{array}{c}\text { Non-responder group } \\
(\mathrm{N}=121)\end{array}$ \\
\hline Male gender, N(\%) & $4,743(51.2)$ & $61(50.4)$ \\
Mean age, years(SD) & $10.9(2.7)$ & $11.4(2.7)$ \\
$\mathrm{BMI}(\mathrm{SD})$ & $17.6(3.2)$ & $18.0(3.4)$ \\
BMI-SDS & -0.03 & 0.03 \\
Current asthma, N(\%) & $709(7.6)$ & $4(3.3)$ \\
Wheezing", N(\%) & $915(9.9)$ & $12(9.9)$ \\
Dry cough at night", N(\%) & $1,554(16.8)$ & $20(16.5)$ \\
Family history of asthma, N(\%) & $2,330(25.1)$ & $26(21.5)$ \\
Breastfeeding, N(\%) & $3,765(40.6)$ & $46(38.0)$ \\
Itchy rash", N(\%) & $1,131(12.2)$ & $15(12.4)$ \\
\hline
\end{tabular}

\# During the previous 12 months. ${ }^{*} \mathrm{p}<0.05$, significant differences between responder and non-responder group. BMI=Body Mass Index, BMI-SDS=BMI - Standard Deviation Score.

Table S2.2 Additional baseline subject characteristics

\begin{tabular}{lccc}
\hline Characteristics & Total group & \multicolumn{2}{c}{ Asthma } \\
& & Yes & No \\
\hline Study population, N(\%) & 9,272 & $709(7.6)$ & $8,563(92.4)$ \\
Active smoking, N(\%) & $82(0.9)$ & $8(1.1)$ & $74(0.9)$ \\
Passive smoking, N(\%) & $2,736(29.5)$ & $230(32.4)$ & $2,506(29.3)$ \\
Maternal smoking during pregnancy, N(\%)* & $1,245(13.4)$ & $116(16.4)$ & $1,129(13.2)$ \\
Use of antibiotics during pregnancy, N(\%) & $457(4.9)$ & $46(6.5)$ & $411(4.8)$ \\
Growing up at a farm, N(\%) & $100(1.1)$ & $6(0.8)$ & $94(1.1)$ \\
Breastfeeding, N(\%) & $5,371(57.9)$ & $380(53.6)$ & $4,991(58.3)$ \\
Duration $\geq 0$ and <2 months, N(\%) & $1,507(28.1)$ & $120(31.6)$ & $1,387(27.8)$ \\
Duration $\geq 2$ and $\leq 6$ months, N(\%)* & $2,925(54.5)$ & $197(51.8)$ & $2,728(54.7)$ \\
Duration >6 months, N(\%) & $939(17.5)$ & $63(16.6)$ & $876(17.6)$ \\
Birth weight, N(\%) & & & \\
$<1500$ gr & $160(1.7)$ & $17(2.4)$ & $143(1.7)$ \\
1500-1999 gr & $271(2.9)$ & $24(3.4)$ & $247(2.9)$ \\
2000-2499 gr & $764(8.2)$ & $69(9.7)$ & $695(8.1)$ \\
2500-3500 gr & $4,885(52.3)$ & $376(53.0)$ & $4,509(52.7)$ \\
$>3500$ gr & $3,025(32.6)$ & $211(29.8)$ & $2,814(32.9)$ \\
Birth delivery, N(\%) & & & \\
Natural birth & $7,990(86.2)$ & $605(85.3)$ & $7,385(86.2)$ \\
Caesarean section planned & $453(4.9)$ & $37(5.2)$ & $416(4.9)$ \\
Caesarean section acute & $764(8.2)$ & $61(8.6)$ & $703(8.2)$ \\
\hline
\end{tabular}




\section{References}

1. Finucane MM, Stevens GA, Cowan MJ, Danaei G, Lin JK, Paciorek CJ, Singh GM, Gutierrez HR, Lu Y, Bahalim AN, Farzadfar F, Riley LM, Ezzati M; Global Burden of Metabolic Risk Factors of Chronic Diseases Collaborating Group (Body Mass Index). National, regional, and global trends in body-mass index since 1980: systematic analysis of health examination surveys and epidemiological studies with 960 country-years and 9.1 million participants. Lancet 2011;377:557-567.

2. Schönbeck $Y$, Talma H, van Dommelen $P$, Bakker B, Buitendijk SE, Hirasing RA, van Buuren S. Increase in prevalence of overweight in Dutch children and adolescents: a comparison of nationwide growth studies in 1980, 1997 and 2009. PLoS One 2011;6:e27608.

3. Anandan $C$, Nurmatov $U$, van Schayck OC, Sheikh A. Is the prevalence of asthma declining? Systematic review of epidemiological studies. Allergy 2010;65:152-167.

4. Flaherman V, Rutherford GW. A meta-analysis of the effect of high weight on asthma. Arch Dis Child 2006;91:334-339.

5. Chen YC, Dong GH, Lin KC, Lee YL. Gender difference of childhood overweight and obesity in predicting the risk of incident asthma: a systematic review and meta-analysis. Obes Rev 2013;14:222-231.

6. Peroni DG, Pietrobelli A, Boner AL. Asthma and obesity in childhood: on the road ahead. Int J Obes 2010;34:599-605.

7. Shore SA. Obesity and asthma: possible mechanisms. J Allergy Clin Immunol 2008;121:1087-1093.

8. van Schayck CP, Smit HA. The prevalence of asthma in children: A reversing trend. Eur Respir J 2005;26:647-650.

9. Sood A. Sex differences: implications for the obesity-asthma association. Exerc Sport Sci Rev 2011;39:48-56.

10. Noal RB, Menezes AM, Macedo SE, Dumith SC. Childhood body mass index and risk of asthma in adolescence: a systematic review. Obes Rev 2011;12:93-104

11. Matricardi PM, Grüber C, Wahn U, Lau S. The asthma-obesity link in childhood: open questions, complex evidence, a few answers only. Clin Exp Allergy 2007;37:476-484.

12. Jensen ME, Collins CE, Gibson PG, Wood LG. The obesity phenotype in children with asthma. Paediatr Respir Rev 2011;12:152-159.

13. Mahut B, Beydon N, Delclaux C. Overweight is not a comorbidity factor during childhood asthma: the GrowthOb study. Eur Respir J 2012;39:1120-1126.

14. von Mutius E, Schwartz J, Neas LM, Dockery D, Weiss ST. Relation of body mass index to asthma and atopy in children: the National Health and Nutrition Examination Study III. Thorax 2001;56:835-838.

15. Antó JM. Recent advances in the epidemiologic investigation of risk factors for asthma: a review of the 2011 literature. Curr Allergy Asthma Rep 2012;12:192-200.

16. Fredriks AM, van Buuren S, Wit JM, Verloove-Vanhorick SP. Body index measurements in 1996-7 compared with 1980. Arch Dis Child 2000;82:107-112.

17. Cole TJ, Bellizzi MC, Flegal KM, Dietz WH. Establishing a standard definition for child overweight and obesity worldwide: international survey. BMJ 2000;320:1240-1243.

18. Cole TJ, Roede MJ. Centiles of body mass index for Dutch children aged 0-20 years in 1980--a baseline to assess recent trends in obesity. Ann Hum Biol 1999;26:303-308.

19. de Muinich Keizer SM, Mul D. Trends in pubertal development in Europe. Hum Reprod Update 2001;7: 287-291.

20. Rodríguez MA, Winkleby MA, Ahn D, Sundquist J, Kraemer HC. Identification of population subgroups of children and adolescents with high asthma prevalence: findings from the Third National Health and Nutrition Examination Survey. Arch Pediatr Adolesc Med 2002;156:269-275.

21. Beuther DA, Sutherland ER. Overweight, obesity, and incident asthma: a meta-analysis of prospective epidemiologic studies. Am J Respir Crit Care Med 2007;175:661-666.

22. Bonds RS, Midoro-Horiuti T. Estrogen effects in allergy and asthma. Curr Opin Allergy Clin Immunol 2012;13:92-99. 


\section{Sex differences in the relationship between asthma and overweight in Dutch children: a survey study}

23. Castro-Rodríguez JA, Holberg CJ, Morgan WJ, Wright AL, Martinez FD. Increased incidence of asthmalike symptoms in girls who become overweight or obese during the school years. Am J Respir Crit Care Med 2001;163:1344-1349.

24. Varraso R, Siroux V, Maccario J, Pin I, Kauffmann F. Asthma severity is associated with body mass index and early menarche in women. Am J Respir Crit Care Med 2005;171:334-339.

25. Kratzsch J, Lammert A, Bottner A, Seidel B, Mueller G, Thiery J, Hebebrand J, Kiess W. Circulating soluble leptin receptor and free leptin index during childhood, puberty, and adolescence. J Clin Endocrinol Metab 2002;87:4587-4594.

26. Ali Assad N, Sood A. Leptin, adiponectin and pulmonary diseases. Biochimie 2012;94:2180-2189.

27. Arriba-Méndez S, Sanz C, Isidoro-García M, Pascual M, Avila C, Dávila I, Lorente F. Analysis of 927T > C CYSLTR1 and -444A > C LTC4S polymorphisms in children with asthma. Allergol Immunopathol (Madr) 2008;36:259-263.

28. Su MW, Tung KY, Liang PH, Tsai CH, Kuo NW, Lee YL. Gene- gene and gene-environmental interactions of childhood asthma: a multifactor dimension reduction approach. PLoS One 2012;7:e30694.

29. Adams RJ, Wilson DH, Appleton S, Taylor A, Dal Grande E, Chittleborough CR, Ruffin RE. Underdiagnosed asthma in South Australia. Thorax 2003;58:846-850.

30. Santillan AA, Camargo CA. Body mass index and asthma among Mexican adults: the effect of using selfreported vs measured weight and height. Int J Obes Relat Metab Disord 2003;27:1430-1433.

31. van Merode T, Maas T, Twellaar M, Kester A, van Schayck CP. Gender-specific differences in the prevention of asthma-like symptoms in high-risk infants. Pediatr Allergy Immunol 2007;18:196-200.

32. Axinn WG, Link CF, Groves RM. Responsive survey design, demographic data collection, and models of demographic behavior. Demography 2011;48:1127-1149

33. Lamberts P, Steenbakkers M, Thijssen NHB, Backus-Mujakovic S, Vreede JJM de et al. Een gezonde kijk op Zuid-Limburg. Regionale Volksgezondheid Toekomst Verkenning [A healthy look at SouthLimburg].2010. Available: http://www.regionaalkompas.nl/object_binary/o16168_Een-gezonde-kijkop-Zuid-Limburg.pdf. [Accessed 16 September 2013]. 


$$
t
$$




\title{
3. Exercise training in children with asthma: a systematic review
}

Br J Sports Med. 2014;8(13):1024-31

\author{
Vera HM Wanrooij \\ Maartje Willeboordse \\ Edward Dompeling \\ Kim DG van de Kant
}
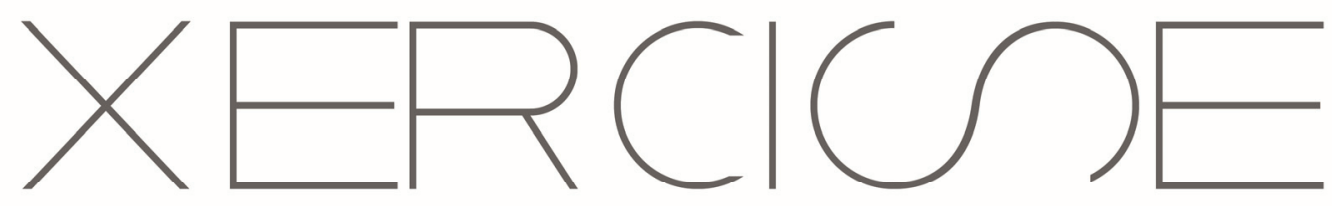


\section{Abstract}

Exercise can provoke asthma symptoms, such as dyspnoea, in children with asthma. Exerciseinduced bronchoconstriction (EIB) is prevalent in $40-90 \%$ of children with asthma. Conversely, exercise can improve physical fitness. The purpose of this paper is to provide a systematic review of the literature regarding the effects of exercise training in children with asthma, particularly in relation to: EIB, asthma control, lung function, cardiorespiratory parameters, and parameters of underlying pathophysiology. A systematic search in several databases was performed. Controlled trials that undertook a physical training program in children with asthma (aged six - eighteen years) were selected. Twenty-nine studies were included. Training had positive effects on several cardiorespiratory fitness parameters. A few studies demonstrated that training could improve EIB, especially in cases where there was sufficient room for improvement. Peak expiratory flow was the only lung function parameter that could be improved substantially by training. The effects of training on asthma control, airway inflammation and bronchial hyper responsiveness were barely studied. Because of the overall beneficial effects of training and the lack of negative effects, it can be concluded that physical exercise is safe and can be recommended in children with asthma. A training program should have a minimum duration of three months, with at least two 60-minute training sessions per week, and a training intensity set at the (personalised) ventilatory threshold. Further research is recommended regarding the effects of exercise on underlying pathophysiological mechanisms and asthma control in children with asthma. 


\section{Introduction}

Asthma is one of the most common chronic diseases in children. Despite a recent decrease in the prevalence of asthma in several Western countries, the worldwide burden of asthma continues to rise ${ }^{1,2}$. A major trigger for asthma symptoms is exercise, which can lead to exercise-induced bronchoconstriction (EIB). EIB is a condition which usually occurs during, or a few minutes after exercise and is defined as reversible narrowing of the airways, resulting in shortness of breath ${ }^{3-5}$. According to the ATS guidelines, EIB is defined by a drop of $\geq 10 \%$ in forced expiratory volume in one second $\left(\mathrm{FEV}_{1}\right)$ after exertion on an exercise test ${ }^{6}$. The prevalence of EIB in children with asthma ranges from 40 to $90 \%^{4,7,8}$. There is an ongoing debate about the mechanism whereby physical exercise can provoke EIB in asthma. It is likely to be caused by an increased ventilatory rate as a result of physical exercise ${ }^{9}$. According to the osmotic theory, the inhalation of an increased volume of dry air requires humidification, which leads to the loss of water from the respiratory mucosa ${ }^{10,11}$. This loss of water from the respiratory mucosa causes an increase in osmolarity in the airway surface, which in turn leads to the release of bronchoconstricting mediators from inflammatory cells such as eosinophils and mast cells ${ }^{10-14}$. These mediators, for example histamine, prostaglandins, and leukotrienes, interact with effector cells (e.g. smooth muscle cells) which can cause a transient bronchoconstrictive response ${ }^{10,12,15}$. A second theory, the thermal theory, states that vasoconstriction during exercise due to inhalation of the relatively cold and dry air followed by rapid rewarming after exercise, leads to a rebound vasodilatation ${ }^{11}$. This results in a reactive hyperaemia of the bronchial microvasculature and oedema of the airway wall which causes airway obstruction ${ }^{12,15,16}$. Asthma medication, such as short-acting $\beta 2$-adrenergic receptor agonists, can be used before exercise to prevent or diminish bronchoconstriction during or after exercise ${ }^{8}$. Despite this, EIB often leads to avoidance of physical activity in children with asthma ${ }^{2,17}$.

Several studies demonstrated a reduced physical activity level and physical condition in asthmatic children compared to children without asthma ${ }^{2,18-20}$. In contrast, other studies could not demonstrate such a difference in both physical condition and physical activity level ${ }^{21,22}$. Several interconnected factors can affect the physical activity participation of asthmatic children, including the asthmatic children's belief that their asthma limits their physical activity level and the concerns and misinterpretation of family members and teachers about asthma and exercise ${ }^{23}$. There is increasing evidence that low physical fitness could play a role in the increase of asthma severity whilst, in contrast, high physical fitness has been related to fewer asthma symptoms ${ }^{2,19,24}$. Therefore, physical training programs could be important in the treatment of asthmatic children.

The objective of this manuscript is to provide a concise overview of the effects of exercise training on EIB and underlying asthma pathophysiology, physical fitness, lung function, disease control, and quality of life in children with asthma. We will provide an 
overview of the most effective components of a training program for children with asthma.

\section{Methods}

\section{Search and review strategy}

Databases of PubMed, Cochrane and Embase were used to select relevant studies. The following keywords/Mesh terms were used: 'asthma' combined with 1) 'child' or 'adolescent' and 2) 'exercise', 'physical activity', 'physical training', 'aerobic fitness', 'physical conditioning' or 'training' (Figure 3.1). Limitations in the search strategy were set to studies in children (six - eighteen years) and with the English language. Titles, abstracts and full-text articles of potentially useful studies were independently screened by three researchers. Furthermore, the reference lists of the included articles were scrutinised to detect studies not captured by the electronic search. Searches were carried out on literature published up to, and including, October 2012.

\section{Criteria for considering studies for inclusion in this review}

Articles were included in this review which met the following inclusion criteria: study population of children with asthma with an age range between six and eighteen years, a training program provided, availability of the full text in English, and the use of a control group of children with asthma. Data from the included studies were summarised for outcome variables. Outcome measures are described and summarised in Tables 3.1 and 3.3. Data were not pooled. A quality assessment of the articles was executed according to the Delphi criteria list ${ }^{25}$. The quality of the included articles was assessed independently by three researchers.

\section{Results}

\section{Description of included studies}

A total number of twenty-nine studies were included in the review (Figure 3.1). In total, 1045 children with asthma were investigated, with ages ranging from six years to eighteen years. All studies were reported between 1972 and 2010. Fourteen studies were conducted in Europe, five in Brazil, four in the USA, two in Taiwan, two in Australia, one in Japan and one in South Africa. The characteristics of the studies with regard to training intervention, randomisation, sample size, patient characteristics and outcome measures are summarised in Table 3.1. 


\section{PRISMA Flow Diagram}

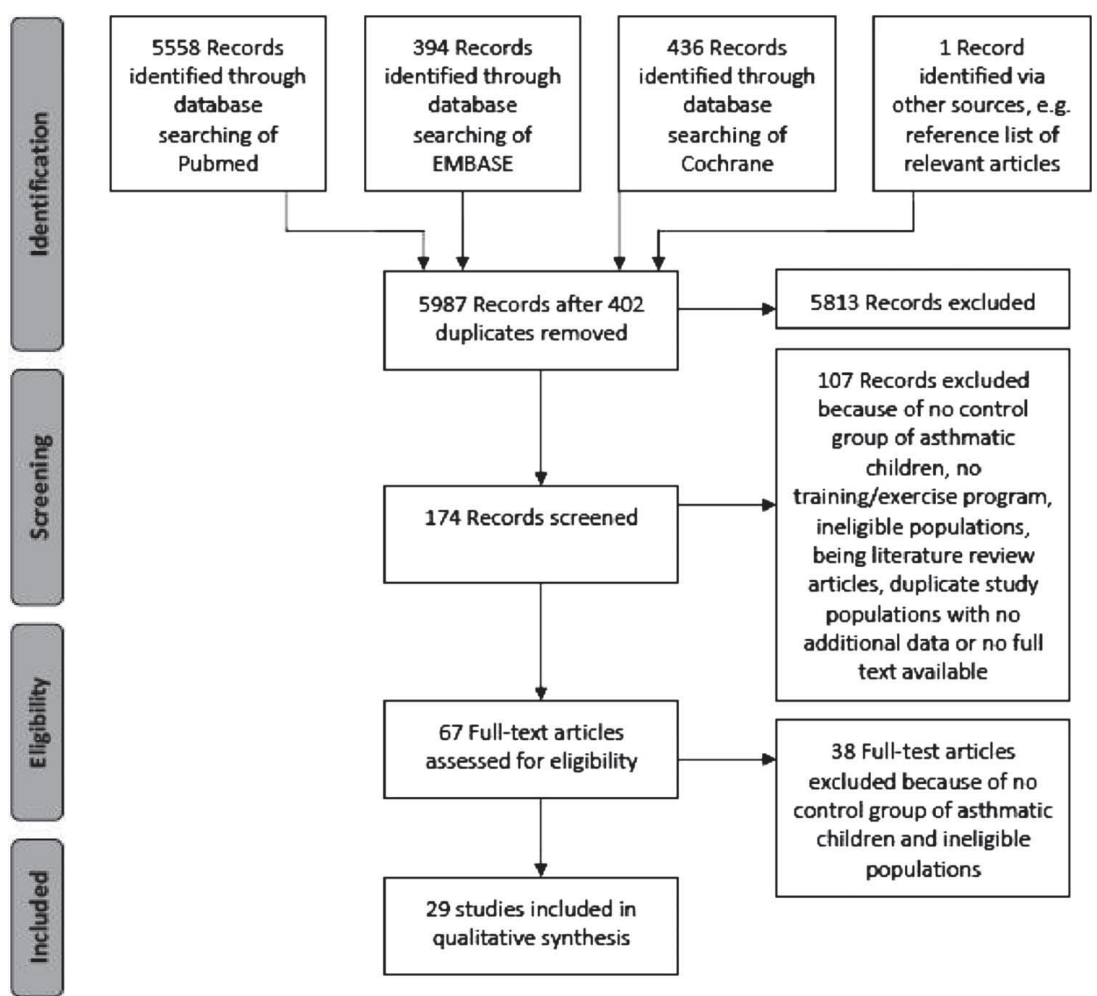

Figure 3.1 Flow chart of literature search. Summary of evidence search and selection according to the PRISMA flowchart ${ }^{78}$

\section{Characteristics of the exercise programs}

The quality assessment of the articles is summarised in Table 3.2 by using the Delphi list ${ }^{25}$. In general, the quality of the studies could be classified as poor to moderate. For example, only fifteen of the twenty-nine selected studies performed randomisation. Other quality criteria, such as blinding of patients, are difficult to fulfil in a training intervention, which results in lower scores on the Delphi list. We decided not to exclude any of the selected studies for this review. 


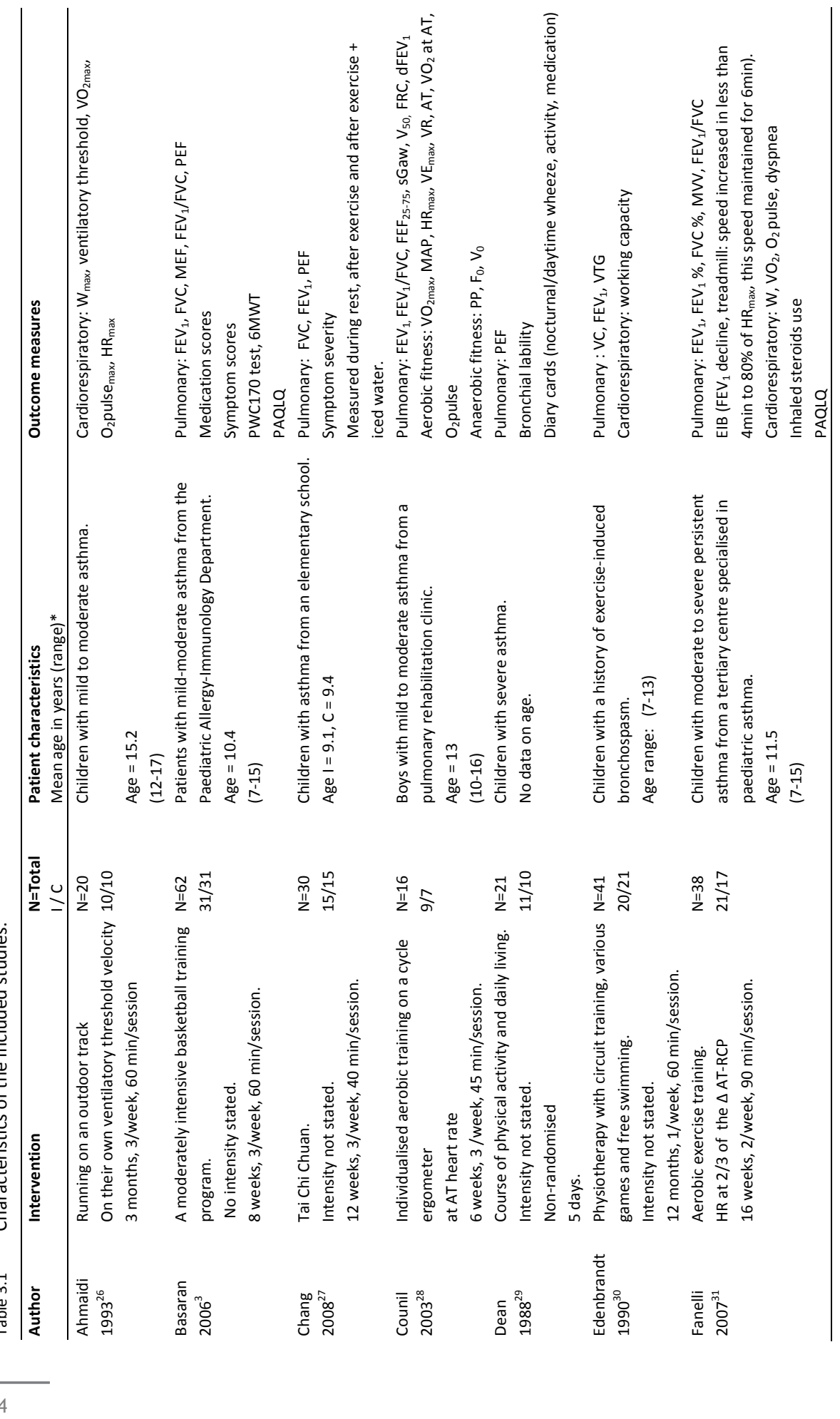


Exercise training in children with asthma:

a systematic review

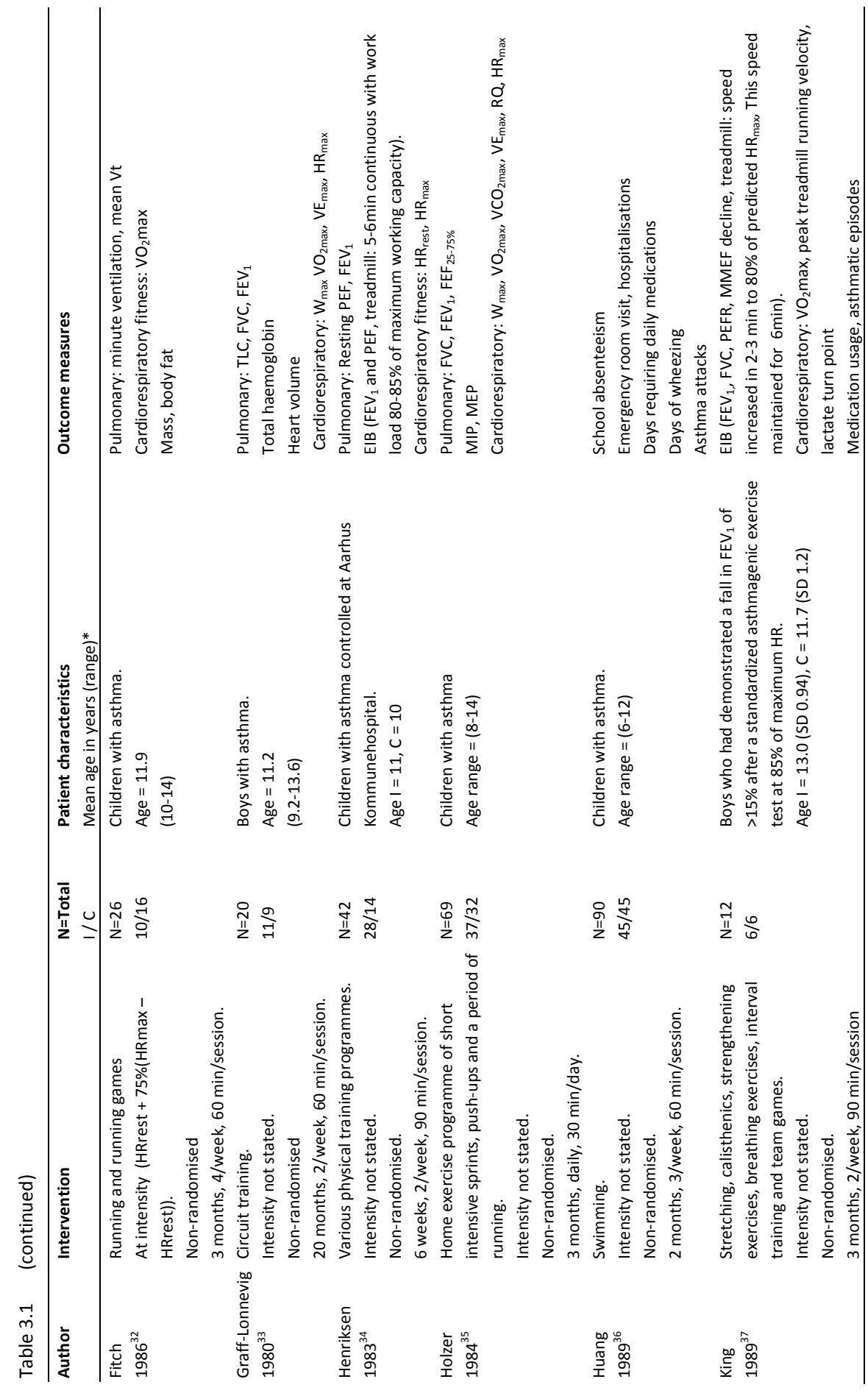




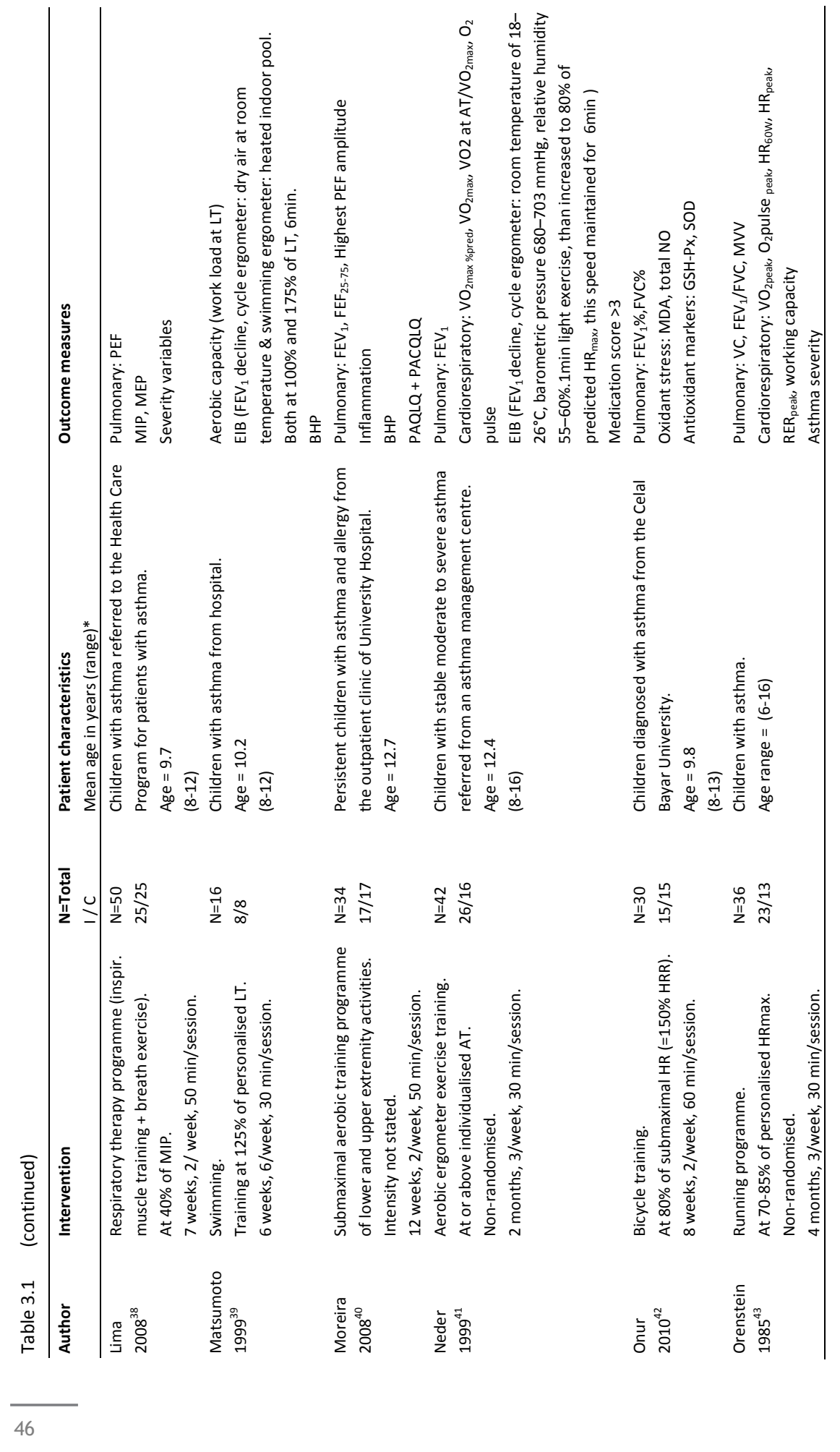


Exercise training in children with asthma:

a systematic review

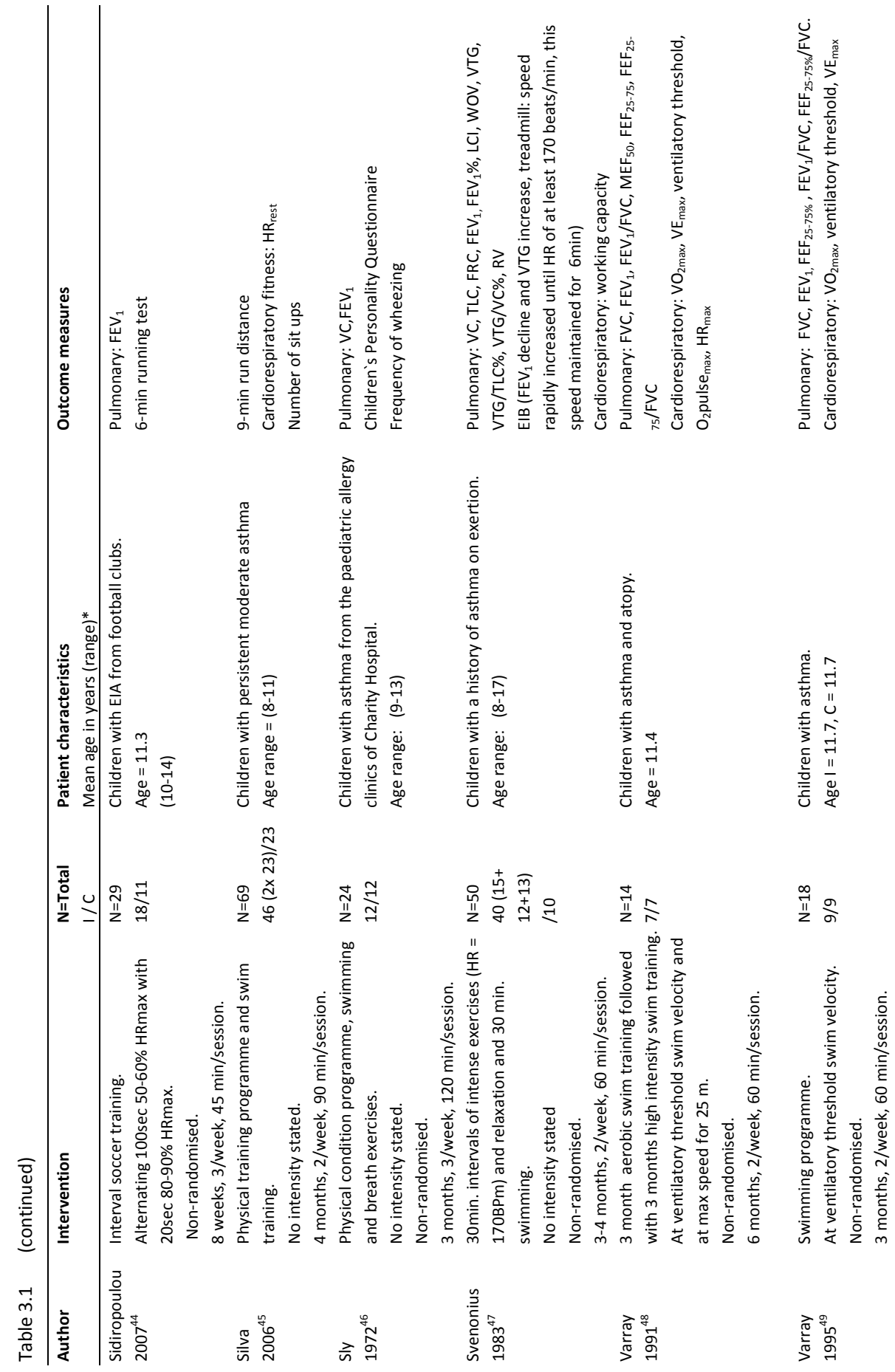




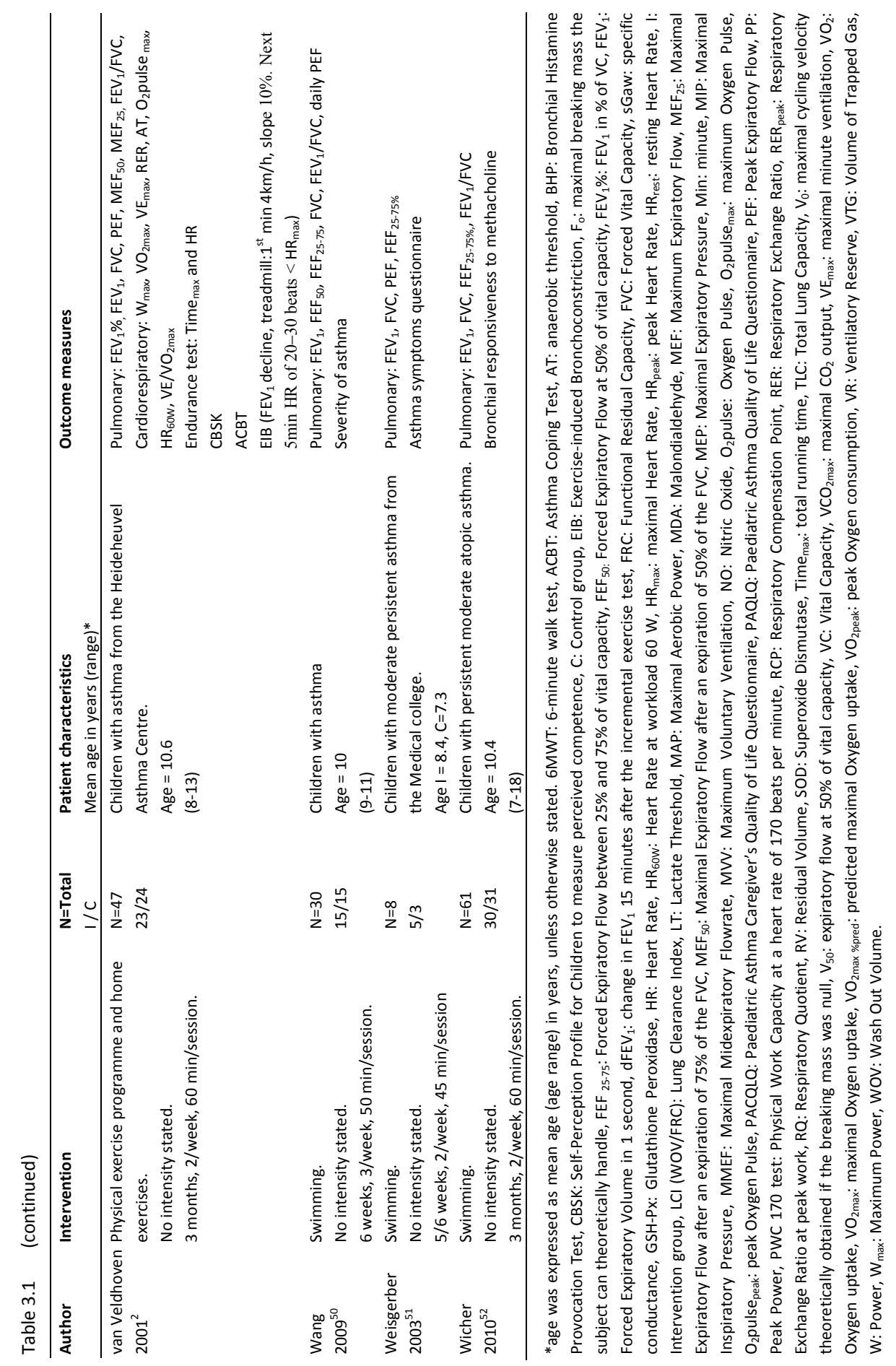


Table 3.2 Quality of the included studies according to the Delphi List ${ }^{25}$.

\begin{tabular}{|c|c|c|c|c|c|c|c|c|c|c|c|}
\hline Author & Year of publication & $1 a$ & $1 b$ & 2 & 3 & 4 & 5 & 6 & 7 & 8 & Total score \\
\hline Ahmaidi $^{26}$ & 1993 & $Y$ & NS & $\mathrm{Y}$ & $\mathrm{Y}$ & $\mathrm{N}$ & $\mathrm{N}$ & $\mathrm{N}$ & $\mathrm{Y}$ & NS & 4 \\
\hline Basaran $^{3}$ & 2006 & $\mathrm{Y}$ & NS & $\mathrm{Y}$ & $\mathrm{N}$ & $\mathrm{N}$ & $\mathrm{N}$ & $\mathrm{N}$ & $\mathrm{Y}$ & $\mathrm{N}$ & 3 \\
\hline Chang $^{27}$ & 2008 & $Y$ & NS & $\mathrm{Y}$ & $\mathrm{N}$ & $\mathrm{N}$ & $\mathrm{N}$ & $\mathrm{N}$ & $\mathrm{Y}$ & NS & 3 \\
\hline Counil $^{28}$ & 2003 & $Y$ & NS & $\mathrm{Y}$ & $\mathrm{Y}$ & $\mathrm{Y}$ & $\mathrm{N}$ & $\mathrm{N}$ & $\mathrm{Y}$ & $\mathrm{N}$ & 5 \\
\hline Dean $^{29}$ & 1988 & $\mathrm{~N}$ & $\mathrm{~N}$ & $\mathrm{~N}$ & $\mathrm{~N}$ & $\mathrm{Y}$ & $\mathrm{N}$ & $\mathrm{N}$ & $\mathrm{N}$ & $\mathrm{N}$ & 1 \\
\hline Edenbrandt ${ }^{30}$ & 1990 & $Y$ & NS & $\mathrm{N}$ & $\mathrm{N}$ & $\mathrm{N}$ & $\mathrm{N}$ & $\mathrm{N}$ & $Y$ & NS & 2 \\
\hline Fanelli $^{31}$ & 2007 & $\mathrm{Y}$ & $\mathrm{N}$ & $\mathrm{Y}$ & $\mathrm{Y}$ & $\mathrm{N}$ & $\mathrm{Y}$ & $\mathrm{N}$ & $Y$ & $Y$ & 6 \\
\hline Fitch $^{32}$ & 1986 & $\mathrm{~N}$ & $\mathrm{~N}$ & $\mathrm{Y}$ & $\mathrm{N}$ & $\mathrm{N}$ & $\mathrm{N}$ & $\mathrm{N}$ & $Y$ & $Y$ & 3 \\
\hline Graff $^{33}$ & 1980 & $\mathrm{~N}$ & $\mathrm{~N}$ & $\mathrm{~N}$ & $\mathrm{~N}$ & $\mathrm{~N}$ & $\mathrm{~N}$ & $\mathrm{~N}$ & $\mathrm{~N}$ & $Y$ & 1 \\
\hline Henriksen $^{34}$ & 1983 & $\mathrm{~N}$ & $\mathrm{~N}$ & $\mathrm{~N}$ & $\mathrm{~N}$ & $\mathrm{~N}$ & $\mathrm{~N}$ & $\mathrm{~N}$ & $Y$ & $Y$ & 2 \\
\hline Holzer $^{35}$ & 1984 & $\mathrm{~N}$ & $\mathrm{~N}$ & $\mathrm{Y}$ & $\mathrm{N}$ & $\mathrm{N}$ & $\mathrm{N}$ & $\mathrm{N}$ & $Y$ & NS & 2 \\
\hline Huang $^{36}$ & 1989 & $\mathrm{~N}$ & $\mathrm{~N}$ & $\mathrm{Y}$ & $\mathrm{N}$ & $\mathrm{N}$ & $\mathrm{N}$ & $\mathrm{N}$ & $\mathrm{N}$ & $\mathrm{N}$ & 1 \\
\hline $\operatorname{Lima}^{38}$ & 2008 & $Y$ & NS & $\mathrm{Y}$ & $\mathrm{Y}$ & $\mathrm{N}$ & $\mathrm{N}$ & $\mathrm{N}$ & $\mathrm{Y}$ & $\mathrm{N}$ & 4 \\
\hline Matsumoto ${ }^{39}$ & 1999 & $Y$ & NS & $\mathrm{Y}$ & $\mathrm{N}$ & $\mathrm{N}$ & $\mathrm{N}$ & $\mathrm{N}$ & $Y$ & $Y$ & 4 \\
\hline Moreira $^{40}$ & 2008 & Y & Y & $\mathrm{Y}$ & $\mathrm{Y}$ & $\mathrm{N}$ & $\mathrm{N}$ & $\mathrm{N}$ & $Y$ & $Y$ & 6 \\
\hline Neder $^{41}$ & 1999 & $\mathrm{~N}$ & $\mathrm{~N}$ & $\mathrm{~N}$ & $\mathrm{~N}$ & $\mathrm{~N}$ & $\mathrm{~N}$ & $\mathrm{~N}$ & $Y$ & $Y$ & 2 \\
\hline Onur $^{42}$ & 2010 & $Y$ & NS & $\mathrm{Y}$ & $\mathrm{Y}$ & $\mathrm{N}$ & $\mathrm{N}$ & $\mathrm{N}$ & $Y$ & $Y$ & 5 \\
\hline Orenstein ${ }^{43}$ & 1985 & $\mathrm{~N}$ & $\mathrm{~N}$ & $\mathrm{Y}$ & $\mathrm{N}$ & $\mathrm{N}$ & $\mathrm{N}$ & $\mathrm{N}$ & $Y$ & $\mathrm{~N}$ & 2 \\
\hline King $^{37}$ & 1989 & $\mathrm{~N}$ & $\mathrm{~N}$ & $\mathrm{~N}$ & $\mathrm{~N}$ & $\mathrm{~N}$ & $\mathrm{~N}$ & $\mathrm{~N}$ & $\mathrm{Y}$ & NS & 1 \\
\hline Sidiropoulou $^{44}$ & 2007 & $\mathrm{~N}$ & $\mathrm{~N}$ & $\mathrm{Y}$ & $\mathrm{Y}$ & $\mathrm{N}$ & $\mathrm{N}$ & $\mathrm{N}$ & $\mathrm{Y}$ & $Y$ & 4 \\
\hline Silva ${ }^{45}$ & 2006 & $\mathrm{Y}$ & NS & $\mathrm{Y}$ & $\mathrm{Y}$ & $\mathrm{N}$ & $\mathrm{N}$ & $\mathrm{N}$ & $Y$ & $Y$ & 5 \\
\hline $\mathrm{Sly}^{46}$ & 1972 & $\mathrm{~N}$ & $\mathrm{~N}$ & $\mathrm{~N}$ & $\mathrm{~N}$ & $\mathrm{~N}$ & $\mathrm{~N}$ & $\mathrm{~N}$ & $\mathrm{~N}$ & $\mathrm{~N}$ & 0 \\
\hline Svenonius $^{47}$ & 1983 & $\mathrm{~N}$ & $\mathrm{~N}$ & $\mathrm{Y}$ & $\mathrm{Y}$ & $\mathrm{N}$ & $\mathrm{N}$ & $\mathrm{N}$ & $\mathrm{Y}$ & $\mathrm{Y}$ & 4 \\
\hline Varray $^{48}$ & 1991 & $\mathrm{~N}$ & $\mathrm{~N}$ & $\mathrm{Y}$ & $\mathrm{Y}$ & $\mathrm{N}$ & $\mathrm{N}$ & $\mathrm{N}$ & $Y$ & NS & 3 \\
\hline Varray $^{49}$ & 1995 & $\mathrm{~N}$ & $\mathrm{~N}$ & $\mathrm{~N}$ & $\mathrm{Y}$ & $\mathrm{N}$ & $\mathrm{N}$ & $\mathrm{N}$ & $\mathrm{Y}$ & NS & 2 \\
\hline Veldhoven $^{2}$ & 2001 & $\mathrm{Y}$ & NS & $\mathrm{Y}$ & $\mathrm{Y}$ & $\mathrm{N}$ & $\mathrm{N}$ & $\mathrm{N}$ & $Y$ & $\mathrm{~N}$ & 4 \\
\hline Wang $^{50}$ & 2009 & $\mathrm{Y}$ & NS & $\mathrm{Y}$ & $\mathrm{N}$ & $\mathrm{N}$ & $\mathrm{N}$ & $\mathrm{N}$ & $\mathrm{N}$ & $Y$ & 3 \\
\hline Weisgerber $^{51}$ & 2003 & $\mathrm{Y}$ & $\mathrm{N}$ & $\mathrm{Y}$ & $\mathrm{N}$ & $\mathrm{N}$ & $\mathrm{N}$ & $\mathrm{N}$ & $Y$ & $\mathrm{~N}$ & 3 \\
\hline Wicher ${ }^{52}$ & 2010 & $Y$ & NS & $\mathrm{N}$ & $Y$ & $\mathrm{~N}$ & $\mathrm{~N}$ & $\mathrm{~N}$ & $Y$ & $\mathrm{~N}$ & 3 \\
\hline
\end{tabular}

N: No, Y: Yes, NS: Not stated. 1a: Treatment allocation: randomisation? 1b: Treatment allocation: concealed? 2: Groups similar at baseline? 3: Eligibility criteria specified? 4: Outcome assessor blinded? 5: Care provider blinded? 6: Patient blinded? 7: Point Estimates given? 8: Intention-to-treat analysis?

All studies differed on the following characteristics: type of training, intensity, frequency, duration and length of the training programme. Seven studies used a training programme that consisted of swim training ${ }^{36,39,48-52}$ and sixteen studies used 
other aerobic physical training, such as basketball- running- soccer- or cycle ergometer training $23,26,28,29,31-35,37,40-44$. Four studies used swim training as well as other aerobic physical training ${ }^{30,45-47}$, while one study used Tai Chi Chuan training ${ }^{27}$ and another study used respiratory therapy as a type of training ${ }^{38}$. The duration of the programmes ranged from six weeks to twenty months, except for the intervention of Dean et al. which only lasted for five days ${ }^{29}$. The frequency of sessions ranged from once a week to seven times a week, with a duration per session ranging from 30 minutes to two hours.

\section{Results of the main outcome parameters}

As listed in Table 3.3, the most studied outcome parameters included lung function parameters, cardiorespiratory fitness parameters, EIB and quality of life. A summary of the main findings is provided below. Detailed information about all the outcome parameters is provided in Table 3.1 and Web only Table W3.1. In order to distinguish the effective components of a training programme, all training programmes were compared with each other according to the Delphi quality score, training type, number of participants, patient group, intensity, duration and frequency of exercise (Tables 3.1-3.3). For the three most studied parameters (measurements of bronchoprovocation, lung function and cardiorespiratory parameters) the effective components of training are summarised below.

\section{Measurements of bronchoprovocation and inflammation}

EIB is an important clinical feature of bronchial hyper responsiveness (BHR) in asthma. Seven studies described the training effects on BHR by using the indirect bronchoprovocation measure EIB (Figure 3.2) 2,31,34,37,39,41,47. EIB was measured by the decrease in $\mathrm{FEV}_{1}$ after running on a treadmill ${ }^{2,31,34,37,47}$, cycle ergometer test ${ }^{39,41}$, or swimming ergometer test ${ }^{39}$. EIB decreased in all studies, and this decrease was statistically significant between the intervention and control group in three out of

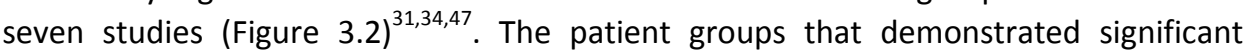
improvements in EIB after training consisted mainly of children who were selected for the study specifically because of their EIB problems or severe asthma ${ }^{31,34,47}$. The studies that did not show significant differences in EIB after training included mainly children with moderate asthma with no or minor EIB problems ${ }^{2,37,39,41}$.

Three studies investigated the effects of training on BHR by using direct bronchoprovocation with methacholine and histamine $e^{39,40,52}$. The study with the highest number of participants ( $N=61)$ was the only one in which a significant decrease was demonstrated in BHR after training ${ }^{52}$. 
Exercise training in children with asthma:

a systematic review






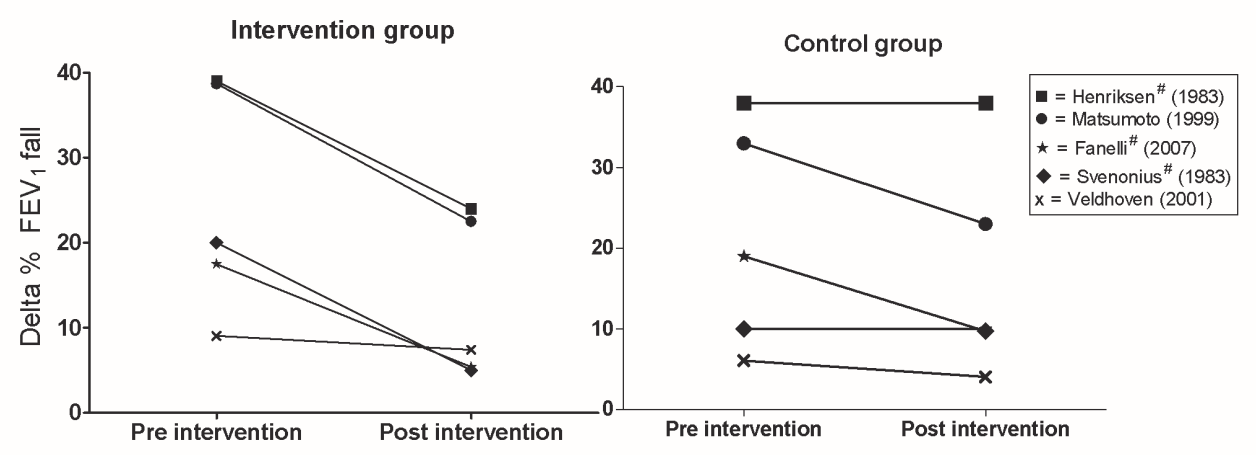

Figure 3.2 Exercise-induced bronchoconstriction pre- and post intervention*.

* This figure for illustrative purposes includes studies which measured EIB as the delta of FEV ${ }_{1}$ fall (in\%) pre and post intervention. Data has been extracted visually from figures in two studies (Svenonius 1983 and Matsumoto 1999). In the study of Henriksen (1983) intervention group 3 was chosen as intervention group. ${ }^{\#}$ Significant difference $(p<0.05)$ between intervention and control group.

EIB can be considered as an indirect measure for airway inflammation. Moreira et al. investigated the effects of regular exercise on airway inflammation in asthmatic children ${ }^{40}$. In this study no significant change in inflammatory markers was found after twelve weeks of exercise (exhaled nitric oxide (FeNO), blood eosinophil number, serum eosinophil cationic protein (ECP), and serum C-reactive protein (CRP). The authors hypothesised that the balance between the pro- and anti-inflammatory effects of exercise in asthma is null. However, the small sample size might have limited the power to measure the exercise effects on airway inflammation.

In addition to inflammation, oxidative stress is an important component of asthma pathophysiology. Onur et al. found that markers of oxidative stress in blood serum (malondialdehyde, total nitric oxide (NO)) were reduced in children with asthma after exercise $^{42}$.

\section{Lung function parameters}

Twenty-four studies measured the effects of training on lung function parameters (Supplementary file Table S3.1) 2,3,27-35,38,40-44,46-52. At baseline, percentage of predicted lung function ((FEV 1 and forced vital capacity (FVC)) was reduced in the vast majority of the studies (Supplementary file Table S3.1). FEV 1 could be improved in three out of twenty studies by exercise training ${ }^{27,42,44}$, whereas the FVC improved in only two studies $^{27,42}$. Peak expiratory flow (PEF) was the main lung function parameter that was improved, albeit mildly, by exercise. Only four studies out of 9 demonstrated a mild 
improvement in $\mathrm{PEF}^{27,29,38,50}$. No significant improvements after training were reported for the other lung function parameters such as $\mathrm{FEV}_{1} / \mathrm{FVC}$, functional residual capacity, thoracic gas volume, total lung capacity, and maximum expiratory flow rate at $50 \%$ of vital capacity.

This review cannot elucidate any successful aspects of training that are accountable for the improvements in PEF or FEV that was demonstrated in some studies $^{2,3,34,40,51}$.

\section{Cardiorespiratory parameters}

The effects of training on aerobic capacity and physical condition were tested in seventeen studies. The cardiorespiratory parameters were measured with an incremental exercise test on a cycle ergometer or treadmill ${ }^{2,26,28,30-33,37,39,41,43,47-49}$, five/six minutes continuous running test ${ }^{34}$, a steady state sub maximal exercise test ${ }^{35^{\prime}}$. or at resting condition ${ }^{45}$. Ten studies determined the training effect on maximal oxygen uptake $\left(\mathrm{VO}_{2 \max }\right)$ (Supplementary file Table S3.1) 2,26,28,32-34,37,41,48,49. Six out of ten studies reported that $\mathrm{VO}_{2 \max }$ increased significantly after training. The ventilatory threshold, as well as the maximum oxygen pulse $\left(\mathrm{O}_{2}\right.$ pulse $\left._{\max }\right)$ increased in all studies that assessed these parameters ${ }^{2,26,48,49}$. Two out of six studies revealed a significant increase in maximal minute ventilation $\left(\mathrm{VE}_{\max }\right)$ in the intervention group ${ }^{2,28,33,35,48,49}$. Maximum heart rate $\left.\left(H R_{\max }\right)\right)^{26,28,33-35,48}$ and maximum power $\left(\mathrm{W}_{\max }\right)^{2,26,33,35}$ were significantly improved following exercise training in half of the studies. Working capacity, defined as percentage of the individual's maximal aerobic power, improved in one out of three studies reporting this parameter ${ }^{30,43,47}$.

$\mathrm{VO}_{2 \max }$ was the most commonly studied cardiorespiratory parameter, and is accepted as a gold standard measure of aerobic fitness. Four of the six studies that showed improvements in $\mathrm{VO}_{2 \max }$ after training, had a training intensity at the ventilatory threshold for at least 60 minutes ${ }^{26,28,48,49}$. The studies that did not show improvements in $\mathrm{VO}_{2 \max }$ after training had intensities that were not well described ${ }^{33,35}$, low ${ }^{32}$, or at the ventilatory threshold for only 30 minutes $^{41}$. In addition to a training intensity at the ventilatory threshold the studies that improved $\mathrm{VO}_{2 \max }$ with exercise training, had at least 120 minutes exercise per week, consisting of at least two training sessions and a training programme duration of at least three months ${ }^{2,26,28,48,49}$.

\section{Asthma control and quality of life}

Three studies described the effects of exercise training on quality of life in children $^{3,31,40}$. Basaran and Fanelli et al. found a significant improvement in quality of life after training ${ }^{3,31}$, which is in contrast to the study of Moreira et al. ${ }^{40}$. This might be explained by a good quality of life at baseline with little room for improvement in the latter study. 
EIB is an important measure of asthma control. Further to EIB, thirteen studies used other measures to describe the effects of training on asthma control, such as school absenteeism, symptom score, and hospitalisations $s^{2,3,27,29,31,36-38,41,43,46,50,51}$. The limited amount of data point to a decrease in number of asthma attacks and days of wheezing (Supplementary file Table S3.1) $36,38,46$. Moreover, symptom scores improved in one out of three studies reporting this parameter ${ }^{3,27,51}$ and medication scores did not improve $3,37,41$.

\section{Discussion}

The main finding of this systematic review is that exercise training induces clear positive effects on cardiorespiratory fitness parameters, whereas a beneficial effect on lung function is limited to the PEF. It appears that EIB can be improved in children with more frequent and severe EIB problems, although evidence is limited. The limited amount of data regarding quality of life and asthma control point to an increase in quality of life and a decrease in number of asthma attacks and days of wheezing after exercise training. In this review we demonstrate that optimal $\mathrm{VO}_{2 \max }$ improvements in children with asthma can be derived when a training program consists of training intensities set at the (personalised) ventilatory threshold, for at least 120 minutes per week divided over two or three sessions with a duration of at least three months ${ }^{2,26,28,48,49}$. In nonasthmatic children, it has been stated previously that training at the ventilatory threshold ${ }^{53}$ or at an intensity higher than $80 \%$ of $\mathrm{HR}_{\max }{ }^{54}$ induces greater and more often significant improvements in aerobic fitness than training below the ventilatory threshold or $80 \%$ of $\mathrm{HR}_{\max }$.

This positive effect of exercise training on cardiorespiratory fitness is found across numerous parameters, such as $\mathrm{VO}_{2 \max }, \mathrm{O}_{2}$ pulse $\mathrm{max}_{\max }$ and ventilatory threshold. The improvements in aerobic parameters are a common result of training. The cardiorespiratory improvements are measured both in children who demonstrate improved EIB and in children with unaltered $\mathrm{EIB}^{2,31,47}$. Some studies suggest that children with asthma have a reduced physical condition ${ }^{2,18-20}$. Yet this review shows that children with asthma are able to improve their cardiorespiratory fitness. Improvements in cardiorespiratory fitness are beneficial for the prevention of several comorbidities of childhood asthma, such as obesity and mental disorders ${ }^{55-57}$.

In our review we show that the degree of EIB improved in all studies after training, although only significantly in three studies. In the studies that did not demonstrate a significant improvement in EIB, it was not reported clearly whether EIB was severe enough to improve, and whether ceiling effects could have hampered the results $2,37,39,41$. Two of the three studies that did show improvements in EIB after training had a population consisting of children with recent, frequent complaints of 
$\mathrm{EIB}^{31,47}$. Therefore, it might be concluded that EIB in children with asthma can be improved by training, particularly when EIB symptoms are more prevalent or severe. Moreover, it can be concluded that as regular physical activity does not have a negative effect on EIB, exercise can be executed safely in most subjects. However, more research is needed on this topic. Optimal control of EIB is most often obtained with inhaled corticosteroids, which has inhibitory effects on airway inflammation ${ }^{15}$. To prevent or reverse EIB during exercise, treatment with bronchodilators, such as shortor long-acting $\beta 2$-adrenergic receptor agonists or ipratropium bromide should be used when needed before physical exercise ${ }^{58}$. Besides medication, there are also other methods to limit EIB, such as breathing through the nose instead of the mouth, or exercising in a warm, humidified environment ${ }^{9,59}$. In some asthmatic patients, warm-up exercise before intense physical exercise might also help to prevent EIB $^{60}$.

As pointed out before, cardiorespiratory fitness can be improved with exercise training in children with asthma. Children with improved cardiorespiratory fitness require a lower minute ventilation during exercise for a given workload compared with a pretraining situation ${ }^{61,62}$. As an increased ventilatory rate is probably the cause of EIB, a lower minute ventilation would lead to a less intense EIB stimulus. However, the extent of improvement in $\mathrm{VO}_{2 \max }$ after training could not explain the degree of improvement in EIB. This is in accordance with the study of Thio et al. who found no relation between EIB and cardiovascular fitness ${ }^{63}$. Hence, it can be assumed that other factors relating to exercise training may be responsible for the improvement in EIB.

As EIB was improved by exercise training in some of the study populations, there is a need for more understanding of the underlying mechanisms and pathophysiology of EIB. It is most likely that bronchoconstriction is caused by airway drying, which is generated by hyperpnoea during exercise. In addition to inducing bronchoconstriction due to an increased ventilatory rate during physical exercise, exercise also has a bronchodilating effect due to the release of mediators such as prostaglandin E2 and NO. Furthermore, deep inspirations during exercise initiate increased mechanical stretching of the smooth muscle cells which bronchodilate the lower airways. During exercise training there seems to be a balance between the bronchodilating and bronchoconstrictor responses in healthy persons, which prevents EIB during physical exercise ${ }^{5}$.

There is increasing evidence that a single bout of exercise can induce acute oxidative stress which initiates augmented airway inflammation leading to an increase in $\mathrm{EIB}^{64,65}$. This inflammatory response is reflected by increased levels of CRP, FeNO, serum ECP concentration and BHR to histamine ${ }^{65}$. Conversely, it is also suggested that regular exercise might decrease airway inflammation and oxidative stress, as shown by a decrease in inflammatory markers such as sputum eosinophil count, FeNO, and oxidative stress after training ${ }^{40,42,65-67}$. Several studies in this review investigated the effects of exercise training on inflammatory markers. Onur et al. found that markers of oxidative stress were reduced after exercise training ${ }^{42}$, whilst Wicher et al. found a 
decreased BHR after exercise training, which could be attributed to changes in airway inflammation, however, it could also be an effect of relaxation of the smooth muscle cells in the airways ${ }^{52}$. Murine models demonstrated that regular exercise decreases airway inflammation by immune-regulatory mechanisms of the airway epithelium ${ }^{68}$. As this review demonstrates that EIB can be slightly optimised after exercise training, more research should focus on inflammatory markers after exercise training. Furthermore, investigations should be conducted into whether the inflammatory response of asthmatics after exercise is different from that of non-asthmatics. Currently, the invasiveness of the techniques available to measure airway inflammation, such as biopsy, hampers this objective. However, there is an increasing interest in the non-invasive assessment of exhaled inflammatory markers, such as FeNO and solutes in exhaled breath condensate. Such feasible techniques can facilitate research on inflammatory responses and exercise in children.

Children with asthma have a lower health-related quality of life compared with healthy children ${ }^{69,70}$. It is probable that exercise training can improve the quality of life in children with asthma. However, only three studies investigated the effects of exercise training on quality of life; therefore more data are needed.

No studies used validated instruments such as the Asthma Control Questionnaire ${ }^{71}$, Childhood Asthma Control Test ${ }^{72}$, or Asthma Control Test ${ }^{73}$ to assess the clinical control of asthma. However, indirect measures of asthma control, including number of asthma attacks and days of wheezing, seemed to be improved by training. As asthma control parameters are not yet studied extensively, more research into this essential aspect of asthma is vital.

In this review we demonstrate that lung function in general does not improve after training in children with asthma. This is in accordance with studies in adults, suggesting that lung volumes and lung function cannot be improved with regular exercise ${ }^{74}$. The PEF seems to be the only lung function parameter which is slightly improved by training, probably due to increased strength of the respiratory muscles after training. This view is strengthened by the finding that changes in PEF after training are not accompanied by changes in $\mathrm{FEV}_{1}$.

The results of our review are in accordance with the results of three previous systematic reviews ${ }^{17,75,76}$. Alongside an update of the literature we provided an overview of additional parameters, such as the effects of exercise training on EIB and pathophysiological pathways.

Based on the studies in this review, some recommendations for new interventions can be made. Firstly, it seems that intensity rather than type of training (e.g. running, aerobic or swimming training) is one of the most important factors in determining the success of an intervention. It is important to individualise the training intensity for each subject. Some studies used the same training intensity for all subjects, which could have decreased the effectiveness of training in these studies ${ }^{2,29,30,36,40,45,51}$. In order to improve oxygen uptake, the training intensity should be set at the (personalised) 
ventilatory threshold ${ }^{31,54}$. To train at this intensity, it is recommended that children have adequate asthma control, which can be achieved through appropriate pharmacological therapy. Secondly, the duration and frequency of the training programme are important for achieving a training effect. Exercise for at least 120 minutes per week, divided across at least two training sessions, with a training programme lasting for at least three months is recommended. Thirdly, the quality of future studies could be improved by increasing the number of subjects, performing an intention-to-treat analysis, specifying the eligibility criteria more precisely and clearly, and blinding of the outcome assessor. Finally, it would be of interest to add measurements of habitual physical activity (e.g. accelerometers) as Santuz et al. demonstrated that habitual physical activity is an important factor for improving exercise performance in children with asthma ${ }^{77}$.

Since this review provided no clear evidence that exercise can improve lung function parameters, whilst EIB can in some cases be improved in children, it is important to investigate whether exercise influences the underlying pathophysiology of asthma. It is necessary to investigate the effects of both single bouts of exercise and exercise training on asthma-related (inflammatory) markers. This might be non-invasively assessed by measuring inflammatory markers in exhaled breath such as FeNO.

This review has demonstrated that an individualised exercise training programme improves cardiorespiratory fitness and has the potential to improve EIB in children with asthma. Physical activity should be recommended to children with asthma by health care providers as it can be considered safe and beneficial. However, exercise has minimal impact on lung function in asthmatic children. 


\section{Supporting information}

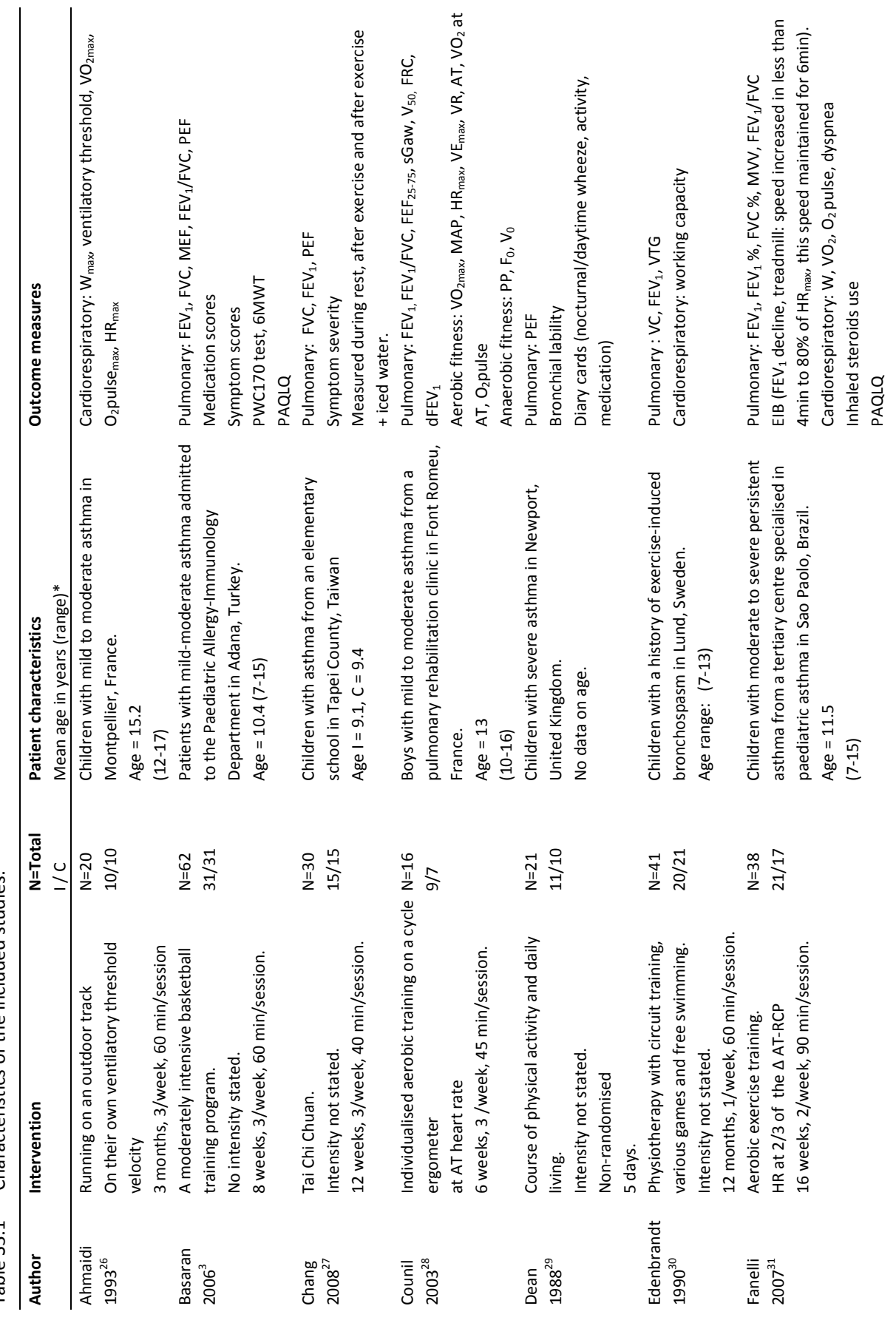


Exercise training in children with asthma:

a systematic review

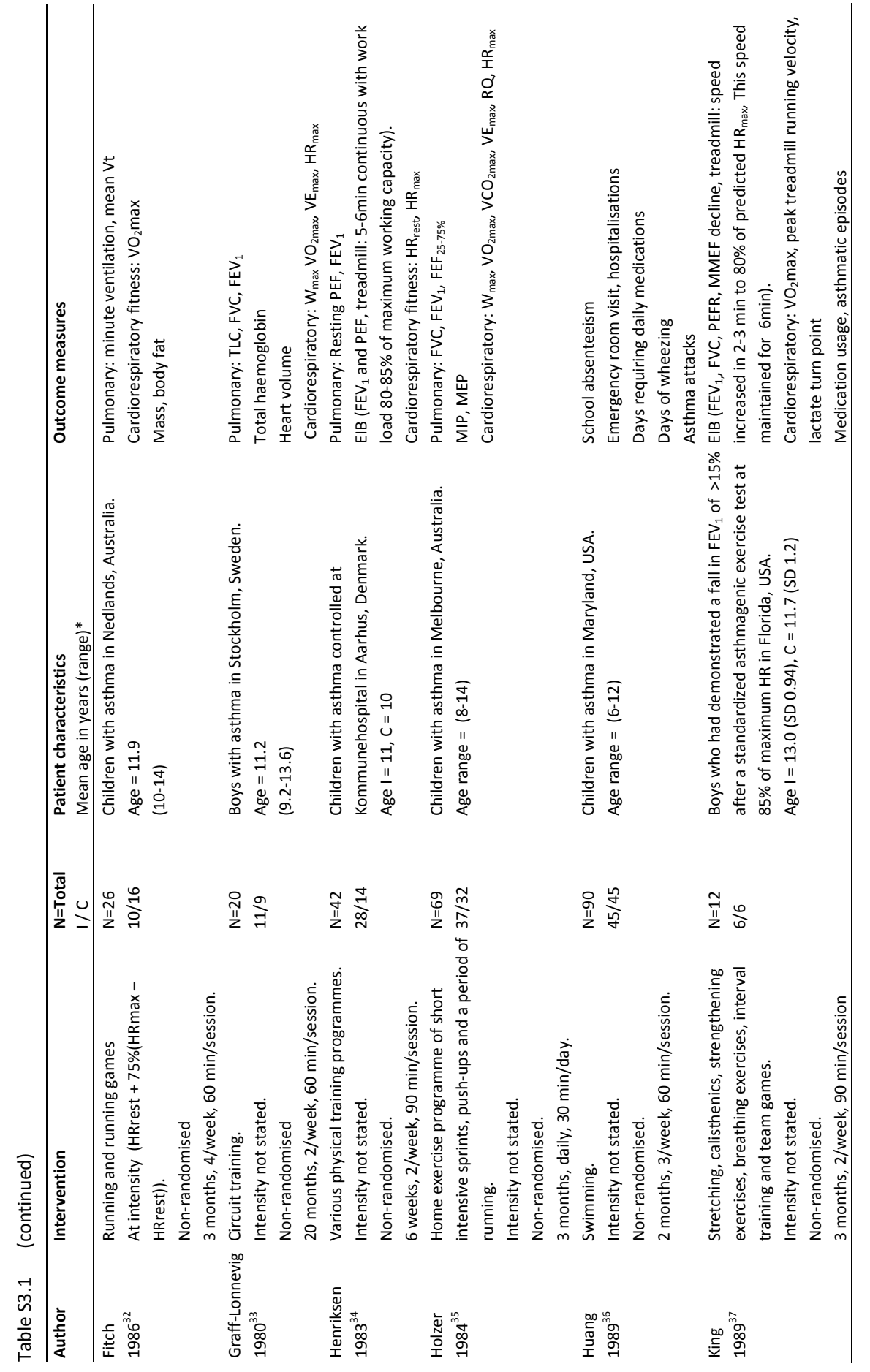




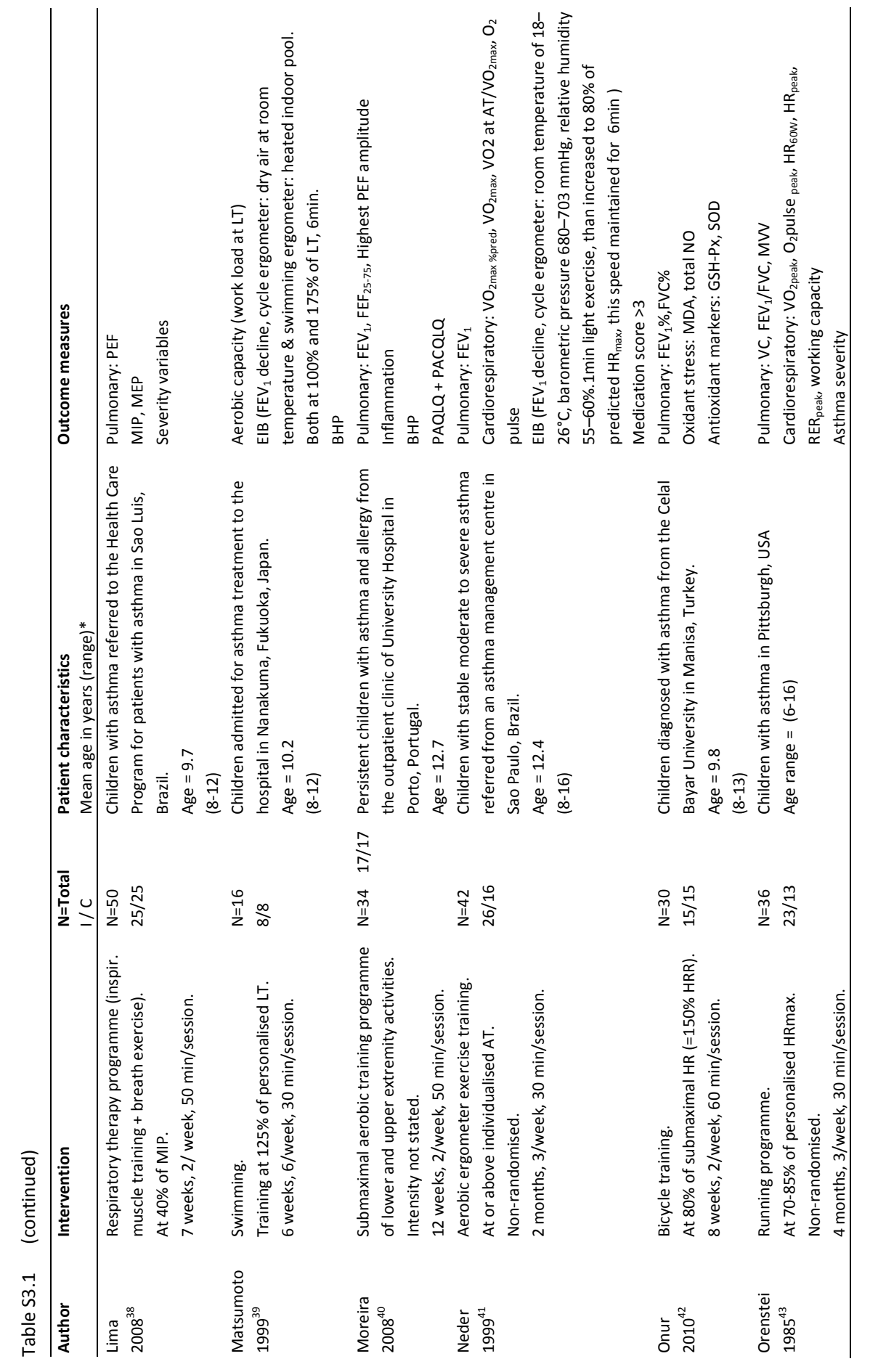


Exercise training in children with asthma:

a systematic review

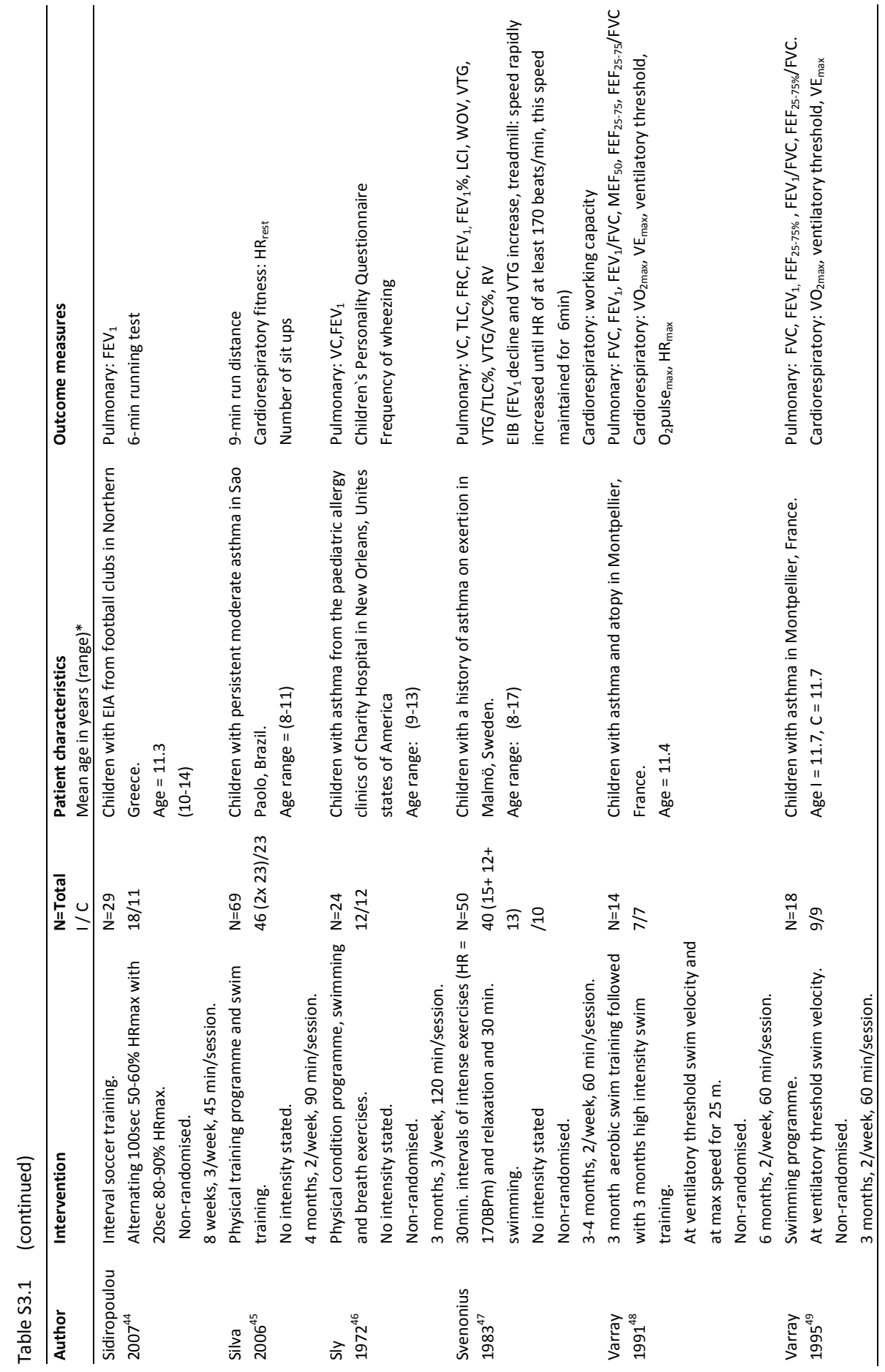




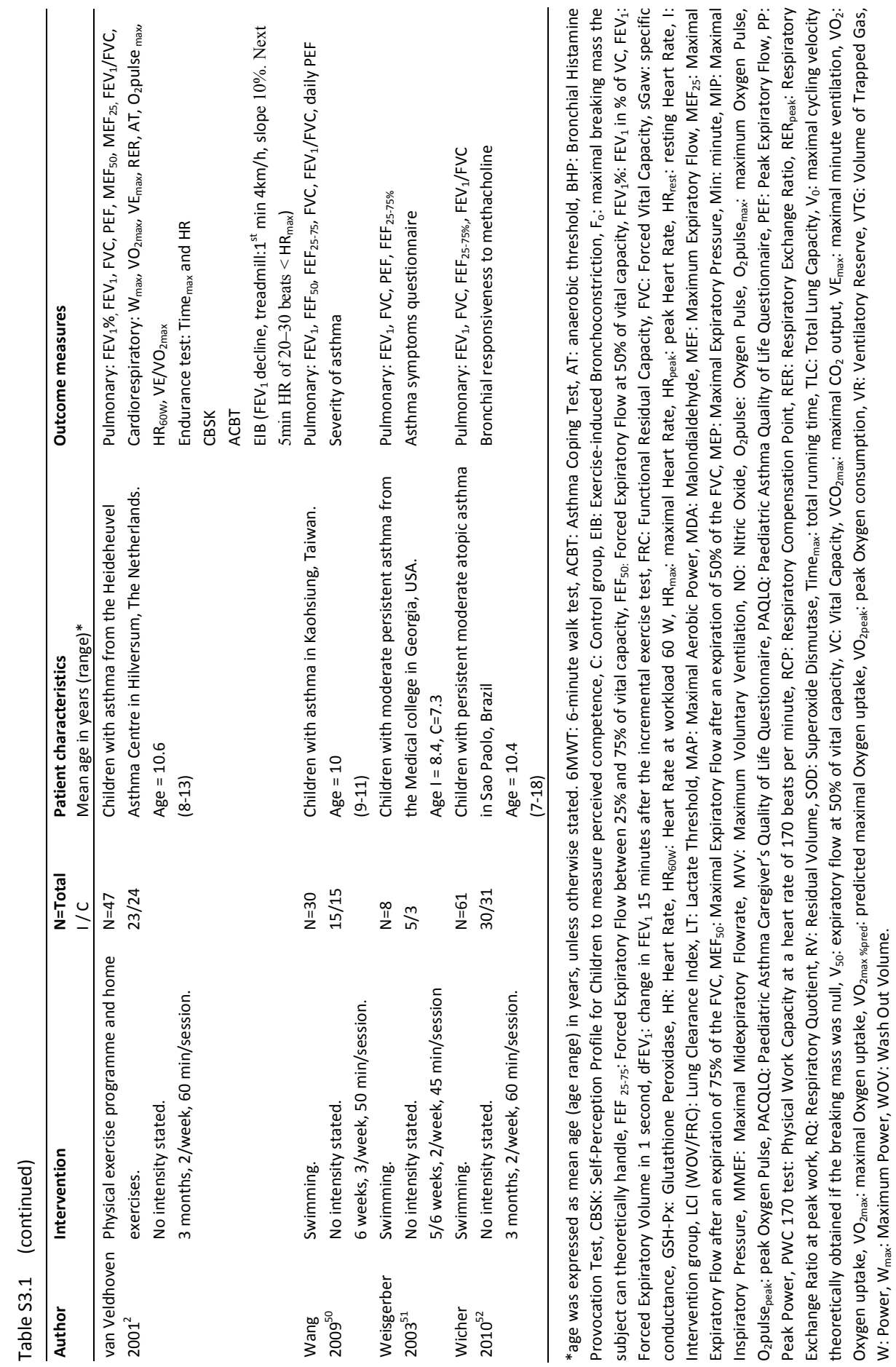




\section{References}

1. Pearce N, Aït-Khaled N, Beasley R, Mallol J, Keil U, Mitchell E, Robertson C; ISAAC Phase Three Study Group. Worldwide trends in the prevalence of asthma symptoms: phase III of the International Study of Asthma and Allergies in Childhood (ISAAC). Thorax 2007;62: 758-766.

2. van Veldhoven NH, Vermeer A, Bogaard JM, Hessels MG, Wijnroks L, Colland VT, van Essen-Zandvliet EE. Children with asthma and physical exercise: effects of an exercise programme. Clin Rehabil 2001;15:360-370.

3. Basaran S, Guler-Uysal F, Ergen N, Seydaoglu G, Bingol-Karakoç G, Ufuk Altintas D. Effects of physical exercise on quality of life, exercise capacity and pulmonary function in children with asthma. J Rehabil Med 2006;38:130-135.

4. Grzelewski T, Stelmach I. Exercise-induced bronchoconstriction in asthmatic children: a comparative systematic review of the available treatment options. Drugs 2009;69:1533-1553.

5. van Leeuwen JC, Driessen JM, de Jongh FH, van Aalderen WM, Thio BJ. Monitoring pulmonary function during exercise in children with asthma. Arch Dis Child 2011;96:664-668.

6. Ross RM. ATS/ACCP statement on cardiopulmonary exercise testing. American Journal of Respiratory and Critical Care Medicine 2003;167:1451-1451.

7. Gotshall RW. Exercise-induced bronchoconstriction. Drugs 2002;62:1725-1739.

8. Price JF. Choices of therapy for exercise-induced asthma in children. Allergy 2001;56 Suppl 66:12-17.

9. Weiler JM, Bonini S, Coifman R, Craig T, Delgado L, Capão-Filipe M, Passali D, Randolph C, Storms W; Ad Hoc Committee of Sports Medicine Committee of American Academy of Allergy, Asthma \& Immunology. American Academy of Allergy, Asthma \& Immunology Work Group report: exerciseinduced asthma. J Allergy Clin Immunol 2007;119:1349-1358.

10. Anderson SD. How does exercise cause asthma attacks? Curr Opin Allergy Clin Immunol 2006;6:37-42.

11. Carlsen KH, Hem E, Stensrud T. Asthma in adolescent athletes. Br J Sports Med 2011;45:1266-1271.

12. Weiler JM, Anderson SD, Randolph C, et al. Pathogenesis, prevalence, diagnosis, and management of exercise-induced bronchoconstriction: a practice parameter. Ann Allergy Asthma Immunol 2010;105(6 Suppl):S1-47

13. Hallstrand TS, Moody MW, Wurfel MM, Schwartz LB, Henderson WR Jr, Aitken ML. Inflammatory basis of exercise-induced bronchoconstriction. Am J Respir Crit Care Med 2005;172:679-686.

14. Anderson SD, Daviskas E. The mechanism of exercise-induced asthma is. J Allergy Clin Immunol 2000;106:453-459.

15. Carlsen K, Carlsen KC. Physical exercise, training and sports in asthmatic children and adolescents. Paediatric Asthma: European Respiratory Society Journals Ltd, 2012:49-58.

16. McFadden ER, Gilbert IA. Exercise-induced asthma. N Engl J Med 1994;330:1362-1367.

17. Ram FS, Robinson SM, Black PN, Picot J. Physical training for asthma. Cochrane Database Syst Rev 2005(4):CD001116.

18. Kitsantas A, Zimmerman BJ. Self-efficacy, activity participation, and physical fitness of asthmatic and nonasthmatic adolescent girls. J Asthma 2000;37:163-174.

19. Lucas SR, Platts-Mills TA. Physical activity and exercise in asthma: relevance to etiology and treatment. J Allergy Clin Immunol 2005;115:928-934.

20. Villa F, Castro AP, Pastorino AC, Santarém JM, Martins MA, Jacob CM, Carvalho CR. Aerobic capacity and skeletal muscle function in children with asthma. Arch Dis Child 2011;96:554-559.

21. Jones SE, Merkle SL, Fulton JE, Wheeler LS, Mannino DM. Relationship between asthma, overweight, and physical activity among U.S. high school students. J Community Health 2006;31:469-478.

22. Welsh L, Roberts RG, Kemp JG. Fitness and physical activity in children with asthma. Sports Med 2004;34:861-870.

23. Williams B, Powell A, Hoskins G, Neville R. Exploring and explaining low participation in physical activity among children and young people with asthma: a review. BMC Fam Pract 2008;9:40.

24. Rasmussen F, Lambrechtsen J, Siersted HC, Hansen HS, Hansen NC. Low physical fitness in childhood is associated with the development of asthma in young adulthood: the Odense schoolchild study. Eur Respir J 2000;16: 866-870. 
25. Verhagen AP, de Vet HC, de Bie RA, Kessels AG, Boers M, Bouter LM, Knipschild PG. The Delphi list: a criteria list for quality assessment of randomized clinical trials for conducting systematic reviews developed by Delphi consensus. J Clin Epidemiol 1998;51:1235-1241.

26. Ahmaidi SB, Varray AL, Savy-Pacaux AM, Prefaut CG. Cardiorespiratory fitness evaluation by the shuttle test in asthmatic subjects during aerobic training. Chest 1993;103:1135-1141.

27. Chang YF, Yang YH, Chen CC, Chiang BL. Tai Chi Chuan training improves the pulmonary function of asthmatic children. J Microbiol Immunol Infect 2008;41:88-95.

28. Counil FP, Varray A, Matecki S, Beurey A, Marchal P, Voisin M, Préfaut C. Training of aerobic and anaerobic fitness in children with asthma. J Pediatr 2003;142:179-184.

29. Dean M, Bell E, Kershaw CR, Guyer BM, Hide DW. A short exercise and living course for asthmatics. Br J Dis Chest 1988;82:155-161.

30. Edenbrandt L, Olséni L, Svenonius E, Jonson B. Effect of physiotherapy in asthmatic children--a one-year follow-up after physical training once a week. Acta Paediatr Scand 1990;79:973-975.

31. Fanelli A, Cabral AL, Neder JA, Martins MA, Carvalho CR. Exercise training on disease control and quality of life in asthmatic children. Med Sci Sports Exerc 2007;39:1474-1480.

32. Fitch KD, Blitvich JD, Morton AR. The effect of running training on exercise-induced asthma. Ann Allergy 1986;57:90-94.

33. Graff-Lonnevig V, Bevegård S, Eriksson BO, Kraepelien S, Saltin B. Two years' follow-up of asthmatic boys participating in a physical activity programme. Acta Paediatr Scand 1980;69:347-352.

34. Henriksen JM, Nielsen TT. Effect of physical training on exercise-induced bronchoconstriction. Acta Paediatr Scand 1983;72:31-36.

35. Holzer FJ, Schnall R, Landau LI. The effect of a home exercise programme in children with cystic fibrosis and asthma. Aust Paediatr J 1984;20:297-301

36. Huang SW, Veiga R, Sila $U$, Reed E, Hines S. The effect of swimming in asthmatic children--participants in a swimming program in the city of Baltimore. J Asthma 1989;26:117-121.

37. King MJ, Noakes TD, Weinberg. EG. Physiological effects of a physical training programme in children with exercise induced asthma. PES 1989;1:137-144.

38. Lima EV, Lima WL, Nobre A, dos Santos AM, Brito LM, Costa Mdo R. Inspiratory muscle training and respiratory exercises in children with asthma. J Bras Pneumol 2008;34:552-558.

39. Matsumoto I, Araki H, Tsuda K, Odajima H, Nishima S, Higaki Y, Tanaka H, Tanaka M, Shindo M. Effects of swimming training on aerobic capacity and exercise induced bronchoconstriction in children with bronchial asthma. Thorax 1999;54:196-201.

40. Moreira A, Delgado L, Haahtela T, Fonseca J, Moreira P, Lopes C, Mota J, Santos P, Rytilä P, CastelBranco MG. Physical training does not increase allergic inflammation in asthmatic children. Eur Respir J 2008;32:1570-1575.

41. Neder JA, Nery LE, Silva AC, Cabral AL, Fernandes AL. Short-term effects of aerobic training in the clinical management of moderate to severe asthma in children. Thorax 1999;54:202-206.

42. Onur E, Kabaroğlu C, Günay O, Var A, Yilmaz O, Dündar P, Tikiz C, Güvenç Y, Yüksel H. The beneficial effects of physical exercise on antioxidant status in asthmatic children. Allergol Immunopathol (Madr) 2011;39:90-95.

43. Orenstein DM, Reed ME, Grogan FT Jr, Crawford LV. Exercise conditioning in children with asthma. J Pediatr 1985;106:556-560.

44. Sidiropoulou MP, Fotiadou EG, Tsimaras VK, Zakas AP, Angelopoulou NA. The effect of interval training in children with exercise-induced asthma competing in soccer. J Strength Cond Res 2007;21:446-450.

45. Silva CS, Torres LA, Rahal A, Terra Filho J, Vianna EO. Comparison of morning and afternoon exercise training for asthmatic children. Braz J Med Biol Res 2006;39:71-78.

46. Sly RM, Harper RT, Rosselot I. The effect of physical conditioning upon asthmatic children. Ann Allergy 1972;30:86-94.

47. Svenonius $E$, Kautto $R$, Arborelius $M$, Jr. Improvement after training of children with exercise-induced asthma. Acta Paediatr Scand 1983;72:23-30.

48. Varray AL, Mercier JG, Terral CM, Prefaut CG. Individualized aerobic and high intensity training for asthmatic children in an exercise readaptation program. Is training always helpful for better adaptation to exercise? Chest 1991;99:579-586. 
49. Varray AL, Mercier JG, Prefaut CG. Individualized training reduces excessive exercise hyperventilation in asthmatics. Int J Rehabil Res 1995;18:297-312.

50. Wang JS, Hung WP. The effects of a swimming intervention for children with asthma. Respirology 2009;14:838-842.

51. Weisgerber MC, Guill M, Weisgerber JM, Butler H. Benefits of swimming in asthma: effect of a session of swimming lessons on symptoms and PFTs with review of the literature. J Asthma 2003;40:453-464.

52. Wicher IB, Ribeiro MA, Marmo DB, Santos Cl, Toro AA, Mendes RT, Cielo FM, Ribeiro JD. Effects of swimming on spirometric parameters and bronchial hyperresponsiveness in children and adolescents with moderate persistent atopic asthma. J Pediatr (Rio J) 2010;86:384-390.

53. Takken T, van Brussel, M., Hulzebos, E. Inspanningsfysiologie bij kinderen. Houten: Bohn Stafleu van Loghum, 2008:63-92.

54. Baquet G, van Praagh E, Berthoin S. Endurance training and aerobic fitness in young people. Sports Med 2003;33:1127-1143.

55. de Groot EP, Duiverman EJ, Brand PL. Comorbidities of asthma during childhood: possibly important, yet poorly studied. Eur Respir J 2010;36:671-678.

56. Hills AP, Andersen LB, Byrne NM. Physical activity and obesity in children. Br J Sports Med 2011;45: 866-870.

57. Tomporowski PD, Lambourne K, Okumura MS. Physical activity interventions and children's mental function: an introduction and overview. Prev Med 2011;52 Suppl 1:S3-9.

58. National Heart L, Blood Institute. National Asthma Education Program. Expert Panel on the Management of A, United States. Dept. of $\mathrm{H}$, et al. Expert Panel report 3 [electronic resource] : guidelines for the diagnosis and management of asthma: full report / National Heart, Lung, and Blood Institute, National Asthma Education and Prevention Program. [Bethesda, Md.] : U.S. Dept. of Health and Human Services, National Institutes of Health, National Heart, Lung, and Blood Institute, 2007.

59. Mangla PK, Menon MP. Effect of nasal and oral breathing on exercise-induced asthma. Clin Allergy 1981;11:433-439.

60. Anderson SD. The prevention of exercise-induced bronchoconstriction: what are the options? Expert Rev Respir Med 2012;6:355-357.

61. Hallstrand TS, Bates PW, Schoene RB. Aerobic conditioning in mild asthma decreases the hyperpnea of exercise and improves exercise and ventilatory capacity. Chest 2000;118:1460-1469.

62. Orenstein DM. Pulmonary problems and management concerns in youth sports. Pediatr Clin North Am 2002;49:709-721, v-vi.

63. Thio BJ, Nagelkerke AF, Ketel AG, van Keeken BL, Dankert-Roelse JE. Exercise-induced asthma and cardiovascular fitness in asthmatic children. Thorax 1996;51:207-209.

64. Barreto M, Villa MP, Olita C, Martella S, Ciabattoni G, Montuschi P. 8-Isoprostane in exhaled breath condensate and exercise-induced bronchoconstriction in asthmatic children and adolescents. Chest 2009;135:66-73.

65. Zietkowski Z, Skiepko R, Tomasiak-Lozowska MM, Mroczko B, Szmitkowski M, Bodzenta-Lukaszyk A. Changes in high-sensitivity C-reactive protein in serum and exhaled breath condensate after intensive exercise in patients with allergic asthma. Int Arch Allergy Immunol 2010;153:75-85.

66. Mendes FA, Almeida FM, Cukier A, Stelmach R, Jacob-Filho W, Martins MA, Carvalho CR. Effects of aerobic training on airway inflammation in asthmatic patients. Med Sci Sports Exerc 2011;43:197-203.

67. Nikolaidis MG, Kyparos A, Vrabas IS. F-isoprostane formation, measurement and interpretation: the role of exercise. Prog Lipid Res 2011;50:89-103.

68. Vieira RP, Toledo AC, Ferreira SC, Santos AB, Medeiros MC, Hage M, Mauad T, Martins Mde A, Dolhnikoff $M$, Carvalho CR. Airway epithelium mediates the anti-inflammatory effects of exercise on asthma. Respir Physiol Neurobiol 2011;175:383-389.

69. Juniper EF. Quality of life in adults and children with asthma and rhinitis. Allergy 1997;52:971-977.

70. van Gent R, van Essen LE, Rovers MM, Kimpen JL, van der Ent CK, de Meer G. Quality of life in children with undiagnosed and diagnosed asthma. Eur J Pediatr 2007;166:843-848.

71. Juniper EF, O'Byrne PM, Guyatt GH, Ferrie PJ, King DR. Development and validation of a questionnaire to measure asthma control. Eur Respir J 1999;14:902-907. 
72. Liu AH, Zeiger R, Sorkness C, Mahr T, Ostrom N, Burgess S, Rosenzweig JC, Manjunath R. Development and cross-sectional validation of the Childhood Asthma Control Test. J Allergy Clin Immunol 2007;119:817-825.

73. Nathan RA, Sorkness CA, Kosinski M, Schatz M, Li JT, Marcus P, Murray JJ, Pendergraft TB. Development of the asthma control test: a survey for assessing asthma control. J Allergy Clin Immunol 2004;113:5965.

74. Satta A. Exercise training in asthma. J Sports Med Phys Fitness 2000;40:277-283.

75. Welsh L, Kemp JG, Roberts RG. Effects of physical conditioning on children and adolescents with asthma. Sports Med 2005;35:127-141.

76. Chandratilleke MG, Carson KV, Picot J, Brinn MP, Esterman AJ, Smith BJ. Physical training for asthma. Cochrane Database Syst Rev 2012;5:CD001116.

77. Santuz P, Baraldi E, Filippone M, Zacchello F. Exercise performance in children with asthma: is it different from that of healthy controls? Eur Respir J 1997;10:1254-1260.

78. Moher D, Liberati A, Tetzlaff J, Altman DG; PRISMA Group. Preferred reporting items for systematic reviews and meta-analyses: the PRISMA statement. J Clin Epidemiol 2009;62:1006-1012. 


$$
\star
$$




\section{Paediatric physical activity: associations with asthma and obesity}

Submitted

Maartje Willeboordse

Kim DG van de Kant

Charlotte A van der Velden

Constant P van Schayck

Edward Dompeling 


\section{Abstract}

\section{Background}

Asthma and obesity are interrelated and highly prevalent in children; this combination results in a difficult-to-treat asthma-obesity phenotype. The exact underlying mechanisms of this phenotype remain unclear, but decreased physical activity (PA) could be an important lifestyle factor. We hypothesise that both asthma and overweight/obesity decrease PA levels and interact on PA levels in overweight/obese asthmatic children.

\section{Methods}

School-aged children $(n=122)$ were divided over 4 groups (healthy control, asthma, overweight/obesity and asthma, and overweight/obesity) and asked to perform lung function tests and wear an activity monitor for 7 days. PA was determined by several measures: step count, active time, screen time, time spent in organised sports and active transport forms. We used multiple linear regression techniques to investigate if asthma, body mass index-standard deviation score (BMI-SDS), or the interaction term asthma $x$ BMI-SDS were associated with PA. Additionally, we tested if asthma features like lung function, medication, and airway reversibility were related to PA levels in asthmatic children.

\section{Results}

Less than 1 in 5 children reached the recommended daily step count criteria of 12,000 step/day. Asthma, BMI-SDS and the interaction between asthma $\times$ BMI-SDS were not related to any of the PA variables $(P \geq 0.05)$. None of the asthma features could predict PA levels $(P \geq 0.05)$.

\section{Conclusions}

We found no significant association between asthma, overweight and PA levels in school-aged children in this study. As PA levels were worryingly low, effective PA promotion is necessary. Future longitudinal studies should investigate if increasing PA has a secondary preventive role in children with overweight/obesity and asthma. 


\section{Background}

In both adults and children, a positive association between obesity and asthma is demonstrated (Figure 4.1, pathway 1$)^{1-3}$. Several studies confirmed that an asthmaobesity phenotype exists, which is dominant among children and middle-aged women $^{1,4}$. Recently, a distinction has been made between an early-onset ( $<12$ years) and a late-onset ( $\geq 12$ years) asthma-obesity phenotype ${ }^{5}$. The early-onset asthmaobesity phenotype is characterized by high medication use, high admissions rates to the intensive care unit for asthma-related problems and a decreased quality of life ${ }^{5}$. Although the exact mechanisms that underlie the asthma-obesity phenotype remain unclear, most studies assume that the increased fat mass in obesity causes both mechanical and systemic inflammatory changes which in turn influence breathing mechanisms and airway inflammation ${ }^{6-8}$.

Next to the inflammatory and mechanical hypothesis, several lifestyle factors could play an important role in the characterisation of the asthma-obesity phenotype. Especially the role of decreased physical activity (PA) deserves further attention, as both asthma and obesity are characterized by exercise-related limitations ${ }^{9}$. Firstly, approximately $40-$ $90 \%$ of all asthma patients experience exercise induced bronchoconstriction (EIB). Several asthma-related characteristics like EIB, uncontrolled symptoms and parental beliefs can cause avoidance of $P A^{10,11}$ (Figure 4.1, pathway 2). Secondly, obesity is also associated with decreased PA, as decreased PA is a cause of the imbalance in energy expenditure in obesity (Figure 4.1, pathway 3 ).

Several studies investigated PA levels among children with asthma, but conflicting results have been found as some studies found lower PA levels in children with asthma while others report no difference ${ }^{9,10,12}$. Common limitations of these studies are that not all studies take factors into account that can influence PA such as seasonal influences, and the use of questionnaires to assess $P A^{9,13}$. In this study we test the hypothesis that both asthma and overweight/obesity are associated with low PA levels and interact on PA levels in children (Figure 4.1, pathway 4). Moreover, we will report if there is a dose-response effect of asthma features (e.g. symptoms and lung function) on decreased PA.

\section{Methods}

\section{Participants}

For this study, 4 groups of children aged 6-12 years were recruited; children with asthma and overweight/obesity $(\mathrm{AO})$, children with asthma and a normal body weight $(A)$, non-asthmatic children with overweight/obesity $(O)$ and healthy children without asthma and overweight/obesity $(\mathrm{HC})$. The $\mathrm{A}, \mathrm{O}$ and $\mathrm{HC}$ group were selected from a 
database of an online questionnaire about respiratory symptoms and anthropometric values, which was sent out in May 2010 to parents of all children in South Limburg, the Netherlands (MEC 09-2-088) ${ }^{14}$. The children of the AO group were recruited in 2013 via the control group of a current study in children with asthma and overweight/obesity ${ }^{15}$. All children in the AO group combined their second or third visit for the RCT with measurements for the current study.

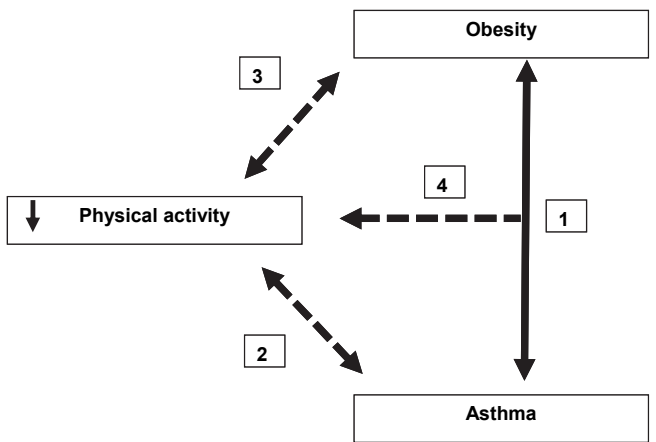

Figure 4.1 Hypothetical associations between asthma, obesity and decreased physical activity.

Pathway 1) Obesity is associated with asthma, and a so-called early-onset asthma-obesitphenotype has been detected $^{5}$. Pathway 2) Asthma is hypothetically associated with decreased PA, as it is accompanied with exercise-related limitations. Pathway 3 ) Obesity is hypothetically associated with decreased PA, as decreased PA is a cause of the imbalance in energy expenditure in obesity. Pathway 4) Obesity and asthma are hypothetically both related to decreased PA levels, therefore it is plausible that an interactive effect of asthma and obesity on decreased PA levels exists.

\section{Study design}

All participants visited the hospital once for anthropometric measurements, completing questionnaires, lung function tests, and a Fractional exhaled nitric oxide (FeNO) measurement. During this visit all children received an activity monitor with the instruction to wear it for 7 consecutive days, and send it back with a physical activity diary by regular mail.

\section{Ethics statement}

Written informed consent was obtained from the caretakers on behalf of the children. The study protocol was approved by the Medical Ethical Committee of Maastricht (MEC 12-2-030).

\section{Eligibility criteria}

A child was considered to be overweight if the BMI- standard deviation score (BMI-SDS) was $\geq 1.1^{16}$. Normal weight was defined as a BMI-SDS $\geq-1.8$ and $<1.1$ according to the 
reference values of the fourth national Dutch growth study [16]. Furthermore, a child was considered asthmatic if the participant fulfilled at least 2 of the following 3 criteria:

1. An asthma diagnosis given by a general practitioner or paediatrician;

2. Current asthma symptoms (wheezing, or dry cough at night during the previous year) or use of asthma medication during the previous year (short acting beta-2agonists (SABA), long acting beta-2agonists (LABA) or ICS), or a combination;

3. Reversibility of airway obstruction on a bronchodilator ( $\geq 9 \%$ improvement in forced expiratory volume in 1 second $\left(\mathrm{FEV}_{1}\right)$ of the predicted value after $400 \mu \mathrm{g}$ salbutamol (Teva Pharma, Leiden, the Netherlands)).

Children were considered non-asthmatic if they were never diagnosed with asthma by a doctor and had not used asthma medication in the previous year. Children were excluded from the study in case of a congenital malformation of the airways or other chronic lung diseases, mental retardation, syndromes, or physical limitations that make intense PA impossible.

\section{Anthropometric measurements}

Children's body weight and height were assessed twice to the nearest $0.1 \mathrm{~kg}$ and $0.5 \mathrm{~cm}$, while wearing underwear, by using a medical calibrated weight scale and stadiometer (Model 877 and 213, Seca, Hamburg, Germany). The BMI-SDS was calculated with reference values of the fourth national Dutch growth study ${ }^{16}$.

\section{Lung function, airway inflammation and respiratory complaints}

Maximal expiratory flow volume curves were obtained with the ZAN100 (ZAN Messgerate, Oberthulba, Germany), according to ATS/ERS guidelines ${ }^{17,18}$. LABA was withheld 48 hours and SABA 8 hours before the measurement. FeNO was obtained with the online NIOX analyser (Aerocrine, Solna, Sweden) according to international guidelines $^{19}$.

Information about respiratory complaints was collected by using a standardised questionnaire on respiratory complaints (International study of asthma and allergies in childhood questionnaire $)^{20}$. Asthma control was measured by the childhood-asthma control test (c-ACT), with a cut-off value of $\leq 19$ for uncontrolled asthma ${ }^{21}$. In addition, questionnaires were used to determine respiratory symptoms and the use of asthma medication in the previous 2 months ${ }^{22}$. Dose equivalents were calculated according to standard dosages of SABA and $\mathrm{ICS}^{23,24}$.

\section{Physical activity measurements}

Step count was measured by a triaxial accelerometer (Yamax EX510 Power Walker, Yamax, Tokyo, Japan). The output of the activity monitor is step count (in steps/day) and time spent in physical activity (in min/day), measured by a triaxial accelerometer 
mechanism. Outcomes of activity monitors produced by Yamax were demonstrated to be valid and reproducible ${ }^{25}$. Children were instructed by a trained researcher to wear the activity monitor for 7 consecutive days during waking hours in their pocket. Data were considered missing when participants wore the activity monitor less than 3 weekdays and 1 weekend day. We calculated if children met the daily PA recommendations of at least $12.000 \mathrm{steps} / \mathrm{day}^{26}$, and whether children were less, equally or more active compared to a reference population of Canadian children ${ }^{27}$. The time spent in PA was calculated by adding the active time measured by the activity monitor (in min/day) with cycling and swimming time derived from a 7-day activity diary (in $\mathrm{min} /$ day) which parents fulfilled in the same week as the children wore the activity monitor.

Screen time, time spent in organised sport activities (without school-regulated sport activities) and active transport forms to school were derived from a standardised Dutch questionnaire which parents fulfilled during the hospital visit ${ }^{28}$. Furthermore, the attitudes towards PA and exercise-related limitations were assessed with a parental questionnaire and an orally administered questionnaire for the child.

\section{Statistical analysis}

SPSS (version 20.0) was used for analysis. Baseline characteristics between the groups were compared by means of ANOVA, relevant post-hoc differences between groups were listed in the results section. There were no missing values, except for several PA values. All missing PA values ( $n=29,5.9 \%$ of the selected PA variables) were imputed by using multiple imputation techniques with 5 imputations, with the assumption that data were missing at random (see Table S4.1 Supporting Information). Variables included in the imputation model were: step count, time spent in PA, screen time, time spent in organised sport activities and active transport forms. Reasons for missing data included lost or broken activity monitors, illness, incomplete data and not returning the activity monitor despite multiple reminders.

Several multiple linear regressions were used to investigate the influence of asthma, BMI-SDS and the interaction term asthma $x$ BMI-SDS on various PA variables: step count, time spent in PA, screen time, time spent in organised sport activities and active transport forms. The variables age, sex and season of measurement were added to the model by the enter method as they are believed to be correlated with individual PA levels in children ${ }^{13,29}$.

To answer the second research question, we performed multiple linear regression analyses (enter method) in all children with asthma. We tested if C-ACT score, $\mathrm{FEV}_{1}$ \%predicted, FeNO, airway reversibility (in percentage), dose equivalent of SABA or parental and children's perception of asthma-related exercise limitations could predict the various PA variables. A significance level of less than 0.05 was used for all analyses. 


\section{Sample size calculation}

A sample size estimation for multiple group comparisons using analysis of variance was performed. As we expected the smallest differences in PA between the $\mathrm{O}$ and $\mathrm{HC}$ group and $A$ and $H C$ group, we based our calculation on a previous study which found a difference between $\mathrm{O}$ and $\mathrm{HC}$ group of 3669 steps $(S D=5576)^{30}$. In total, 116 children (29 per group) are sufficient to detect a significant difference in average daily step count with a power of $80 \%$, a two-sided alpha of 0.05 and a drop-out rate of $10 \%$.

\section{Results}

\section{Baseline characteristics}

All PA measurements were conducted during regular school weeks between May 2012 and February 2013. Baseline characteristics are presented in Table 4.1. All children were Caucasian. Forty percent of the asthmatic children showed airway reversibility and the majority of the asthmatic children had a good asthma control and used maintenance asthma medication. The groups differed slightly in age, with significantly younger children in the $\mathrm{A}$ and $\mathrm{HC}$ groups and older children in the $\mathrm{AO}$ and $\mathrm{O}$ groups. Relatively more boys were included in the $A$ and $A O$ groups than in the $\mathrm{HC}$ and $\mathrm{O}$ group. Children in the AO group had a significantly wider waist circumference than the children in the $\mathrm{O}$ group, but did not differ in other anthropometric values compared to the $O$ group. Asthma-related variables were not different between A and AO groups, except for a significantly higher amount of children in the $A O$ group which used more than 1 dose equivalent of ICS. Persons with imputated missing values were more often measured in summer season and had more often uncontrolled asthma compared to persons without imputated values (see Table S4.2 Supporting Information).

\section{Physical activity levels}

Less than 1 in 5 children met the current step count guidelines for school-aged children of 12.000 steps/day (Table 4.1), and children spent on average less than 60 minutes in organised sport activities outside school (Figure 4.2). Compared to a Canadian reference population, the majority of the children was less active (Table 4.1). Children measured in the summer, made on average 2307 more steps/day $(P<0.01)$, and spent on average 41 more minutes in $\mathrm{PA} /$ day, than children measured during the autumn (Table 4.2). Boys made on average 2489 more daily steps than girls $(P<0.05)$ and children spent on average 10.7 minutes more in weekly active transport forms to school for every year they were older $(P<0.05)$ (Table 4.2). 
Table 4.1 Baseline characteristics.

\begin{tabular}{|c|c|c|c|c|c|}
\hline & $\begin{array}{l}\text { Total group } \\
(n=122)\end{array}$ & $\begin{array}{c}\mathrm{HC} \\
(\mathrm{n}=33)\end{array}$ & $\begin{array}{c}A \\
(n=29)\end{array}$ & $\begin{array}{c}0 \\
(n=30)\end{array}$ & $\begin{array}{c}\mathrm{AO} \\
(\mathrm{n}=30)\end{array}$ \\
\hline \multicolumn{6}{|l|}{ Baseline and PA variables } \\
\hline Age in years, median (IQR)* & $10.8(2.2)$ & $10.3(2.1)$ & $10.1(2.5)$ & $11.2(1.9)$ & $11.9(2.1)$ \\
\hline Sex boys/girls, \%* & $52 / 48$ & $36 / 64$ & $69 / 31$ & $40 / 60$ & $63 / 37$ \\
\hline $\begin{array}{l}\text { Measurement during summer } \\
\text { season, \% }\end{array}$ & 22 & 27 & 24 & 10 & 27 \\
\hline Meeting at least 12.000 steps/day, \% & 19 & 21 & 36 & 11 & 10 \\
\hline $\begin{array}{l}\text { Equally, or more active as reference } \\
\text { population }{ }^{27}, \%\end{array}$ & 36 & 28 & 48 & 25 & 42 \\
\hline \multicolumn{6}{|l|}{ Anthropometric variables } \\
\hline $\mathrm{BMI}$ in $\mathrm{kg} / \mathrm{m}^{2}$, median (IQR)* & $18.8(7.0)$ & $16.5(3.0)$ & $16.1(1.5)$ & $22.9(1.8)$ & $23.6(5.5)$ \\
\hline BMI-SDS, median (IQR)* & $0.93(2.28)$ & $-0.11(1.31)$ & $-0.21(0.90)$ & $1.94(0.52)$ & $2.20(0.76)$ \\
\hline Hip circumference in $\mathrm{cm}$, mean $(\mathrm{SD})^{*}$ & $78.1(11.7)$ & $70.0(6.7)$ & $68.3(6.4)$ & $86.5(7.4)$ & $88.6(8.3)$ \\
\hline $\begin{array}{l}\text { Waist circumference in } \mathrm{cm} \text {, median } \\
(\mathrm{IQR})^{*}\end{array}$ & $69.5(19.9)$ & $59.5(12.4)$ & $60.8(8.9)$ & $78.5(9.0)$ & $85(20.4)$ \\
\hline \multicolumn{6}{|l|}{ Asthma-related variables } \\
\hline $\mathrm{FEV}_{1} \%$ predicted, mean (SD)* & $96(16)$ & $103(14)$ & $93(10)$ & $102(12)$ & $85(20)$ \\
\hline Airway reversibility, \%* & 22 & 0 & 31 & 10 & 50 \\
\hline Uncontrolled asthma, \% & 10 & n.a. & 8 & n.a. & 14 \\
\hline Asthma medication use, $\% *$ & 33 & 0 & 69 & 0 & 67 \\
\hline $\begin{array}{l}\text { SABA use, } \% \text { ( } \% \text { of those children } \\
\text { using more than } 1 \text { dose equivalent)* }\end{array}$ & 25 & $0(0)$ & $59(35)$ & $0(0)$ & $47(50)$ \\
\hline $\begin{array}{l}\text { ICS use, } \% \text { (\% of those children using } \\
\text { more than } 1 \text { dose equivalent)* }\end{array}$ & 23 & $0(0)$ & $52(21)$ & $0(0)$ & $43(46)$ \\
\hline FeNO in ppb, median (IQR)* & $13.0(12.6)$ & $12.9(7.4)$ & $19.0(27.4)$ & $10.6(5.0)$ & $20.9(18.5)$ \\
\hline
\end{tabular}

* Significant differences between groups with $\mathrm{P}<0.05$, measured by ANOVA. BMI: body mass index, BMI-SDS: body mass index-standard deviation score, FeNO: fractional exhaled nitric oxide, $\mathrm{FEV}_{1}$ : forced expiratory volume in 1 second, ICS: inhaled corticosteroid, n.a.: not applicable, SABA: short acting beta2-agonists, SD: standard deviation

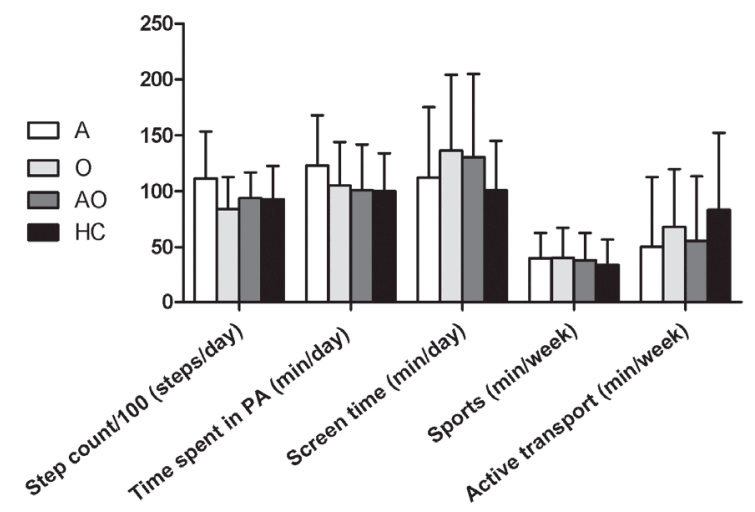

Figure 4.2 Physical Activity levels per group

There were no significant differences between groups in each of the categories $(P \geq 0.05)$.

$\mathrm{A}$ : asthma, O: overweight/obesity, AO: asthma and overweight/obesity, HC: healthy control, PA:physical activity 
Table 4.2 Standardized B values for the prediction models of several PA variables.

\begin{tabular}{lccccccc}
\hline Dependent variable & BMI-SDS & Asthma & $\begin{array}{c}\text { Asthma } x \\
\text { BMI-SDS }\end{array}$ & Age & Sex & $\begin{array}{c}\text { Autumn } \\
\text { season }\end{array}$ & Step count \\
\hline Step count & -.12 & .08 & -.03 & -.18 & $-.30^{*}$ & $-.36^{*}$ & n.a. \\
Time spent in PA & .04 & .02 & -.02 & .14 & -.03 & $-.28^{*}$ & $.54^{*}$ \\
Screen time & .17 & $<-.01$ & -.10 & .11 & .02 & -.11 & -.06 \\
Time spent in organised & .06 & -.06 & -.07 & .03 & -.18 & .06 & $.31^{*}$ \\
$\begin{array}{l}\text { sports } \\
\text { Time spent in active }\end{array}$ & -.09 & -.19 & .04 & $.23^{*}$ & -.09 & -.11 & -.10 \\
transport to school & & & & & & & \\
\hline
\end{tabular}

* Significant correlation $(\mathrm{P}<0.05)$ with the dependent variable, \# Boys are coded as 0, girls as $1,{ }^{\wedge}$ As opposed to the summer season. BMI: body mass index, BMI-SDS: body mass index - standard deviation score, n.a.: not applicable, PA: physical activity.

\section{Physical activity, asthma and BMI-SDS}

Neither asthma nor BMI-SDS were correlated to any of the PA variables (Table 4.2, Figure 4.2). Also the interaction term asthma by BMI-SDS could not explain variability in PA levels. When compared to the model without imputations, interpretation of the tests remained unchanged, except for the variable age which was a significant predictor for step count in the model without imputations, but not in the model with imputations (see Table S4.3 Supporting Information).

Table 4.3 Standardized B values for the relation between asthma related parameters and PA levels.

\begin{tabular}{lccccccc}
\hline Dependent variable & c-ACT & FEV $_{1} \%$ & $\begin{array}{c}\text { Airway } \\
\text { reversibility }\end{array}$ & $\begin{array}{c}\text { SABA dose } \\
\text { equivalent }\end{array}$ & $\begin{array}{c}\text { Parental } \\
\text { perception }\end{array}$ & $\begin{array}{c}\text { Child's } \\
\text { perception }\end{array}$ & FeNO \\
\hline Step count & -.07 & .03 & -.18 & -.08 & .01 & -.02 & .16 \\
Time spent in PA & -.01 & -.18 & -.02 & $<.01$ & -.14 & -.11 & .16 \\
Screen time & -.09 & -.25 & .06 & -.07 & .11 & .16 & .06 \\
Time spent in & -.06 & -.14 & -.15 & -.09 & .07 & -.19 & -.06 \\
organised sports & & & & & & & \\
Time spent in active & -.13 & -.26 & .09 & .03 & -.29 & -.06 & .14 \\
transport to school & & & & & & & \\
\hline
\end{tabular}

* Significant correlation $(\mathrm{P}<0.05)$ with the dependent variable. $\mathrm{C}-\mathrm{ACT}$ : childhood-asthma control test, FeNO: fractional exhaled nitric oxide, $\mathrm{FEV}_{1} \%$ : forced expiratory volume in 1 second in percentage of predicted, PA: physical activity.

\section{Physical activity and asthma features}

In the group of asthmatic children, we assessed whether asthma features could explain variability in PA levels. The overall model fitting was low as $\mathrm{R}$ squares ranged from 0.05 to 0.20 . Asthma control, $\mathrm{FEV}_{1} \%$ predicted value, airway reversibility, SABA dose equivalent, FeNO, and perception of asthma-related exercise limitations by both child and parents could not predict any of the PA variables $(P \geq 0.05)$ (Table 4.3). When 
compared to the model without imputations, interpretation of the tests remained unchanged (see Table S4.4 Supporting Information).

\section{Discussion}

We found no associations of asthma, BMI-SDS or an interaction between asthma and BMI-SDS with PA levels in school aged children. Less than twenty percent of all children met the minimum recommended daily step count guidelines. In addition, asthma features and attitudes towards asthma-related exercise limitations were not related to PA levels in asthmatic children.

We hypothesised that children with asthma would have decreased PA levels, as asthma is associated with exercise-related limitations (Figure 4.1). In addition, we hypothesized that a dose-response effect of several asthma features on decreased PA levels would be visible in asthmatic children. Although we measured PA by several outcome measures, neither asthma diagnosis nor asthma features were associated with any of the PA outcome measures. One explanation for the lack of effect of either asthma, asthma features or BMI-SDS, is that PA levels were considerably low in all groups, resulting in hardly any 'room for worsening'. Less than twenty percent of all children met the minimum recommended daily step count guidelines. Compared to a reference population of Canadian school aged children, the majority of our study population had a lower step count ${ }^{27}$. Not only step count, but also other PA variables were alarmingly low, as on average children spent more minutes in sedentary position behind screens than being physically active (Figure 4.2). This implies that despite several attempts of Western politics to increase children's PA, PA levels still remain too low, which could lead to considerable health threats.

Although it is plausible that we did not found deteriorations in PA levels in asthma or overweight/obesity because PA levels are already low, it can also be argued that we should refute our hypothesis in this population (Figure 4.1). Firstly, as we found that not only an asthma diagnosis, but also asthma features were not associated with decreased PA, it seems unlikely that asthma is associated with decreased PA levels. Several other studies investigated the possible association of asthma with PA levels in children, but conflicting results have been found. Tsai et al reported 12 cross-sectional studies, (their own study included), which measured PA levels in children with and without asthma ${ }^{9}$. Six studies found decreased PA levels, 5 studies found equal PA levels and 1 study found increased PA levels in children with asthma/a history of wheezing compared to healthy controls ${ }^{9}$. Neither differences in methodology (e.g. different PA outcome measures), population characteristics, country or comorbidities could explain the inconsistencies in those studies. More studies are necessary to investigate why childhood asthma is in some cases, but not all, associated with decreased PA. 
Secondly, it is also possible that BMI-SDS is indeed not associated with decreased PA in school-aged children, as obesity is to a large extent caused by an increase in energy intake, instead of a decrease in energy expenditure ${ }^{31}$. A recent meta-analysis of Wilks et al. confirmed that individual differences in PA are often not associated with obesity in childhood, as a healthy diet plays a far more important role in childhood obesity than PA levels ${ }^{32}$. Thirdly, it is possible that our results have been influenced by recent Dutch asthma guidelines, which promote overweight prevention and PA stimulation actively in children with asthma ${ }^{24}$.

Although PA does not seem to be correlated to current asthma, decreased PA may play a small role in the development of asthma. Sheriff et al. and Rasmussen et al. demonstrated that low PA levels and frequent television viewing were associated with the development of asthma from pre-school and school-age into adolescence, independent from BMI status ${ }^{33,34}$. In addition, a meta-analysis in adults showed that subjects with high PA levels have a lower risk to develop asthma (OR: $0.87(95 \% \mathrm{CI}$ 0.77-0.99) $)^{35}$.

A strong point of this study is the inclusion of 4 groups of children, which made it possible to investigate the interaction effect of asthma and overweight/obesity. Another strong point is that we measured both asthma and PA objectively in this study, in contrast with most other studies which frequently use self-reported outcome measures ${ }^{9}$.

Some potential limitations should be mentioned. Firstly, children with asthma and overweight were recruited from the control group of a weight-reduction intervention study $^{15}$. Possibly, these children had increased PA levels, because these children were initially interested in a weight-reduction intervention. Secondly, we used activity monitors which could not distinguish moderate from intense PA. It is conceivable that only high intensity activities were decreased in asthma and/or overweight/obesity, as exercise-related limitations are most pronounced during high intensity activities. However, as organised sport participation was not associated with either asthma or BMI-SDS, this hypothesis can most likely be refuted. Thirdly, the age range of our study population could have influenced variability in PA levels, as individual differences in PA are quite small during childhood due to school-regulated activity patterns.

Although our results plea for a rejection of our hypothesis that both asthma and BMISDS are associated with decreased PA, it is of importance to study our hypothesis in populations with higher PA levels. Moreover, it is relevant to assess if increasing PA could be a secondary preventive tool in children with asthma and overweight/obesity ${ }^{15}$. Although the effects of exercise training on lung function in asthmatic children are negligible, there is evidence of positive effects on cardiorespiratory fitness, EIB and possibly also on quality of life and asthma control ${ }^{36}$. Besides, several studies in adults showed that weight reduction resulted in improved asthma control, lung function, and less medication use ${ }^{37}$. 


\section{Conclusions}

We found no associations between either asthma, asthma features or BMI-SDS with PA in school aged children. It can be concluded that PA plays a smaller role in paediatric asthma and overweight/obesity than initially hypothesised. Yet, it must be mentioned that PA levels were alarmingly low in the entire study population, which could possibly have led to a 'no room for worsening' effect. As decreased PA levels are related to higher health risks, we want to emphasize the importance of PA in school aged children. Future studies should focus on effective interventions to increase PA in school-aged children, and investigate whether increasing PA could be an effective secondary preventive tool for children with asthma and overweight/obesity. 


\section{Supporting information}

Table S4.1 Amount of multiple imputations for all PA variables.

\begin{tabular}{lc}
\hline PA variables & Amount of missing variables, (\% of total) \\
\hline Step count & $10(8.2)$ \\
Time spent in PA & $12(9.8)$ \\
Screen time & $4(3.3)$ \\
Time spent in organised sport activities & $3(2.5)$ \\
\hline
\end{tabular}

PA: physical activity.

Table S4.2 Baseline differences between individuals with and without imputations.

\begin{tabular}{|c|c|c|c|}
\hline & $\begin{array}{l}\text { Original dataset } \\
\qquad(n=122)\end{array}$ & $\begin{array}{c}\text { Participants without } \\
\text { imputated values } \\
(n=101)\end{array}$ & $\begin{array}{c}\text { Participants with } \\
\text { imputated values } \\
(n=21)\end{array}$ \\
\hline \multicolumn{4}{|l|}{ Baseline variables } \\
\hline Age in years, median (IQR) & $10.8(2.2)$ & $10.8(2.3)$ & $11.6(2.1)$ \\
\hline Sex male/female, \% & $52 / 48$ & $54 / 45$ & $33 / 67$ \\
\hline Measurement during summer season, $\% *$ & 22 & 21 & 29 \\
\hline \multicolumn{4}{|l|}{ Anthropometric variables } \\
\hline $\mathrm{BMI}$ in $\mathrm{kg} / \mathrm{m}^{2}$, median (IQR) & $18.8(7.0)$ & $18.6(6.9)$ & $22.4(7.0)$ \\
\hline BMI-SDS, median (IQR) & $0.93(2.28)$ & $0.82(2.33)$ & $1.64(1.87)$ \\
\hline Hip circumference in $\mathrm{cm}$, mean (SD) & $78.1(11.7)$ & $77.5(11.4)$ & $73.0(20.5)$ \\
\hline Waist circumference in $\mathrm{cm}$, median (IQR) & $69.5(19.9)$ & $69.2(19.5)$ & $80.9(13.0)$ \\
\hline \multicolumn{4}{|l|}{ Asthma-related variables } \\
\hline $\mathrm{FEV}_{1} \%$ predicted (SD) & $96(16)$ & $96(15)$ & $94(20)$ \\
\hline Airway reversibility, \% & 22 & 22 & 24 \\
\hline Uncontrolled asthma, \%* & 10 & 6 & 38 \\
\hline Asthma medication use, $\%$ & 33 & 35 & 24 \\
\hline SABA use, $\%$ & 25 & 26 & 24 \\
\hline ICS use, $\%$ & 23 & 26 & 10 \\
\hline FeNO in ppb, median (IQR) & $13.0(12.6)$ & $14.0(14.6)$ & $11.0(6.8)$ \\
\hline
\end{tabular}

* Significant difference between groups $(\mathrm{P}<0.05)$. BMI: body mass index, BMI-SDS: body mass index-standard deviation score, FeNO: fractional exhaled nitric oxide, $\mathrm{FEV}_{1}$ : forced expiratory volume in 1 second, ICS: inhaled corticosteroid, IQR: inter quartile range, SABA: short acting beta2-agonists, SD: standard deviation.

Table S4.3 Standardized B values for the prediction models without multiple imputation techniques.

\begin{tabular}{lccccccc}
\hline Dependent variable & BMI-SDS & Asthma & $\begin{array}{c}\text { Asthma x } \\
\text { BMI-SDS }\end{array}$ & Age & Sex & $\begin{array}{c}\text { Autumn } \\
\text { season }\end{array}$ & Step count \\
\hline Step count & -0.14 & 0.07 & $-<0.01$ & $-0.22^{*}$ & $-0.33^{*}$ & $-0.39^{*}$ & n.a. \\
Time spent in PA & 0.02 & $<0.01$ & $<-0.01$ & 0.17 & -0.01 & $-0.27^{*}$ & $0.58^{*}$ \\
Screen time & 0.22 & 0.03 & -0.14 & 0.12 & 0.04 & -0.09 & -0.03 \\
Time spent in & 0.02 & -0.03 & -0.04 & $<-0.01$ & -0.18 & 0.03 & $0.29^{*}$ \\
organised sports & & & & & & & \\
\hline
\end{tabular}

* Significant correlation $(\mathrm{P}<0.05)$ with the dependent variable, \# Boys are coded as 0 , girls as $1,{ }^{\wedge}$ As opposed to the summer season. BMI: body mass index, BMI-SDS: body mass index - standard deviation score, n.a.: not applicable, PA: physical activity. 
Table S4.4 Standardized B values for the relation between various asthma related parameters on PA levels without multiple imputation techniques.

\begin{tabular}{lccccccr}
\hline Dependent variable & c-ACT & FEV $_{1} \%$ & $\begin{array}{c}\text { Airway } \\
\text { reversibility }\end{array}$ & $\begin{array}{c}\text { SABA dose } \\
\text { equivalent }\end{array}$ & $\begin{array}{c}\text { Parental } \\
\text { perception }\end{array}$ & $\begin{array}{c}\text { Child's } \\
\text { perception }\end{array}$ & FeNO \\
\hline Step count & -0.06 & -0.02 & -0.14 & -0.07 & -0.01 & $<-0.01$ & 0.18 \\
Time spent in PA & -0.06 & -0.20 & -0.03 & $<0.01$ & -0.18 & -0.10 & 0.16 \\
Screen time & -0.09 & -0.21 & $<0.01$ & -0.10 & 0.12 & 0.11 & 0.03 \\
Time spent & -0.04 & -0.12 & -0.14 & -0.08 & 0.08 & -0.17 & -0.02 \\
organised sports & & & & & & & \\
\hline
\end{tabular}

* Significant correlation $(\mathrm{P}<0.05)$ with the dependent variable, $\mathrm{C}-\mathrm{ACT}$ : childhood asthma control test, FeNO: fractional exhaled nitric oxide, $\mathrm{FEV}_{1} \%$ : forced expiratory volume in 1 second in \% of predicted, PA: physical activity. 


\section{References}

1. Papoutsakis C, Priftis KN, Drakouli M, Prifti S, Konstantaki E, Chondronikola M, Antonogeorgos G, Matziou V. Childhood overweight/obesity and asthma: is there a link? A systematic review of recent epidemiologic evidence. J Acad Nutr Diet 2013;113:77-105.

2. Chen YC, Dong GH, Lin KC, Lee YL. Gender difference of childhood overweight and obesity in predicting the risk of incident asthma: a systematic review and meta-analysis. Obes Rev 2013;14:222-231.

3. Beuther DA, Sutherland ER. Overweight, obesity, and incident asthma: a meta-analysis of prospective epidemiologic studies. Am J Respir Crit Care Med 2007;175:661-666.

4. Lang JE, Hossain J, Dixon AE, Shade D, Wise RA, Peters SP, Lima JJ; American Lung Association-Asthma Clinical Research Centers. Does age impact the obese asthma phenotype? Longitudinal asthma control, airway function, and airflow perception among mild persistent asthmatics. Chest 2011;140:1524-1533.

5. Holguin F, Bleecker ER, Busse WW, Calhoun WJ, Castro M, Erzurum SC, Fitzpatrick AM, Gaston B, Israel E, Jarjour NN, Moore WC, Peters SP, Yonas M, Teague WG, Wenzel SE. Obesity and asthma: an association modified by age of asthma onset. J Allergy Clin Immunol 2011;127:1486-1493

6. Lucas SR, Platts-Mills TA. Paediatric asthma and obesity. Paediatr Respir Rev 2006;7:233-238.

7. Jensen ME, Collins CE, Gibson PG, Wood LG. The obesity phenotype in children with asthma. Paediatr Respir Rev 2011;12:152-159.

8. Ali Z, Ulrik CS. Obesity and asthma: A coincidence or a causal relationship? A systematic review. Respir Med 2013;107:1287-1300.

9. Tsai SY, Ward T, Lentz MJ, Kieckhefer GM. Daytime Physical Activity Levels in School-Age Children With and Without Asthma. Nurs Res 2012;61:252-259.

10. Lang DM, Butz AM, Duggan AK, Serwint JR. Physical activity in urban school-aged children with asthma. Pediatrics 2004;113:e341-346.

11. Vahlkvist $\mathrm{S}$, Pedersen S. Fitness, daily activity and body composition in children with newly diagnosed, untreated asthma. Allergy 2009;64:1649-1655.

12. Walders-Abramson N, Wamboldt FS, Curran-Everett D, Zhang L. Encouraging physical activity in pediatric asthma: a case-control study of the wonders of walking (WOW) program. Pediatr Pulmonol 2009;44:909-916.

13. Rich C, Griffiths $\amalg$, Dezateux C. Seasonal variation in accelerometer-determined sedentary behaviour and physical activity in children: a review. Int J Behav Nutr Phys Act 2012;9:49.

14. Willeboordse M, van den Bersselaar DLCM, van de Kant KDG, Muris JWM, van Schayck CP, Dompeling E. Sex differences in the relationship between asthma and overweight in Dutch children: a survey study. PLoS One 2013;8:e77574.

15. Willeboordse M, van de Kant KD, de Laat MN, van Schayck OC, Mulkens S, Dompeling E. Multifactorial intervention for children with asthma and overweight (Mikado): study design of a randomised controlled trial. BMC Public Health 2013;13:494.

16. Fredriks A, van Buuren S, Wit J, Verloove-Vanhorick S. Body index measurements in 1996-7 compared with 1980. Arch Dis Child 2000;82:107-112.

17. Zapletal A PT, Samanek N. Die Bedeutung heutiger Methoden der Lungenfunktionsdiagnostik zur Feststellung einer Obstruktion der Atemwege bei Kindern und Jugendlichen. Atm-Org 1977;149: 343-371.

18. Miller MR, Hankinson J, Brusasco V, Burgos F, Casaburi R, Coates A, Crapo R, Enright P, van der Grinten CP, Gustafsson P, Jensen R, Johnson DC, Maclntyre N, McKay R, Navajas D, Pedersen OF, Pellegrino R, Viegi G, Wanger J; ATS/ERS Task Force. Standardisation of spirometry. Eur Respir J 2005;26:319-338.

19. Silkoff PE, Erzurum, S.C., Deykin, A., Dweik, R., Laskowski, D., Baraldi, E., Lundberg, J.O., George, S.C., Marczin, N., Mehta, S. ATS/ERS Recommendations for Standardized Procedures for the Online and Offline Measurement of Exhaled Lower Respiratory Nitric Oxide and Nasal Nitric Oxide, 2005. Am J Respir Crit Care Med 2005;171:912-930. 
20. Asher MI, Montefort S, Björkstén B, Lai CK, Strachan DP, Weiland SK, Williams H; ISAAC Phase Three Study Group. Worldwide time trends in the prevalence of symptoms of asthma, allergic rhinoconjunctivitis, and eczema in childhood: ISAAC Phases One and Three repeat multicountry crosssectional surveys. Lancet 2006;368:733-743.

21. Liu AH, Zeiger R, Sorkness C, Mahr T, Ostrom N, Burgess S, Rosenzweig JC, Manjunath R. Development and cross-sectional validation of the Childhood Asthma Control Test. J Allergy Clin Immunol 2007; 119:817-825.

22. Asher MI, Montefort S, Björkstén B, Lai CK, Strachan DP, Weiland SK, Williams H; ISAAC Phase Three Study Group. Worldwide time trends in the prevalence of symptoms of asthma, allergic rhinoconjunctivitis, and eczema in childhood: ISAAC Phases One and Three repeat multicountry crosssectional surveys. Lancet 2006;368:733-743.

23. Bindels PJE, Van de Wouden JC, Ponsioen BP, Brand PLP, Salome PL, Van Hensbergen W. NHGstandaard Astma bij kinderen [Dutch General Practitioners guidelines, asthma in children]. 2006: 557-572.

24. Jongste JC, Vrijlandt, EJLE Astma bij kinderen; herziene richtlijnen van de sectie kinderlongziekten van de NVK. Paediatric Asthma; revised guidelines of the paediatric department of the Dutch Paediatric Society. Amsterdam: Jurriaans Lindenbaum Grafimedia. 2008:1-122.

25. De Vries SI, Van Hirtum HW, Bakker I, Hopman-Rock M, Hirasing RA, Van Mechelen W Validity and reproducibility of motion sensors in youth: a systematic update. Med Sci Sports Exerc 2009;41:818-827.

26. Colley RC, Janssen I, Tremblay MS. Daily step target to measure adherence to physical activity guidelines in children. Med Sci Sports Exerc 2012;44:977-982.

27. Craig CL, Cameron C, Tudor-Locke C. CANPLAY pedometer normative reference data for 21,271 children and 12,956 adolescents. Med Sci Sports Exerc 2013;45:123-129.

28. RIVM. Lokale en Nationale Monitor Gezondheid. Local and National Health Monitor. 2005

29. Bauman AE, Reis RS, Sallis JF, Wells JC, Loos RJ, et al. Correlates of physical activity: why are some people physically active and others not? Lancet 2012;380:258-271.

30. Al-Hazzaa HM. Pedometer-determined physical activity among obese and non-obese 8- to 12-year-old Saudi schoolboys. J Physiol Anthropol 2007;26:459-465.

31. Metcalf BS, Hosking J, Jeffery AN, Voss LD, Henley W, Wilkin TJ. Fatness leads to inactivity, but inactivity does not lead to fatness: a longitudinal study in children (EarlyBird 45). Arch Dis Child 2011;96:942-947.

32. Wilks DC, Sharp SJ, Ekelund U, Thompson SG, Mander AP, Turner RM, Jebb SA, Lindroos AK. Objectively measured physical activity and fat mass in children: a bias-adjusted meta-analysis of prospective studies. PLoS One 2011;6: e17205.

33. Rasmussen F, Lambrechtsen J, Siersted HC, Hansen HS, Hansen NC. Low physical fitness in childhood is associated with the development of asthma in young adulthood: the Odense schoolchild study. Eur Respir J 2000;16:866-870.

34. Sherriff A, Maitra A, Ness AR, Mattocks C, Riddoch C, Reilly JJ, Paton JY, Henderson AJ. Association of duration of television viewing in early childhood with the subsequent development of asthma. Thorax 2009;64:321-325.

35. Eijkemans $M$, Mommers M, Draaisma JM, Thijs C, Prins MH. Physical activity and asthma: a systematic review and meta-analysis. PLoS One 2012;7:e50775.

36. Wanrooij VH, Willeboordse M, Dompeling E, van de Kant KD. Exercise training in children with asthma: a systematic review. Br J Sports Med: 2014; in press.

37. Moreira A, Bonini M, Garcia-Larsen V, Bonini S, Del Giacco SR, Agache I, Fonseca J, Papadopoulos NG, Carlsen $\mathrm{KH}$, Delgado L, Haahtela T. Weight loss interventions in asthma: EAACl evidence-based clinical practice guideline (part I). Allergy 2013;68:425-439. 


$$
\text { రే }
$$


5. Multifactorial intervention for

\section{children with asthma and overweight (MIKADO): study design of a randomised controlled trial}

BMC Public Health. 2013;13:494

Maartje Willeboordse

Kim DG van de Kant

Maroeska $\mathrm{N}$ de Laat

Constant $P$ van Schayck

Sandra Mulkens

Edward Dompeling 


\section{Abstract}

\section{Background}

In children, the prevalence's of both obesity and asthma are disconcertingly high. Asthmatic children with obesity are characterised by less asthma control and a high need for asthma medication. As the obese asthmatic child is becoming more common in the clinical setting and the disease burden of the asthma-obesity phenotype is high, there is an increasing need for effective treatment in these children. In adults, weight reduction resulted in improved lung function, better asthma control and less need for asthma medication. In children this is hardly studied. The Mikado study aims to evaluate the effectiveness of a long term multifactorial weight reduction intervention, on asthma characteristics in children with asthma and a high body weight.

\section{Methods/design}

The Mikado study is a two-armed, randomised controlled trial. In total, 104 participants will be recruited via online questionnaires, pulmonary paediatricians, the youth department of the municipal health services and cohorts of existing studies. All participants will be aged 6-16 years, will have current asthma, a Body Mass Index in the overweight or obesity range, and no serious comorbidities (such as diabetes, heart diseases). Participants in the intervention arm will receive a multifactorial intervention of 18 months consisting of sessions concerning sports, parental involvement, individual counselling and lifestyle advices including dietary advices and cognitive behavioural therapy. The control group will receive usual care. The primary outcome variables will include Forced Expiratory Volume in one second and Body Mass Index - Standard Deviation Score. Secondary outcomes will include other lung function parameters (including dynamic and static lung function parameters), asthma control, asthma-specific quality of life, use of asthma medication and markers of systemic inflammation and airway inflammation.

\section{Discussion}

In this randomised controlled trial we will study the potential of a multifactorial weight reduction intervention to improve asthma-related outcome measures in asthmatic children with overweight. Moreover, it will provide information about the underlying mechanisms in the relationship between asthma and a high body weight in children. These findings can contribute to optimal management programs and better clinical guidelines for children with asthma and overweight. 


\section{Background}

The increase in childhood obesity in recent decades is a worldwide problem. The global prevalence of overweight and obesity in children increased from $4.2 \%$ in 1990 to $6.7 \%$ in $2010^{1}$. Similar to childhood obesity, the prevalence of childhood asthma has been rising in the previous decades ${ }^{2}$. Asthma is a common chronic disease in children, and accounts for many disability-adjusted life years and considerable medical costs ${ }^{3}$.

Several studies demonstrated an association between obesity and childhood asthma ${ }^{4,5}$. A recent meta-analysis by Chen et al. showed a dose-responsiveness of elevated BMI on asthma incidence, expressed as a relative risk (RR) of $1.19(95 \% \mathrm{Cl}: 1.03-1.37)$ for overweight and a RR of $2.02(95 \% \mathrm{Cl}: 1.16-3.50)$ for obesity to develop future asthma ${ }^{5}$. Furthermore, obesity is associated with less asthma control and more use of oral corticosteroids ${ }^{6,7}$.

Various potential pathophysiological theories have been proposed to explain the association between obesity and asthma. The first theory supports the mechanical effect of obesity on asthma, as obesity can adversely impact lung volumes. It is associated with reductions in vital capacity (VC), forced expiratory volume in 1 second $\left(F_{1} V_{1}\right.$ ) and expiratory reserve volume $(E R V)^{8,9}$. Reduced lung volumes in obesity may result in reduced peripheral airway diameter, which subsequently may disturb smooth muscle function and potentially increase airway obstruction and bronchial hyperresponsiveness $(\mathrm{BHR})^{8}$. A second theory that has received growing attention is the effect of obesity on asthma via inflammatory pathways ${ }^{7,10}$. The chronic inflammatory process created by excess adiposity has been implicated as being an underlying factor in asthma pathogenesis. An increase in fat mass is associated with an increase in systemic inflammatory mediators which can exacerbate airway inflammation via inflammatory mediators such as leptin, adiponectin, interleukin-6 (IL-6) and tumour necrosis factor-alpha $(T N F-\alpha)^{7,10}$. Several studies noted that the pro-inflammatory effects of serum leptin can modulate airway inflammation ${ }^{7,11,12}$.

In addition to those theories, multiple factors are studied which possibly play a role in the asthma-obesity relationship such as dietary factors, a sedentary lifestyle, genetic predisposition, metabolic abnormalities and associated comorbidities such as gastrooesophageal reflux disease and sleep apnoea ${ }^{4}$. It is most likely that these influential factors and theories are not mutually exclusive, but altogether explain the relationship between asthma and obesity ${ }^{12}$.

As obesity has a major impact on several asthma parameters, the effect of weight reduction in obese asthmatic children could be of great value for current treatment guidelines. Studies in adults concerning weight loss and its effect on asthma are promising ${ }^{13-15}$. Significant improvements have been found on asthma control, lung function, exacerbations and use of asthma medication after weight loss ${ }^{14}$. In children, the effects of weight loss have been hardly studied. As the obese asthmatic child is becoming more common in the clinical setting, there is need for a well-designed 
randomised controlled trial $(\mathrm{RCT})$ in which the effects of weight reduction on asthma in children are studied.

\section{Objective and hypothesis}

The Mikado study is an RCT in which the effects of an 18-month multifactorial intervention, on several asthma parameters and anthropometric outcomes in children with asthma and overweight are studied. We hypothesise that a multifactorial intervention will decrease the body mass index -standard deviation score (BMI-SDS) of children with asthma and overweight and will improve asthma related parameters including lung function, airway inflammation, asthma control and the use of asthma medication.

\section{The primary research question is}

What are the effects of an 18-month multifactorial intervention on $\mathrm{FEV}_{1} \%$ predicted and BMI-SDS?

\section{The secondary research questions are}

- What is the effect of a multifactorial intervention on the severity and control of asthma as indicated by lung function ( $\left.F E V_{1} / F V C, E R V\right)$, asthma symptoms, asthma control, asthma-related quality of life, exercise induced bronchoconstriction (EIB), use of asthma medication and exacerbations?

- What are the underlying mechanisms? Is the intervention accompanied by decreased levels of adipokines and diminished airway inflammation? Can we detect a beneficial effect on airway mechanics/lung function?

- What are the potential moderators and mediators of the intervention effects (e.g. BMI-SDS reduction, changes in physical activity and dietary behaviour, socio economic status, comorbidities and smoking exposure)?

\section{Methods/design}

\section{Study design}

The study design is an RCT for children with overweight and asthma (Figure 5.1). Children aged 6-16 years living in Southern Limburg, the Netherlands will be recruited. After a screening visit, participants will be randomised into an intervention group or a control group (Figure 5.1). The intervention group will receive an intervention lasting for 18 months (see details below), while the control group will receive standard usual 


\section{Multifactorial intervention for children with asthma and overweight (Mikado): study design of a randomised controlled trial}

care according to the standards of the Dutch Society of General Practitioners and the Paediatric Pulmonology section of the Dutch Society of Paediatrics ${ }^{16,17}$.

Regular measurements including lung function outcomes, anthropometric outcomes, inflammatory outcomes and intervention mediators and moderators will be performed at baseline (T0), after 6 months (T6), 12 months (T12) and at the end of the intervention (T18). Every 3 months, participants will receive various questionnaires (Table 5.1). All procedures and materials are approved by the Medical Ethic Committee of Maastricht (MEC 09-2-088).



Figure $5.1 \quad$ Flow diagram study design 


\section{Recruitment}

Children will be recruited from 4 sources. The first source is a community-based random online questionnaire to parents of 40000 children in Southern Limburg. The second source includes pulmonary paediatricians of 3 local hospitals. Thirdly, children are recruited via the youth section of the municipal health services in Southern Limburg. Additionally, children are recruited via cohorts of several other studies ${ }^{18,19}$. All parents will be asked to fulfil an online questionnaire about anthropometric values and asthma symptoms. Children who are overweight or obese according to the parental reported BMI and who reported current asthmatic symptoms and/or use of asthma medication will be invited for a screening visit. Written informed consent will be obtained from all parents and from children aged 12 years or older.

\section{Eligibility criteria}

All children with asthma and overweight, aged 6-16 year, living in Southern Limburg will be invited to participate. Overweight will be defined as a BMI-SDS $\geq 1.2$ according to the lambda mu and sigma (LMS) method of Cole et al. ${ }^{20}$ based on the reference charts of the Dutch fourth Nationwide Growth Study ${ }^{21}$. During the screening visit, participants will undergo lung function measurements to verify the diagnosis of asthma. A child will be considered asthmatic if at least 2 of the 3 following criteria are fulfilled: 1 . asthmatic symptoms in the previous 12 months based on the International study of asthma and allergy in childhood (ISAAC) questionnaire ${ }^{22}$; 2 . use of short acting beta2agonists (SABA), long acting beta2agonists (LABA) or inhaled corticosteroids (ICS) in the previous 6 months; 3. reversibility; defined as an increase of $\geq 9 \%$ of the predictive value of the $\mathrm{FEV}_{1}$ after inhalation of $400 \mu \mathrm{g}$ Airomir (Teva Pharma, Leiden, the Netherlands) or a positive BHR test; defined as a histamine concentration of $\leq 8 \mathrm{mg} / \mathrm{ml}$ necessary to provoke a drop of $20 \%$ in $\mathrm{FEV}_{1}$.

Children will be excluded in the case of a congenital malformation of the airways or other chronic lung diseases, syndromes accompanied by mental retardation or metabolic diseases, physical limitations to exercise, and/or a heart disease.

\section{Randomisation}

All children who meet the inclusion criteria after the screening visit will be randomised to either the control or intervention group. Generalised block randomisation including 10 participants per block will be performed by a computer program, with an allocation ratio of $1: 1^{23}$. Because this is a lifestyle study, blinding is not possible. 


\section{Outcome measures}

An overview of all the outcome measurements and corresponding time points can be found in Table 5.1.

\section{Lung function measurements}

Maximal expiratory flow volume (MEFV) curves will be measured with a spirometer (ZAN Messgerate, Oberthulba, Germany) according to American thoracic society / European respiratory society (ATS/ERS) guidelines ${ }^{24}$. LABA will be withheld 48 hours and SABA 8 hours before the measurement. During these measurements all children will be instructed by experienced researchers and nurses specialised in lung function measurements. The highest value of 3 technically appropriate measurements will be recorded and predictive values will be calculated according to prediction formulas of Zapletal et al. ${ }^{25}$. Reversibility will be defined as a change of $\geq 9 \%$ in $\mathrm{FEV}_{1}$ after $400 \mu \mathrm{g}$ of extra-fine salbutamol (Airomir, Teva Pharma, Leiden, the Netherlands). During $t=0$ reversibility will be determined after the completion of the BHR test.

Static lung function indices will be determined by body plethysmography (Viasys, Hoechberg, Germany) according to the ATS/ERS guidelines [24]. BHR will be determined by a histamine provocation test. A dose of histamine will be increasingly administered until a drop of $20 \%$ of the $\mathrm{FEV}_{1}$ is obtained or until a dose of $16 \mathrm{mg} / \mathrm{ml}$ histamine is reached $^{26}$. The provocative concentration that will lead to a drop of $20 \%$ of the $\mathrm{FEV}_{1}$ (PC20) will be determined by linear interpolation of the last 2 points on the log doseresponse curve.

\section{Anthropometric measurements}

Children will be weighed while wearing underwear and without shoes. Length will be measured twice to the nearest 0.5 centimetre (Stadiometer model 213, Seca, Birmingham, United Kingdom). Weight will be measured twice to the nearest 0.1 kilograms using a medical calibrated weight scale (Model 877, Seca, Hamburg, Germany). The average weight and height measurement will be used to calculate the BMI. BMI-SDS scores will be defined by the LMS-method of Cole et al. ${ }^{20}$ based on the reference charts of the Dutch fourth Nationwide Growth Study ${ }^{21}$.

Skinfold thickness will be derived from the triceps, biceps, subscapular and supra iliacic skinfolds by a Skinfold Calliper (Harpenden, British Indicators, Sussex, United Kingdom). Fat percentages will be generated by using the formulas of Deurenberg et al. ${ }^{27}$. Waisthip ratio will be obtained by measuring the hip and waist circumference for each visit. Both skin fold thickness and waist-hip circumference measurements will be performed twice according to international guidelines ${ }^{28}$. 


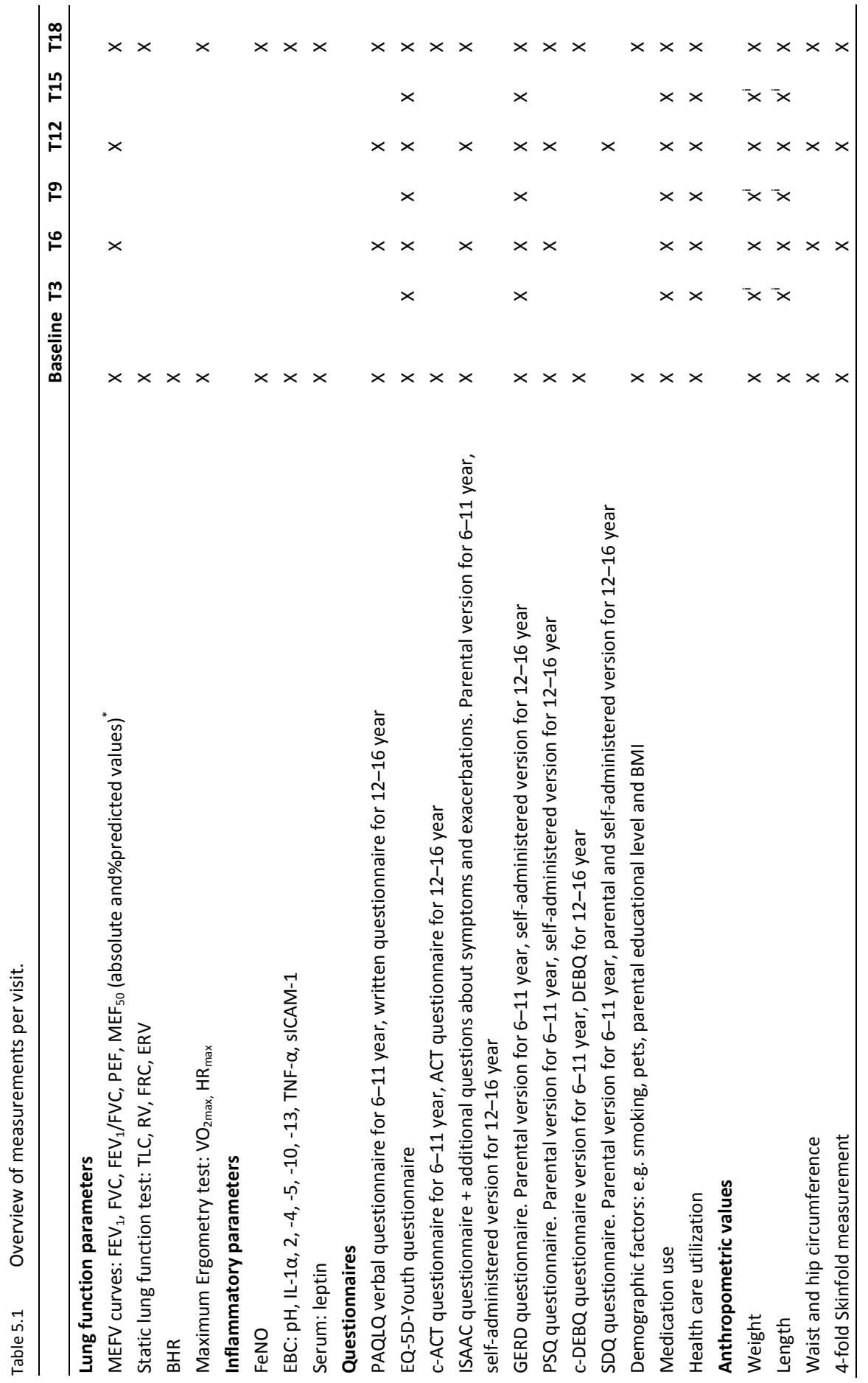


Multifactorial intervention for children with asthma and overweight (Mikado): study design of a randomised controlled trial

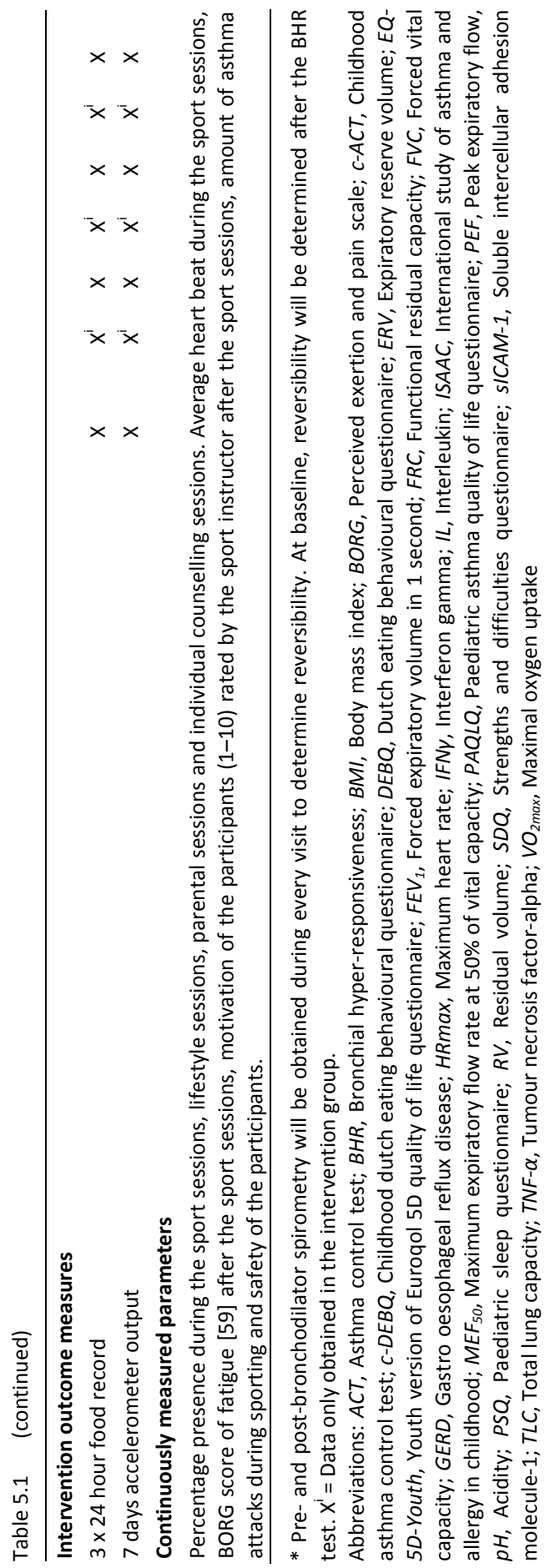




\section{Maximal ergometry test}

All patients will perform a maximal incremental ergometer test (Reha Ergometer, Ergoline, Bitz, Germany) by using a continuous ramp protocol ${ }^{29}$. LABA will be withheld 48 hours and SABA 8 hours before the maximal ergometry test. During the test, breath by breath gas exchange will be analysed by a mass spectrometer (Oxicon Pro, Carefusion, Hochberg, Germany), and heart rate (HR) by means of a continuous 12-lead electrocardiogram (Masterscreen ECG, Carefusion, Hochberg, Germany).

The pedalling frequency will be held at $60 \mathrm{rpm}$ and participants will be encouraged during the test to continue as long as possible. At the start, children will rest for 3 minutes in seated position followed by 3 minutes of cycling at the first increment, which is determined by length. Children below $120 \mathrm{~cm}$ will undergo a protocol with 10 $\mathrm{W} / \mathrm{min}$ increment, children $120-150 \mathrm{~cm}$ will undergo a protocol with $15 \mathrm{~W} / \mathrm{min}$ and a $20 \mathrm{~W} / \mathrm{min}$ increment will be used in children $>150 \mathrm{~cm}$.

During the test, the wattage will incrementally increase until children can no longer continue the pedalling frequency for at least 5 seconds, or if termination is required according to other standard safety criteria. After exhaustion, children will continue to cycle for 3 more minutes at the first increment. The test will be accepted if at least 2 of the following criteria will be reached: $1 .<2 \mathrm{ml} / \mathrm{kg} / \mathrm{min}$ increase in oxygen uptake $\left(\mathrm{VO}_{2}\right)$ with increasing work load, 2. Respiratory Exchange Ratio $>1.00,3$. HR $\geq 85 \%$ predicted (as assessed by 220 minus age). During the test the following variables will be measured: $\mathrm{HR}$, minute ventilation $\left(\mathrm{V}^{\prime} \mathrm{E}\right)$ and $\mathrm{VO}_{2}$ in $\mathrm{L} / \mathrm{min}$ and in $\mathrm{L} / \mathrm{min} / \mathrm{kg}$ bodyweight. The Anaerobic Threshold will be determined by the V-slope method as described by Beaver et al. ${ }^{30}$, predicted values will be calculated according to normal values of Ten Harkel et al. ${ }^{31}$.

MEFV curves will be determined by a spirometer (ZAN Messgerate, Oberthulba, Germany) before exercise, 10 and 30 minutes after completion of the maximal exercise test. The severity of EIB will be measured as the difference in pre-exercise and postexercise $\mathrm{FEV}_{1}$.

\section{Questionnaires}

Information on socio-demographic characteristics such as age, sex, ethnicity, parental $\mathrm{BMI}$, social economic status and smoking exposure will be collected. Asthma control will be measured by the asthma control test (ACT) in children $>11$ years ${ }^{32}$. The childhood ACT (C-ACT) will be used in children $\leq 11$ years ${ }^{32,33}$. A score of $\leq 19$ will be defined as uncontrolled asthma ${ }^{34}$. Medication use will be evaluated over the 2 months period prior to the clinic visit and dose equivalents will be calculated according to standard dosage of SABA, LABA and ICS ${ }^{16,17,35,36}$. The GINA guidelines will be used to determine asthma severity (intermittent, mild, moderate and severe) based on the intensity of treatment ${ }^{37}$. A Dutch questionnaire and the ISAAC questionnaire will be used to measure asthma symptoms ${ }^{38}$. Asthma-related quality of life will be measured 


\section{Multifactorial intervention for children with asthma and overweight (Mikado): study design of a randomised controlled trial}

by the paediatric asthma quality of life questionnaire (PAQLQ) ${ }^{39}$. According to the PAQLQ guidelines, the minimal important difference will be defined as a difference of 0.42 points $^{40}$. The Euroqol 5D Youth version will be used as a measurement tool for general health related quality of life ${ }^{41}$.

To investigate commonly associated morbidity in children with asthma, sleep related breathing disorders will be assessed by means of the paediatric sleep questionnaire $(P S Q)^{42}$. A score of $>0.33$ will be defined as having a high risk for developing a sleeprelated breathing disorder ${ }^{42}$. The existence of gastro-oesophageal reflux disease (GERD) symptoms will be assessed by the GERD questionnaire ${ }^{43}$. A suspicion of GERD is present when the score is $\geq 3$ points ${ }^{43}$. Psychosocial problems will be determined by an abnormal score on the Dutch version of the strength and difficulties questionnaire (SDQ) according to the SDQ scoring guidelines ${ }^{44}$. In addition, the Dutch eating behaviour questionnaire (DEBQ) will be used to determine whether children have high scores on the subscales: emotional eating (13 items), external eating (10 items) or restrained eating $(10 \text { items })^{45}$.

\section{Atopy, systemic and airway inflammation}

Systemic inflammation will be determined in blood serum. The serum concentration of leptin will be determined in 100 microliter of plasma by means of multiplex immunoassay (Luminex Corporation, Austin, TX, USA). Airway inflammation will be measured by means of fractional exhaled nitric oxide ( $\mathrm{FeNO}$ ) and markers in exhaled breath condensate $(E B C)$. FeNO will be obtained with the online NIOX analyser (Aerocrine, Solna, Sweden) according to international guidelines ${ }^{46}$. EBC will be collected by means of an optimised glass tube, cooled by counter-current circulating ice water as described previously ${ }^{18}$. In short, children will breathe tidally into the cooled glass tube for 10 minutes, while wearing a nose-clip, through a mouthpiece connected to a 2-way non-rebreathing valve. Subsequently, acidity will be measured and the EBC samples will be frozen by using dry ice and stored at $-80^{\circ} \mathrm{C}$. Levels of various cytokine, chemokines, and soluble intercellular adhesion molecule-1 (sICAM-1) will be measured in 100 microliter EBC with multiplex immunoassay (Luminex, Luminex Corporation, Austin, USA $)^{47}$.

\section{Physical activity and dietary behaviour}

Physical activity level will be measured as the average step count per day measured over a week. All children will be instructed to wear a triaxial accelerometer (Yamax EX510 Power Walker, Yamax, Tokyo, Japan) for 7 consecutive days. While wearing the accelerometer, all children will keep a diary about the time spent on swimming and cycling.

Dietary intake will be measured by means of 3-day food records. Parents and children will receive a standardised instruction based on the multiple-pass method about 
fulfilling dietary records at the start of the study ${ }^{48}$. An online program (Vodiweb, Vodisys Medical Software, Groningen, The Netherlands) will be used to calculate nutrition composition, based on Western and local food tables and normalised portion sizes $^{49}$. The purpose of this tool is to measure intake of energy and macronutrients (fat, carbohydrate, protein) as well as to differentiate between healthy and unhealthy snacking during the day. A trained researcher will check all food diaries for completeness.

\section{Intervention}

We incorporated the most effective components of current weight reduction programs for children in our intervention ${ }^{50-53}$. Several reviews and meta-analyses concluded that long-term (>1 year) multi-component lifestyle interventions targeted at both children and caregivers are most efficient ${ }^{50-53}$. The health counselling model is the theoretical basis of our intervention ${ }^{54}$. The most important components of this intervention are sport sessions, lifestyle sessions including dietary advices and cognitive behavioural therapy, parental sessions, and individualised counselling. Children will be divided in small groups of 8 to 12 children. Intervention group allocation will occur according to place of residence and age (6-11 years and 12-15 years). To secure that intervention professionals adhere to the protocol, all intervention professionals will meet on a regular basis with a study coordinator as supervisor. The intervention is divided in an initial phase (months 0-6) and a follow-up phase (months 7-18) (Figure 5.1).

\section{Theoretical basis of intervention}

The theoretical foundation of the intervention is derived from the health counselling model [54]. Health counselling is a model in which 3 phases for lifestyle changes are included: preparations, behaviour change and follow-up. The initial (preparation and behaviour change) phase will be imbedded during the first 6 months of the intervention in which there are frequent contact moments; the follow-up phase will be imbedded in the last 12 months (Figure 5.1). In each phase, well-known behavioural change theories such as the Stages of Change Model, Theory of Planned Behaviour, Social Cognitive Theory and Relapse Prevention Model are imbedded ${ }^{55-58}$. The preparation phase consists of 3 steps: 1. awareness (e.g. unhealthy eating and sedentary behaviour leads to obesity, which leads to health problems and stigmatising), 2 . consideration of the new behaviour (e.g. benefits and disadvantages of losing weight) and 3 . decision making (e.g. shared decision making including detecting and removing barriers). During the behaviour change phase children will receive more information about healthy behaviour and will be encouraged in each session to set a specific goal which they add to their personal goal list (e.g.: 'I will walk the dog at least 4 days a week for 30 minutes'). In the follow-up phase children will learn how to preserve their behaviour (e.g. creating reminders of their goal-lists in their home environment, avoiding risk 


\section{Multifactorial intervention for children with asthma and overweight (Mikado): study design of a randomised controlled trial}

situations, learning social and coping skills) and eventually relapse strategies will be made (e.g. making a 'first aid box for difficult situations').

\section{Sport sessions}

Sport sessions will consist of regular group exercises (twice a week during initial phase, three times a month during the follow-up phase, Figure 5.1), with a duration of 60 minutes per session. All sport sessions will be guided by an experienced paediatric physiotherapist or a paediatric sport instructor. A session will consist of 10 minutes warming-up, 20 minutes aerobic exercises, 20-25 minutes interval exercise games and 5 minutes cooling-down. In order to offer an enjoyable program, several recreational sports will be played such as basketball, soccer, rope skipping, and tag games. The duration and intensity of the exercises will gradually increase during the first 3 months of the exercise program. Intensity of the exercise will be held at $60-75 \%$ of the ageadjusted maximal HR. All participants will wear a heart rate monitor (polar FS3c, Polar Electro Oy, Kempele, Finland,) during each sport sessions. During and after the sport sessions the (average) HR of each participant will be evaluated by the sports instructor. In addition, Borg's perceived exertion scale is used to monitor exertion ${ }^{59}$. If advised by the children's physician, sport instructors will encourage participants to use SABA 15 minutes before exercise.

During the initial phase participants will be motivated by their sports instructor to choose a supervised sport in their own environment, which children will practice during the follow-up phase. All participants will be encouraged to visit at least 3 different sport clubs in the vicinity of their residence. Folders with sport facilities in the environment will be provided. All parents will be encouraged to support their child to find a new sport during the parental sessions.

\section{Lifestyle sessions}

An experienced dietician and psychologist will guide 18 lifestyle sessions with a duration of 75-90 minutes. A session will consist of weighing, evaluation of the previous weeks, personalised goals and BMI-SDS curve, dietary advice usually incorporated in a game, psychological training, personalised goal setting and discussing home work. All children will receive a workbook with additional information for each lifestyle session, homework and space for individualised goal setting. All children will set at least one new personalised goal per session during the initial phase. In the follow-up phase, children will be encouraged to maintain their goals and modify goals in case of no BMI-SDS reduction. Small presents will be provided as incentives for participation and achievements. Individualised incentives will be obtained if personalised goals are reached and group incentives will be obtained in case of high participation rates and preparations for the lifestyle sessions. The dietician and psychologist will put emphasis on positive reinforcement during the lifestyle sessions. 
All dietary advices are based on the Dutch dietary guidelines for children with a high body weight ${ }^{60}$ and modelled after the work of Dutch programs to prevent childhood obesity, Realfit and Slimkids ${ }^{61}$. During the sessions, children will follow 3 basic dietary guidelines: 1 . healthy food choice, 2 . regular eating pattern, and 3. normalised portion sizes. Other dietary themes that will be dealt with during the lifestyle sessions are among others: energy balance, fruit and vegetable intake, mindful eating, finding social support, trying new food items (including 2 taste session sessions) inspecting food labels and, if applicable, alcoholic beverages. Special attention will be paid to emotional eating, body dissatisfaction and disordered eating. Also, children will regularly comment on their own and other's dietary journals. If children have not reduced their BMI-SDS after 6 lifestyle sessions, the dietician will provide the children with a personalised balanced hypo caloric diet with low-fat, nutrient dense foods of moderate proportion sizes. The diet will consist of a caloric restriction of $15 \%$ less than required ${ }^{62}$. Participants and parents will be guided and encouraged by the dietician to follow the hypo caloric diet and to adjust the diet with the nutritional knowledge they have gained during the previous sessions.

The psychologist will teach cognitive behavioural techniques. Children will learn how to identify, challenge and change dysfunctional cognitions about weight/obesity, food/eating, bullying, self-esteem, sedentary behaviour and physical activity by means of background information and homework assignments including 'thought diaries'. Other themes on which the psychologist will focus are motivation monitoring, stimulus control, recognizing emotions and social skills. Children will be taught how to cope with real-life situations such as holidays, parties, celebrations, and restaurants. During the follow-up phase a relapse prevention schedule will be made by all participants. The cognitive behaviour protocols were modelled after the work of Werrij et al. ${ }^{63,64}$.

The dietician and psychologist will guide participants to decrease sedentary behaviour. Children will be motivated to reach the advised daily 60 minutes of moderate to vigorous physical activity and to perform exhaustive physical activity for 20 minutes at least 3 days per week. Main themes to be discussed are screen time, active transportation ways and daily activity patterns.

\section{Parental sessions}

Parents will follow 10 parental sessions of 60 minutes guided by the dietician and psychologist who also guide the lifestyle sessions. A parental session will consist of an evaluation of the prior period, summarising the content of children's lifestyle sessions, dietary or psychological information and goal setting. The parents will receive a workbook including background information, healthy recipes and sport facilities in their residence. The dietary information will consist of standard nutritional education that is also taught to the children. In addition, advices are given about healthy cooking habits, preparing healthy snacks for children and visibility of (un)healthy food at home. The 


\section{Multifactorial intervention for children with asthma and overweight (Mikado): study design of a randomised controlled trial}

psychologist will focus on parental techniques such as positive rewarding, managing problem behaviours and modelling behaviour of the parents. Emphasis will be put on the importance of individual incentives if children reach their personalised learning goals.

\section{Individual counselling sessions}

In addition to the lifestyle sessions, children will receive individualised counselling sessions. The individualised counselling sessions will be guided by either the dietician or the psychologist, dependent on the needs of the child. The individualised counselling sessions will focus on the learning goals, motivational problems, personal barriers for maintaining the leaning goals and possible depressive symptoms. Children aged 6-11 years always attend the individual sessions accompanied by a parent. Older children will be accompanied by a parent if one of the parties (e.g. dietician, psychologist, child or parents) deems a parental visit beneficial. If the child still experiences severe problems with weight reduction despite the regular lifestyle sessions and individual consults, the dietician or psychologist will schedule extra telephonic consults with the child and/or parent.

\section{Statistics}

\section{Sample size calculation}

Earlier studies on weight loss in asthmatic adults demonstrated improvements in FEV of $8 \%$ and $6 \%$ respectively ${ }^{65,66}$. In adolescents with asthma, improvements in $\mathrm{FEV}_{1}$ of up to $24 \%$ were found after a weight reduction program ${ }^{67}$. In total, 104 participants are sufficient to detect a change of $5 \%$ in $\mathrm{FEV}_{1} \%$, assuming a five-repeated measurement design of Hedeker et al., a two-sided alpha of 5\%, a correlation between measurements of 0.7 , a power of $80 \%$, a sample size ratio of $1: 1$, a drop-out rate of $5 \%$ and an autoregressive(1) variance-covariance matrix structure ${ }^{68}$.

According to the Fleisch method of power calculation, 80 participants are sufficient to detect a clinical relevant decrease of 0.25 BMI-SDS, with a two-sided alpha of 0.05 , a drop-out rate of $20 \%$ and a power of $90 \%{ }^{69}$.

\section{Data analysis of primary and secondary research question}

Data will be analysed by using Statistical Package for the Social Sciences (version 20.0, SPSS, Chicago, USA). Standard statistical techniques will be used for the baseline characteristics. Normal distributed variables will be expressed as means and standard deviations, non-normal distributed data will be presented as median with interquartile ranges. Multi-level analyses techniques will be used to test whether within-subject changes in $\mathrm{FEV}_{1}$ \%predicted after 18 months intervention differ between intervention 
and control group. Both per-protocol and intention-to-treat-analyses will be performed. The primary outcome $\mathrm{FEV}_{1} \%$ predicted will be tested two-tailed with an alpha of $5 \%$. Correction for multiple testing will be conducted for the secondary outcomes.

\section{Discussion}

This paper describes the design of the Mikado study, an RCT testing the effects of a multifactorial weight loss intervention on asthma parameters in children with overweight and asthma. The multifactorial intervention consists of sessions concerning diet and behaviour, sport, parental involvement and individual counselling. Emphasis is put on individual goal setting, positive reflections and reinforcements. The efficacy of the Mikado study will be measured by regular anthropometric and lung function measurements. In addition, this study should provide enhanced understanding of the underlying pathophysiology of the asthma-obesity relation in children.

The Mikado study is the first RCT to investigate the effects of a weight reduction intervention on asthma parameters in children. Strengths of the Mikado study include its long duration, its broad range of outcome measures and the fact that the intervention is comprised of successful components of previous studies.

There are several critical success factors that should be mentioned. Previous lifestyle studies in children have frequently reported recruitment problems and dropout rates as high as $42 \%{ }^{51,70}$. The main reasons for these were parental attitudinal issues, such as denial that their child would benefit from improved nutrition and exercise, inflexibility in making room in the family's schedule for the program, prohibitive costs and an unwillingness to change the home environment. We will try to minimise these barriers for recruitment by training the researchers in telephonic skills, and by inviting hesitant participants for a personal informative meeting regarding the study. Offering an individualised programme and closely monitoring the participants by the intervention team should minimalize dropout. In case of high dropout rates, we will perform a responsive evaluation to investigate the reasons ${ }^{71}$.

Asthma is a chronic disease characterised by regular symptoms, a decreased quality of life, and medication use throughout the entire lifespan. Asthma in childhood has many non-modifiable risk factors such as a family history of asthma, sex and atopy ${ }^{72}$. Obesity is one of the few modifiable risk factors for asthma, which implies the necessity to investigate whether or not weight reduction has the potential to improve asthmarelated characteristics. If proven effective, a weight reduction program should be incorporated into the guidelines for childhood asthma. Weight reduction in asthmatic children might lead to an improved asthma prognosis via an improved asthma-related quality of life, asthma control, and lung function. 


\section{References}

1. de Onis $\mathrm{M}$, Blossner M, Borghi E. Global prevalence and trends of overweight and obesity among preschool children. Am J Clin Nutr 2010;92:1257-1264.

2. Anandan $C$, Nurmatov $U$, van Schayck OC, Sheikh A. Is the prevalence of asthma declining? Systematic review of epidemiological studies. Allergy 2010;65:152-167.

3. Cruz A, Mantzouranis E, Matricardi PM, Minelli E. Global surveillance, prevention and control of chronic respiratory diseases: a comprehensive approach. Geneva: WHO press; 2007.

4. Papoutsakis C, Priftis KN, Drakouli M, Prifti S, Konstantaki E, Chondronikola M, Antonogeorgos G, Matziou V. Childhood overweight/obesity and asthma: is there a link? A systematic review of recent epidemiologic evidence. J Acad Nutr Diet 2013;113:77-105.

5. Chen YC, Dong GH, Lin KC, Lee YL. Gender difference of childhood overweight and obesity in predicting the risk of incident asthma: a systematic review and meta-analysis. Obes Rev 2012;13:222-231.

6. Lang JE, Hossain J, Smith K, Lima JJ. Asthma severity, exacerbation risk, and controller treatment burden in underweight and obese children. J Asthma 2012;49:456-463.

7. Jensen ME, Collins CE, Gibson PG, Wood LG. The obesity phenotype in children with asthma. Paediatr Respir Rev 2011;12:152-159.

8. Jones RL, Nzekwu MM. The effects of body mass index on lung volumes. Chest 2006;130(Suppl 3): 827-833.

9. Littleton SW. Impact of obesity on respiratory function. Respirology 2012;17:43-49.

10. Sin DD, Sutherland ER. Obesity and the lung: 4. Obesity and asthma. Thorax 2008;63: 1018-1023.

11. Shore SA. Obesity and asthma: possible mechanisms. J Allergy Clin Immunol 2008;121: 1087-1093.

12. Farah CS, Salome CM. Asthma and obesity: a known association but unknown mechanism. Respirology 2012;17:412-421.

13. Eneli IU, Skybo T, Camargo CA Jr. Weight loss and asthma: a systematic review. Thorax 2008;63: 671-676.

14. Juel CT, Ali Z, Nilas L, Ulrik CS. Asthma and obesity: does weight loss improve asthma control? a systematic review. J Asthma Allergy 2012;5:21-26.

15. Adeniyi FB, Young T. Weight loss interventions for chronic asthma. Cochrane Database Syst Rev 2012;7, CD009339.

16. Jongste JC, Vrijlandt ELE. Astma bij kinderen; herziene richtlijnen van de sectie kinderlongziekten van de NVK [Asthma in children; revised guidelines of the paediatric department of the Dutch Paediatric Society]. Amsterdam: Jurriaans Lindenbaum Grafimedia; 2008.

17. Bindels PJE, Van de Wouden JC, Ponsioen BP, Brand PLP, Salome PL, Van Hensbergenm W. NHGstandaard Astma bij kinderen (tweede herziening) [Dutch General Practitioners guidelines, asthma in children]. Huisarts en Wetenschap 2006;49:557-572.

18. van de Kant KDG, Klaassen EM, Jobsis Q, Nijhuis AJ, van Schayck OC, Dompeling E. Early diagnosis of asthma in young children by using non-invasive biomarkers of airway inflammation and early lung function measurements: study protocol of a case-control study. BMC Publ Health 2009;9:210.

19. Schonberger HJ, Dompeling E, Knottnerus JA, Maas T, Muris JW, van Weel C, van Schayck CP. The PREVASC study: the clinical effect of a multifaceted educational intervention to prevent childhood asthma. Eur Respir J 2005; 25:660-670.

20. Cole TJ, Green PJ. Smoothing reference centile curves: the LMS method and penalized likelihood. Stat Med 1992;11:1305-1319.

21. Fredriks A, van Buuren S, Wit J, Verloove-Vanhorick S. Body index measurements in 1996-7 compared with 1980. Arch Dis Child 2000;82:107-112.

22. Asher MI, Montefort S, Bjorksten B, Lai CK, Strachan DP, Weiland SK, Williams H. Worldwide time trends in the prevalence of symptoms of asthma, allergic rhinoconjunctivitis, and eczema in childhood: ISAAC phases one and three repeat multicountry cross-sectional surveys. Lancet 2006;368:733-743.

23. Addelman S. The generalized randomized block design. Am Stat 1969;23:35-36. 
24. Miller MR, Hankinson J, Brusasco V, Burgos F, Casaburi R, Coates A, Crapo R, Enright $P$, van der Grinten $C P$, Gustafsson P, Jensen R, Johnson DC, Maclntyre N, McKay R, Navajas D, Pedersen OF, Pellegrino R, Viegi G, Wanger J; ATS/ERS Task Force. Standardisation of spirometry. Eur Respir J 2005;26:319-338.

25. Zapletal A, Paul T, Samanek N. Die Bedeutung heutiger Methoden der Lungenfunktionsdiagnostik zur Feststellung einer Obstruktion der Atemwege bei Kindern und Jugendlichen. Atm-Org 1977;149: 343-371.

26. American thoracic society. Guidelines for methacholine and exercise challenge testing. Am J Respir Crit Care Med 2000;161:309-329.

27. Deurenberg P, Pieters JJ, Hautvast JG. The assessment of the body fat percentage by skinfold thickness measurements in childhood and young adolescence. Br J Nutr 1990;63:293-303.

28. Marfell-Jones M, Olds T, Stewart AD, Carter L. International Standards for Anthropometric Assessment, International Society for the Advancement of Kinanthropometry (ISAK): 2006. Potchefstroom, South Africa; 2006.

29. Davis JA, Whipp BJ, Lamarra N, Huntsman DJ, Frank MH, Wasserman K. Effect of ramp slope on determination of aerobic parameters from the ramp exercise test. Med Sci Sports Exerc 1982;14: 339-343.

30. Beaver WL, Wasserman K, Whipp BJ. A new method for detecting anaerobic threshold by gas exchange. J Appl Physiol 1986;60:2020-2027.

31. Ten Harkel AD, Takken T, Van Osch-Gevers M, Helbing WA. Normal values for cardiopulmonary exercise testing in children. Eur J Cardiovasc Prev Rehabil 2011;18:48-54.

32. Nathan RA, Sorkness CA, Kosinski M, Schatz M, Li JT, Marcus P, Murray JJ, Pendergraft TB. Development of the asthma control test: a survey for assessing asthma control. J Allergy Clin Immunol 2004; 113: 59-65.

33. Liu AH, Zeiger R, Sorkness C, Mahr T, Ostrom N, Burgess S, Rosenzweig JC, Manjunath R. Development and cross-sectional validation of the childhood asthma control test. J Allergy Clin Immunol 2007; 119: 817-825.

34. Koolen BB, Pijnenburg MW, Brackel HJ, Landstra AM, van den Berg NJ, Merkus PJ, Hop WC, VaessenVerberne AA. Comparing global initiative for asthma (GINA) criteria with the childhood asthma control test (C-ACT) and asthma control test (ACT). Eur Respir J 2011;38:561-566.

35. Nightingale JA, Rogers DF, Barnes PJ. Comparison of the effects of salmeterol and formoterol in patients with severe asthma. Chest 2002;121:1401-1406.

36. Wong CS, Pavord ID, Williams J, Britton JR, Tattersfield AE. Bronchodilator, cardiovascular, and hypokalaemic effects of fenoterol, salbutamol, and terbutaline in asthma. Lancet 1990;336:1396-1399.

37. Bateman ED, Hurd SS, Barnes PJ, Bousquet J, Drazen JM, FitzGerald M, Gibson P, Ohta K, O'Byrne P, Pedersen SE, Pizzichini E, Sullivan SD, Wenzel SE, Zar HJ. Global strategy for asthma management and prevention: GINA executive summary. Eur Respir J 2008;31:143-178.

38. Asher MI, Keil U, Anderson HR, Beasley R, Crane J, Martinez F, Mitchell EA, Pearce N, Sibbald B, Stewart AW. International study of asthma and allergies in childhood (ISAAC): rationale and methods. Eur Respir J 1995;8:483-491.

39. Juniper EF, Guyatt GH, Feeny DH, Ferrie PJ, Griffith LE, Townsend M. Measuring quality of life in children with asthma. Qual Life Res 1996;5:35-46.

40. Raat H, Bueving HJ, de Jongste JC, Grol MH, Juniper EF, van der Wouden JC. Responsiveness, longitudinal- and cross-sectional construct validity of the pediatric asthma quality of life questionnaire (PAQLQ) in dutch children with asthma. Qual Life Res 2005;14:265-272.

41. Wille N, Badia X, Bonsel G, Burström K, Cavrini G, Devlin N, Egmar AC, Greiner W, Gusi N, Herdman M, Jelsma J, Kind P, Scalone L, Ravens-Sieberer U. Development of the EQ-5D-Y: a child-friendly version of the EQ-5D. Qual Life Res 2010;19: 875-886.

42. Chervin RD, Hedger K, Dillon JE, Pituch KJ. Pediatric sleep questionnaire (PSQ): validity and reliability of scales for sleep-disordered breathing, snoring, sleepiness, and behavioral problems. Sleep Med 2000;1: 21-32.

43. Nelson SP, Chen EH, Syniar GM, Christoffel KK. Prevalence of symptoms of gastroesophageal reflux during childhood: a pediatric practice-based survey. Pediatric practice research group. Arch Pediatr Adolesc Med 2000;154:150-154. 


\section{Multifactorial intervention for children with asthma and overweight (Mikado): study design of a randomised controlled trial}

44. Muris P, Meesters C, van den Berg F. The strengths and difficulties questionnaire (SDQ)-further evidence for its reliability and validity in a community sample of Dutch children and adolescents. Eur Child Adolesc Psychiatry 2003;12:1-8.

45. van Strien T, Oosterveld P. The children's DEBQ for assessment of restrained, emotional, and external eating in 7- to 12-year-old children. Int J Eat Disord 2008, 41(Suppl 1):72-81.

46. American Thoracic Society; European Respiratory Society. ATS/ERS recommendations for standardized procedures for the online and offline measurement of exhaled lower respiratory nitric oxide and nasal nitric oxide, 2005. Am J Respir Crit Care Med.2005;171:912-930.

47. van de Kant KDG, Klaassen EM, Jobsis Q, Koers K, Rijkers GT, van der Grinten CP, van Schayck OC, Passos VL, Dompeling E. Wheezing in preschool children is associated with increased levels of cytokines/chemokines in exhaled breath condensate. J Allergy Clin Immunol 2010;126:669-671.

48. Moshfegh AJ, Rhodes DG, Baer DJ, Murayi T, Clemens JC, Rumpler WV, Paul DR, Sebastian RS, Kuczynski $\mathrm{KJ}$, Ingwersen LA, Staples RC, Cleveland LE. The US department of agriculture automated multiple-pass method reduces bias in the collection of energy intakes. Am J Clin Nutr 2008;88:324-332.

49. National Institute for Public Health and the Environment. NEVO Dutch Food Composition Database online version 2011/3.0. http://www.rivm.nl/en/Topics/Topics/D/Dutch_Food_Composition_Database/ Access_NEVO_data/NEVO_online. Accessed 2014 March 28.

50. McGovern L, Johnson JN, Paulo R, Hettinger A, Singhal V, Kamath C, Erwin PJ, Montori VM. Clinical review: treatment of pediatric obesity: a systematic review and meta-analysis of randomized trials. $J$ Clin Endocrinol Metab 2008;93:4600-4605.

51. Oude Luttikhuis H, Baur L, Jansen H, Shrewsbury VA, O'Malley C, Stolk RP, Summerbell CD. Interventions for treating obesity in children. Cochrane Database Syst Rev 2009;CD001872CD001872(Suppl 1):CD001872.

52. Snethen JA, Broome ME, Cashin SE. Effective weight loss for overweight children: a meta-analysis of intervention studies. J Pediatr Nurs 2006;21:45-56.

53. Waters E, de Silva-Sanigorski A, Hall BJ, Brown T, Campbell KJ, Gao Y, Armstrong R, Prosser L, Summerbell CD. Interventions for preventing obesity in children. Cochrane Database Syst Rev 2011;(Suppl 12):CD001871.

54. Gerards F, Borgers R. Health counseling; Het adviesgesprek in de (para)medische en verpleegkundige zorg [health counselling; advisory conversations in the (para)medical care and nursery care]. Soest: Uitgeverij Nelissen; 2006.

55. Prochaska JDCC. The transtheoretical approach. 2nd edition. New York: Oxford University Press; 2005.

56. Ajzen I. The theory of planned behavior. Organ Behav Hum Decis Process 1991;50:179-211.

57. Bandura A. Self-efficacy: toward a unifying theory of behavioral change. Psychol Rev 1977;84:191-215.

58. Marlatt GA, George WH. Relapse prevention: introduction and overview of the model. Br J Addict 1984; 79:261-273.

59. Borg G. Borg's perceived exertion and pain scales. Champaigne: Human Kinetics; 1998.

60. Wezel BJ. Dieetbehandelingsrichtlijnen: Te hoog gewicht bij kinderen en adolescenten (4-18 jaar) [Dietary guidelines: An increased bodyweight in children and adolescents (aged 4-18)]. Maarssen: Elsevier Gezondheidszorg; 2004.

61. Huis voor voor de Sport Westelijke Mijnstreek Universiteit Maastricht. Guidebook Realfit, information for professionals. Sittard; 2005.

62. Schofield WN. Predicting basal metabolic rate, new standards and review of previous work. Hum Nutr Clin Nutr 1985;39:5-41.

63. Werrij MQ, Jansen A, Mulkens S, Elgersma HJ, Ament AJ, Hospers HJ. Adding cognitive therapy to dietetic treatment is associated with less relapse in obesity. J Psychosom Res 2009;67:315-324.

64. Mulkens S, Fleuren D, Nederkoorn C, Meijers J. Realfit: een multidisciplinaire groepsbehandeling voor jongeren met overgewicht [Realfit: a multidisciplinary group treatment program for adolescents with overweight]. Gedragstherapie 2007;40:27-48.

65. Stenius-Aarniala B, Poussa T, Kvarnstrom J, Gronlund EL, Ylikahri M, Mustajoki P. Immediate and long term effects of weight reduction in obese people with asthma: randomised controlled study. BMJ Clinical research ed 2000;320:827-832. 
66. Hakala K, Stenius-Aarniala B, Sovijarvi A. Effects of weight loss on peak flow variability, airways obstruction, and lung volumes in obese patients with asthma. Chest 2000;118:1315-1321.

67. da Silva PL, de Mello MT, Cheik NC, Sanches PL, Correia FA, de Piano A, Corgosinho FC, Campos RM, do Nascimento CM, Oyama LM, Tock L, Tufik S, Dâmaso AR. Interdisciplinary therapy improves biomarkers profile and lung function in asthmatic obese adolescents. Pediatr Pulmonol 2012;47:8-17.

68. Hedeker D, Gibbons RD, Waternaux C. Sample size estimation for longitudinal designs with attrition. J Educ Behav Stat 1999;24:70-93.

69. Ford AL, Hunt LP, Cooper A, Shield JP. What reduction in BMI SDS is required in obese adolescents to improve body composition and cardiometabolic health? Arch Dis Child 2010;95:256-261.

70. Rice J, Thombs D, Leach R, Rehm R. Successes and barriers for a youth weight-management program. Clin Pediatr 2008;47:143-147.

71. Abma TA. Responsive evaluation in health promotion: its value for ambiguous contexts. Health Promot Int 2005;20:391-397.

72. Anto JM. Recent advances in the epidemiologic investigation of risk factors for asthma: a review of the 2011 literature. Curr Allergy Asthma Rep 2012;12:192-200. 


$$
V
$$




\section{A multifactorial weight reduction program in children with overweight and asthma: a randomised controlled trial}

Submitted

Maartje Willeboordse Kim DG van de Kant Frans ES Tan Sandra Mulkens Julia Schellings Yvonne Crijns

Liesbeth van der Ploeg Constant P van Schayck Edward Dompeling 


\section{Abstract}

\section{Research question}

There is increasing evidence that obesity is related to asthma development and severity. However, it is largely unknown whether weight reduction can influence asthma management, especially in children. We aim to investigate the effects of a multifactorial weight reduction intervention on asthma features in children with asthma and overweight/obesity.

\section{Methods}

An 18 month weight reduction randomised controlled trial was conducted in 87 children with overweight/obesity and asthma/high risk of asthma. Every 6 months, measurements of anthropometry, lung function, lifestyle parameters and inflammatory markers were assessed. Analyses were performed with linear mixed models for longitudinal analyses.

\section{Results}

After 18 months, body mass index-standard deviation score decreased with $-0.14 \pm 0.29$ point $(p<0.01)$ in the intervention group and $-0.12 \pm 0.34$ point $(p<0.01)$ in the control group. This change over time was not different between groups ( $p>0.05$ ). Asthma features (including asthma control and quality of life) and most lung function indices (static and dynamic) improved significantly over time in both intervention and control group. Forced vital capacity was the only outcome parameter that significantly improved more in the intervention than the control group $(p<0.05)$.

\section{Discussion}

No intervention effect was found on BMI-SDS and asthma features, as in the intervention group BMI-SDS, lung function and asthma features improved to the same extent as the control group. Possible reasons for the low effectiveness of the intervention are high attrition rates, low compliance to the intervention, and weight reduction in the control group. Future studies should resolve whether weight reduction is an efficient secondary prevention tool for asthma in children. 


\section{A multifactorial weight reduction program in children with overweight and asthma: a RCT}

\section{Introduction}

The high childhood obesity prevalence is a major public health problem ${ }^{1}$. Recently, the American medical association classified obesity as a disease, rather than a "health concern' ${ }^{2}$. A high body mass index (BMI) increases the risk of developing asthma. Prospective studies suggested that a high BMI precedes asthma symptoms ${ }^{3}$. Moreover, a dose-response effect of BMI on asthma symptoms has been detected ${ }^{4}$. In comparison to their lean counterparts, the obese-asthmatic population is characterised by decreased asthma control, high medication use, and frequent asthma-related hospital admissions ${ }^{5-7}$. As obese children often become obese adults, it is necessary to tackle obesity early in life ${ }^{8}$.

Although obesity leads to more severe asthma, it is largely unknown whether weight reduction is an effective secondary preventive tool for asthma ${ }^{9,10}$. Most weight reduction studies in asthmatic patients have been conducted in adults ${ }^{9,10}$. After weight reduction, improvements in lung function, asthma symptoms, asthma control and use of rescue medication have been found. However, most studies have sample sizes $<40$ participants and weight loss is frequently achieved with bariatric surgery ${ }^{9}$. In children, only limited data are available ${ }^{11-13}$. Three paediatric studies showed improvements on several asthma features after weight reduction interventions, in accordance with adult studies $^{11-13}$. Although these results are promising, not all three studies reported effects on asthma control, quality of life, and lung function uniformly ${ }^{11-13}$. Besides, also in paediatric studies methodological issues such as small sample sizes and a frequent lack of control groups hamper the results ${ }^{10}$.

Next to these methodological issues, there is lack in knowledge about the underlying mechanisms responsible for the asthma improvements after weight loss. Obesity causes mechanical, metabolic, and immunological changes that may affect the respiratory system ${ }^{10}$. Both mechanical changes (such as improvements in chest wall compliance as a result of less mass loading effect of fat in and around the chest wall) and inflammatory changes (e.g. increases in adiponectin, reductions in c-reactive protein and leptin) have been proposed to cause asthma improvements after weight reduction ${ }^{10,11,14}$. Nevertheless, limited weight reduction studies in asthmatic children studied outcome parameters of both pathways ${ }^{9,11}$.

The primary aim of this study was to investigate the effects of a longitudinal, multidisciplinary, randomised controlled trial directed towards weight reduction in children with asthma and overweight/obesity. Our primary outcomes included forced expiratory volume in 1 second ( $\mathrm{FEV}_{1} \%$ predicted) and $\mathrm{BMI}$-standard deviation score (SDS). Secondary outcomes were various asthma features such as dynamic and static lung function, asthma control, medication use and markers of the mechanical (lung volumes) and inflammatory (e.g. leptin) pathways. 


\section{Methods}

\section{Study design}

Children with asthma and overweight/obesity were included in a multifactorial randomised controlled trial entitled MIKADO (clinicaltrial.gov NCT00998413). The study protocol of the MIKADO study has been described previously ${ }^{15}$. In short, the intervention group received an 18-month lasting multifactorial weight intervention consisting of regular sport sessions, 18 lifestyle sessions, 10 parental sessions and 8 individual sessions. The intervention was based on the 'Health counselling model' and divided in an initial phase (month 1-6) and a follow up phase (month 7-18). The control group received regular care according to the Dutch national standards ${ }^{16,17}$. Regular outcome measurements were performed at baseline (T0), 6 months (T6), 12 months (T12) and at the end of the 18-month intervention (T18) (Figure 6.1). The study was approved by the Medical Ethic Committee of Maastricht University Medical Centre (MEC 09-2-088).

\section{Study sample}

Eligibility criteria included: aged between 6 and 16 years, with overweight or obesity according to reference charts of the Dutch Fourth Nationwide Growth Study and an asthma diagnosis, based on asthmatic symptoms, asthma medication use and/or airway reversibility $^{15,18}$ (Figure 6.1). In addition, 19 participants with a high-risk of asthma (as defined by at least one first-grade family member with asthma) and with overweight/obesity were included.

\section{Measurements}

All outcome measures have been described in detail previously ${ }^{15}$. A summary is given below.

\section{Primary outcome variables}

$\mathrm{FEV}_{1}$ \%predicted was obtained via maximal expiratory flow volume (MEFV) curves, measured with a spirometer (ZAN Messgerate, Oberthulba, Germany) according to international guidelines with predictive values of Zapletal et al. ${ }^{19,20}$. Weight and height were measured twice and averaged to calculate the BMI (weight/height ${ }^{2}$ ). BMI-SDS was based on the reference charts of the Dutch fourth Nationwide Growth Study ${ }^{21}$. 


\section{A multifactorial weight reduction program in children with overweight and asthma: a RCT}

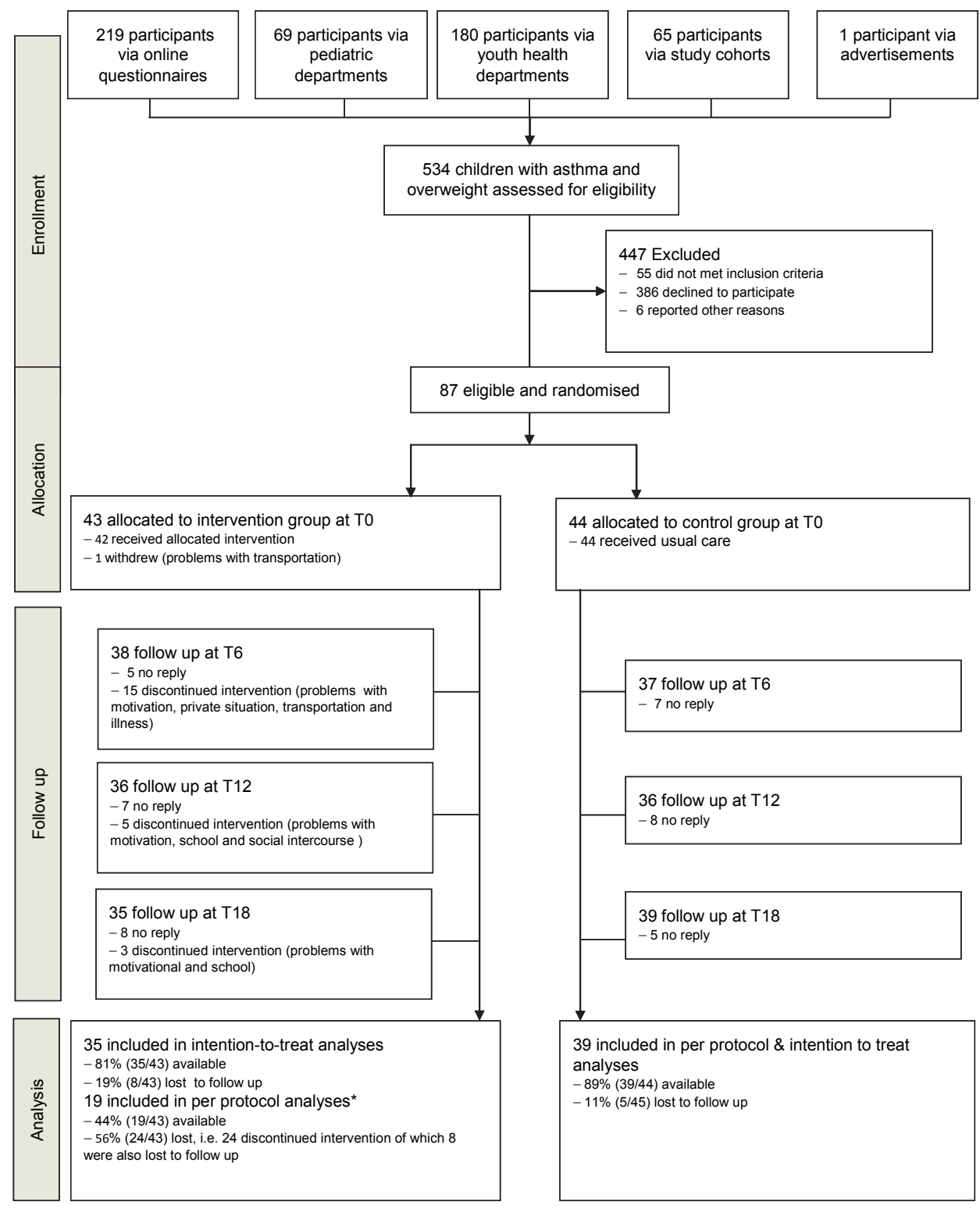

Figure 6.1 Consort flow diagram.

* Two participants discontinued the sport sessions during the follow-up phase of the intervention due to membership of an organised sports association, but did continue to attend the lifestyle, individual and parental sessions. Those participants were included in the per protocol analysis. 


\section{Secondary outcome variables: Asthma features}

Asthma related outcome measures were measured by the (childhood)-asthma control test ((c)-ACT), the paediatric asthma quality of life questionnaire (PAQLQ) and a medication questionnaire ${ }^{22-24}$. Exercise induced bronchoconstriction (EIB) was measured as the difference in $\mathrm{FEV}_{1}$ before, 10 and 30 minutes after a maximal ergometer test. Dynamic lung function indices (forced vital capacity (FVC\%predicted)) were obtained with MEFV curves as described above. Static lung function indices (total lung capacity (TLC\%predicted), ERV\%predicted) were determined by body plethysmography (Viasys, Hoechberg, Germany) ${ }^{19}$.

Systemic inflammatory markers were determined in blood serum. The serum concentrations of leptin and adiponectin were determined by using a commercial available ELISA (DY398 DuoSet, R\&D Systems, Minneapolis, USA) and RIA kit (Cat. No. HADP-61HK, Millicore corporation, Billerica, USA). All samples underwent duplicate testing.

\section{Baseline and lifestyle outcome variables}

Co morbidities of asthma and obesity were monitored by several questionnaires as described before ${ }^{15}$. Physical activity level was defined as the average step count per day measured over 7 days by a tri-axial accelerometer (Yamax EX510 Power Walker, Yamax, Tokyo, Japan). A maximal incremental ergometer test was used to determine maximal aerobic capacity $\left(\mathrm{VO}_{2}\right.$ peak) with predicted values of Bongers et al. ${ }^{25}$. Dietary intake was measured by means of 3-day food records. Dietary intake was ranked on quality (scale range $0-16$ ) based on amount of principal meals, fruit consumptions, unhealthy snacks and healthy milk consumption, as advised by the Dutch guidelines for healthy paediatric dietary intake ${ }^{26}$. Atopy was defined as an IgE serum concentration of $\geq 35 \mathrm{kU} / \mathrm{l}$ for a specific mixture for inhalant allergens (Phadiatop test, Pharmacia, Uppsala, Sweden).

\section{Statistical analysis}

All data were assessed for normality. The power analysis was described previously ${ }^{15}$. Results are presented as mean \pm SD unless stated otherwise. Loss to follow up was in this article defined as discontinuation of the measurements, independent of completion of the intervention (Figure 6.1). Attrition was defined as discontinuation of the intervention program, independent of completion of the measurements. Participants who were loss to follow up where missing at random, as loss to follow up status (yes/no) was not associated with the most important baseline characteristics, and change in BMI-SDS and $\mathrm{FEV}_{1} \%$ predicted.

For all analyses, linear mixed model analysis techniques were used, as this technique corrects for correlation within individuals within groups, which occurs in repeated- 


\section{A multifactorial weight reduction program in children with overweight and asthma: a RCT}

measures RCT designs. Another advantage of this technique is that it naturally handles missing values, in case data were missing at random. For the primary analysis, two linear mixed models were built with both $\mathrm{FEV}_{1} \%$ predicted and BMI-SDS as dependent factors. The levels participants and measurements were included. An extensive description of all primary, secondary and additional analytical models is provided in online supporting information S4.1. For the primary analysis, results are shown for intention-to-treat analyses, unless stated otherwise.

\section{Results}

\section{Baseline characteristics}

Baseline characteristics are displayed in Table 6.1. The study population consisted of slightly more boys than girls. Half of the children were classified as obese. The majority of the children demonstrated good asthma control and a high asthma-related quality of life. Additional baseline characteristics can be found in Table S6.2 in the online supporting information.

\section{Intervention and control group adherence}

In total, 24 participants (56\%) did not complete the intervention (Figure 6.1). The majority of the discontinuers (63\%) stopped during the initial phase of the intervention. The average presence for sport, group, parental and individual sessions was respectively $71 \%, 65 \%, 63 \%$ and $68 \%$. The average heart rate for each sport session was (mean \pm SD) $149 \pm 9$ beats per minute, which correspondents to $79 \%$ of maximum heart rate.

In the control group, 29 participants (89\% of the control group, not taking into account loss-to follow-up participants) reported that they received professional help to facilitate weight reduction during the 18 month study period (e.g. help of a dietician, a weight reduction consultant, specialised obesity care in a hospital, other weight reduction programs, or online weight reduction advice). Of control group participants who received professional help, ten participants (34\%) received more than five consultations with a health professional during the intervention period.

All trends in lifestyle parameters were not significantly different between intervention and control group (for all parameters, $\mathrm{p}>0.05$ ) (Figure $\mathrm{S} 4.3$ in online supporting information). In the intervention group, the lifestyle parameters diet score $(p=0.35)$, step count $(p=0.65)$ and eating behaviours (restraint- $(p=0.90)$, emotional- $(p=0.55)$, external eating $(p=0.08)$ ) did not significantly change during the intervention period. Aerobic fitness $\left(\mathrm{VO}_{2}\right.$ peak\%predicted) was the only lifestyle parameter which 
significantly changed over time $(p<0.01)$ in the intervention group, albeit not significantly different from the control group.

Table 6.1 Baseline characteristics

\begin{tabular}{|c|c|c|c|}
\hline & $\begin{array}{l}\text { Total group } \\
(n=87)\end{array}$ & $\begin{array}{l}\text { Intervention } \\
\text { group }(n=43)\end{array}$ & $\begin{array}{c}\text { Control group } \\
(n=44)\end{array}$ \\
\hline \multicolumn{4}{|l|}{ Baseline characteristics } \\
\hline Age in years, median (IQR) & $12.2(3.5)$ & $12.3(14.5)$ & $11.9(2.5)$ \\
\hline Males, n/N (\% male) & $53 / 87(61)$ & $26 / 43(61)$ & $27 / 44(61)$ \\
\hline Parents with a low educational level, n/N* (\%) & $30 / 87(34)$ & $21 / 43(49)$ & $9 / 44(20)$ \\
\hline Average parental BMI, median (IQR) & $27.7(6.6)$ & $26.9(6.8)$ & $28.4(6.2)$ \\
\hline \multicolumn{4}{|l|}{ Anthropometrics } \\
\hline $\mathrm{BMI}$ in $\mathrm{kg} / \mathrm{m}^{2}$, median (IQR) & $25.2(5.3)$ & $25.0(6.6)$ & $25.2(5.1)$ \\
\hline BMI-SDS, mean (SD) & $2.34(0.55)$ & $2.37(0.58)$ & $2.32(0.52)$ \\
\hline Obese children (BMI-SDS $\geq 2.3$ ), n/N* (\%) & $45 / 87(52)$ & $23 / 43(53)$ & $22 / 44(50)$ \\
\hline Skinfold thickness in cm, median (IQR) & $129.8(59.0)$ & $125.0(75.5)$ & $130.0(45.5)$ \\
\hline Waist circumference in $\mathrm{cm}$, median (IQR) & $92.9(16.1)$ & $90.5(19.5)$ & $94.0(10.4)$ \\
\hline \multicolumn{4}{|l|}{ Asthma features } \\
\hline Diagnosed asthma, n/N*(\%) & $68 / 87(78)$ & $32 / 87(74)$ & $36 / 87(82)$ \\
\hline Atopic, $n / N^{*}(\%)$ & $16 / 67(24)$ & $9 / 34(27)$ & $7 / 33(21)$ \\
\hline $\mathrm{FEV}_{1}$ in $\%$ predicted, mean (SD) & $90.0(15.2)$ & $90.4(13.6)$ & $89.7(16.8)$ \\
\hline FVC in \% predicted, mean (SD) & $93.9(11.4)$ & $93.8(10.1)$ & $94.0(12.7)$ \\
\hline $\mathrm{FEV}_{1} / \mathrm{FVC}$ in $\%$, mean (SD) & $80.3(8.5)$ & $80.6(7.6)$ & $80.1(9.4)$ \\
\hline ERV in \% predicted, mean (SD) & $79.2(25.3)$ & $75.9(26.2)$ & $82.1(24.5)$ \\
\hline $\mathrm{PC}_{20}$ histamine, median (IQR) & $1.81(4.92)$ & $2.08(4.31)$ & $1.40(5.57)$ \\
\hline Uncontrolled asthma according to (c)-ACT, $n / N^{*}(\%)^{\dagger}$ & $23 / 68(34)$ & $11 / 32(34)$ & $12 / 36(33)$ \\
\hline PAQLQ, median (IQR) + & $6.26(0.87)$ & $6.17(0.72)$ & $6.30(1.35)$ \\
\hline Use of SABA, $n / N(\%)^{\dagger}$ & $29 / 68(43)$ & $14 / 32(44)$ & $15 / 36(42)$ \\
\hline Use of more than 1 dose equivalent SABA, $n / N^{*}(\%)^{\dagger}$ & $16 / 68(24)$ & $11 / 32(34)$ & $5 / 36(14)$ \\
\hline Use of ICS, n/N* (\%)† & $29 / 68(43)$ & $10 / 32(31)$ & $19 / 36(53)$ \\
\hline Use of more than 1 dose equivalent ICS, $n / N^{*}(\%)^{\dagger}$ & $12 / 68(18)$ & $3 / 32(9)$ & $9 / 36(25)$ \\
\hline \multicolumn{4}{|l|}{ Inflammatory parameters } \\
\hline FeNO in ppb, median (IQR) & $15.8(30.7)$ & $15.0(34.0)$ & $16.8(29.5)$ \\
\hline Serum leptin in ng/ml, median (IQR) & $1.83(2.45)$ & $1.83(2.40)$ & $1.83(2.49)$ \\
\hline Serum adiponectin in $\mathrm{mg} / \mathrm{mL}$, mean (SD) & $11.6(4.2)$ & $11.2(4.6)$ & $12.0(3.7)$ \\
\hline
\end{tabular}

${ }^{*} \mathrm{n} / \mathrm{N}$ : Amount of participants with a positive outcome for this parameter / Amount of participants measured. Numbers (N) may not add up to 87, 43 and 44 respectively due to missing values or, in case of asthma related parameters $(+)$, because those parameters are only demonstrated for asthmatic participants (not for participants with high risk of asthma).

Abbreviations: ACT: asthma control test, BMI: body mass index, BMI-SDS: body mass index standard deviation score, ERV: expiratory reserve volume, FeNO: fraction of exhaled nitric oxide, $\mathrm{FEV}_{1}$ : forced expiratory volume in 1 second, FVC: forced vital capacity, ICS: inhaled corticosteroids, IQR: inter quartile range, PAQLQ, paediatric asthma quality of life questionnaire, $\mathrm{PC}_{20}$ histamine: histamine concentration that lead to a drop of $20 \%$ in $\mathrm{FEV}_{1}$, SABA: short acting beta2agonists, SD: standard deviation. 


\section{A multifactorial weight reduction program in children with overweight and asthma: a RCT}

\section{Primary research question: $\mathrm{FEV}_{1}$ and BMI-SDS (Figure 6.2)}

There was no effect of group allocation on decreases in BMI-SDS, in both the intention to treat $(p=0.84)$ and per protocol analysis $(p=0.65)$. BMI-SDS decreased slightly after the 18 month period with $-0.14 \pm 0.29$ point $(p<0.01)$ in the intervention group, and $0.12 \pm 0.34$ point $(p<0.01)$ in the control group. The changes over time in $\mathrm{FEV}_{1} \%$ predicted were not significantly different between the intervention and control group ( $p \geq 0.05$ ). FEV 1 improved significantly after 18 months from $90.5 \pm 12.5$ to $99.7 \pm 11.0(p<0.05) \%$ predicted in the intervention group and from $89.3 \pm 17.1$ to $95.1 \pm 16.6(p<0.05) \%$ predicted in the control group.


Figure 6.2 Changes over time in: A) BMI-SDS, B) FEV1\%predicted, C) FVC\%predicted, D) ERV\%predicted, E) TLC\%predicted, F) FEV 1 /FVC. $\S$

Data are presented as mean (SEM). *: Significant difference over time in the intervention group $(p<0.05)$; + : Significant difference over time in the control group $(p<0.05)$; $¥$ : Significant difference between intervention and control group over time $(p<0.05)$; $\S$ : Intention to treat analyses are shown

\section{Secondary research question: Asthma features (Figure 6.2, 6.3, 6.4)}

The improvement in FVC\%predicted was significantly greater in the intervention group compared to the control group $(p<0.05)$. All changes in other lung function indices did not differ between intervention and control group ( $p>0.05)$. FVC\%predicted improved over time with $10.1 \pm 8.7$ points $(p<0.001)$ in the intervention group and $6.1 \pm 8.4$ points $(p<0.05)$ in the control group. In the intervention group, ERV\%predicted improved with $12.0 \pm 20.5$ points after 18 months $(p<0.01)$ and TLC\%predicted with $4.0 \pm 8.8$ points $(p<0.05)$. FEV $1 / F V C \%$ predicted, and the degree of EIB remained unchanged during 
18 months in the intervention group. The same trends were observed in the control group for all lung function indices.
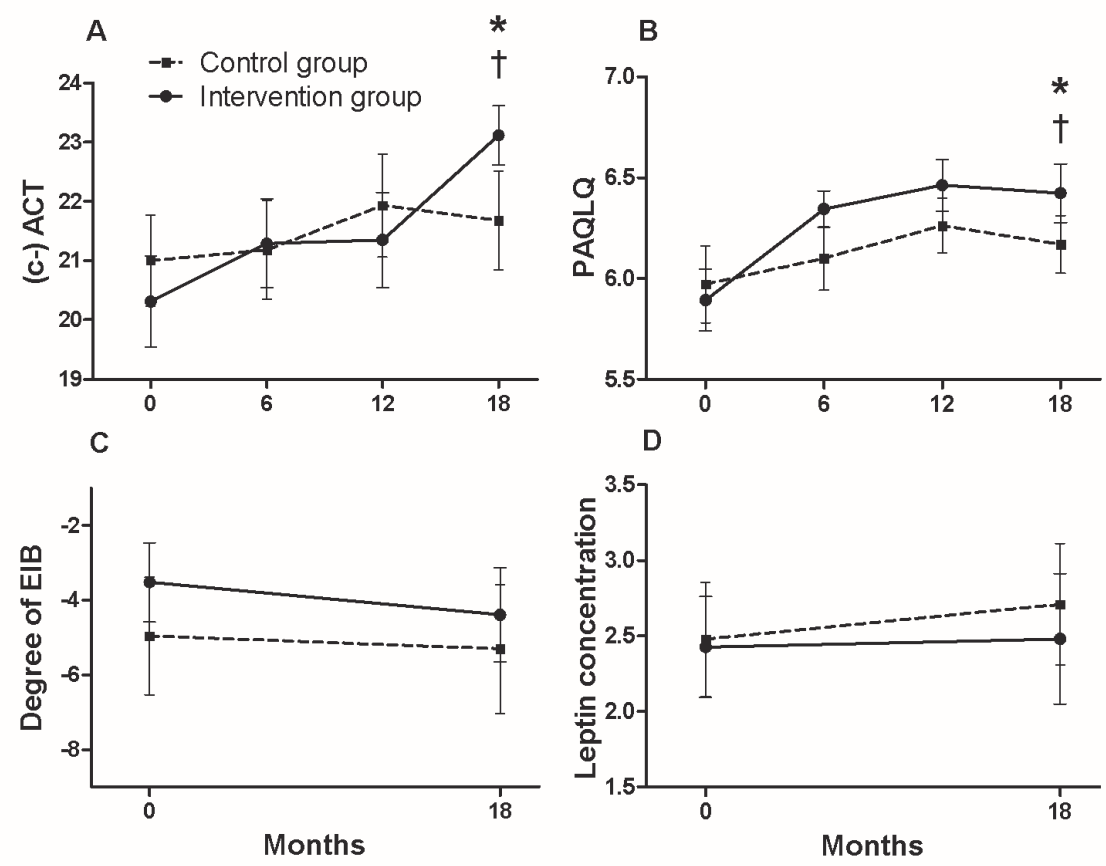

Figure 6.3 Changes over time in: A) (c)- ACT II, B) PAQLQ II, C) Degree of EIB D) Leptin concentration. § Data are presented as mean (SEM). *: Significant difference over time in the intervention group $(p<0.05)$; + : Significant difference over time in the control group $(p<0.05)$; $\neq$ : Significant difference between intervention and control group over time $(p<0.05) ; \S$ : Intention to treat analyses are shown; II: Only subjects with an asthma diagnosis are shown

Changes over time in asthma control, and the number of patients who used medication (either SABA or ICA) were not statistically different between intervention and control group (for all parameters $p>0.05$ ). PAQLQ improved slightly more in the intervention group than the control group, although the improvement was not significantly different between groups $(p=0.06)$. PAQLQ significantly improved with an average $0.48 \pm 0.72$ point $(p<0.001)$ in children with asthma in the intervention group. This is a clinically important difference, as an increase of 0.42 is considered clinically relevant ${ }^{27}$. (c)-ACT score improved significantly in asthmatic children in the intervention group during 18 months $(p<0.05)$.

Changes in inflammatory parameters during 18 months were not significantly different between groups (leptin: $p=0.93$; adiponectin: $p=0.22$ ). None of the systemic 


\section{A multifactorial weight reduction program in children with overweight and asthma: a RCT}

inflammation parameters) significantly changed in the intervention (leptin: $p=0.60$; adiponectin: $p=0.66$ ) or control group (leptin: $p=0.32$, adiponectin $p=0.24$ ).
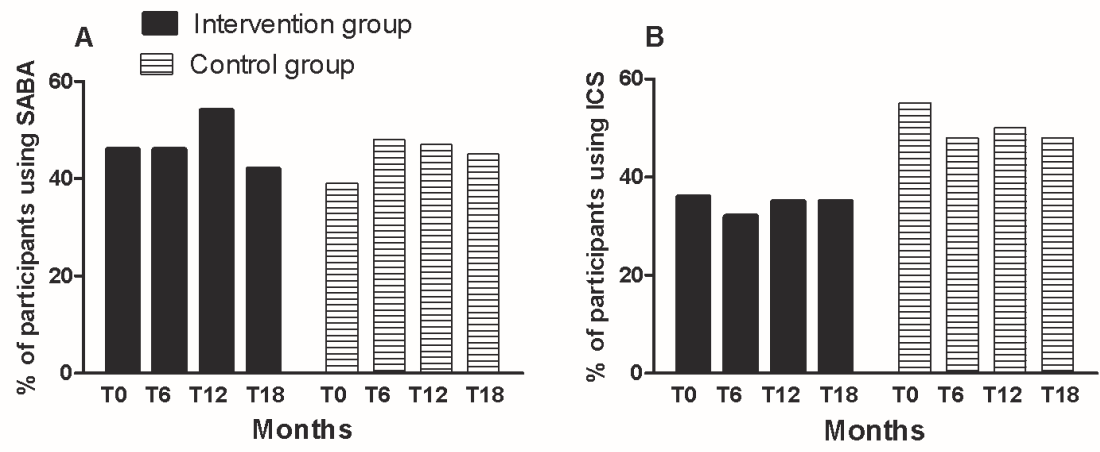

Figure 6.4 Changes over time in: A) Participants using SABA II, B) Participants using ICS II.§

Data are presented as mean (SEM). *: Significant difference over time in the intervention group $(p<0.05)$; + : Significant difference over time in the control group $(p<0.05)$; $\ddagger$ : Significant difference between intervention and control group over time $(p<0.05)$; $\S$ : Intention to treat analyses are shown; II: Only subjects with an asthma diagnosis are shown

\section{Discussion}

The primary aim of this study was to investigate the effects of a weight reduction intervention on asthma in overweight/obese, asthmatic children. In spite of the intensive intervention, the intervention was not effective in changing lifestyle behaviours such as physical activity and dietary intake. The lack in contrast regarding lifestyle behaviour change between the intervention and control group can be due to the fact that a considerable number of children/parents in the intervention group stopped with the intervention, whereas various families in the control group received professional help to facilitate weight reduction. Consequently, BMI-SDS did not decrease to a larger extent in the intervention group than the control group. In the intervention group, lung function ( $\mathrm{FEV}_{1} \%$ predicted, ERV\%predicted, TLC\%predicted), asthma control and quality-of life improved to the same extent as was visible in the control group. Only FVC\%predicted improved significantly more in the intervention group compared to the control group.

We did not succeed in achieving more weight reduction in the intervention than the control group. Unfortunately this is in line with previous intervention studies reporting that weight reduction in children is often disappointedly small ${ }^{28}$. However, in asthmatic children, three studies did succeed in achieving (limited) weight loss. In the studies of 
Jensen et al. and van Leeuwen et al. small, but significant reductions in BMI-SDS of 0.2 point were found ${ }^{12,13}$. In the study of da Silva et al., by far the most impressive weight reduction was achieved with reductions in BMI of $6 \mathrm{~kg} / \mathrm{m}^{2}$, but the results should be interpreted with caution as only per protocol analyses were shown and no control group was used ${ }^{11}$.

We did many efforts to stimulate intervention adherence in the intervention group, including imbursements for children if they reached their personal goals, additional social bonding activities, and regular evaluations. However, despite these efforts the effects of the intervention on weight reduction were still low. There are several explanations for the low effectiveness of our intervention on weight reduction. Firstly, attrition rates were high (e.g. 56\%), which hampered the results. In a follow-up study, we (qualitatively) analyzed the reasons for attrition in interviews with both children and caregivers. In those interviews, it was often reported that the high intensity of the program was difficult to combine with daily life routines, despite numerous efforts of the researchers to adjust time schedules. Secondly, participants did not succeed in applying the learned behaviours at home. Although our multifactorial intervention included all advised components of successful weight loss programs, the intervention group did not significantly change the lifestyle behaviours at which the intervention was aimed ${ }^{15}$. Thirdly, our results are distorted by the weight loss in the control group. Usually, children with overweight and obesity do not decrease, but increase their BMISDS over time ${ }^{8}$. Most likely, the control group was motivated to reduce weight because of the extra attention and perceived awareness of the problem ${ }^{29}$. This is reflected by the high percentage of participants who arranged professional help for weight reduction during the study period (89\%).

We did not find convincing differences in lung function and asthma features between the intervention and control group. Only FVC\%predicted improved significantly more in the intervention group than in the control group. Moreover, there was a small nonsignificant trend towards more improvements in asthma-related quality of life in the intervention group compared to the control group. We cannot explain these differences as a result of weight reduction due to change in lifestyle behaviours, as there was no significant difference in those parameters between the groups. Concordantly, three other paediatric weight reduction studies in asthma found small improvements on asthma severity, lung function, asthma-related quality of life and EIB after a weight reduction intervention ${ }^{11-13}$.

In both the intervention and control group, we observed improvements in lung function and asthma features (including $\mathrm{FEV}_{1} \%$ predicted, FVC\%predicted, asthma control, and asthma-related quality of life) over time. As also improvements in BMI-SDS were seen in both groups, the question rises whether the lung function improvements in the total group could be attributed to improvements in BMI-SDS, and/or mechanical and inflammatory changes in the total group. We performed a post-hoc analysis independent of group allocation, to investigate if (changes in) asthma features 


\section{A multifactorial weight reduction program in children with overweight and asthma: a RCT}

(FEV ${ }_{1} \%$ predicted, FVC\%predicted and asthma control) were associated with (changes in) BMI-SDS, (changes in) an inflammatory marker (leptin), or (changes in) a marker of the mechanical pathway (ERV\%predicted) (online supporting information S4.4). We found that changes over time in either BMI-SDS, leptin and ERV\%predicted were not related to changes in lung function (including $\mathrm{FEV}_{1} \%$ predicted, FVC\%predicted) or asthma control, which may be the consequence of the small changes within children over time. If data of all measurements were clustered and analyzed cross-sectional, we detected an association between more severe asthma features (including $\mathrm{FEV}_{1} \%$ predicted, FVC\%predicted), and a high BMI-SDS and low ERV\%predicted. This implies that children with the most severe asthma features had more severe obesity. Also, we showed an association between a reduced marker of the mechanical pathway (ERV\%predicted), but not the inflammatory pathway (leptin) with lower lung functions in overweight/obese children.

Improvements in lung function and asthma control in the total group may be explained by a learning effect (especially in the first 6 months of the study) ${ }^{30}$, a better adherence to asthma treatment, and a lower reporting of symptoms in the course of the study.

This study has several methodological strengths, compared to other paediatric weight reduction studies in asthma ${ }^{15}$. This is the first weight reduction study in children with asthma and overweight/obesity with an RCT design, a long-term longitudinal weight reduction intervention ( $>1$ year), and outcome measures of both the inflammatory and mechanical pathways. However, due to the low effectiveness of the intervention, this study is not able to answer the question whether weight reduction is a secondary prevention tool for asthma. We acknowledge that this study has some limitations. Firstly, the researchers and participants were not blinded for group allocation, which is difficult to perform in longitudinal studies directed at changing lifestyle behaviours. Secondly, we included some participants with a high risk of asthma. It can be expected that effects of weight reduction on lung function are slightly lower in this group. Thirdly, the degree of EIB is determined after a maximal ergometer test, while ideally EIB is determined after a submaximal test until exhaustion.

Future trials are necessary to investigate the effects of weight reduction in children with overweight/obesity and asthma, as weight reduction has the potential to be an important secondary prevention tool for asthma. Based on our experience, it can be advised to incorporate future studies in a daily routine, such as a school environment, to avoid attrition and low success rates on weight reduction. Another point of interest is the underlying mechanism of the asthma-obesity relationship. In our population we saw a weak association between a marker of the mechanical pathway (ERV\%predicted) with BMI-SDS, but no association between a marker of the inflammatory pathway (leptin) with BMI-SDS. As obese asthmatic patients are often insensitive for corticosteroid therapy, more information on the pathways by which this steroid insensitivity develops is necessary ${ }^{7}$. 


\section{Conclusion}

In this RCT, the weight reduction intervention did not result in greater weight reduction, or more improvements in lung function and asthma features in the intervention group compared to the control group. Because current paediatric studies including ours show weak evidence for an effect of weight reduction on lung function and asthma features ${ }^{11-13}$, it is too early to identify weight reduction as an effective secondary preventive tool for asthma in children. Yet, as weight reduction is beneficial for several health outcomes children with overweight/obesity should always be motivated to lose weight. Future research should focus at reducing attrition and improving efficiency in paediatric weight reduction programs. 


\section{Supporting information $\mathbf{S 6 . 1}$}

\section{Statistical analysis}

\section{Primary analysis: BMI-SDS and FEV $\mathrm{V}_{1} \%$ predicted}

The dependent variables for the secondary analyses were BMI-SDS and $\mathrm{FEV}_{1}$ \%predicted. Participants were treated as a second-level random factor, and the first level measurements (T0, T6, T12, T18) were included by repeated measures, with a compound symmetry covariance structure for both $\mathrm{FEV}_{1} \%$ predicted and BMI-SDS. Intervention group was included as a between-subjects covariate, and measurement as a categorical within-subject covariate with TO as reference category. The interaction term 'measurement by group' was included as a covariate. As measurements within one measurement moment took place within a range of 5 months, seasonal differences may have occurred which could influence $\mathrm{FEV}_{1}$ \%predicted [34]. Therefore, in the analysis with $\mathrm{FEV}_{1} \%$ predicted, season of the measurement, and an interaction term of season by group were also included as covariates. Both intention-to treat (with all participants who completed the measurements) and per-protocol analyses (with only participants who continued the intervention) were performed. Results are shown for intention-to-treat analyses, unless stated otherwise.

\section{Secondary analysis: Asthma features}

The dependent variables for the secondary analyses were: FVC\%predicted, FEV $1 / F V C$, TLC\%predicted, ERV\%predicted, asthma control, asthma-related quality of life (PAQLQ score), degree of EIB, leptin, adiponectin, ICS use and SABA use. For asthma control, PAQLQ scores, and medication use, analyses were conducted without subjects with a high risk of asthma development. For all analyses two levels were used: participants and measurements (T0, T6, T12, T18). Asthma control was determined by the C-ACT for the children aged 6-12 (outcome range 0-27) and ACT score for the children aged $\geq 12$ at baseline (outcome range 5-25). Analyses for asthma control were performed with (c)ACT scores as the continuous dependent variable, and ACT-group (e.g. C-ACT or ACT) as a covariate to correct for differences between the two questionnaires. Participants were treated as a second-level random factor, and the first level measurements were included by repeated measures, with a compound symmetry covariance structure for all dependent variables except PAQLQ. In the analysis with PAQLQ as dependent variable, an unstructured covariance structure was used. Intervention group was included as a between-subjects covariate. Measurement was included as a withinsubject covariate. In variables with 4 measurements (e.g. FVC\%predicted, FEV $_{1} / F$ C, asthma control, PAQLQ score), measurements were included by using dummy coding 
with TO as reference category. In all analyses the interaction term between group and measurement was included.

ICS use and SABA use were analyzed with binary mixed models for longitudinal analysis (logit link function), as those are categorical dependent variables. The same independent variables as in the linear mixed models analysis models were included and a compound covariance matrix was used.

\section{Analyses of lifestyle variables}

Differences in the lifestyle variables diet score, step count, $\mathrm{VO}_{2}$ peak\%predicted and eating behaviours (DEBQ emotional, restraint and external eating score) over time were calculated with mixed models for longitudinal analyses. Participants were treated as a second-level random factor, and the first level measurements were included by repeated measures, with a compound symmetry covariance structure for all lifestyle variables. Measurement was included as a within-subject covariate. In variables with more than 2 measurements (e.g. diet score, step count), measurements were included by using dummy coding with TO as reference category. In all analyses the interaction term between group and measurement was included. Per-protocol analyses were not performed for this secondary analysis as this would mean a considerable loss of power. 


\section{A multifactorial weight reduction program in children with overweight and asthma: a RCT}

\section{Supporting information $\mathbf{S 6 . 2}$}

Table S6.2 Additional baseline characteristics.

\begin{tabular}{|c|c|c|c|}
\hline & $\begin{array}{l}\text { Total group } \\
(\mathrm{n}=87)\end{array}$ & $\begin{array}{l}\text { Intervention group } \\
\quad(n=43)\end{array}$ & $\begin{array}{l}\text { Control group } \\
(n=44)\end{array}$ \\
\hline \multicolumn{4}{|l|}{ Questionnaires } \\
\hline $\begin{array}{l}\text { Suspicion of Sleep Related Breathing Disorders } \\
\text { according to PSQ, n/N* (\%) }\end{array}$ & $37 / 87(43)$ & $20 / 43(47)$ & $17 / 44(39)$ \\
\hline $\begin{array}{l}\text { Suspicion of Gastro Oesophageal Reflux disease } \\
\text { according to GERD, n/N* (\%) }\end{array}$ & $11 / 87(13)$ & $3 / 43(7)$ & $8 / 44$ (19) \\
\hline $\begin{array}{l}\text { Score for strengths and difficulties questionnaire } \\
(t=12) \text {, median (IQR) }\end{array}$ & $9.0(7.0)$ & $9.0(7.0)$ & $9.5(7.0)$ \\
\hline \multicolumn{4}{|l|}{ Dutch eating behaviour questionnaire } \\
\hline External eating, median (IQR) & $8.0(7.0)$ & $7.0(6.3)$ & $8.0(7.5)$ \\
\hline Emotional eating, median (IQR) & $9.0(15.0)$ & $9.0(14.3)$ & $9.0(16.0)$ \\
\hline Restraint eating, median (IQR) & $10.0(11.0)$ & $10.0(9.0)$ & $11.0(10.5)$ \\
\hline $\begin{array}{l}\text { VAS score self-rated health EQ-5D-Youth, median } \\
\text { (IQR) }\end{array}$ & $80(23)$ & $80(26)$ & $80(25)$ \\
\hline $\begin{array}{l}\text { Experienced wheezing episodes in the previous } \\
12 \text { months }{ }^{+}, \mathrm{n} / \mathrm{N}^{*}(\%)\end{array}$ & $50 / 68(74)$ & $22 / 32(69)$ & $28 / 36(78)$ \\
\hline \multicolumn{4}{|l|}{ Lifestyle parameters } \\
\hline Daily step count, median (IQR) & 8267 (3009) & $8358(3273)$ & $8246(3137)$ \\
\hline $\mathrm{VO}_{2 \text { peak }}$ in $\mathrm{ml} / \mathrm{min}$, mean $(\mathrm{SD})$ & $2021(583)$ & $2093(630)$ & $1940(522)$ \\
\hline $\mathrm{VO}_{2 \text { peak }}$ in $\mathrm{ml} / \mathrm{min} / \mathrm{kg}$, mean (SD) & $31.2(6.1)$ & $31.8(6.0)$ & $30.6(6.3)$ \\
\hline Wmax, median (IQR) & $150(62)$ & $152(70)$ & $144(60)$ \\
\hline W\%pred, mean (SD) & $108(20)$ & $108(21)$ & $108(21)$ \\
\hline VO2peak\%pred, mean (SD) & $70.9(12.6)$ & $72.1(12.2)$ & $69.5(13.1)$ \\
\hline EIB†‡, n/N* (\%) & $12 / 64$ (19) & 4/31 (13) & $8 / 33(24)$ \\
\hline Diet score, mean (SD) & $9.6(2.1)$ & $10.0(2.1)$ & $9.2(2.1)$ \\
\hline
\end{tabular}

$* \mathrm{n} / \mathrm{N}$ : Amount of participants with a positive outcome for this parameter / Amount of participants measured. Numbers (N) may not add up to 87,43 and 44 respectively due to missing values or, in case of asthma related parameters $(\dagger)$, because those parameters are only demonstrated for asthmatic participants (not for participants with high risk of asthma).

¥EIB was defined as a fall in $\mathrm{FEV}_{1} \%$ predicted of $\geq 10 \%$ compared to baseline after a maximal exercise test.

EQ-5D-Youth: euroqol 5 dimensions youth questionnaire for quality of life, EIB: exercise induced bronchoconstriction, GERD: gastro oesophageal reflux disease, IQR: inter quartile range, PSQ: paediatric sleep questionnaire, $\mathrm{SD}$ : standard deviation, $\mathrm{VO}_{2}$ peak: peak oxygen uptake during a maximal exercise test, $\mathrm{Wmax}$ : Maximum resistance (watt) during a maximal exercise test. 


\section{Supporting information $\mathbf{S 6 . 3}$}
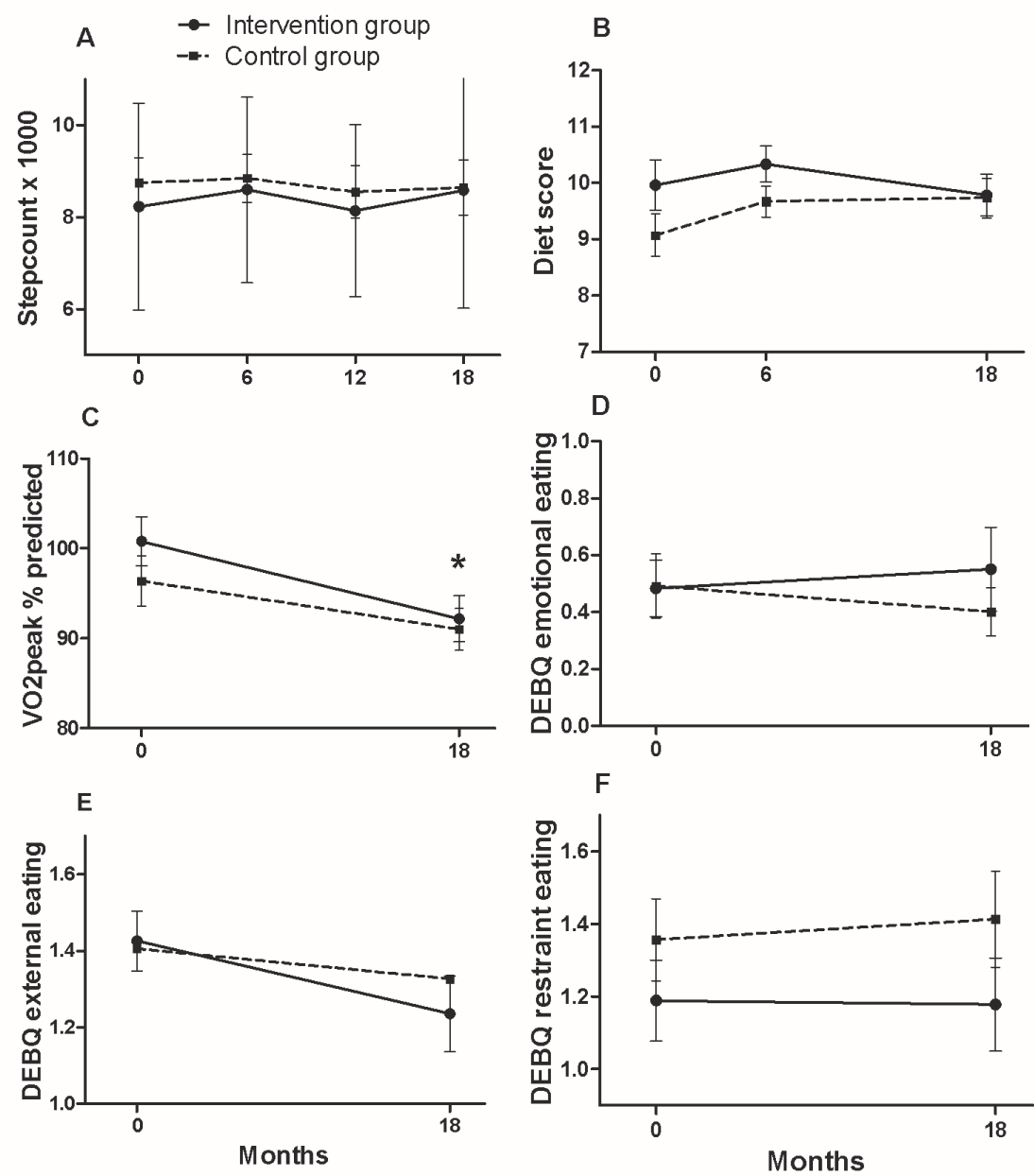

Figure S6.3 Change over time in A) Step count, B) Diet score, C) VO2peak\%predicted, D) DEBQ emotional eating score, E) DEBQ external eating score, F) DEBQ restraint eating score.

Data are presented as mean (SEM). *: Significant difference over time in the intervention group $(p<0.05)$; + : Significant difference over time in the control group $(p<0.05)$; $¥$ : Significant difference between intervention and control group over time $(p<0.05) ; \S$ : Intention to treat analyses are shown. 


\section{Supporting information S6.4}

\section{Post-hoc analysis}

\section{Methods post-hoc analysis}

The dependent variables for the post-hoc analysis were $\mathrm{FEV}_{1} \%$ predicted, FVC\%predicted and (c)-ACT score. A multilevel linear mixed model with 2 levels (participants and measurements) was conducted. Participants were treated as a second-level random factor, and the first level measurements were included by repeated measures, with a compound symmetry covariance structure. Measurement (TO as reference category), BMI-SDS, leptin concentration (as a marker for the inflammatory pathway) and ERV\%predicted (as a marker for the mechanical pathway) were included as within-subject covariates. The interaction terms BMISDS*measurement, ERV*measurement and leptin*measurement were included in the model to determine if changes in BMI-SDS, ERV and leptin were related to changes in $\mathrm{FEV}_{1} \%$ predicted, FVC\%predicted and asthma control.

For the model with asthma control, also ACT-group (e.g. c-ACT or ACT) was included as a covariate. The inclusion of this covariate enabled us to correct for differences between the c-ACT questionnaire (aged 6-12 (outcome range 0-27)) and ACT score (children aged $\geq 12$ at baseline (outcome range 5-25)).

\section{Results post-hoc analysis}

All changes over time in BMI-SDS, ERV and leptin were not related to $\mathrm{FEV}_{1} \%$ predicted, FVC\%predicted or asthma control $(\mathrm{P}<0.05)$.

When examining data cross-sectional, it was observed that BMI-SDS was significantly related to $\mathrm{FEV}_{1} \%$ predicted, $\mathrm{FVC}$ \%predicted and asthma control. Participants with higher BMI-SDS scores, had slightly lower lung functions ( $\mathrm{FEV}_{1} \%$ predicted: Estimates -6.62 , $(p<0.05))$ and FVC\%predicted: Estimates $-7.74(p<0.001))$ and a lower ACT score (Estimates $-0.30,(p<0.05)$ ). A higher ERV was associated with a higher $\mathrm{FEV}_{1} \%$ predicted (Estimates $0.15(p<0.01)$, and higher FVC\%predicted (Estimates 0.18 , $(p<0.001)$ ), but was not related to ACT score $(\mathrm{p} \geq 0.05)$. Leptin was not related to $\mathrm{FEV}_{1} \%$ predicted, FVC\%predicted and asthma control. 


\section{References}

1. Wang $\mathrm{Y}$, Lim $\mathrm{H}$. The global childhood obesity epidemic and the association between socio-economic status and childhood obesity. Int Rev Psychiatry 2012;24:176-188.

2. American Medical Association. Proceedings of the 2013 annual meeting of the house of delegates. 2013 [cited 2013 13-08]. Available from: http://www.ama-assn.org/ama/pub/about-ama/our-people/housedelegates/ meeting-archives/2013-annual-meeting.page.

3. Chen YC, Dong GH, Lin KC, Lee YL. Gender difference of childhood overweight and obesity in predicting the risk of incident asthma: A systematic review and meta-analysis. Obes Rev 2013;14:222-231.

4. Beuther DA, Sutherland ER. Overweight, obesity, and incident asthma: A meta-analysis of prospective epidemiologic studies. Am J Respir Crit Care Med. 2007;175:661-666.

5. Lang JE, Hossain J, Smith K, Lima JJ. Asthma severity, exacerbation risk, and controller treatment burden in underweight and obese children. J Asthma 2012;49:456-463.

6. Jensen ME, Collins CE, Gibson PG, Wood LG. The obesity phenotype in children with asthma. Paediatr Respir Rev. 2011;12:152-159.

7. Juel CT, Ulrik CS. Obesity and asthma: Impact on severity, asthma control, and response to therapy. Respir Care 2013;58:867-873.

8. Singh AS, Mulder C, Twisk JW, van Mechelen W, Chinapaw MJ. Tracking of childhood overweight into adulthood: A systematic review of the literature. Obes Rev 2008;9:474-488.

9. Moreira A, Bonini M, Garcia-Larsen V, Bonini S, Del Giacco SR, Agache I, Fonseca J, Papadopoulos NG, Carlsen KH, Delgado L, Haahtela T. Weight loss interventions in asthma: Eaaci evidence-based clinical practice guideline (part i). Allergy 2013;68:425-439.

10. Adeniyi FB, Young T. Weight loss interventions for chronic asthma. Cochrane Database Syst Rev 2012;7:CD009339.

11. da Silva PL, de Mello MT, Cheik NC, Sanches PL, Correia FA, de Piano A, Corgosinho FC, Campos RM, do Nascimento CM, Oyama LM, Tock L, Tufik S, Damaso AR. Interdisciplinary therapy improves biomarkers profile and lung function in asthmatic obese adolescents. Pediatr Pulmonol 2012;47:8-17.

12. Jensen ME, Gibson PG, Collins CE, Hilton JM, Wood LG. Diet-induced weight loss in obese children with asthma: A randomized controlled trial. Clin Exp Allergy 2013;43:775-784.

13. van Leeuwen JC, Hoogstrate M, Duiverman EJ, Thio BJ. Effects of dietary induced weight loss on exercise-induced bronchoconstriction in overweight and obese children. Pediatr Pulmonol 2013. [Epub ahead of print]

14. Boulet LP, Turcotte H, Martin J, Poirier P. Effect of bariatric surgery on airway response and lung function in obese subjects with asthma. Respir Med 2012;106:651-660.

15. Willeboordse M, van de Kant KD, de Laat MN, van Schayck OC, Mulkens S, Dompeling E. Multifactorial intervention for children with asthma and overweight (mikado): Study design of a randomised controlled trial. BMC Public Health 2013;13:494.

16. Jongste JC, Vrijlandt, E.L.J.E. Astma bij kinderen; herziene richtlijnen van de sectie kinderlongziekten van de nvk [paediatric asthma; revised guidelines of the paediatric department of the Dutch paediatric society]. Amsterdam: Jurriaans Lindenbaum Grafimedia; 2008.

17. Bindels PJE, Van de Wouden JC, Ponsioen BP, Brand PLP, Salome PL, Van Hensbergenm W. Nhgstandaard astma bij kinderen [dutch general practitioners guidelines, asthma in children]. 2006.

18. Schonbeck Y, Talma H, van Dommelen P, Bakker B, Buitendijk SE, Hirasing RA, van Buuren S. Increase in prevalence of overweight in dutch children and adolescents: A comparison of nationwide growth studies in 1980, 1997 and 2009. PloS One 2011;6:e27608.

19. Miller MR, Hankinson J, Brusasco V, Burgos F, Casaburi R, Coates A, Crapo R, Enright $P$, van der Grinten CP, Gustafsson P, Jensen R, Johnson DC, Maclntyre N, McKay R, Navajas D, Pedersen OF, Pellegrino R, Viegi G, Wanger J, Force AET. Standardisation of spirometry. Eur Respir J 2005;26:319-338.

20. Zapletal A PT, Samanek N. Die bedeutung heutiger methoden der lungenfunktionsdiagnostik zur feststellung einer obstruktion der atemwege bei kindern und jugendlichen. Atm-Org 1977;149:343-371.

21. Fredriks A, van Buuren S, Wit J, Verloove-Vanhorick S. Body index measurements in 1996-7 compared with 1980. Arch Dis Child 2000;82:107-112. 


\section{A multifactorial weight reduction program in children with overweight and asthma: a RCT}

22. Nathan RA, Sorkness CA, Kosinski M, Schatz M, Li JT, Marcus P, Murray JJ, Pendergraft TB. Development of the asthma control test: A survey for assessing asthma control. J Allergy Clin Immunol 2004;113: 59-65.

23. Liu AH, Zeiger R, Sorkness C, Mahr T, Ostrom N, Burgess S, Rosenzweig JC, Manjunath R. Development and cross-sectional validation of the childhood asthma control test. J Allergy Clin Immunol 2007;119:817-825.

24. Juniper EF, Guyatt GH, Feeny DH, Ferrie PJ, Griffith LE, Townsend M. Measuring quality of life in children with asthma. Qual Life Res 1996;5:35-46.

25. Bongers B, Hulzebos, HJ., van Brussel, M., Takken, T. Pediatric norms for cardiopulmonary exercise testing: In relation to gender and age. 's Hertogenbosch: BOXpress; 2012.

26. Gezondheidsraad. Richtlijnen goede voeding 2006. In: Gezondheidsraad, editor: Den Haag; 2006.

27. Raat H, Bueving HJ, de Jongste JC, Grol MH, Juniper EF, van der Wouden JC. Responsiveness, longitudinal- and cross-sectional construct validity of the pediatric asthma quality of life questionnaire (paqlq) in dutch children with asthma. Qual Life Res 2005;14:265-272.

28. Waters E, de Silva-Sanigorski A, Hall BJ, Brown T, Campbell KJ, Gao Y, Armstrong R, Prosser L, Summerbell CD. Interventions for preventing obesity in children. Cochrane Database Syst Rev 2011:CD001871.

29. Waters E, de Silva-Sanigorski A, Hall BJ, Brown T, Campbell KJ, Gao Y, Armstrong R, Prosser L, Summerbell CD. Interventions for preventing obesity in children. Cochrane Database Syst Rev 2011;12:CD001871.

30. Loeb JS, Blower WC, Feldstein JF, Koch BA, Munlin AL, Hardie WD. Acceptability and repeatability of spirometry in children using updated ats/ers criteria. Pediatr Pulmonol 2008;43:1020-1024. 


$$
\xi
$$




\section{Attrition in a paediatric weight reduction program: perspectives from participants and parents}

Submitted

Maartje Willeboordse

Danielle P de Vaan

Frans ES Tan

Raesita Hudales

Kim DG van de Kant

Edward Dompeling Constant P van Schayck Anja Krumeich 


\section{Abstract}

The treatment programmes for paediatric obesity are characterized by low to moderate effectiveness and high attrition rates. In an 18 month lasting multifactorial randomised controlled trial directed toward weight reduction in children with asthma and overweight/obesity (MIKADO-programme) we also experienced low effectiveness and a high attrition rate of the intervention of $56 \%$. We carried out a qualitative study to investigate the deliberation process of caregivers and children for dis- or continuation of this programme. Semi-structured interviews were conducted with 16 children and 16 caregivers between April and June 2013. All interviews were transcribed and coded by using Nvivo. The expectations and reasons to participate, experiences of the programme and the reasons for dis- or continuation were questioned. Overall, participants were positive about the programme components, organisation, and enjoyed making contact with fellow overweight peers. Yet, the majority disliked the monotony of the group sessions and found it difficult to combine the intense programme with their daily life routine. The prominent theme in the ongoing deliberation process was the lacking sense of purpose, which was already present prior to the programme. The sense of purpose was too weak to make people decide to opt for continuation throughout the programme. Consequently, participants developed a low motivation to actively engage in the programme. This study provides directions to reduce attrition and improve efficiency, including closely monitoring purposes of participants, and experimenting with timing and locations. In addition, several practical suggestions to improve participant's motivation are given such as providing health feedback measurements and social bonding activities. 


\section{Introduction}

Paediatric obesity is a progressively growing problem in health care worldwide ${ }^{1,2}$. In the Netherlands, $13-15 \%$ of the children aged $2-21$ years is overweight, and $2 \%$ is obese ${ }^{3}$. Paediatric obesity can result in short term and long term complications such as diabetes, cardiovascular disease, asthma, joint problems and psychological problems ${ }^{4-7}$. Moreover, childhood obesity frequently persists into adulthood ${ }^{8}$.

Because of the growing obesity epidemic, health professionals developed several childhood obesity weight loss treatment programmes. Although no gold standard for weight reduction programmes exists yet, several reviews confirm that the most effective paediatric weight reduction programmes should consist of multiple elements including diet, physical activity and behavioural components directed towards the entire family ${ }^{9-12}$. However, most paediatric weight reduction programmes are not optimally efficient, due to a limited effectiveness of the weight reducing measures, and high attrition rates ranging from $27-73 \%{ }^{9}$. The low efficiency and high attrition rates threaten the validity of paediatric weight reduction studies ${ }^{13,14}$. Therefore, there is a high need for studies that elaborate on the reasons for the low efficiency and high attrition.

In a review of ten quantitative studies, several weak-moderate predictors for attrition in paediatric obesity programmes were found ${ }^{9}$, including a higher $\mathrm{BMI}^{11,15,16}$, AfricanAmerican ethnicity ${ }^{11,16}$ and problems with insurance coverage ${ }^{16,17}$. Next to these quantitative predictors, several studies investigated the reasons families give for discontinuing a programme by using questionnaires. Well-known reasons for discontinuation are problems with organisation and logistics and not meeting parental expectations ${ }^{15,17-19}$. However, as most studies in this area are quantitative, the complex interplay of deliberations that participants continuously make about maintaining engagement cannot fully be explored. This results in several unanswered questions. Most previous studies only focused on participants' reasons of not completing the programme and did not provide insight into factors that contribute to continuation of the programme ${ }^{20}$. Also, most of the studies focused on parental reasons for not completing the programme and did not consider the children's own experiences ${ }^{21,22}$. As these crucial factors of attrition remain underexposed in current literature, qualitative research that focuses on these elements is needed.

In this study, we aim to frame the deliberation process of caregivers and children for engagement and (dis)continuation of an 18 month lasting multifactorial weight reduction programme aimed at children with asthma and overweight/obesity ${ }^{23}$. The results of this qualitative study can be used to optimise future obesity treatment programmes in children. 


\section{Methods}

\section{Study design and population}

All data were collected by using semi-structured interviews with children and their caregivers who participated in the MIKADO randomised controlled trial (RCT) from September 2011 until March $2013^{23}$. In this multifactorial RCT, the effectiveness of an 18 month multifactorial intervention directed towards weight reduction on asthma outcomes in children with asthma and overweight/obesity has been studied ${ }^{23}$. The intervention consisted of an intensive program with frequent sport sessions, group lifestyle sessions, parental sessions and individual consults ${ }^{23}$. In total, 87 children aged 6-16 years were included, of which 43 children were allocated to the intervention group and 44 to the control group (Figure 7.1). During the intervention period, 24 children discontinued the intervention programme of which 8 were also lost to follow up, resulting in an attrition rate of $56 \%{ }^{23}$. During the course of the intervention, many efforts were done to reduce attrition, such as additional motivational phone calls, regular evaluations. Also, adjustments were made to the time schedule, locations and intervention content to meet the needs of the participants. The effect of the intervention on weight reduction was low. To evaluate the deliberation process of disor continuation of the programme, children and caregivers of the intervention group were asked to participate in a qualitative evaluation during the final measurements of the MIKADO programme. In this paper, we refer to attrition as premature discontinuation of the intervention, independent of completing the measurements.

\section{Interviews}

The interviews took place after receiving consent of caregivers and children. Caregivers and children were selected for the interviews to ensure a proper representation based on age, gender, intervention location, and dis- or continuation of the programme. A total of 16 children and 16 caregivers (not purposely matched family members) were interviewed separately between April and June 2013. Half of the interviewees continued the intervention ( 7 children and 9 caregivers), see Table 7.1. The 8 participants who were loss to follow up could not be included in this qualitative evaluation as they gave no permission to further contact them regarding the MIKADO programme (Figure 7.1). 


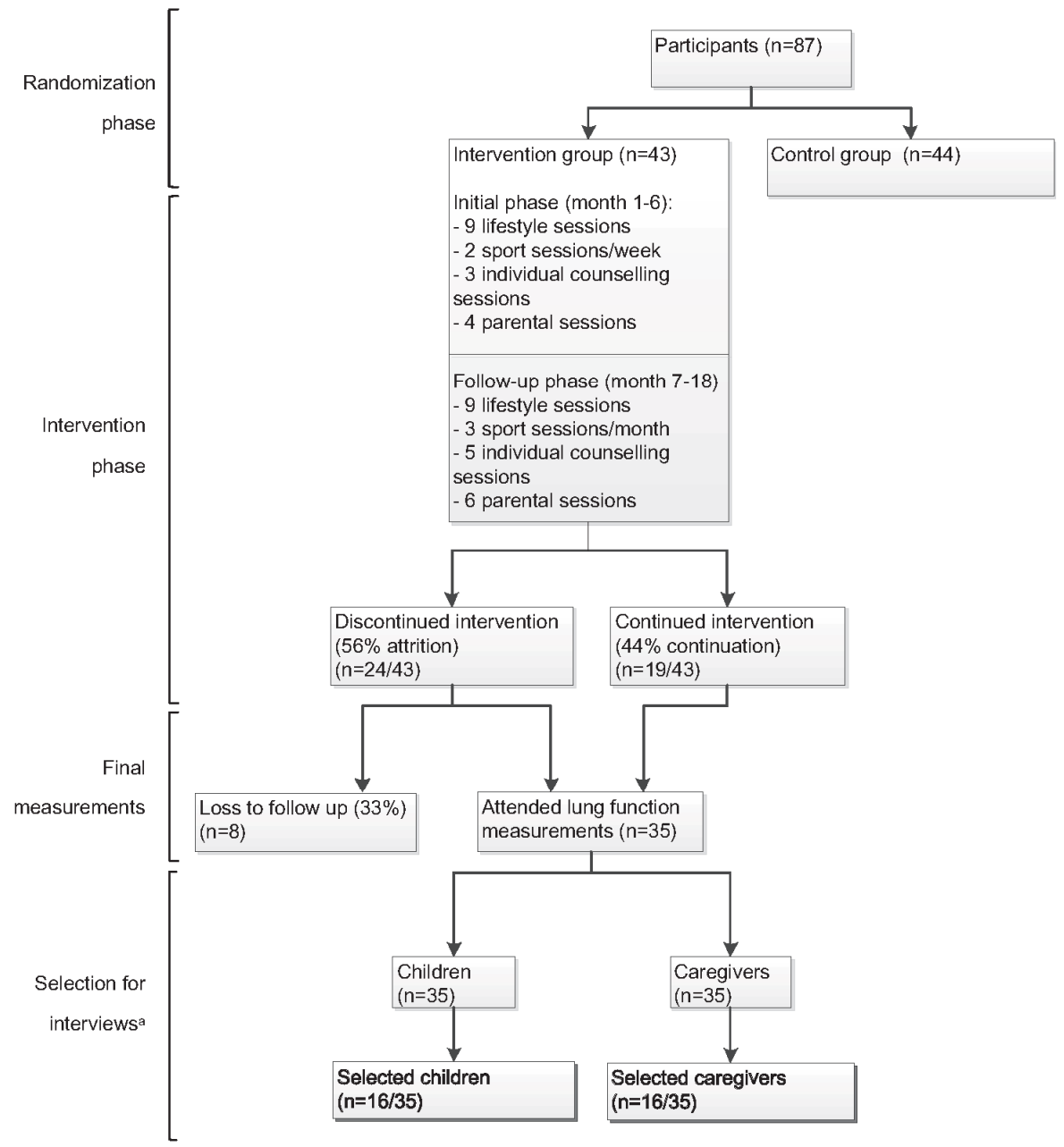

Figure 7.1 Flow diagram of MIKADO study and selection for interviews

a Selection for caregivers and children included in this evaluation was based on age, gender and dis- or continuation of the programme in order to ensure a proper representation of the total intervention group.

All the interviews were conducted by a well-trained health sciences master student who was unknown to the participants prior to the interviews. Duration of the interviews ranged from 9 to 40 minutes. The interviews were conducted in the research lab at the hospital and were audio taped with permission of the interviewees. Both caregivers and children were informed that the interviews were confidential and anonymous. Caregivers and children were interviewed separately. 
An interview guide was specifically developed for this study and based on a literature review and expert opinions of the research team (Supporting information S7.1). The guide included questions about the content and expectations of the programme, reasons for participation, experiences of the programme and possible considerations about the decision to (dis)continue the programme. The interviews were continued until the interviewer and one of the researchers agreed that data saturation was reached. Of all participants asked for this evaluation study, none refused to participate.

\section{Analysis}

All audiotapes were fully transcribed by one of the researchers. Subsequently, two researchers, including the transcriber, independently read and coded the first five interviews. They identified a list of codes that represent the categories in the text, by using Nvivo (Nvivo qualitative data analysis software; QSR International Pty Ltd. Australia; Victoria Version 10, 2012). Peer consultation between the two researchers took place frequently to discuss the initial codes and to modify the codes through consensus. All the codes were categorised into major themes. Both researchers kept a self-reflective diary to evaluate their own subjective views on the interpretation of the interviews. Once an initial coding frame was agreed upon, one researcher coded all the transcripts and continuously added new codes and visions. Again frequent consultation between the two researchers took place to reach consensus about codes and to avoid subjective interpretations during data interpretation. Eventually, main themes and patterns during the course of the programme were identified by two researchers independently. This was frequently discussed with a third researcher.

\section{Results}

For this study, 16 caregivers and 16 children were interviewed. The characteristics of the participants in this qualitative evaluation are noted in Table 7.1. The study sample was a good representation of all participants in the MIKADO programme.

In general, the interviews with children were of lower quality than the interviews with caregivers. Main reasons for the lower quality were the lack of depth, and children's inability to remember and substantiate why they decided to quit the programme. Analysis showed that the decision to discontinue the programme was the result of an ongoing deliberation about whether the effort that had to be made to continue the programme was outweighing the benefits. Evaluation of the deliberation process about discontinuation or maintaining engagement will be presented below by discussing: 1) expectations and reasons for participating, 2) experiences of the programme elements, 3) experiences of the programme format, and finally 4) by describing reasons participants mentioned to dis- or continue the programme. 
Table 7.1 Participant's baseline characteristics.

\begin{tabular}{|c|c|c|}
\hline $\begin{array}{l}\text { Participants } \\
\text { Total } n=32 \\
\end{array}$ & $\begin{array}{c}\text { Caregivers } \\
\mathrm{n}=16\end{array}$ & $\begin{array}{c}\text { Children } \\
n=16\end{array}$ \\
\hline \multicolumn{3}{|l|}{ Gender participating child } \\
\hline Male & $9^{a}(53)$ & $10(63)$ \\
\hline Female & $8^{a}(47)$ & $6(37)$ \\
\hline \multicolumn{3}{|l|}{ Age-group assigned } \\
\hline Young (6-11 years) & $11(69)$ & $10(63)$ \\
\hline Old (12-16 years) & $5(31)$ & $6(37)$ \\
\hline \multicolumn{3}{|l|}{ Intervention continuation } \\
\hline Continued & $7(44)$ & $9(56)$ \\
\hline Discontinued & $9(56)$ & $7(44)$ \\
\hline \multicolumn{3}{|l|}{ Location intervention } \\
\hline Location A (Hoensbroek) & $10(63)$ & $8(50)$ \\
\hline Location B (Maastricht) & $6(37)$ & $8(50)$ \\
\hline
\end{tabular}

All data are represented as $\mathrm{n}$ (\% of group (e.g. caregivers/children)). ${ }^{a}$ There was one caregiver included in this evaluation who had two children involved (one girl and one boy).

\section{Expectations and reasons for participating}

\section{Familiarisation with MIKADO}

To study why participants decided to enrol in the programme, participants were asked how they were recruited for the MIKADO programme, and what they expected to gain from participation. The majority was referred to the programme through direct contact with their paediatric pulmonologist. Some of them remembered that they were explicitly advised to participate in this trial because of their child's overweight and asthma, while others remembered they were merely asked by the paediatric pulmonologist to take part in a new trial.

Caregiver 7: 'The paediatrician in this hospital... He advised name child to participate in this programme... He mentioned that it was a study for children with ehm, asthmatic problems. And also, ehm, actually, name child had more problems, also related to his eating habits.'

In another large group of people, an invitation letter or questionnaire by the researchers or the youth health department ${ }^{23}$ brought them into contact with the MIKADO programme. Remarkably, a substantial group, including some caregivers, did not remember how they came in contact with the programme. 
Caregiver 5: 'I wouldn't remember.'

Interviewer: 'There were different ways how we recruited participants, a questionnaire over the internet, youth health department, the pulmonologist?' Caregiver 5: 'youth health department? Or no no, the paediatrician?'

\section{Motivation for enrolment}

The motivations that participant's had to initially engage in the programme could influence the engagement with the programme. The reasons that participants provided for participating in the MIKADO programme can be divided in three categories: losing weight, frequent exercise, and asthma management. Often participants stated that the actual reason to start the MIKADO programme was a combination of these reasons.

The first frequent mentioned group of reasons to participate was related to weight problems. Caregivers stated that they did not want their children to participate to actually lose weight but mainly to make them aware of their weight problems. Reasons why participants mentioned this need for awareness were quite abstract, and included concerns about future health, or future prevention of medical complications (for example cardiovascular diseases and diabetes). Parents also mentioned their concerns about bullying and comments of other children and caregivers.

Caregiver 10: 'Well, I am scared of diabetes or cardiovascular diseases, as they are common in my husband's family.'

In addition to the somewhat abstract referral to health, problems with physical fitness of the children, problems with buying clothes and problems linked to their eating habits were also mentioned as reasons to lose weight. On the other hand a couple of participants explicitly mentioned that losing weight was not a reason to participate. Some of them stated that losing weight was just an additional advantage of participating.

Secondly, participants often referred to the exercise programme as their motivation to participate. For most participants, exercise was considered as an efficient way to lose weight and others mentioned it would stimulate their physical capabilities.

A third group of reasons participants referred to, was asthma management. Some, both children and caregivers, hoped that their asthma would improve by participating, whilst others mentioned that they hoped they would receive useful information about their asthma. Participants explicitly stated they appreciated that there would be guidance for asthma and shortness of breath during the exercise sessions.

Child 22: 'Yes, it is with a group of children who all suffer from asthma. And during exercise moments they will take your asthma into consideration. And every time, we will proceed a bit.' 
Finally, there were reasons people gave for participation that did not converge with the objectives of the MIKADO intervention. These included availability of regular health checks during MIKADO. Some caregivers appreciated that they could monitor their children's weight, fitness and lung function. Less frequently mentioned was the financial incentive after completion of the intervention and the importance of weight reduction studies for (future) asthma patients.

\section{Expectations of programme}

Assuming that the initial reasons to participate are strongly related to the expectations people had prior to the programme expectations were also discussed during the interviews. Although people were able to indicate more or less why they decided to start the programme, they were far less able to explicitly state exact, concrete expectations. Most participants (children and caregivers) could not give any indications about what they aimed to achieve by participating in the MIKADO programme. Two major reasons included that they were scared about their future health and therefore adopted a 'wait and see' attitude towards participation in the programme. Other caregivers expressed a prudent hope that their child would become more interested in sports and that participation would lead to a greater awareness of their weight problems. But actual hopes and expectations (about losing weight) were not often formulated and participants (both parents and children) seemed to lack an explicit sense of purpose.

Child 19: 'ehm, I did not really expect anything from participating MIKADO; I just thought I start this programme and I will see what follows.'

\section{Experiences with the programme' activities}

Subsequently to examining of the enrolment phase, all participants were asked what happened after they enrolled in the program, and how they experienced the programme's activities and different components. The majority of the participants and caregivers reported the exercise sessions as the best part of the intervention. Overall, the children enjoyed the games they played and appreciated the exercise sessions with other children. However, a few participants and their caregivers mentioned that the lack of diversity and challenge in the exercises made them dislike the intervention over time. Another substantial group of participants, mainly the children in the older group, referred to the offered programme of exercises as being childish.

The aim of the lifestyle sessions was to improve participant's knowledge on obesity and obesity prevention, to monitor motivation, and to encourage participants to make healthy choices. The lifestyle sessions were considered helpful, especially in improving awareness of the problem of overweight and in providing advices of dietary and behavioural changes. However, at the same time children often found the sessions 
boring and too long. Both caregivers and children stated that they often forgot, or did not want to put too much effort in achieving the personal goals they set during the sessions (examples of personal goals included: walking the dog every other afternoon, eating fruit during school breaks, or stop snacking after dinner). Some participants even described the sessions as horrible to attend.

Caregiver 14: 'About the group sessions, well... she thought they were horrible, she ehm... she really did not want to go.'

Extra activities (cooking, craftwork, or a bowling trip) were primarily considered positive, but they thought these could be organised more often.

Caregiver 7: 'For example, there was this session in which they made all those nice snacks, he really enjoyed that session. But that was because he was doing practical things, and didn't have to listen and pay attention all the time.'

Regarding the parental sessions, two inconsistent comments were mentioned. A group of caregivers appreciated learning new things which encouraged them to apply several healthy lifestyles in their own lives.

Caregiver 9: 'I really liked the parental sessions, I really learned a lot, we all started dieting when the MIKADO started. We all joined him.'

However, others did not experience the sessions as being useful. They mentioned that they already knew a lot about a healthy life style and did not learn anything new by participating.

Caregiver 11: '...the group sessions for children, and the conversations with the parents and so on, what a nonsense was that, I am very sorry to say this.'

\section{Experiences of the intervention format}

\section{Organisational factors}

Besides experiences with activities offered, we also investigated how participants experienced organisational factors. Overall the participants stated that the programme was very well organised. They found members of the MIKADO team friendly and structured in their guidance and communication. A major problem, however turned out to be the compatibility of the programme with the participant's daily life routine. Caregivers stated that the combination with the time schedules of the rest of the family, conditions of transport, and the combination with their own working schedule 
was the major downside of the programme. Children reported to have experienced the same problems with the combination of their school schedules and personal hobby's. Several participants stated that they appreciated the flexibility of the researchers towards adapting the time schedules to their needs. Yet, participants recognised it was impossible to make a time schedule which was optimal for all involved parties. The pressure the programme put on their life routines was the main reason to quit. The positive experiences with the physical exercise and the extra activities did not outweigh the efforts it took to stay in the programme, especially as the lacking sense of purpose participants had prior to the programme made it difficult for them to appreciate the programmes benefits. A part was not prepared to make an effort to fit the programme in their routine, or make changes in their daily life. There were also participants who mentioned a change in their working schedule, marriage or financial status as a reason the programme was not compatible with their life any more. Many participants mentioned that the amount of sessions in a week was too much.

Another negative and demotivating factor participants experienced, was the high number of participants that discontinued the programme. The majority of participants reported it was unfortunate to see so many participants leaving the programme. Not only because they had become very good friends but also because the group of participants became too small to perform group related sports.

Child 23: 'The number of participants was okay in the beginning, but after a while it was not okay anymore. After a while you made some friends, you really had your own group of friends, and then half of them quit.'

\section{(Positive) outcomes because of MIKADO}

Although the majority of the participants did not have a clear sense of purpose of the MIKADO-programme, and therefore did not appreciate the programme's benefits, most participants did notice several changes and positive outcomes as a result of joining the programme. Overall, participants described the fun they had with the group of participants; they really enjoyed making new friends. A large number of children and some caregivers stated that they really appreciated the fact that they came in contact with children and/or caregivers with the same problems. They mentioned that it was stimulating for their own participation and motivation.

Caregiver 9: 'and that was really motivating for my child, like: I am not the only one with a weight problem or that is being bullied.'

Important positive outcomes of enrolment included an increased motivation to exercise (during and after the programme), a healthier diet, and awareness of their capability to change their eating and lifestyle habits. Some caregivers stated that their 
child's self-confidence had progressed during MIKADO. A couple of participants mentioned a positive change in physical shape or weight reduction. Due to these positive experiences, several participants were able to formulate clear and relevant purposes of the programme and became motivated to actively engage in the programme.

Another positive item participants mentioned, was the quality of the measurements during the programme. Many caregivers stated that they valued the monitoring of the children during the sessions, and some caregivers were proud that they still continued the measurement session, even though they quit the intervention programme. A few downsides, mentioned mainly by children, were the fear of drawing blood and the aversion towards the weight measurements.

Caregiver 5: 'I really liked the fact that they monitored her closely during the past 1,5 year. Because normally she only gets a lung function test every six months, and I think they are just snapshots.'

\section{Factors that provided the motivation to dis- or continue the programme}

As mentioned above, main reasons to quit the programme were the lack of compatibility with everyday lives, the intensity of the program and the fact that the programme wasn't fun anymore. In the absence of a clear sense of purpose, the efforts required to remain involved in the programme did therefore not outweigh the programme's benefits. People did have abstract notions about the importance of a healthy weight and a good asthma control, but they had assumed that this would happen more or less automatically after joining the MIKADO-programme. When it became apparent that they actually had to stop doing things they liked, and started doing strenuous, time-consuming activities, their motivation instantly dropped.

In the group of participants who continued the intervention, there were some participants who mentioned that they never considered quitting, because they really enjoyed and appreciated it. Several other participants had considered quitting at some point, but decided to continue. The main reason for continuation given by these participants was the attitude they had, stating that once you start a programme, or anything in live, you are morally obliged to finish. Therefore, a couple of participants still continued, although they no longer enjoyed or appreciated the programme. 


\section{Discussion}

Despite many efforts of the researchers and intervention professionals to reduce attrition in the MIKADO-programme, the attrition rate of the MIKADO intervention was high (e.g. 56\%). The attrition rate is remarkable, as the elements incorporated in the MIKADO-programme were in line with other successful weight programmes found in literature, with often lower attrition rates ${ }^{10,12,23-25}$. This study aimed to investigate the on-going deliberation process of children and their caregivers in the decision to dis- or continue this programme.

Our most striking finding was that participants did not seem to have a clear sense of purpose of why they had decided to enrol in the programme. They were not able to mention exact goals, other than some vague notion of health benefits. While they in general enjoyed the physical activities (after some adjustments), the extra activities, making new friends, and the programme's organisational structure, this was not sufficient to prevent them to quit the program. Because of the lacking sense of purpose, participants were more susceptible to quit the program. The participants 'wait and see attitude', the time investment, and the problems they encountered to fit the intensive program in their daily life, got the overhand in their decision to quit the program. The sessions aimed at creating a sense of purpose and personal learning goals, were the least appreciated parts of the intervention. A major reason to continue the programme was the attitude compromising that 'you simply finish what you start with'. At first sight this attitude seemed to tip the balance in favour of continuation. However, it may have been a major explanation for the low motivation to fully engage in the activities. Those who did continue may have done so with limited effort. And this may explain the low effectiveness of our intervention regarding achieving weight loss among those who did continue. In Table 7.2, the major findings of this study were translated in implications for health care professionals and researchers to prevent attrition in paediatric obesity programmes.

Limited other studies investigated the expectations and motivations of participants in paediatric weight reduction programs by using qualitative methods. Some studies in children did describe that mismatched expectations are a source of attrition ${ }^{15,19}$. However, no previous study describes that a lacking sense of purpose plays an important role. A promising study in obese women, did show that when a weight reduction programme is better adapted to participant's initial reasons to engage, there is a higher effectiveness ${ }^{26}$. Therefore, we advise health care professionals to closely monitor and stimulate expectations and purposes of caregivers and children, and where possible, adjust the programme to fit those expectations and purposes (Table 7.2). It is difficult to create a sense of purpose in participants, as we experienced that 
the sessions in our intervention aimed at creating purposes were evaluated as the dreary parts of the intervention.

Table 7.2 Implications for health care professionals and policy makers in the paediatric weight-reduction research area

1. Clinical: Regularly evaluate and stimulate the expectations and purposes of both children and caregivers. Adjust the programme to these expectations and purposes where possible.

2. Clinical: Continuously influence participants' motivation before and during weight reduction programmes. This can be achieved by:

- $\quad$ providing health feedback measurements,

- emphasizing on the achievements participants book as a result of the programme,

- $\quad$ incorporating practical applications in the lifestyle sessions such as cooking workshops,

- $\quad$ adding extra social bonding activities,

- $\quad$ closely monitoring purposes and reasons for continuation of the program.

3. Clinical: Adopt a flexible attitude towards adjustments in time schedules. Also, experimental set-ups should be considered, such as school-based programmes or interventions implemented directly after school.

4. Research: There is a need for studies that investigate how participants of paediatric weight programs form expectations and purposes at the start of a program. Also, studies should focus on how a lacking sense of purpose can be optimally influenced.

The lacking sense of purpose was already present before the start of the intervention, and the high attrition rate was therefore more or less inevitable. The numerous efforts of the researchers and intervention professionals to improve engagement and reduce attrition were appreciated by the participants, but not successful in preventing participant's to quit the program. There are several possible explanations for the lacking sense of purpose we found in this study. The lack of expectation and low motivation could originate from exhaustion from society's pressure on the importance of weight reduction. Most parents already know that their child's overweight is problematic and they experience great social pressure to do something about it. Weight reduction is something which is not easily reached, and many caregivers dread changing their family's lifestyles. This could lead to an overall scepticism towards weight reduction programmes and a lack of expectations and low motivation. Also, the lacking sense of purpose can be caused by not enough emphasis on engagement of the entire family. Most paediatric weight reduction studies, including ours, include a parental component. Yet, the majority of the activities of weight reduction programmes are usually directed towards children. It has been shown previously that expectations and internal motivations towards paediatric weight reduction programmes heavily depend on parental opinions ${ }^{11}$. Especially in paediatric weight reduction programs, in which self-discipline plays a major role, children will easily drop out if there is little parental support. It can be speculated that focussing more on the monitoring of expectations and purposes of the entire family, especially during initial and early contact, could contribute to lower attrition rates and improved efficiency. There is a 
need for studies to investigate the development of a sense of purpose in participants of paediatric weight reduction programs. This can optimally be investigated during the inclusion phase of a paediatric weight reduction programme (Table 7.2).

Next to the lacking sense of purpose, we also identified other reasons that influenced the engagement and attrition rates. Some of the above mentioned positive reasons for engagement (e.g. enjoyment and satisfaction with the programme, positive changes in weight or self-confidence, flexibility of time-schedules) have already been described by previous studies to contribute to the process of maintenance ${ }^{15,17,18,27,28}$. Due to the limited ability to adjust time schedules in a multifactorial intervention, experimenting with alternative time schedules could be advised. An example of a promising alternative to implement intervention components easily in daily routines, is a schoolbased program (Table 7.2). Several studies mention that a well-established child-trainer relationship is a crucial point for continuation with and success of weight reduction programmes ${ }^{15,20}$. In the current study, the importance of this relationship was confirmed. Also, Barlow et al. highlighted that economic barriers, caused by for instance insurance coverage, lead to more participants seizing to continue ${ }^{15}$. In this study, this was not applicable because of the financial incentive the families received for participating in this programme. Finally, two studies mentioned that not involving children in the decision to participate could be a reason for their lack of engagement $\mathrm{t}^{20,21}$. Due to the time delay between the decision to participate and this evaluation, children in this evaluation often did not remember how they came in contact with the programme and why they started. We did aim to actively engage the children in this study in the decision to attend the programme, by sending all children age-appropriate information leaflets and information prior to the programme.

\section{Strengths and limitations}

A couple of strengths of this qualitative study should be acknowledged. Unlike previous studies, both caregivers and children were included in this evaluation ${ }^{22}$. Also, caregivers and children were interviewed separately $y^{20,21}$ and face-to face ${ }^{29}$. This led to a rich data set of both parent's and children's deliberations on the decision to dis- or continue. This evaluation includes both continuers and discontinuers of the MIKADO programme; they were approached and interviewed in exactly the same way, which is not often done in this research field ${ }^{21}$. This enabled the elaboration of all possible motivations participants had to dis- or continue the programme and thus made it possible to evaluate why some successfully engaged in the programme while others did not. All interviews were conducted face-to-face creating more interaction between interviewer and interviewee leading to more in-depth conversations. This provides a better way to understand the complex deliberations participants continuously make. All the interviews have been recorded and transcribed, so they could be analysed in detail and no data were lost in this process ${ }^{21}$. The analysis, including the coding, was performed by 
two researchers separately to obtain consensus and to avoid any subjective interpretation of the data.

On the other hand, some limitations should be mentioned. First, participants who were loss to follow up were not included in this evaluation (see Figure 7.1). There is a possibility that these participant may have had different reasons for discontinuation. However, as the interviews were held until saturation was reached, it is deemed unlikely that much information was lost by excluding the lost to follow up group from this study. Second, a few interviews were of poor quality. Especially the interviews conducted with children were of lesser quality than the ones conducted with caregivers. Third, the evaluation was retrospective and thereby heavily relied on posthoc interpretations. It is possible that participants did not want to express their expectations they had prior to the programme, as they already knew that they/their child had not fulfilled those expectations. However, this was explicitly addressed by the (independent) interviewer, and participants stated they did express their expectations they had prior to the programme. Finally, as in all qualitative studies, it is possible that participants gave social desirable answers. If one of the researchers suspected answers were socially desirable, this was stated in memo's and information was interpreted with caution.

\section{Conclusion}

Globally paediatric obesity is a growing health care problem. There is an urgent need for effective weight reduction interventions as the potential gain in quality of life, reduction of health problems and costs of care in this group of children is great. It is important to identify the reasons for dis- or continuation of weight reduction programmes as many face high attrition rates. In this study, the lacking sense of purpose outweighed the positive experiences participants encountered by participating in this programme. This lacking sense of purpose generally led to a low motivation to actively engage in the programme, and people experienced the programme as difficult to combine with their daily life routines. Continuation of the programme was often more determined by the moral duty they encountered to finish the program, then by their motivation to change their lifestyles. Our study highlights the necessity of exploring where this lacking sense of purpose originates from, and how this best can be influenced. 


\section{Supporting information S7.1}

\section{Semi-structured interview guide}

The following Introduction was given orally prior to every interview:

'Hello, I am one of the researchers who is involved in the MIKADO programme, but I was not involved in the intervention sessions. My purpose is to evaluate the MIKADO programme with you. With your permission, I would like to record this conversation using a voice recorder, so I can process it later. All information in this evaluation will be treated confidentially and anonymously. It is very important that you answer the questions honestly, so that we get a clear picture of the MIKADO programme. Also, if you think something is strong or weak, or if you did not appreciate some parts, you can tell us. We will use this evaluation to adjust and improve similar programmes in the future. Do you have any questions before we start?"

Questions part 1: 'The first part of this evaluation covers the period when you first heard about MIKADO and the decision to participate.' ${ }^{a, b}$

1. How did you find out about MIKADO? What kind of information did you receive?

2. Why did you choose to participate in the MIKADO programme?

3. Have you considered another programme or tactic during the decision to participate? If yes, which one?

4. Why did you (nevertheless) choose to enrol in the MIKADO programme?

5. Was your child's overweight a reason to participate? If yes/no, why?

6. Could you specify whether or not you experienced your child's overweight as problematic?

7. Why did you think (whether or not) this programme was appropriate for the treatment of your (child's) overweight?

8. Was your child's asthma a reason to participate? If yes/no, why?

9. Could you specify whether or not you experienced your child's asthma as problematic?

10. Why did you think (whether or not) this programme was appropriate for the treatment of your child's asthma?

11. Could you specify if the MIKADO asthma measurements were reason to participate? If yes/no, why?

12. Could you specify if the financial incentive for participation was a reason to participate? If yes why?

13. Did you think, during the enrolment phase, that the money compensated for the expected load of the programme? If yes/no, why?

14. Did you have any expectations for your child as a result of MIKADO? If yes, which one? 
15. Have your expectations of MIKADO been fulfilled? If not, why? If yes, which one(s) and why?

16. Do you also have long term/future expectations for your child as a result of MIKADO? If yes, which one?

Questions part 2: 'We have finished the first part of the questions about the decision to participate. The second part covers your own experiences with MIKADO.' ${ }^{a, b}$

1. Could you specify the different parts of MIKADO? What do you think of the different parts of MIKADO? Why?
a. Exercise
b. Group/lifestyle sessions
c. Parental
d. Individual counselling

2. In general, what do you think of MIKADO? Why?

3. Does MIKADO include any strong parts? If not, why? If yes, which one(s) and why?

4. Does MIKADO include any weak parts? If not, why? If yes, which one(s) and why?

5. Are there any parts that you would remove from MIKADO? If not, why? If yes, which one(s) and why?

6. Did your child enjoy MIKADO? What exactly did he/she enjoy? Why?

7. What do you think of the following characteristics of MIKADO:
a. Location
b. Content of the program
c. Group size
d. Time schedule
e. Organization
f. Communication
g. Amount of time MIKADO took up
h. Supervision

8. Did you continue the MIKADO programme until the end?

\footnotetext{
${ }^{\text {a }}$ Not all the questions were asked similarly or in the same order, because the interviews were conducted semi-structured. ${ }^{b}$ The phrasing of the questions was slightly adapted when children were interviewed.
}

Sub questions for participants who quit the programme:

1. When did you quit the programme?

2. Why did you quit the intervention?

3. Was this a hard decision? If yes/no, why?

4. What was the most important factor? And why?

5. Do want to mention anything else regarding this interview or the evaluation of MIKADO? 


\section{Attrition in a paediatric weight reduction programme: \\ Perspectives from participants and parents}

Sub questions for participants who completed the programme:

1. Did you ever consider quitting the programme? If yes/no, why?

2. Was this a hard decision? If yes/no, why?

3. Why did you continue the programme?

4. Do you have any other things you want to mention regarding this evaluation of MIKADO?

'Thank you very much for the evaluation of MIKADO. By performing these interviews we hope to identify how people experienced MIKADO, the success factors of the programme and areas for improvement. Again, all information will be treated confidentially.' 


\section{References}

1. de Onis $\mathrm{M}$, Blossner $\mathrm{M}$, Borghi E. Global prevalence and trends of overweight and obesity among preschool children. Am J Clin Nutr 2010;92:1257-1264.

2. WHO. Obesity and overweight; fact sheet $n^{\circ} 311.2013$ [cited 2014 February 3]. Available from: http://www.who.int/mediacentre/factsheets/fs311/en/\#.

3. Schonbeck Y, Talma H, van Dommelen P, Bakker B, Buitendijk SE, Hirasing RA, van Buuren S. Increase in prevalence of overweight in dutch children and adolescents: A comparison of nationwide growth studies in 1980, 1997 and 2009. PLoS One 2011;6:e27608.

4. Flaherman V, Rutherford GW. A meta-analysis of the effect of high weight on asthma. Arch Dis Child 2006;91:334-339.

5. Pulgaron ER. Childhood obesity: A review of increased risk for physical and psychological comorbidities. Clin Ther 2013;35:18-32.

6. Shore SA. Obesity and asthma: Possible mechanisms. J Allergy Clin Immunol 2008;121:1087-1093; 1094-1085.

7. Han JC, Lawlor DA, Kimm SY. Childhood obesity. Lancet 2010;375:1737-1748.

8. Singh AS, Mulder C, Twisk JW, van Mechelen W, Chinapaw MJ. Tracking of childhood overweight into adulthood: A systematic review of the literature. Obes Rev 2008;9:474-488.

9. Skelton JA, Beech BM. Attrition in paediatric weight management: A review of the literature and new directions. Obes Rev 2011;12:e273-281.

10. Oude Luttikhuis H, Baur L, Jansen H, Shrewsbury VA, O'Malley C, Stolk RP, Summerbell CD. Interventions for treating obesity in children. The Cochrane database of systematic reviews 2009:CD001872.

11. Heinberg L, Kutchman EM, Berger NA, Lawhun SA, Cuttler L, Seabrook RC, Horwitz SM. Parent involvement is associated with early success in obesity treatment. Clin Pediatr 2010;49:457-465.

12. Waters E, de Silva-Sanigorski A, Hall BJ, Brown T, Campbell KJ, Gao Y, Armstrong R, Prosser L, Summerbell CD. Interventions for preventing obesity in children. The Cochrane database of systematic reviews 2011:CD001871.

13. Karlson CW, Rapoff MA. Attrition in randomized controlled trials for pediatric chronic conditions. J Pediatr Psychol 2009;34:782-793.

14. Marcellus L. Are we missing anything? Pursuing research on attrition. Can J Nurs Res 2004;36:82-98.

15. Barlow SE, Ohlemeyer CL. Parent reasons for nonreturn to a pediatric weight management program. Clin Pediatr 2006;45:355-360.

16. Zeller M, Kirk S, Claytor R, Khoury P, Grieme J, Santangelo M, Daniels S. Predictors of attrition from a pediatric weight management program. J Pediatr 2004;144:466-470.

17. Cote MP, Byczkowski T, Kotagal U, Kirk S, Zeller M, Daniels S. Service quality and attrition: An examination of a pediatric obesity program. Int J Qual Health Care 2004;16:165-173.

18. Kitscha CE, Brunet K, Farmer A, Mager DR. Reasons for non-return to a pediatric weight management program. Can J Diet Pract Res 2009;70:89-94.

19. Hampl S, Demeule M, Eneli I, Frank M, Hawkins MJ, Kirk S, Morris P, Sallinen BJ, Santos M, Ward WL, Rhodes E. Parent perspectives on attrition from tertiary care pediatric weight management programs. Clin Pediatr 2013;52:513-519.

20. Twiddy $M$, Wilson I, Bryant $M$, Rudolf $M$. Lessons learned from a family-focused weight management intervention for obese and overweight children. Public Health Nutr 2012;15:1310-1317.

21. Banks J, Cramer H, Sharp DJ, Shield JP, Turner KM. Identifying families' reasons for engaging or not engaging with childhood obesity services: A qualitative study. J Child Health Care 2013.

22. Stewart L, Chapple J, Hughes AR, Poustie V, Reilly JJ. Parents' journey through treatment for their child's obesity: A qualitative study. Arch Dis Child 2008;93:35-39.

23. Willeboordse M, van de Kant KD, de Laat MN, van Schayck OC, Mulkens S, Dompeling E. Multifactorial intervention for children with asthma and overweight (mikado): Study design of a randomised controlled trial. BMC Public Health 2013;13:494. 


\section{Attrition in a paediatric weight reduction programme: \\ Perspectives from participants and parents}

24. McGovern L, Johnson JN, Paulo R, Hettinger A, Singhal V, Kamath C, Erwin PJ, Montori VM. Clinical review: Treatment of pediatric obesity: A systematic review and meta-analysis of randomized trials. J Clin Endocrinol Metabol 2008;93:4600-4605.

25. Werrij MQ, Jansen A, Mulkens S, Elgersma HJ, Ament AJ, Hospers HJ. Adding cognitive therapy to dietetic treatment is associated with less relapse in obesity. J Psychosom Res 2009;67:315-324.

26. Kalarchian MA, Levine MD, Klem ML, Burke LE, Soulakova JN, Marcus MD. Impact of addressing reasons for weight loss on behavioral weight-control outcome. Am J Prev Med 2011;40:18-24.

27. Hampl S, Paves H, Laubscher K, Eneli I. Patient engagement and attrition in pediatric obesity clinics and programs: Results and recommendations. Pediatrics 2011;128 Suppl 2:S59-64.

28. Skelton JA, Goff DC, Jr., Ip E, Beech BM. Attrition in a multidisciplinary pediatric weight management clinic. Child Obes 2011;7:185-193.

29. Sallinen BJ, Schaffer S, Woolford SJ. In their own words: Learning from families attending a multidisciplinary pediatric weight management program at the ymca. Child Obes 2013;9:200-207. 


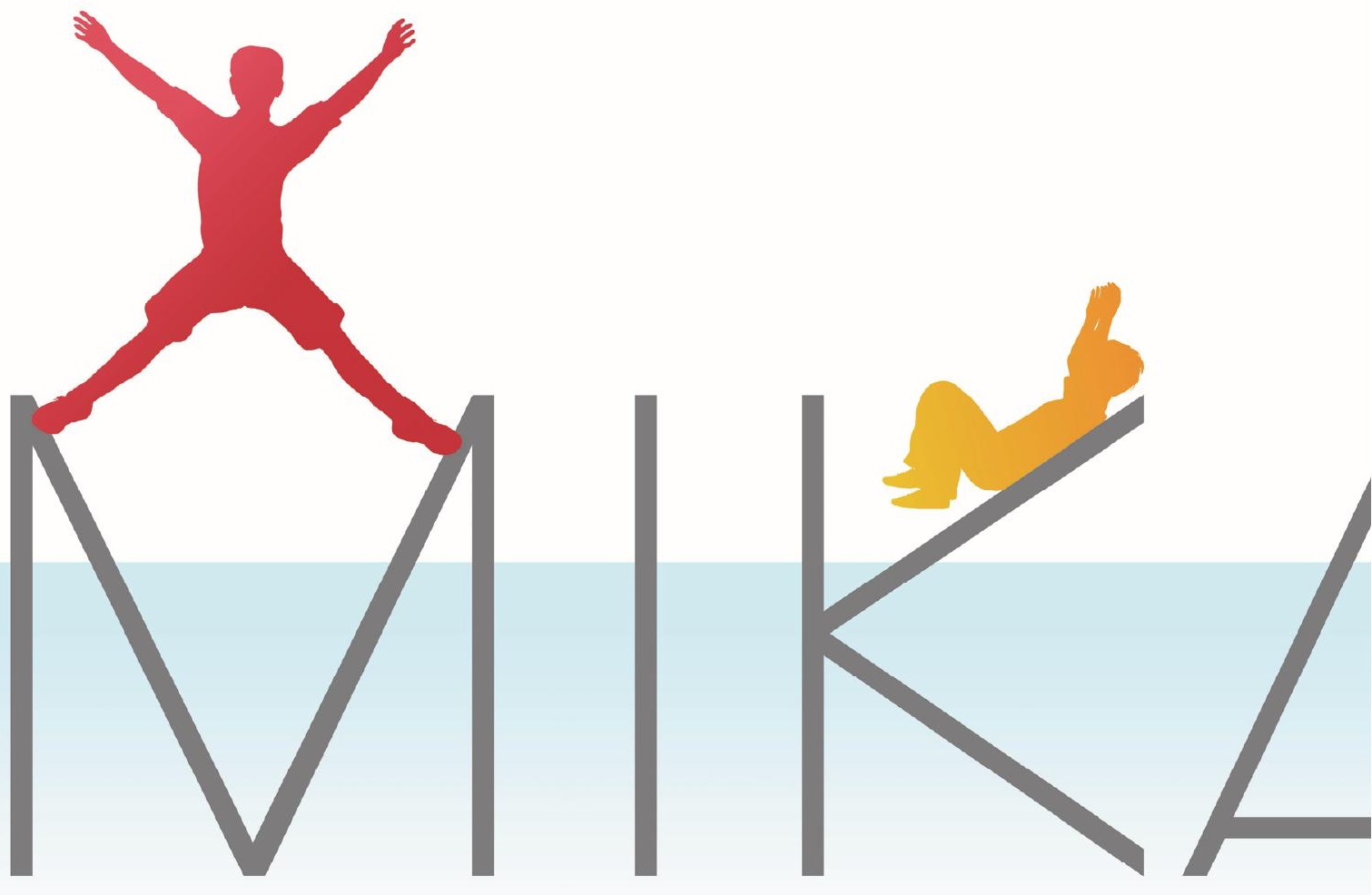




\section{General discussion}

\section{Overview}

Asthma and obesity are among the most common chronic diseases in childhood. It has been reported that obese asthmatic children have more asthma symptoms and require more medication than lean asthmatic children ${ }^{1-4}$. The major treatment for children with asthma and obesity consists of pharmacotherapy. Currently, it is largely unknown whether weight loss will lead to improved asthma management in obese children with asthma. The primary aim of this dissertation was to investigate whether a multifactorial weight reduction intervention is an effective secondary prevention tool for asthma in children with asthma and overweight/obesity. In the current chapter, the results of this dissertation will be considered in a broader perspective. First, the key findings of the studies in this dissertation will be summarised and compared to the literature. Second, covering themes of this dissertation will be evaluated and discussed. Finally, conclusions and (clinical) relevance will be presented.

\section{Main results of this dissertation in relation to existing knowledge}

In chapter two, more than nine thousand questionnaires on respiratory symptoms and anthropometrics were analysed. All questionnaires were completed by parents of children (aged 6-16 years) in the South of the Netherlands. It was demonstrated that a high bodyweight (measured as body mass index - standard deviation score (BMI-SDS)) was positively related to asthma prevalence (OR: $1.29,95 \% \mathrm{Cl} 1.14-1.45$ ). The strength of the asthma-obesity relationship in the study of chapter two is somewhat smaller, although still comparable to other studies in children ${ }^{5,6}$. When stratified for sex, it appeared that the asthma-obesity relationship was only significant in girls. This sexeffect on the asthma-obesity relationship is in line with adult studies ${ }^{7}$. In children however, studies are inconclusive. While some studies found no effect of $\operatorname{sex}^{8,9}$, others reported both stronger relationship in boys ${ }^{5}$, and in girls ${ }^{9-11}$

In the third chapter, published training programmes in children with asthma were systematically reviewed. Exercise training hardly improved lung function, but significantly improved several cardiorespiratory fitness parameters. Limited evidence was available indicating that training programmes can improve asthma control, airway inflammation, bronchial hyper responsiveness and exercise induced bronchoconstriction (EIB). Based on the systematic literature search, it was concluded that training programmes for asthmatic children should have a minimum duration of three months, with at least two 60 min training sessions per week, and a training intensity set at the (personalised) ventilatory threshold. These results are in accordance with three previous systematic reviews ${ }^{12-14}$. This review was the first study to address the effects 
of exercise training on EIB. Moreover, it was the first review that provided guidelines for training protocols in children with asthma.

In the cross-sectional study in chapter four it was shown that physical activity levels were worryingly low in Dutch school-aged children, independent of asthma or bodyweight status. Only one in five Dutch school aged children reached the step count guideline of 12000 steps per day. Based on the results, we could not confirm our hypothesis that the combination of asthma and obesity would interact on decreased physical activity levels. This is in line with the limited number of studies that were performed earlier in this area ${ }^{15,16}$.

The study design and main results of the randomised controlled trial (RCT) with a multifactorial weight reduction intervention were described in chapter five and six. Despite our longitudinal, intensive and multifactorial intervention, the intervention was not effective in reducing BMI-SDS to a greater extent in the intervention group compared to the control group. In both the intervention and control group, improvements in lung function parameters (including forced expiratory volume in 1 second $\left(\mathrm{FEV}_{1}\right)$, forced vital capacity (FVC) and expiratory reserve volume) and asthma features (including asthma control and quality of life) were visible after the eighteen month intervention. As the intervention was not effective in achieving more weight reduction in the intervention than the control group, the primary research question whether secondary prevention of asthma is possible by means of a weight reduction intervention could not be answered. Recently, three other studies did succeed in achieving weight loss in children with asthma and obesity ${ }^{17-19}$. In the intervention groups of those studies, small improvements were seen on several lung function indices and asthma features (e.g. asthma control, quality of life $)^{17-19}$. However, methodological issues such as small sample sizes, a frequent lack of (randomised) control groups, and presentation of only per-protocol analyses, limit the generalizability of those studies $^{17-19}$. Reasons for the low effectiveness of our intervention on weight reduction were the low adherence to the intervention, the high attrition rates and the considerable weight reduction in the control group.

Despite numerous efforts to actively engage the children in the intervention, the intervention had an attrition rate of $56 \%$. This percentage is slightly higher than generally reported in paediatric weight reduction interventions ${ }^{20,21}$. The high attrition rates and low effectiveness of the intervention were evaluated by means of qualitative analysis of interviews with participants and their parents. The lacking in sense of purpose prior to the programme and a subsequent low motivation to actively engage in the programme were shown to be key factors in the deliberation process to (dis)continue the intervention. In other studies, it is confirmed that a mismatch in participants' and health professionals' expectations of intervention goals play an important role in the decision to quit a programme ${ }^{22,23}$. Our results demonstrated that emphasis should be put on creating and stimulating purposes in participants to 
positively influence the deliberation process of participants to continue and actively engage in a weight reduction intervention.

\section{Characteristics of obese children with asthma}

In adults, it has frequently been reported that obesity negatively impacts the severity of asthma symptoms and level of asthma control ${ }^{3,24-27}$. For example, a study of Lavoie et al. among 382 adult asthmatic patients showed that a higher BMI was associated with lower asthma control and a lower asthma-related quality of life, independent of age, sex and asthma severity ${ }^{28}$. Obese asthmatic adults also have a higher rate of hospitalisation for acute asthma and unscheduled doctor visits than lean asthmatic adults $^{3}$. In addition, a lower response to inhaled corticosteroids (ICS) is reported in obese asthmatic adults compared to lean asthmatic adults ${ }^{3,24}$. Some, but not all, studies report an effect of obesity on bronchial hyper responsiveness and airway reversibility in adults $^{27.29-31}$.

In children, the differences between lean and obese children with asthma seem to be less distinct than in adults. In this dissertation, obesity-related changes on asthma symptoms and asthma control were hardly observed. In the survey of chapter two among more than nine thousand children aged 6-16 years, we observed that within asthmatic patients, BMI-SDS was not related to frequency of wheezing, dry cough at night, or ICS use. Moreover, in the cross-sectional study of chapter four, there were no differences observed in asthma control, short acting beta 2 (SABA) or ICS use between lean asthmatic children and overweight/obese asthmatics. In chapter six, the baseline characteristics of the participants in the RCT exhibited that most of the patients had a good level of asthma control, a high asthma-related quality of life, and a low use of medication. In contrast, we did observe that patients with a higher BMI-SDS had slightly lower lung function and slightly lower asthma control.

When reviewing current literature, findings regarding obesity-related influences on asthma features in children seem to be inconclusive. Several studies reported that obese asthmatic children have more asthma symptoms than their lean asthmatic peers, although the influence of obesity on symptoms is often small ${ }^{6,32-36}$. Regarding asthma features such as asthma control and asthma severity, findings are conflicting ${ }^{37-43}$. In a large-scale retrospective study among American asthmatic children, BMI-SDS was related to asthma severity ${ }^{42}$. However, several other paediatric cohorts found very little obesity-related asthma severity and asthma control differences ${ }^{37,40,41}$. Often, obesityrelated differences are subtle. For example, Ginde et al. observed that obesity prevalence was high among 672 asthmatic children visiting the emergency department for acute asthma symptoms ${ }^{43}$. However, obesity was not related to either chronic asthma severity, pulmonary index or admission status ${ }^{43}$.

Several studies did efforts to identify asthma phenotypes in adults, based on onset of asthma, asthma symptoms, allergy and response to therapy. In adults, an asthma- 
obesity phenotype has been described ${ }^{44,45}$. Due to the heterogeneous nature of obesity-related influences on asthma, the asthma-obesity phenotype should be divided in two clusters ${ }^{45-47}$. The first cluster consists of patients with early-onset (<12 year), mostly allergic, asthma. In these patients, asthma is often aggravated by obesity, and patients often have severe asthma, high symptom expression and persistently lower asthma control despite treatment with ICS ${ }^{46}$. The second cluster is characterised by late-onset ( $\geq 12$ years) asthma, a female predominance and mostly neutrophilic inflammation. Patients in this cluster, often develop asthma as a results of obesity ${ }^{45-47}$. Compared to patients in the first cluster, these patients often have more mildmoderate asthma, less symptom expression, and a better asthma control ${ }^{46}$.

In children, no cluster analysis has been performed to identify an asthmatic-obese phenotype. However, it can be expected that children comply most with the first cluster asthma-obesity phenotype, because of the early-onset asthma. As the first cluster is characterised by severe asthma and low asthma control, it is remarkable that obesity-related influences on asthma are more inconclusive in children than in adults. As the relationship between asthma and obesity is complex, we can only speculate on the reasons for these inconclusive results. Santamaria et al. reported that lung function is affected more by obesity with increasing duration, independent of the severity of obesity $^{48}$. This indicates that time of exposure to obesity is related to its effects on the respiratory system. This can explain the more prominent findings on asthma-obesity relationship in adults than in children.

Additionally, it should be noted that the exact pathways by which obesity leads to (worsening of) asthma are still unknown (Figure 1.3, general introduction). If obesity indeed leads to asthma via mechanical pathways, the reduced airway compliance and breathing at low lung volumes lead to airway narrowing, thereby increased airway resistance and asthma symptoms ${ }^{27,49}$. In the RCT described in chapter six of this dissertation, prudent evidence is presented for reductions in lung volume (e.g. mechanical pathway) and not for changes in inflammatory markers in severe obese asthmatics. However, the study in chapter six did not provide enough evidence to refute the inflammatory hypothesis. If obesity leads to asthma via inflammatory changes, the increase in airway inflammation markers can cause an inflammatory cascade and can lead to sensitive airways and a high likelihood of reaction to asthma triggers ${ }^{2,50}$. As long as these pathways remain unclear, it also remains unclear how obesity exactly leads to reduced asthma control. It remains a major challenge for future studies to gain more insight in the pathways by which obesity could cause or aggravate asthma.

\section{Should weight reduction be recommended in asthmatic children?}

Our intervention was not successful in reducing BMI-SDS when compared with the control group. Therefore, this dissertation cannot provided evidence for a relationship 
between weight reduction and increased lung function and asthma features in children. The question remains whether weight reduction is an effective secondary preventive measure for asthma.

Three other paediatric studies performed a weight reduction intervention in children with asthma and overweight/obesity. All three studies succeeded in achieving weight reduction ${ }^{17-19}$. Especially the intervention of Da Silva et al. was successful in reducing bodyweight ${ }^{17}$. In the intervention of Da Silva et al. beneficial effects of weight reduction were demonstrated on asthma severity, $\mathrm{FEV}_{1}, \mathrm{FVC}$, peak expiratory flow, amount of asthma symptoms, daily rescue medication doses and inflammatory markers such as leptin, c-reactive protein and adiponectin ${ }^{17}$. However, the results of this study should be interpreted with caution, as only per-protocol analyses were shown. In the studies of Jensen et al. and van Leeuwen et al. the weight reduction was smaller, and only minor beneficial effects were seen on asthma-related quality of life, degree of EIB, and asthma control ${ }^{18,19}$. None of the studies reported adverse effects of weight reduction on asthma.

In adults, considerably more studies reported the effects of weight reduction on asthma ${ }^{51-56}$. An advantage of conducting research in adults, is that weight reduction can be achieved both by lifestyle programmes, and by bariatric surgery. The studies on bariatric surgery usually have no (randomised) control group. Most studies that used bariatric surgery showed striking effects on a broad range of clinically relevant asthma features such as lung function, asthma control and medication use $\mathrm{s}^{53,56-58}$. Effects of weight reduction on lung function (e.g. $\mathrm{FEV}_{1}$ and $\mathrm{FVC}$ ) have been found up to five years after surgery ${ }^{57}$. Besides, in a substantial group of patients, asthmatic symptoms disappeared completely after surgery ${ }^{56-58}$. Also in lifestyle studies, beneficial effects of weight reduction have been seen on asthma features, which lasted even one year after the intervention ${ }^{59-61}$. Juel et al. found improvements of asthma symptoms and use of asthma medication after weight loss in $48-100 \%$ of obese individuals with doctordiagnosed asthma ${ }^{56}$. Comparable, Scott et al. and Dias-Junior et al. concluded on basis of their lifestyle RCT's that $5-10 \%$ of weight loss assists in the clinical management of asthma $^{60,61}$.

Recently, the European academy of allergy and clinical immunology (EAACl) wrote an evidence-based clinical practice guideline for clinical relevant improvements after weight reduction on asthma. They concluded that for adults, evidence for asthma improvements after weight reduction is still weak, and for children evidence is considered very weak ${ }^{52}$. They noted that it remains difficult to extrapolate the majority of the findings to clinical guidelines, because of weak evidence, and methodological issues which limit generalizability. There is large heterogeneity in the reported effects of weight reduction on asthma features, and only a few studies used RCT designs. Also, most studies have small sample sizes, a risk of selection bias (e.g. not specified how randomisation took place) and a high risk of detection bias (e.g. not blinding assessors for study arm $)^{51,52}$. Although our intervention was not effective, the majority of the 
methodological issues of current programmes (e.g. lack of RCT design, risk of selection bias, very small sample size) were addressed in our RCT.

As weight reduction could be beneficial for the respiratory system, and is beneficial for cardiovascular, metabolic and psychosocial health, weight reduction should always be advised in obese asthmatic patients. However, it is too early to identify weight reduction as a validated secondary preventive tool for asthma in a paediatric population.

\section{Should physical activity be recommended in asthmatic children?}

Currently, the asthma guidelines for children do not include primary prevention measures for obesity, such as advises to increase physical activity. Neither the Global Initiative for Asthma Guidelines (GINA), nor the Dutch guidelines for children with asthma include recommendations on exercise as part of asthma management ${ }^{52,62,63}$. The major reasons for not including exercise in the treatment plan is that it is unknown whether exercise is beneficial for asthma. Moreover, exercise is a recognised trigger for asthma symptoms ${ }^{64}$. In this dissertation, evidence is provided that stresses the importance of regular physical activity and exercise in children with asthma.

As shown in chapter four of this dissertation, an increase in daily physical activity levels could be recommended for almost all school-aged children, including asthmatic children. Low physical activity levels can have severe health consequences in later life, such as an increased burden from coronary heart disease, type two diabetes, breast cancer and colon cancer ${ }^{65}$. Increasing daily physical activity levels can be achieved by increasing low intensity activities and by reducing sedentary behaviours such as television watching, use of smart phones and playing computer games. Examples of low intensity activities are walking the dog, playing outside and increasing active transport forms (e.g. walking or cycling to school). Usually, these activities are of such low intensity that there is no risk for exercise-induced asthma symptoms. Daily physical activity levels can easily be monitored by cheap pedometers, or free mobile phone applications. The increased attention for monitoring activity levels in clinical setting should be encouraged.

Health professionals should not only advice on daily, low intensity physical activity levels, but also monitor whether children practice sufficient intense exercise. The Dutch 'Norm values for healthy exercise' recommend at least one hour of moderate-intense exercise ( $\geq 5$ metabolic equivalent of task ${ }^{66}$ ) daily ${ }^{67}$. In addition, those activities should be directed towards improvement or enhancement of fitness (strength, flexibility and coordination) minimally twice a week ${ }^{67}$. In chapter three of this dissertation it was demonstrated that exercise training is safe in children with asthma when asthma medication is properly dispensed. There are no harmful effects on asthma, and fitness levels can be increased to the same degree as in healthy children. Besides, there is weak evidence that exercise training could be beneficial for several asthma outcomes 
such as the degree of EIB and asthma-related quality of life. Examples of physical activities at high intensity are participation in organised sport activities such football, swimming and basketball, or active outdoor games such as skating or tag games.

In conclusion, recommendations on increasing daily physical activity levels and intense exercise bouts should be included in the guidelines for children with asthma as it is both safe and beneficial for children with asthma.

\section{Challenges in paediatric weight reduction}

This study did not succeed in implementing a successful weight reduction programme. We undertook numerous attempts to stimulate intervention adherence in the intervention group, including imbursements for children if they reached their personal goals, additional social bonding activities, regular evaluations, and flexibility in time schedules to meet participants needs. Unfortunately, these efforts were not sufficient. Low success rates in paediatric weight reduction interventions are not uncommon. Our findings are in line with a literature search showing that the low effectiveness of weight reduction is a major problem in paediatric obesity programmes. In a meta-analysis by Waters et al., 49 RCT's on childhood obesity prevention were summarised $^{68}$. In one third of these studies, the effects of the intervention on BMI were comparable with the control group, or the control group improved their BMI more than the intervention group. As the other studies did demonstrate that the intervention group improved their $\mathrm{BMI}$ more than the control group, it can be concluded that a large heterogeneity in effect sizes was observed. Waters et al. studied whether this high level of heterogeneity could be explained by factors such as age of participants, type of intervention (e.g. physical activity, diet or combined), setting (educational, noneducational) or duration of intervention. None of these factors could explain the heterogeneity in effect size. Apparently, there are more factors that play a role in the effectiveness of intervention studies. As the success of an intervention is difficult to measure with quantitative outcome measures (e.g. measured by questionnaires, or ranking), there is a high need for qualitative studies. Qualitative studies provide the opportunity to study the underlying processes that determine the success of a weight reduction intervention.

The low effectiveness could be partly explained by the high attrition rates observed in paediatric weight reduction programmes. Oude Luttikhuis et al. showed in their metaanalysis that attrition rates up to $52 \%$ have been found in paediatric RCT weight loss interventions ${ }^{20}$. Skelton et al. found even higher attrition rates in their literature review, ranging from $27-72 \%{ }^{21}$. In chapter seven, the reasons for the high attrition rates and low efficiency of the intervention study of chapter six were studied by means of a qualitative approach. Although various parts of the intervention were meant to increase motivation, the lacking in sense of purpose prior to the programme and not the design of the intervention was the most important factor for discontinuation of the 
study. Because of the low expectations and little knowledge on the programme intensity and components, subjects were not motivated to actively engage in the study. This could also partly explain the low effectiveness of the intervention. Several lessons learned from this dissertation that could improve effectiveness and reduce attrition in future studies are 1) to regularly evaluate and stimulate the expectations and purposes of both children and caregivers during a weight reduction programme, 2) continuously motivate participants before and during weight reduction programmes, for example by providing health feedback measurements and adding extra social bonding activities, and 3 ) adjust time schedules and logistics into participant's daily routines as much as possible.

The problems of low effectiveness and high attrition rates have dominated paediatric weight reduction programmes during the last few decades. As there is still no optimal strategy to overcome these problems, it is time to consider new approaches in paediatric obesity. The primary reason for children to become obese is not simply what they eat, but to a greater extent influenced by their environment. Both the social and natural environment influence healthy lifestyle behaviours ${ }^{69}$. Children are constantly being tempted to engage in sedentary behaviour. The convenience of transportation to school by car, ease of use of elevators, computer games, smart phones and television all stimulate a sedentary lifestyle. Also, unhealthy foods are easily available and cheap. Offerings of unhealthy snacks in addition to the daily food pattern occur almost on a daily basis. The multifactorial approach which is now mostly used in weight reduction programmes (e.g. including components of both dietary, physical activity and psychological disciplines), should shift towards a trans factorial approach.

In a trans factorial approach, preventive measures are embedded in several settings including, but not limited to, health care, education, advertisements and environment. A battery of preventive measures could change the current 'obesogenic' environment towards a healthy stimulating environment. In a healthy environment the healthiest route is the easiest to follow. Several studies showed that environmental approaches can be successful in changing lifestyles behaviours ${ }^{70-73}$. In the Netherlands, there is much room for improvement in the school-environment. Several examples by which schools could effectively encourage active transport forms (e.g. walking, biking) to school are by providing more sidewalks in the school environment, removing litter from the streets, equipping schools with sufficient bike racks, and encouraging a 'safe' environment ${ }^{70,71}$. Also, less children will develop obesity when healthy meals are provided at school, when sugar-sweetened beverages are banned in the schoolenvironment, and when fruit- and vegetables are provided during school hours ${ }^{72,73}$. Finally, parental involvement in healthy lifestyle behaviours of children could be encouraged by making contributions of sport clubs more affordable, organising parental sessions with useful tips to apply parenting skills for healthy behaviours and by involving parents in the school's policy towards healthy lifestyles. 
However, there are some critical factors that need to be taken into account for a successful implementation of a trans factorial approach. There should be support from both macro- (National government, European Union), meso- (province, local authorities, youth health departments) and micro level (schools, sports club, parents). However, as worldwide obesity prevalence continues to grow, a new approach towards obesity prevention needs to be a priority.

\section{Conclusions of this dissertation}

This dissertation provides some important conclusions for both scientists, health professionals and society.

Scientists: The scientific conclusion of this dissertation is that asthma and obesity are interrelated in girls. Physical activity levels are low in Dutch school-aged children, and not associated with either asthma and/or overweight. The intervention described in this dissertation was not successful in reducing bodyweight more than in the control group, and could therefore not answer the research question whether weight reduction might be an effective secondary preventive tool for children with asthma. Weight reduction in children is not easily achieved and there remains a major challenge for scientist to, firstly, overcome the current problems of low efficiency and high attrition in paediatric weight reduction programmes, and secondly, map the effects and accompanying pathways of weight reduction on paediatric asthma features in children with asthma and obesity.

Policy makers: Several clinical paediatric guidelines can be adjusted, or reconsidered as a result of this dissertation. In the systematic review of chapter three it was shown that exercise is safe for children with asthma, and possibly beneficial for several asthmarelated outcomes. Therefore, guidelines for children with asthma should include recommendations for regular bouts of intense exercise ${ }^{62,63,74,75}$. Also, health policy makers should strongly consider to include preventive measures for obesity in several paediatric guidelines, such as advices on increasing daily physical activity levels and decreasing sedentary time. In chapter four of this dissertation it was shown that physical activity guidelines are worryingly low in school-aged children. Frequent monitoring and stimulating of physical activity by health care professionals levels could lead to a higher awareness and improved physical activity levels in youth. Finally, the advices in chapter seven to reduce attrition and improve effectiveness can be considered in the evaluation or improvement of recognised youth obesity prevention programmes $^{76}$. 
Health professionals: This dissertation emphasises the role that health professionals hold in health promotion and education. All clinicians should monitor physical activity levels in asthmatic children, as they are often worryingly low. Besides, this dissertation shows that exercise is both safe and beneficial for children with asthma. Exercise training programmes for children with asthma should include: 1 ) a personalised training intensity, 2) a duration of at least three months, and 3) at least two 60-minutes training sessions per week. In addition, to improve effectiveness and reduce attrition in paediatric weight reduction programmes, health professionals should closely monitor expectations and purposes of participants and adjust the programme where possible. Also, they should consider experimenting with timing and locations, and continuously motivate the participants. Participant's motivation can be influenced for example by providing regular health feedback measurements and incorporating practical applications in lifestyle education sessions.

Society: Society benefits from this dissertation, by gaining more insight in the interrelationship between the two most common chronic conditions in childhood. Parents with asthmatic children learn from this dissertation that it is safe and beneficial for their children to exercise. Also, this dissertation identified some key factors which help to improve current weight reduction programmes. This will result in better weight management strategies for asthmatic and non-asthmatic children with overweight/obesity. 


\section{References}

1. Peters-Golden M, Swern A, Bird SS, Hustad CM, Grant E, Edelman JM. Influence of body mass index on the response to asthma controller agents. Eur Respir J 2006;27:495-503.

2. Jensen ME, Collins CE, Gibson PG, Wood LG. The obesity phenotype in children with asthma. Paediatr Respir Rev 2011;12:152-159.

3. Juel CT, Ulrik CS. Obesity and asthma: Impact on severity, asthma control, and response to therapy. Respir Care 2013;58:867-873.

4. Forno E, Lescher R, Strunk R, Weiss S, Fuhlbrigge A, Celedon JC, Childhood Asthma Management Program Research Group. Decreased response to inhaled steroids in overweight and obese asthmatic children. J Allergy Clin Immunol 2011;127:741-749.

5. Chen YC, Dong GH, Lin KC, Lee YL. Gender difference of childhood overweight and obesity in predicting the risk of incident asthma: A systematic review and meta-analysis. Obes Rev 2013;14:222-231.

6. Papoutsakis C, Priftis KN, Drakouli M, Prifti S, Konstantaki E, Chondronikola M, Antonogeorgos G, Matziou V. Childhood overweight/obesity and asthma: Is there a link? A systematic review of recent epidemiologic evidence. J Acad Nutr Diet 2013;113:77-105.

7. Beuther DA, Sutherland ER. Overweight, obesity, and incident asthma: A meta-analysis of prospective epidemiologic studies. Am J Respir Crit Care Med 2007;175:661-666.

8. Rzehak P, Wijga AH, Keil T, Eller E, Bindslev-Jensen C, Smit HA, Weyler J, Dom S, Sunyer J, Mendez M, Torrent M, Vall O, Bauer CP, Berdel D, Schaaf B, Chen CM, Bergstrom A, Fantini MP, Mommers M, Wahn U, Lau S, Heinrich J, Cohorts G-WB. Body mass index trajectory classes and incident asthma in childhood: Results from 8 european birth cohorts--a global allergy and asthma european network initiative. J Allergy Clin Immunol 2013;131:1528-1536.

9. Noal RB, Menezes AM, Macedo SE, Dumith SC. Childhood body mass index and risk of asthma in adolescence: A systematic review. Obes Rev 2011;12:93-104.

10. Flaherman V, Rutherford GW. A meta-analysis of the effect of high weight on asthma. Arch Dis Child 2006;91:334-339.

11. Matricardi PM, Gerber C, Wahn U, Lau S. The asthma-obesity link in childhood: Open questions, complex evidence, a few answers only. Clin Exp Allergy 2007;37:476-484.

12. Ram FS, Robinson SM, Black PN, Picot J. Physical training for asthma. Cochrane Database Syst Rev 2005:CD001116.

13. Welsh L, Kemp J, Roberts RGD. Effects of physical conditioning on children and adolescents with asthma. Sports Med 2005;35:127-141.

14. Chandratilleke MG, Carson KV, Picot J, Brinn MP, Esterman AJ, Smith BJ. Physical training for asthma. Cochrane Database Syst Rev 2012;5:CD001116.

15. Fedele DA, Janicke DM, Lim CS, Abu-Hasan M. An examination of comorbid asthma and obesity: Assessing differences in physical activity, sleep duration, health-related quality of life and parental distress. J Asthma 2014. In press.

16. Eijkemans M, Mommers M, Draaisma JM, Thijs C, Prins MH. Physical activity and asthma: A systematic review and meta-analysis. PLoS One 2012;7:e50775.

17. da Silva PL, de Mello MT, Cheik NC, Sanches PL, Correia FA, de Piano A, Corgosinho FC, Campos RM, do Nascimento CM, Oyama LM, Tock L, Tufik S, Damaso AR. Interdisciplinary therapy improves biomarkers profile and lung function in asthmatic obese adolescents. Pediatr Pulmonol 2012;47:8-17.

18. Jensen ME, Gibson PG, Collins CE, Hilton JM, Wood LG. Diet-induced weight loss in obese children with asthma: A randomized controlled trial. Clin Exp Allergy 2013;43:775-784.

19. van Leeuwen JC, Hoogstrate M, Duiverman EJ, Thio BJ. Effects of dietary induced weight loss on exercise-induced bronchoconstriction in overweight and obese children. Pediatr Pulmonol 2013. In press.

20. Oude Luttikhuis H, Baur L, Jansen H, Shrewsbury VA, O'Malley C, Stolk RP, Summerbell CD. Interventions for treating obesity in children. Cochrane Database Syst Rev 2009;CD001872CD001872:CD001872. 
21. Skelton JA, Beech BM. Attrition in paediatric weight management: A review of the literature and new directions. Obes Rev 2011;12:e273-281.

22. Barlow SE, Ohlemeyer CL. Parent reasons for nonreturn to a pediatric weight management program. Clin Pediatr (Phila) 2006;45:355-360.

23. Hampl S, Demeule M, Eneli I, Frank M, Hawkins MJ, Kirk S, Morris P, Sallinen BJ, Santos M, Ward WL, Rhodes E. Parent perspectives on attrition from tertiary care pediatric weight management programs. Clin Pediatr (Phila) 2013;52:513-519.

24. Stream AR, Sutherland ER. Obesity and asthma disease phenotypes. Curr Opin Allergy Clin Immunol 2012;12:76-81.

25. Farah CS, Kermode JA, Downie SR, Brown NJ, Hardaker KM, Berend N, King GG, Salome CM. Obesity is a determinant of asthma control independent of inflammation and lung mechanics. Chest 2011;140: 659-666.

26. Dixon AE, Holguin F, Sood A, Salome CM, Pratley RE, Beuther DA, Celedon JC, Shore SA, American Thoracic Society Ad Hoc Subcommittee on O, Lung D. An official american thoracic society workshop report: Obesity and asthma. Proc Am Thorac Soc 2010;7:325-335.

27. Boulet LP. Asthma and obesity. Clin Exp Allergy 2013;43:8-21.

28. Lavoie KL, Bacon SL, Labrecque M, Cartier A, Ditto B. Higher bmi is associated with worse asthma control and quality of life but not asthma severity. Respir Med 2006;100:648-657.

29. Cetlin AA, Gutierrez MR, Bettiol H, Barbieri MA, Vianna EO. Influence of asthma definition on the asthma-obesity relationship. BMC Public Health 2012;12:844.

30. Kwon JW, Kim SH, Kim TB, Kim SH, Park HW, Chang YS, Jang AS, Cho YS, Nahm DH, Park JW, Yoon HJ, Cho YJ, Choi BW, Moon HB, Cho SH. Airway hyperresponsiveness is negatively associated with obesity or overweight status in patients with asthma. Int Arch Allergy Immunol 2012;159:187-193.

31. Shore SA. Obesity, airway hyperresponsiveness, and inflammation. J Appl Physiol 2009.

32. Jensen ME, Wood LG, Gibson PG. Obesity and childhood asthma - mechanisms and manifestations. Curr Opin Allergy Clin Immunol 2012;12:186-192.

33. Kattan M, Kumar R, Bloomberg GR, Mitchell HE, Calatroni A, Gergen PJ, Kercsmar CM, Visness CM, Matsui EC, Steinbach SF, Szefler SJ, Sorkness CA, Morgan WJ, Teach SJ, Gan VN. Asthma control, adiposity, and adipokines among inner-city adolescents. J Allergy Clin Immunol 2010;125:584-592.

34. Ulger Z, Demir E, Tanac R, Goksen D, Gulen F, Darcan S, Can D, Coker M. The effect of childhood obesity on respiratory function tests and airway hyperresponsiveness. Turk J Pediatr 2006;48:43-50.

35. Wang D, Qian Z, Wang J, Yang M, Lee YL, Liu F, Liu MM, Zhao Y, Liu YQ, Huang MM, Liu Y, Sun J, Liu YZ, Wu CC, Dong GH. Gender-specific differences in associations of overweight and obesity with asthma and asthma-related symptoms in 30056 children: Result from 25 districts of northeastern china. J Asthma 2014. In press.

36. Lang JE. Obesity and asthma in children: Current and future therapeutic options. Paediatric Drugs 2014. In press.

37. Lang JE, Holbrook JT, Wise RA, Dixon AE, Teague WG, Wei CY, Irvin CG, Shade D, Lima JJ, American Lung Association-Asthma Clinical Research Group. Obesity in children with poorly controlled asthma: Sex differences. Pediatr Pulmonol 2013;48:847-856.

38. Kwong KY, Rhandhawa I, Saxena J, Morphew T, Jones CA. Ability to control persistent asthma in obese versus non-obese children enrolled in an asthma-specific disease management program (breathmobile). J Asthma Asthma 2006;43:661-666.

39. Peters JI, McKinney JM, Smith B, Wood P, Forkner E, Galbreath AD. Impact of obesity in asthma: Evidence from a large prospective disease management study. Ann Allergy Asthma Immunol 2011;106:30-35.

40. Giese JK. Pediatric obesity and its effects on asthma control. J Am Assoc Nurse Pract 2014;26:102-109.

41. Forte GC, Grutcki DM, Menegotto SM, Pereira RP, Dalcin Pde T. Prevalence of obesity in asthma and its relations with asthma severity and control. Rev Assoc Med Bras 2013;59:594-599.

42. Michelson PH, Williams LW, Benjamin DK, Barnato AE. Obesity, inflammation, and asthma severity in childhood: Data from the national health and nutrition examination survey 2001-2004. Ann Allergy Asthma Immunol 2009;103:381-385. 
43. Ginde AA, Santillan AA, Clark S, Camargo CA, Jr. Body mass index and acute asthma severity among children presenting to the emergency department. Pediatr Allergy Immunol 2010;21:480-488.

44. Haldar P, Pavord ID, Shaw DE, Berry MA, Thomas M, Brightling CE, Wardlaw AJ, Green RH. Cluster analysis and clinical asthma phenotypes. Am J Respir Crit Care Med 2008;178:218-224.

45. Rasmussen F, Hancox RJ. Mechanisms of obesity in asthma. Curr Opin Allergy Clin Immunol 2013. In press.

46. Sutherland ER, Goleva E, King TS, Lehman E, Stevens AD, Jackson LP, Stream AR, Fahy JV, Leung DY, Asthma Clinical Research N. Cluster analysis of obesity and asthma phenotypes. PLoS One 2012;7:e36631.

47. Holguin F, Bleecker ER, Busse WW, Calhoun WJ, Castro M, Erzurum SC, Fitzpatrick AM, Gaston B, Israel E, Jarjour NN, Moore WC, Peters SP, Yonas M, Teague WG, Wenzel SE. Obesity and asthma: An association modified by age of asthma onset. J Allergy Clin Immunol 2011;127:1486-1493

48. Santamaria F, Montella S, Greco L, Valerio G, Franzese A, Maniscalco M, Fiorentino G, Peroni D, Pietrobelli A, De Stefano S, Sperli F, Boner AL. Obesity duration is associated to pulmonary function impairment in obese subjects. Obesity 2011;19:1623-1628.

49. Brashier B, Salvi S. Obesity and asthma: Physiological perspective. J Allergy (Cairo) 2013;2013:198068.

50. Ali Z, Ulrik CS. Obesity and asthma: A coincidence or a causal relationship? A systematic review. Respir Med 2013;107:1287-1300.

51. Adeniyi FB, Young T. Weight loss interventions for chronic asthma. Cochrane Database Syst Rev 2012;7:CD009339.

52. Moreira A, Bonini M, Garcia-Larsen V, Bonini S, Del Giacco SR, Agache I, Fonseca J, Papadopoulos NG, Carlsen KH, Delgado L, Haahtela T. Weight loss interventions in asthma: Eaaci evidence-based clinical practice guideline (part 1). Allergy 2013;68:425-439.

53. Eneli IU, Skybo T, Camargo CA, Jr. Weight loss and asthma: A systematic review. Thorax 2008;63:671676.

54. Gibson PG. Obesity and asthma. Ann Am Thorac Soc 2013;10 Suppl:S138-142.

55. Sideleva O, Black K, Dixon AE. Effects of obesity and weight loss on airway physiology and inflammation in asthma. Pulm Pharmacol Ther 2013;26:455-458.

56. Juel CT, Ali Z, Nilas L, Ulrik CS. Asthma and obesity: Does weight loss improve asthma control? A systematic review. J Asthma Allergy 2012;5:21-26.

57. Hewitt S, Humerfelt S, Sovik TT, Aasheim ET, Risstad H, Kristinsson J, Mala T. Long-term improvements in pulmonary function 5 years after bariatric surgery. Obes Surg 2014. In press

58. Boulet LP, Turcotte H, Martin J, Poirier P. Effect of bariatric surgery on airway response and lung function in obese subjects with asthma. Respir Med 2012;106:651-660.

59. Stenius-Aarniala B, Poussa T, Kvarnstrom J, Gronlund EL, Ylikahri M, Mustajoki P. Immediate and long term effects of weight reduction in obese people with asthma: Randomised controlled study. BMJ 2000;320:827-832.

60. Scott HA, Gibson PG, Garg ML, Pretto JJ, Morgan PJ, Callister R, Wood LG. Dietary restriction and exercise improve airway inflammation and clinical outcomes in overweight and obese asthma: $A$ randomized trial. Clin Exp Allergy 2013;43:36-49.

61. Dias-Junior SA, Reis M, de Carvalho-Pinto RM, Stelmach R, Halpern A, Cukier A. Effects of weight loss on asthma control in obese patients with severe asthma. Eur Respir J 2013. In press.

62. Jongste JC, Vrijlandt, E.L.J.E. Astma bij kinderen; herziene richtlijnen van de sectie kinderlongziekten van de nvk [Paediatric asthma; revised guidelines of the paediatric department of the dutch paediatric society]. Amsterdam: Jurriaans Lindenbaum Grafimedia; 2008.

63. Bateman ED, Hurd SS, Barnes PJ, Bousquet J, Drazen JM, FitzGerald M, Gibson P, Ohta K, O'Byrne P, Pedersen SE, Pizzichini E, Sullivan SD, Wenzel SE, Zar HJ. Global strategy for asthma management and prevention: Gina executive summary. Eur Respir J 2008;31:143-178.

64. Vernon MK, Wiklund I, Bell JA, Dale P, Chapman KR. What do we know about asthma triggers? A review of the literature. J Asthma 2012;49:991-998.

65. Lee IM, Shiroma EJ, Lobelo F, Puska P, Blair SN, Katzmarzyk PT, Lancet Physical Activity Series Working G. Effect of physical inactivity on major non-communicable diseases worldwide: An analysis of burden of disease and life expectancy. Lancet 2012;380:219-229. 
66. Ainsworth BE, Haskell WL, Herrmann SD, Meckes N, Bassett DR, Jr., Tudor-Locke C, Greer JL, Vezina J, Whitt-Glover MC, Leon AS. 2011 compendium of physical activities: A second update of codes and met values. Med Sci Sports Exerc 2011;43:1575-1581.

67. Kemper HGC OW, Stiggelbout M. Consensus over de nederlandse norm voor gezond bewegen. [Consensus on the Dutch Norm for healthy physical activity] Tijdschr Soc Gezondheidsz 2000;78:180183.

68. Waters E, de Silva-Sanigorski A, Hall BJ, Brown T, Campbell KJ, Gao Y, Armstrong R, Prosser L, Summerbell CD. Interventions for preventing obesity in children. Cochrane Database Syst Rev 2011:CD001871.

69. Bauman AE, Reis RS, Sallis JF, Wells JC, Loos RJ, Martin BW, Lancet Physical Activity Series Working Group. Correlates of physical activity: Why are some people physically active and others not? Lancet 2012;380:258-271.

70. Chriqui JF, Taber DR, Slater SJ, Turner L, Lowrey KM, Chaloupka FJ. The impact of state safe routes to school-related laws on active travel to school policies and practices in u.S. Elementary schools. Health Place 2012;18:8-15.

71. Gropp KM, Pickett W, Janssen I. Multi-level examination of correlates of active transportation to school among youth living within 1 mile of their school. Int J Behav Nutr Phys Act 2012;9:124.

72. Zenzen W, Kridli S. Integrative review of school-based childhood obesity prevention programs. J Pediatr Health Care 2009;23:242-258.

73. Hu FB. Resolved: There is sufficient scientific evidence that decreasing sugar-sweetened beverage consumption will reduce the prevalence of obesity and obesity-related diseases. Obes Rev 2013;14:606-619.

74. National Asthma E, Prevention P. Expert panel report 3 (epr-3): Guidelines for the diagnosis and management of asthma-summary report 2007. J Allergy Clin Immunol 2007;120:S94-138.

75. Bindels PJE, Van de Wouden JC, Ponsioen BP, Brand PLP, Salome PL, Van Hensbergenm W. Nhgstandaard astma bij kinderen [Dutch general practitioners guidelines, asthma in children]. 2006;49. 2nd edition.

76. Dale Dv, M. Zwikker, T. Dunnink, R. Bisseling, P. Rensen. Erkenningstraject interventies; criteria voor gezamenlijke kwaliteitsbeoordeling 2013-2018.[Traject for akcknowledeged interventions; criteria for collective quality judgement 2013-2018] Utrecht: MOVISIE / NCJ / NISB / NJi / RIVM; 2013. 


\section{Summary}




\section{Summary}

In this dissertation, the relationship between asthma and overweight/obesity in children is described. The strength of the asthma-obesity relationship is measured and the effects of a weight reduction programme in children with asthma are presented. Special attention is given to the role of exercise and physical activity in asthma.

In chapter 1, the asthma-obesity relationship in children is described. Asthma and obesity are among the most common chronic diseases in childhood. The majority of the studies describe that children with obesity suffer more frequently from asthma than their normal weight peers. It is commonly accepted that obesity precedes asthma and asthma symptoms in the majority of the patients. Data are conflicting regarding the strength of the asthma-obesity relationship. Two different pathways (e.g. the mechanical and inflammatory) are described which could possibly explain the asthmaobesity association. Currently, it is not clear whether weight reduction can lead to better asthma control in children. This chapter concludes that there is a high need for studies investigating whether weight reduction interventions can be an effective secondary preventive tool for asthma in asthmatic children with overweight/obesity.

In a large survey in chapter 2, the prevalence of paediatric asthma, overweight and obesity in Limburg, The Netherlands were presented. Parents of 39,316 children (6-16 years) in Limburg were invited to complete an online questionnaire on respiratory symptoms, anthropometric variables (such as weight and height) and several potentially confounding factors (such as sex, birth weight and breastfeeding). The response rate of the questionnaire was $24 \%$, and a total of 9,272 participants were included. The prevalence of asthma, overweight and obesity was $8 \%, 15 \%$ and $2 \%$ respectively. Children with obesity suffered more frequently from asthma than children with a normal body weight. However, when analyses were performed separately for sex, obesity was only significantly related to asthma in girls, and not in boys. Therefore, it is concluded that future studies on the relationship between obesity and asthma should correct for sex in their analyses.

In the $3^{\text {th }}$ chapter, scientific articles on the effects of exercise training in children with asthma were systematically reviewed. All controlled trials that undertook a physical training programme in children with asthma (aged 6-18 years) were included in this systematic review $(n=29)$. It was demonstrated that training had positive effects on several cardiorespiratory fitness parameters. A few studies demonstrated that training could improve exercise induced asthma symptoms, especially in children who had severe symptoms prior to the training programme. The peak expiratory flow rate was the only lung function parameter that slightly improved by training. Asthma control, airway inflammation, and bronchial hyper-responsiveness seemed to improve slightly 
with exercise training, although too little studies investigated these parameters to draw firm conclusions. Owing to the overall beneficial effects of training and the lack of negative effects, it can be concluded that physical exercise is safe and should be recommended in children with asthma.

Both asthma and obesity are associated with exercise-related limitations. However it is unknown wether children with obesity and asthma move less than healthy children without obesity. In chapter $\mathbf{4}$, the hypothesis was tested that children with asthma and/or overweight/obesity would have lower physical activity (PA) levels than children without these conditions. PA levels were compared between 4 groups of children: 1 ) children with asthma, 2) children with overweight/obesity, 3) children with both asthma and overweight/obesity, and 4) children without asthma and without overweight/obesity. A total of 122 children aged 6-12 years were divided over the 4 groups. All children were asked to perform lung function tests and to wear an activity monitor in their pocket for 7 consecutive days. PA was determined by: step count, amount of non-sedentary minutes, screen time, time spent in organised sports, and active transport forms to school such as cycling or walking. Less than 1 in 5 children reached the recommended daily step count guidelines of 12,000 steps/day. Neither asthma, not overweight/obesity, was related to physical activity levels in children. Also, asthma severity (as measured by lung function, reversibility, medication dose and selfperceived asthma-related impairments) was not related to any of the PA outcome measures. In conclusion, the initial hypothesis that children with asthma and/or overweight/obesity would have lower physical activity (PA) levels than children without these conditions could be refuted. As PA levels were worryingly low in school aged children, PA should be effectively promoted in this target group.

In chapter 5, the study design of a weight reduction intervention study in children with asthma and overweight/obesity is described, entitled MIKADO (Multifactorial Intervention in Children with Asthma and Obesity). Children with asthma and overweight/obesity will randomly be divided over a control group which will receive care as usual and an intervention group which will receive an intensive group-based weight reduction intervention. This randomised controlled trial will be based on previous effective weight reduction programs, and will consist of an intensive 18 months program of sport-, lifestyle-, parental- and individual sessions. The effects of the programme will be measured every 6 months and outcome measures include lung function tests, anthropometry, asthma symptoms, inflammatory parameters and lifestyle indices.

The effects of the MIKADO study on body weight and clinical asthma characteristics are described in chapter 6 . In total, 43 children were randomised to the intervention group, and 44 to the control group. The majority of the lifestyle parameters (including diet, 
step count, physical fitness) did not change over time in either intervention or control group. After 18 months, the age-and gender-specific ratio between height and length (e.g. degree of obesitas) decreased slightly but significantly in the intervention group, but a similar decrease was visible in the control group. Clinical asthma characteristics (including asthma control, quality of life) and lung function improved over time, however equally in the intervention and control group. Only improvements in the lung function parameter forced vital capacity improved more in the intervention than the control group. It can be concluded that despite numerous efforts to improve intervention effects, the intervention was not effective. In both the intervention and control group, significant improvements in obesity, lung function, asthma control and asthma-related quality of life were found. As participants showed only little weight reduction, we could not determine which mechanisms (e.g. mechanical or inflammatory) were associated with the asthma-related changes. Possible reasons for the lack in effectiveness of the intervention are the high number of participants who stopped with the intervention (56\%) (also called the attrition rate), low intervention compliance, and considerable weight reduction in the control group.

From international literature it is known that many paediatric weight reduction programmes, including MIKADO, are hampered by high attrition rates and low effectiveness. In order to explain this trend, the deliberation process of parents and children for (dis)continuing the MIKADO intervention was studied in chapter 7 . Interviews were conducted using a semi-structured interview guide. This facilitates an in-depth analysis of deliberations participants continuously made during the intervention. In total, 16 children and 16 caregivers were interviewed on their expectations and reasons for participation, experiences of the programme and the reasons for (dis)continuation. All interviews were transcribed, labelled and analysed using a specialised computer program. Frequent consultation between researchers took place. Overall, participants were positive about the programme components and organisation. Yet, the majority disliked the monotony of the group sessions and found the intense programme difficult to combine with their daily life routines. The prominent themes in the decision to discontinue were the low expectations and the lacking sense of purpose which was already present prior to the programme. Consequently, participants developed a low motivation to actively engage. On basis of our experiences we provided advices to reduce attrition and improve effectiveness, such as closely monitor purposes of participants, and variations with timing and locations. In addition, several concrete tips to improve participant's motivation are given such as providing health feedback measurements and social bonding activities.

Chapter $\mathbf{8}$ encompassed the general discussion of this dissertation. Parallels were drawn across chapters and compared with other International studies. It can be concluded that the influence of obesity on asthma characteristics (e.g. asthma control, medicine use, asthma symptoms) differs strongly between studies. It is unknown what 
causes these differences; probably several (partly unknown) factors influence the paediatric asthma-obesity relationship. For example, the asthma-obesity relationship is stronger in girls than in boys. This complicates research in this area. Based on the studies in this dissertation it can be concluded that children with asthma should be stimulated to increase daily physical activity levels, and engage in intense exercise bouts. Weight reduction could be beneficial for asthma management in children. However, there is not (yet) enough evidence to identify weight reduction as an effective secondary preventive tool for asthma. Finally, the limited effects of weight reduction studies, including ours, are described. New strategies and approaches to prevent childhood obesity are presented. Taken together, this dissertation provides several new insights in the asthma-obesity relationship in children, and emphasizes the need for more research on effective weight reduction strategies in children. 


\section{Samenvatting}




\section{Samenvatting}

In dit proefschrift, getiteld 'Astma, overgewicht en inspanning bij kinderen: secundaire preventie van astma middels een gewichtsreductie interventie' wordt de relatie tussen astma en overgewicht/obesitas bij kinderen omschreven. De sterkte van de relatie tussen astma en obesitas is onderzocht en de effecten van een gewichtsverliesprogramma bij kinderen met astma worden gepresenteerd. In dit proefschrift is bijzondere aandacht voor de rol van sport en fysieke activiteit bij kinderen met astma.

In hoofdstuk 1 wordt een algemene inleiding gegeven en de astma-obesitas relatie bij kinderen beschreven. Astma en obesitas zijn de meest voorkomende chronische ziekten onder kinderen. De meerderheid van de studies beschrijft dat kinderen met obesitas vaker astma hebben dan leeftijdgenoten met een gezond lichaamsgewicht. De ontwikkeling van obesitas lijkt in de meeste gevallen voor te gaan aan de ontwikkeling van astma en astmatische klachten. Echter, niet alle studies zijn het eens over de sterkte van de astma-obesitas relatie. Twee verschillende mechanismen (genaamd het mechanistische en inflammatoire mechanisme) worden benoemd welke de astmaobesitas relatie mogelijk kunnen verklaren. Momenteel is het niet duidelijk of gewichtsreductie zal leiden tot betere astma controle bij kinderen met astma en obesitas. Dit hoofdstuk eindigt met de conclusie dat er een grote behoefte is aan studies die onderzoeken of een gewichtsverliesprogramma kan leiden tot minder astma klachten bij kinderen met astma en overgewicht/obesitas.

In een groot vragenlijstonderzoek in hoofdstuk $\mathbf{2}$ wordt de prevalentie van astma, overgewicht en obesitas onderzocht bij kinderen in Limburg, Nederland. Ouders van 39.316 kinderen (6-16 jaar) in Limburg werden uitgenodigd om een online vragenlijst in te vullen over respiratoire klachten, antropometrische waarden (zoals lengte en gewicht), en verschillende factoren die mogelijk de relatie tussen astma en obesitas kunnen beïnvloeden (bijvoorbeeld geslacht, geboortegewicht en borstvoeding). In totaal reageerden $24 \%$ van de ouders op de vragenlijst wat resulteerde in 9.272 respondenten die geïncludeerd konden worden in het onderzoek. De prevalentie van astma, overgewicht en obesitas was respectievelijk $8 \%, 15 \%$ en $2 \%$. Kinderen met obesitas hadden vaker astma dan kinderen met een gezond lichaamsgewicht. Echter, als de analyses werden opgesplitst voor geslacht werd zichtbaar dat obesitas alleen significant gerelateerd was aan astma bij meisjes, en niet bij jongens. Toekomstige studies over obesitas en astma zullen rekening moeten houden met geslacht in hun analyses.

In het $\mathbf{3}^{\mathbf{e}}$ hoofdstuk, worden wetenschappelijke artikelen over de effecten van trainingsprogramma's voor kinderen met astma systematisch samengevat. Voor deze systematische review werden alle gecontroleerde studies die een fysiek trainingsprogramma aanboden aan kinderen met astma (6-18 jaar) geanalyseerd 
$(n=29)$. Er werd aangetoond dat training een positief effect had op verschillende cardiorespiratoire fitheid parameters. Een paar studies lieten zien dat na training, inspanning gebonden astma klachten minder vaak voorkwamen, vooral bij kinderen die bij aanvang van het trainingsprogramma veel klachten hadden. De peak expiratory flow was de enige longfunctie parameter die in kleine mate verbeterd kon worden met training. Astma controle, luchtwegontsteking en bronchiale hyperreactiviteit leken enigszins te verbeteren als gevolg van trainingsprogramma's, alhoewel het kleine aantal studies dat deze parameters heeft onderzocht het trekken van sterke conclusies niet mogelijk maakt. Aangezien trainingsprogramma's veel positieve effecten laten zien bij kinderen en geen negatieve effecten, kan geconcludeerd worden dat fysieke inspanning veilig is en aanbevolen kan worden voor kinderen met astma.

Zowel astma als obesitas gaan gepaard met inspannings-gebonden beperkingen. Het is echter onbekend of kinderen met astma en obesitas andere dagelijkse fysieke activiteitenniveaus hebben dan gezonde kinderen zonder deze aandoeningen. In hoofdstuk 4 wordt de hypothese getest dat kinderen met astma en/of overgewicht/obesitas minder bewegen dan gezonde controle kinderen. Niveaus van fysieke activiteit (FA) werden vergeleken tussen 4 groepen kinderen: 1 ) kinderen met astma, 2) kinderen met overgewicht/obesitas, 3) kinderen met zowel astma als overgewicht/obesitas, en 4) kinderen zonder astma en overgewicht/obesitas. In totaal werden 122 kinderen tussen 6 en 12 jaar oud verdeeld over de 4 groepen. Kinderen werden gevraagd om longfunctietesten uit te voeren en een activiteitenmonitor in de broekzak te dragen voor 7 aaneengesloten dagen. FA werd bepaald op verschillende manieren: stappenaantal, hoeveelheid tijd besteed aan fysieke activiteit, hoeveelheid tijd besteed achter een scherm (bijvoorbeeld computer of tv), hoeveelheid tijd besteed aan georganiseerde sportactiviteiten en hoeveelheid tijd besteed aan actieve transportvormen naar school zoals fietsen en wandelen. Minder dan 1 op de 5 kinderen haalde de aanbevolen richtlijn voor kinderen van 12.000 stappen per dag. Noch het hebben van astma, of van overgewicht/obesitas was gerelateerd aan FA niveaus van kinderen. Ook de ernst van astma (gemeten middels longfunctie en astma symptomen) was niet gerelateerd aan FA niveaus. Jongens hadden iets hogere FA niveaus dan meisjes. Er werd geconcludeerd dat de initiële hypothese dat kinderen met astma en/of overgewicht/obesitas minder bewegen dan gezonde controle kinderen verworpen kon worden. Gezien de alarmerende lage FA niveaus van schoolgaande kinderen, dient FA in deze doelgroep gestimuleerd te worden op een effectieve manier.

In hoofdstuk 5 wordt het studie design van een gewichtsreductie interventie studie bij kinderen met astma en overgewicht/obesitas omschreven, genaamd MIKADO (Multifactoriële Interventie voor Kinderen met Astma en Overgewicht). Kinderen met astma en overgewicht/obesitas zullen random verdeeld worden over een controle 
groep die reguliere zorg zal ontvangen en een interventiegroep die een intensief groepgebaseerd gewichtsverliesprogramma zal ontvangen. Deze gerandomiseerde gecontroleerde trial zal gebaseerd zijn op componenten van eerdere effectieve gewichtsverlies programma's en bestaan uit een intensief programma van 18 maanden bestaande uit sport-, lifestyle-, ouder,- en individuele sessies. De effecten van het programma zullen iedere 6 maanden worden gemeten en uitkomstmaten bestaan uit longfunctietesten, antropometrie, astma symptomen, inflammatoire uitkomstmaten en lifestyle uitkomstmaten.

De resultaten van de MIKADO studie worden omschreven in hoofdstuk 6. In totaal werden 43 kinderen gerandomiseerd in de interventiegroep en 44 in de controlegroep. De meeste leefstijl parameters (waaronder dieet, stappenaantal, fysieke fitheid) veranderden niet gedurende 18 maanden in zowel de interventie als de contolegroep. Na 18 maanden verminderde de mate van obesitas significant in de interventiegroep, echter in de controlegroep was dezelfde afname van lichaamsgewicht te zien. Klinische astma karakteristieken (waaronder astma controle en kwaliteit van leven) en longfunctie verbeterden in zowel de interventie en controlegroep evenveel. Enkel de verbetering in de longfunctieparameter 'forced vital capacity' was significant groter in de interventiegroep dan de controlegroep. Ondanks herhaalde pogingen om de effectiviteit van de interventie te verbeteren, bleek de interventie niet effectief. In zowel de interventie als controle groep waren verbeteringen in de mate van obesitas, longfunctie, astma controle en astma gerelateerde kwaliteit van leven te zien. Aangezien deelnemers slechts weinig lichaamsgewicht hadden verloren, kon niet bepaald worden welk mechanisme (bijvoorbeeld mechanisch of inflammatoir) geassocieerd was met de verbeteringen in longfunctie, astmacontrole en kwaliteit van leven. Mogelijke redenen voor de lage effectiviteit van de interventie zijn de hoge hoeveelheid deelnemers die gestopt zijn met de interventie (56\%) (ook wel attrition rate genoemd), de lage therapie trouw aan de interventie, en gewichtsreductie in de controlegroep.

Uit internationale literatuur blijkt dat vele gewichtsreductieprogramma's voor kinderen, waaronder MIKADO, te maken hebben met hoge attrition rates en een lage effectiviteit. Om deze trend te verklaren, werden de afwegingen van ouders en kinderen om te stoppen of doorgaan met de MIKADO interventie bestudeerd in hoofdstuk 7. Er is gekozen om gebruik te maken van semigestructureerde interviews, omdat met deze methode een diepgaande analyse gemaakt kan worden van alle overwegingen die deelnemers maken. In totaal werden 16 kinderen en 16 ouders geïnterviewd over hun verwachtingen en redenen voor deelname, ervaringen met het programma en de redenen voor het stoppen of doorgaan met de interventie. Alle interviews werden uitgeschreven, gelabeld en geanalyseerd met behulp van een gespecialiseerd computer programma. $\mathrm{Er}$ was herhaaldelijk overleg tussen onderzoekers. De deelnemers waren zeer positief over de onderdelen van het 
programma en de organisatie. Desondanks vond de meerderheid de eentonigheid van de groep sessies een zwak punt en vond vrijwel iedereen het lastig om het programma te combineren met de dagelijkse routine van het gezin. De belangrijkste thema's in de beslissing om te stoppen bleken de lage verwachtingen en de afwezigheid van doelstellingen van deelnemers voorafgaand aan de interventie. Zodoende ontwikkelden deelnemers een lage motivatie om actief deel te nemen aan de interventie. Gebaseerd op deze ervaringen hebben we adviezen geformuleerd om attrition rates te verminderen en effectiviteit te verbeteren, zoals het nauw bewaken van de doelstellingen van de deelnemers en variëren met tijden en locaties. Aanvullend worden verschillende concrete tips om de motivatie van deelnemers te verbeteren gegeven zoals het geven van feedback over de gezondheid van de deelnemer en sociale groepsactiviteiten.

Hoofdstuk 8 omvat de algehele discussie van dit proefschrift. Parallellen worden getrokken tussen hoofdstukken en vergeleken met andere internationale studies. $\mathrm{Er}$ kan geconcludeerd worden dat de invloed van obesitas op klinische astma kenmerken bij kinderen (bv astma controle, medicijngebruik, astma symptomen) sterk varieert tussen studies. Het is onbekend waardoor deze verschillen worden veroorzaakt, het is mogelijk dat vele (nog deels onbekende) factoren de astma-obesitas relatie beïnvloeden. Zo is de astma-obesitas relatie bijvoorbeeld sterker bij meisjes dan bij jongens. Dit maakt onderzoek in deze populatie ingewikkeld. Gebaseerd op de studies in dit proefschrift kan geconcludeerd worden dat kinderen met astma meer gestimuleerd moeten worden om dagelijkse fysieke activiteit niveaus te verbeteren en deel te nemen aan intensieve inspanning. Gewichtsreductie kan bevorderlijk zijn voor astma management van kinderen, echter er is (nog) niet genoeg bewijs om gewichtsverlies in te zetten als effectieve secundaire preventie voor astma bij kinderen met obesitas. Ten slotte worden de beperkte effecten van gewichtsverliesprogramma's voor kinderen, waaronder die van MIKADO, uiteengezet. Nieuwe strategieën en benaderingen om obesitas bij kinderen te voorkomen worden gepresenteerd. Dit proefschrift geeft meer inzicht in de astma-obesitas relatie bij kinderen, en benadrukt de behoefte voor meer onderzoek naar effectieve gewichtsverliesstrategieën voor kinderen. 
Valorisation 


\section{Valorisation}

The research presented in this dissertation has both highly visible and less-visible valorisation potential. In chapter eight, relevant conclusions of this dissertation were given for different target groups such as policy makers, health professionals and families. In this addendum, the valorisation potential of this dissertation will be presented, together with barriers and risks that need to be overtaken.

\section{Improving exercise guidelines for children with asthma}

In the review presented in chapter three it was shown that exercise is safe for children with asthma, beneficial for several cardiorespiratory fitness parameters, and possibly beneficial for asthma-related outcomes. In addition, in chapter four of this dissertation it was shown that physical activity levels are worryingly low in Dutch school-aged children, including in children with asthma. Low physical activity levels are modifiable risk factors for many diseases such as coronary heart disease, type 2 diabetes and various types of cancer ${ }^{1}$. Besides, low physical activity levels in children usually track into adulthood ${ }^{2}$. Therefore, guidelines for children with asthma should include concrete recommendations to increase regular bouts of intense exercise ${ }^{3-6}$. The majority of paediatric clinical asthma guidelines include a statement on physical activity. The Dutch asthma guidelines for paediatricians states that there is no evidence that exercise could improve asthma, and therefore only advices to maintain asthma control in children to warrant no limitation of activities, including exercise ${ }^{4}$. The GINA guidelines also include a 'passive' statement on physical activity: 'Physical activity is a common cause of asthma symptoms but patients should not avoid exercise ${ }^{3}$. Two other guidelines actively promote physical activity ${ }^{5,6}$. The third Expert Panel Report from the American Academy of Allergy, Asthma \& Immunology on diagnosis and management of asthma advices to 'Promote active participation in physical activities, exercise, and sports because physical activity is an essential part of a child's life $e^{\prime 6}$. The Dutch guidelines of general practitioners includes a statement to stimulate children to adhere to the Dutch paediatric norms for physical activity ${ }^{5}$. None of the abovementioned guidelines include concrete advise (i.e. frequency, intensity, duration) to increase exercise and/or physical activity.

Chapter three of this dissertation provides guidelines for an optimal training programme for children with asthma. Effective exercise training programmes for children with asthma included: 1) a personalised high training intensity (at the Ventilatory threshold), 2) a duration of at least three months, and 3) at least two 60-minutes training sessions per week. To stimulate implementation of training programmes in clinical guidelines, several studies should be conducted. Currently, most studies have been performed in subjects with mild to moderate asthma symptoms and asthma control (chapter three). Moreover, not many studies have been performed in 
severe asthmatic children with high medication use and frequent exacerbations. Therefore, randomised controlled trials should be conducted in patients with severe asthma. As emphasized in chapter three, more information is needed on the effects of training programs on asthma-related parameters such as asthma-related quality of life, exercise-induced bronchoconstriction, airway inflammation and asthma control. Although no negative effects of exercise training on asthma parameters were found, and some studies explicitly showed positive effects, there is not enough evidence to conclude whether exercise training can influence these parameters. More information on this topic could aid health professionals in their recommendations regarding an exercise training. According to one of the largest databases of clinical studies with human participants conducted around the world (clinicaltrial.gov), several research groups are currently performing studies to investigate the effects of exercise on asthma in severe asthmatic patients, and to improve understanding of training effects on several asthma-related parameters. Within a time-frame of one to three years, more knowledge will have been generated which will facilitate including evidence on the safety and effects of exercise training on several asthma outcomes. This information could aid health professionals in their recommendations of exercise training, and will stimulate to include evidence-based training programmes in guidelines for children with asthma.

\section{Improving weight reduction programmes}

Weight reduction programmes often have high attrition rates and low effectiveness ${ }^{7}$. In chapter eight of this dissertation, a qualitative study is presented on the reasons children and their caregivers give to (dis)continue a weight reduction program. The knowledge generated from this research could be of high value for future weight reduction programmes. Several concrete advices are provided in this chapter which could directly be used by health care professionals in this area. For example, health professionals should closely monitor expectations and purposes of participants, and adjust the programme to these expectations where possible. During an intervention program, health professionals should vary with timing, locations and content, in order to meet needs of participants and prevent habituation and boredom as much as possible. Participant's motivation can be positively influenced for example by providing regular health feedback measurements and by incorporating practical applications in lifestyle education sessions. The use of applications on mobile phones and portable lung function devices are low-cost, easy applicable examples of how regular health feedback measurements can be incorporated to monitor physical activity levels ${ }^{8,9}$. The Dutch government is currently working on guidelines to improve paediatric lifestyle programs ${ }^{10}$. The findings of the qualitative study in this dissertation can aid in the development of these lifestyle programs. 


\section{Studying secondary prevention of asthma by weight reduction}

The initial goal of this dissertation was to investigate whether secondary prevention of paediatric asthma by means of weight reduction was possible. Our study could not answer this research question, as the weight reduction intervention presented in chapter five was not highly effective. In children, only limited studies investigated the effects of weight reduction on asthma, and effects are limited and conflicting ${ }^{11-13}$. Therefore, it is currently too early to identify weight reduction as a secondary preventive measure for overweight/obese children with asthma. The effects of lifestyle interventions are often small in children ${ }^{7,14}$, and the question rises whether the small amount of weight reduction achieved by lifestyle interventions is enough to result in asthma-related changes. Within one to five years, it can be expected that at least five to ten well-designed studies have investigated the effects of weight reduction interventions on asthma-related parameters in children. If lifestyle interventions prove to be an effective secondary measure of asthma, this could highly influence clinical care for children with asthma.

At present, several clinical paediatric asthma guidelines already recommend weight reduction for obese children with asthma, with the acknowledgement that there is up till now no strong evidence to support effectiveness on asthma characteristics ${ }^{3,5,6}$. If sufficient evidence is gathered to certify lifestyle interventions as proven effective secondary measures of asthma, this could lead to concrete actions such as including weight reduction advice for overweight/obese asthma patients in guidelines for paediatricians, general practitioners and other healthcare professionals. Also, promotion campaigns supported by the Dutch Lung Foundation and the Dutch ministry of care could raise awareness of the problem (e.g. high prevalence of asthma and obesity) and the solution (e.g. weight reduction). Furthermore, if proven cost-effective, insurance companies could stimulate children with asthma and obesity to lose weight by free or reduced admission to proven effective weight reduction programs. 


\section{References}

1. Lee IM, Shiroma EJ, Lobelo F, Puska P, Blair SN, Katzmarzyk PT, Lancet Physical Activity Series Working Group. Effect of physical inactivity on major non-communicable diseases worldwide: an analysis of burden of disease and life expectancy. Lancet. 2012;380:219-229.

2. Telama R. Tracking of physical activity from childhood to adulthood: a review. Obesity Facts. 2009;2:187-195.

3. Bateman ED, Hurd SS, Barnes PJ, Bousquet J, Drazen JM, FitzGerald M, Gibson P, Ohta K, O'Byrne P, Pedersen SE, Pizzichini E, Sullivan SD, Wenzel SE, Zar HJ. Global strategy for asthma management and prevention: GINA executive summary. Eur Respir J. 2008;31:143-178.

4. Jongste J, Vrijlandt, ELJE. Astma bij kinderen; herziene richtlijnen van de sectie kinderlongziekten van de NVK [Paediatric Asthma; revised guidelines of the paediatric department of the Dutch Paediatric Society]. 1st Edn. Amsterdam: Jurriaans Lindenbaum Grafimedia; 2014.

5. Bindels PJE, Van de Griendt EJ, Grol MH, et al. NHG-standaard Astma bij kinderen derde herziening [Dutch General Practitioners guidelines, asthma in children third revision]. Vol 57. 2014.

6. Expert Panel Report 3 (EPR-3): Guidelines for the Diagnosis and Management of Asthma-Summary Report 2007. J Allergy Clin Immunol 2007;120(5 Suppl):94-138.

7. McGovern L, Johnson JN, Paulo R, Hettinger A, Singhal V, Kamath C, Erwin PJ, Montori VM. Clinical review: treatment of pediatric obesity: a systematic review and meta-analysis of randomized trials. J Clin Endocrinol Metab 2008;93:4600-4605.

8. Verwey R, van der Weegen S, Spreeuwenberg M, Tange H, van der Weijden T, de Witte L. Technology combined with a counseling protocol to stimulate physical activity of chronically ill patients in primary care. Stud Health Technol Inform 2014;201:264-270.

9. van Vliet $D$, van Horck M, van de Kant $K$, Vaassen S, Gulikers S, Winkens B, Rosias P, Heynens J, Muris J, Essers B, Jöbsis Q, Dompeling E. Electronic monitoring of symptoms and lung function to assess asthma control in children. Ann Allergy Asthma Immunol. 2014pii:S1081-1206(14)00340-8.

10. Dale Dv, M. Zwikker, T. Dunnink, R. Bisseling, P. Rensen. Erkenningstraject interventies; criteria voor gezamenlijke kwaliteitsbeoordeling 2013-2018. Utrecht: MOVISIE / NCJ / NISB / NJi / RIVM; 2013.

11. da Silva PL, de Mello MT, Cheik NC, Sanches PL, Correia FA, de Piano A, Corgosinho FC, Campos RM, do Nascimento CM, Oyama LM, Tock L, Tufik S, Dâmaso AR. Interdisciplinary therapy improves biomarkers profile and lung function in asthmatic obese adolescents. Pediatr Pulmonol 2012;47:8-17.

12. Jensen ME, Gibson PG, Collins CE, Hilton JM, Wood LG. Diet-induced weight loss in obese children with asthma: a randomized controlled trial. Clin Exp Allergy 2013;43:775-784.

13. van Leeuwen JC, Hoogstrate M, Duiverman EJ, Thio BJ. Effects of dietary induced weight loss on exercise-induced bronchoconstriction in overweight and obese children. Pediatr Pulmonol 2013. [Epub ahead of print]

14. Oude Luttikhuis H, Baur L, Jansen H, Shrewsbury VA, O'Malley C, Stolk RP, Summerbell CD. Interventions for treating obesity in children. Cochrane Database Syst Rev. 2009;(1):CD001872. 
List of publications 


\section{List of publications}

\section{List of publications}

Willeboordse M, van den Bersselaar DL, van de Kant KDG, Muris JWM, van Schayck CP, Dompeling $\mathrm{E}$. Sex differences in the relationship between asthma and overweight in Dutch children: a survey study. PLoS One 2013;8:e77574.

Willeboordse M, van de Kant KDG, de Laat MN, van Schayck CP, Mulkens S, Dompeling E. Multifactorial intervention for children with asthma and overweight (Mikado): study design of a randomised controlled trial. BMC Public Health 2013;13:494.

Wanrooij VH, Willeboordse M, Dompeling E, van de Kant KDG. Exercise training in children with asthma: a systematic review. Br J Sports Med 2014;48:1024-1031.

Willeboordse M. Gewichtsverliesprogramma's bij kinderen: do's and don'ts. 'Reumachirurgie Congressen 2011 en 2012.' ISBN 978-94-90583-03-3. Published in Rotterdam 2013. Editors: H.J.L. van der Heide, J.P.W. Don Griot. P71-76.

Willeboordse M, van de Kant KDG, van der Velden CA, van Schayck CP, Dompeling E. Paediatric physical activity: associations with asthma and overweight. (Submitted).

Willeboordse M, van de Kant KDG, Tan FES, Mulkens S, Schellings J, Crijns Y, van de Ploeg L, van Schayck CP, Dompeling E. A multifactorial weight reduction program in children with overweight and asthma: an RCT. (Submitted).

Willeboordse M, de Vaan DP, Tan FES, Hudales R, van de Kant KDG, Dompeling E, van Schayck $C P$, Krumeich $A$. Attrition in a paediatric weight reduction programme: Perspectives from participants and parents. (Submitted). 
Dankwoord 


\section{Dankwoord}

Goede samenwerking is mijns inziens de sleutel tot goed onderzoek, en dit hoofdstuk wil ik dan ook in zijn geheel richten aan alle mensen die op velerlei manieren hebben bijgedragen aan de totstandkoming van dit proefschrift. Wanneer ik terugdenk aan mijn promotie, voelt het traject als een duurtraining met uiteindelijk maar één doel: de eindstreep halen en er met een goed gevoel op terug kijken. En dat doe ik zeker!

Ten eerste wil ik graag alle jongeren en hun ouders/verzorgers die hebben deelgenomen aan de MIKADO studie van harte bedanken. In verband met privacy redenen wil ik jullie niet allemaal bij naam benoemen, maar ik wil hier graag benadrukken hoe ongelooflijk belangrijk jullie waren voor de totstandkoming van dit proefschrift. Velen van jullie heb ik goed leren kennen en ik heb genoten van jullie verhalen en enthousiasme. De tijd vloog altijd voorbij tijdens de sportlessen en metingen. Jullie hebben heel wat angsten overwonnen tijdens bloedprikken, fietstesten en bodybox metingen. Bedankt voor jullie tomeloze inzet.

Grote dank gaat uit naar mijn promotieteam, Prof. Dr. E Dompeling, Prof. Dr. CP van Schayck, en Dr. Kim van de Kant. Ondanks drukke agenda's en enkele moeilijke persoonlijke periodes, zorgden jullie er voor dat ik altijd voor vragen en advies bij iemand terecht kon, hiervoor veel waardering en dank. Beste Edward, ik heb veel geleerd van onze werkbesprekingen en jouw gedrevenheid als onderzoeker, arts en mens. Jouw input als kinderlongarts was van groot belang in dit onderzoek. Je gaf me de ruimte om zelf mijn promotietraject in te richten, waar ik je erg dankbaar voor ben. Onno, door jouw enthousiasme bleef ik ook altijd positief en trots op mijn werk. Mede dankzij jou is de tijdplanning van deze promotie niet veel uitgelopen. Ik kijk er naar uit om te blijven samenwerken aan nieuwe wetenschappelijke uitdagingen. Kim, ik had me geen betere co-promotor kunnen wensen dan jij. Altijd kon ik bij jou binnenlopen, en je hielp me altijd oplossingen te bedenken voor zowel de praktische als de theoretische vraagstukken. Waar ik in het begin nog wel eens schrok van de knalrode documenten vol opmerkingen, keek ik naarmate mijn promotietraject vorderde steeds meer uit naar je feedback. Door onze vele overleggen heb ik mijn promotietraject vanuit nieuwe invalshoeken kunnen bekijken.

Ik heb een hele fijne tijd gehad bij kindergeneeskunde, en dat is grotendeels te danken aan alle fijne collega's. Dillys, kamergenoot, koptelefoon collega, burpee partner, Barcelona verkenner, theeleut en soepverslaafde, wat heb ik veel met jou gelachen als kamergenoot. Ik vind het heel fijn dat jij mijn paranimf bent. Het hechte clubje medepromovendi Bob, Ester, Inge, Marieke, Sasha, Marlou, Jesse en Britt is zeker verantwoordelijk voor mijn leuke tijd bij kindergeneeskunde. Het kostte af en toe wat moeite, maar ik kreeg jullie toch altijd zo ver om mee te gaan lunchen. Ik hoop dat jullie de komende jaren mijn wetenschappelijke boekenkast blijven vullen met mooie 
promotieboekjes en dat er nog veel leuke promotiefeesten zullen komen. Sylvia, naast al je hulp bij metingen, rekrutering en logistiek, wil ik je ook bedanken voor alle gezelligheid. Onze excursie naar Rome was denk ik wel het hoogtepunt van onze samenwerking, alhoewel ik ook enkele hilarische carnavalsmomenten zeker niet zal vergeten. Cecile, je hebt me vaak geholpen bij het relativeren van werk, en het vinden van een houding als 'broekie' bij de kindergeneeskunde. We hebben veel gelachen, en ik kom zeker nog eens langs om te buurten. Ook Rijn, Sanne, Mark, Jeroen en Hendrik wil ik bedanken voor de prettige samenwerking. Ten slotte dank ik ook Nico, Lilian en Tim van het lab kindergeneeskunde voor hun samenwerking en interesse.

$\mathrm{Na}$ een snelle rekensom, ben ik tot de conclusie gekomen dat tijdens de MIKADO interventie ruim 320 sportlessen hebben plaatsgevonden, 72 groepsessies, 40 oudersessies en meer dan 100 individuele gesprekken. Al deze activiteiten hadden nooit kunnen plaatsvinden zonder een enthousiast, groot 'interventieteam'. Ten eerste wil ik de personen bedanken die hebben geholpen bij het schrijven van de interventie: Anouk Reijnen, Liesbeth van der Ploeg en Sandra Mulkens. Anouk, jij hebt niet alleen een belangrijk gedeelte van de interventie vormgegeven, maar bent ook mijn vaste partner-in-crime geweest van de interventie. Gewapend met de MIKADO-mobiel, een boel papieren en af en toe een weegschaal heb jij heel zuid Limburg af gereden om de interventie uit te voeren. Dank voor je inzet. De diëtisten Miranda Coenjaerts, Veronique Hall en Anja Ritterbeeks en de sportdocenten Yvonne Crijns, Julia Schellings, Andreas Minne en Koen Loddewijkx wil ik bedanken voor al hun inzet. Regelmatig heb ik aanspraak gedaan op jullie creativiteit en flexibiliteit, en vrijwel altijd ging dat goed. Jullie toonden altijd oprechte interesse in alle kinderen, de voortgang van het onderzoek, en de effecten, wat ik zeer waardeer. Daarnaast wil ik nog enkele mensen bedanken die op de achtergrond een belangrijke rol hebben gespeeld bij de uitvoering van de interventie: Petra Paulus, Phil Geerlings, Lilian Limpens, Marion Willemsen, George Roox en Ton Lenssen.

Net als voor het interventiegedeelte, heb ik ook een rekensom gemaakt voor het wetenschappelijke gedeelte. Voor MIKADO hebben we ruim 393 metingen uitgevoerd, en voor het 'beweegmeteronderzoek' kwamen daar nog eens 90 metingen bij. Ook dit was niet mogelijk geweest zonder de inzet van een groot team. Misschien wel de belangrijkste succesfactor van dit proefschrift zijn de vele studenten die hebben meegeholpen met het MIKADO onderzoek. Vera, Donna, Maroeska, Laura vd H. Lianne, Charlotte, Laura B, Raesita, Danielle en de grote hoeveelheid studenten die hebben geholpen bij de rekrutering en sportlessen: Bedankt! Zonder twijfel durf ik te zeggen dat het zonder jullie hulp nooit was gelukt. Daarnaast ben ik de gehele longfunctie afdeling, en in het bijzonder Paul Bongers, Marie-José Jaspers, Chris van der Grinten, Stephan Vervuuren, Manon Godding-Broekhuijzen en Sylvia Bloothoofd- 
Cornelussen dankbaar voor het gebruik van apparatuur, ruimtes, assistentie bij metingen, en de vele broodnodige adviezen over longfunctietesten.

Ik dank de leden van de beoordelingscommissie Prof. Dr. Frans Feron, Prof. Dr Wim van Aalderen, Prof. Dr. Thys van der Molen, Dr. Anita Vreugdehil en Prof. Dr. Luc Zimmermann voor hun bereidheid om dit proefschrift op wetenschappelijke inhoud te beoordelen.

Een aantal mensen wil ik graag bedanken voor de totstandkoming van dit proefschrift middels rekrutering van proefpersonen, input voor artikelen, hulp bij referentie-waarden, statistisch advies of hulp van andere aard. Medewerkers van de Jeugdgezondheidszorg Limburg, Tiny Dauven, Han Hendriks, Tiny Wouters, Jeannette Dankert, Sanne Gerards, Barbara Vernooy, Jean Muris, Bart Bongers, Valeria Limapassos en Frans Tan bedankt.

Peggy, Tamara, Lea en Daisy, bedankt voor de onmisbare secretariële ondersteuning. Erie en Margareth, wat fijn dat ik altijd bij jullie terecht kon met financiële vragen, een onmisbaar aspect van onderzoek. Jacqueline en Ralf van het MEMIC ben ik dankbaar voor het opzetten van de onlinevragenlijst en het onmisbare logistiek systeem.

Naast mensen op werk, wil ik ook nog een aantal mensen in mijn privé kring bedanken die hebben bijgedragen aan dit promotieonderzoek. Lieve vrienden: Floor, Christel, Angelique, Annemiek, Jiska, Jeske, Aniek, Marloes, Susanne, Eveline, Maaike, Loes, Charlotte, Gaston, Rik en Anne, dank voor alle leuke momenten en steun. Jullie zorgden bewust en onbewust voor de broodnodige afleiding. We maken er een goed feestje van op 7 november! Marcel, bedankt voor de prachtige omslag van dit proefschrift en ontwerp van het MIKADO logo. Ook de borrel-collega's van bewegingsweten-schappen, en leden van de Denktank kwalitatief onderzoek bedankt voor gezelligheid en meedenken over mijn onderzoek. Lieve Christ, Geertjan en Marjanne, of het nu van dichtbij is of heel ver weg, altijd tonen jullie interesse in mij en mijn werk, ik voel me thuis bij jullie. Papa, mama, Floor, Guus en Bas, dank voor jullie interesse, en het fijne thuis in Dongen waar ik me zelfs na 9 jaar Maastricht nog steeds thuis voel. Jullie hebben mij allemaal op je eigen manier geholpen en gestimuleerd in mijn keuzes voor studie en baan. Ik vind het erg fijn dat jullie, wat er ook gebeurd, altijd achter mij staan. Floor, wat ben ik blij dat jij 'ceremoniemeester' van mijn promotie bent.

Ten slotte, lieve Pieter, jij doet me elke dag weer inzien dat werk alleen maar werk is, en dat liefde het allerbelangrijkste is. Bedankt voor je luisterend oor afgelopen jaren en je onvoorwaardelijke steun. Ik kan echt genieten van onze brainstormsessies over onderzoek en heb veel respect voor de gezonde sportmentaliteit waarmee jij je eigen onderzoek uitvoert. Nu ben jij aan de beurt!

Maartje Willeboordse,

September 2014 
Curriculum Vitae 


\section{Curriculum vitae}

\section{Curriculum vitae}

Maartje Willeboordse was born on April $15^{\text {th }} 1987$ in Oosterhout, the Netherlands. She graduated from high school at the Sint Oelbert Gymnasium in 2005, after which she started the Bachelor programme in Health Sciences at Maastricht University. In her second year, she enrolled in the major 'Biology of Human Performance' and the minor 'Health education and promotion'. During her third year she received an Erasmus grant to follow courses on physical activity, ageing and word health issues at the University of Jyväskylä, Finland. She graduated in 2008, and subsequently started the Master 'Biology of human performance in health, ageing and disease'. She did her internship at $\mathrm{CIRO}$, the expertise centre for chronic organ failure, where she was trained in research and physical activity assessment methods in patients with pulmonary disease. After her graduation in 2009, she started working in 2010 as a PhD candidate under the supervision of Prof. Dr. Edward Dompeling, Prof. Dr. Onno van Schayck and Dr. Kim van de Kant at the paediatric department of Maastricht University Medical Centre. During her PhD on paediatric asthma, obesity and physical activity she supervised 9 Master students from Health Sciences and Medicine. She successfully completed courses on qualitative research (Antwerp, Belgium), clinical exercise testing in respiratory disease (Rome, Italy) and advanced statistical techniques (Maastricht, The Netherlands). In 2013 she received a Dutch Lung Foundation travel award for her contribution to the European Respiratory Society Congress in Barcelona. Currently, she is working as a post-doctoral researcher at the Department of Family Medicine at Maastricht University. In her current occupancy she coordinates a school-based intervention with special focus on physical activity, exercise, healthy nutrition and cultural development. She has been together with Pieter for over six years and they live together in Maastricht. 
